\title{
Mapping Israel, mapping Palestine : how segregated landscapes shape scientific knowledge
}

Citation for published version (APA):

Bier, J. (2014). Mapping Israel, mapping Palestine : how segregated landscapes shape scientific knowledge. [Doctoral Thesis, Maastricht University]. Datawyse / Universitaire Pers Maastricht. https://doi.org/10.26481/dis.20140403jb

Document status and date:

Published: 01/01/2014

DOI:

10.26481/dis.20140403jb

Document Version:

Publisher's PDF, also known as Version of record

\section{Please check the document version of this publication:}

- A submitted manuscript is the version of the article upon submission and before peer-review. There can be important differences between the submitted version and the official published version of record. People interested in the research are advised to contact the author for the final version of the publication, or visit the DOI to the publisher's website.

- The final author version and the galley proof are versions of the publication after peer review.

- The final published version features the final layout of the paper including the volume, issue and page numbers.

Link to publication

\footnotetext{
General rights rights.

- You may freely distribute the URL identifying the publication in the public portal. please follow below link for the End User Agreement:

www.umlib.nl/taverne-license

Take down policy

If you believe that this document breaches copyright please contact us at:

repository@maastrichtuniversity.nl

providing details and we will investigate your claim.
}

Copyright and moral rights for the publications made accessible in the public portal are retained by the authors and/or other copyright owners and it is a condition of accessing publications that users recognise and abide by the legal requirements associated with these

- Users may download and print one copy of any publication from the public portal for the purpose of private study or research.

- You may not further distribute the material or use it for any profit-making activity or commercial gain

If the publication is distributed under the terms of Article $25 \mathrm{fa}$ of the Dutch Copyright Act, indicated by the "Taverne" license above, 
Mapping Israel, Mapping Palestine 
(C) Copyright Jess Bier, Maastricht 2014

Printed by Datawyse | Universitaire Pers Maastricht 


\title{
Mapping Israel, Mapping Palestine:
}

\section{How Segregated Landscapes Shape}

\author{
Scientific Knowledge
}

\author{
DISSERTATION \\ To obtain the degree of Doctor at Maastricht University, \\ on the authority of the Rector Magnificus, Prof. dr. L.L.G. Soete \\ in accordance with the decision of the Board of Deans, to be defended in public \\ on Thursday, the $3^{\text {rd }}$ of April 2014 at 12.00 hours. \\ by \\ JESS BIER
}

born on 18 August 1980 in St. Louis, Missouri, USA 


\section{Supervisor}

Prof. dr. S. Wyatt

\section{Co-supervisor}

Dr. B. Van Heur, Free University of Brussels (VUB)

\section{Assessment Committee}

Prof. dr. ir. W.E. Bijker (Chair)

Prof. dr. C.M.J.M. van den Heuvel, University of Amsterdam

Dr. A. Hommels

Dr. J. Lachmund

Prof. dr. C. Parker, Ghent University

The printing of this dissertation has been financially supported by the Netherlands Graduate School for Science, Technology, and Modern Culture (WTMC) and the Faculty of Arts and Social Sciences (FASoS) at Maastricht University.

The map on the cover of this book is adapted from "The Occupied Palestinian Territory: Overview Map", which was produced in 2010 by the United Nations Office for the Coordination of Humanitarian Affairs (UNOCHA). 
In memory of Oliver Milton Bier 



\section{Contents}

List of Figures 9

List of Abbreviations 13

Dates Mentioned in the Text 15

$\begin{array}{ll}\text { Acknowledgements } & 17\end{array}$

1 Where Cartographies Collide 19

$\begin{array}{ll}\text { On the variegated use of maps } & 19\end{array}$

The Significance of Segregated Landscapes $\quad 23$

A Nation of Scattered Documents: $\quad 29$

Traveling Cartographers, Traveling Ethnography

$2 \quad$ The Materiality of Theory 37

Making Empires, Making Maps $\quad 40$

The Rational Landscape of Palestine and Israel $\quad 50$

GIS and Landscapes of Technological Practice 56

Conclusion: Postcolonial GIS $\quad 65$

3 Subtracting Palestinians and Remaking Borders: 67 Israeli Population Maps after 1967

$\begin{array}{ll}\text { The Methodology of Curfew } & 67\end{array}$

$\begin{array}{ll}\text { The Critical Cartography of Census History } & 73\end{array}$

Locating Existence under Occupation, $1968 \quad 76$

The War of Scattered Boundaries, 1999

Conclusion: The Continuity of Computer Cartography 92 
4 The Colonizer in the Computer:

International Influence in Palestinian Authority Maps

The Steadfast Colonial Legacy

Moving Mountains of Data: Mobilities Studies under Occupation 102

All the Data that Remains: The Stasis of British Mandate Maps 106

Staying Put in Palestine: Palestinian Authority Stasis 112

Preservation in Pieces: The Dispersal of Palestinian Data

5 Validating Segregated Observers:

Mapping West Bank Settlements from without and within

On the Appropriation of Empirical Facts

Triangulating Standpoints: Paradigms are Made in Landscapes 136

Mapping Israeli Settlements: An Atlas of Dirt 140

Mapping Palestinian Communities: Inside-Out 148 in Palestine

Conclusion: Validating the View from the Top of the Wall

6 The Geographic Production of Knowledge 163

Mapping This Book's Hidden, Ubiquitous International Landscapes 163

$\begin{array}{ll}\text { The Significance of Cartographic Maps } & 167\end{array}$

Appendix A: List of Interviews and Fieldwork 173

$\begin{array}{ll}\text { Bibliography } & 177\end{array}$

$\begin{array}{ll}\text { Samenvatting } & 201\end{array}$

$\begin{array}{ll}\text { Summary } & 207\end{array}$

$\begin{array}{ll}\text { About the Author } & 211\end{array}$ 


\section{List of Figures}

1.1 A Google Maps Screenshot from 29 June, 2010, showing the Western Wall placed mistakenly on the edge of East Jerusalem

1.2 A base map showing Israel and the Palestinian Territories, including the West Bank and Gaza Strip, as well as select major cities

2.1 A United Nations (UN) map of East Jerusalem which lists over one dozen borders and barrier types

3.1 An example of Roberto Bachi's Graphical Rational Patterns (GRPs): A Chart of the Symbols for the numbers from 1 to 100

3.2 An example of a Map Made Using GRPs: Detail of Jerusalem population from an Israeli state population map

3.31 A sample choropleth map from the 1961 Israeli census

3.32 A sample graduated circle map of Jewish population in Israel in 1953

3.4 A 1983 map showing subdistricts of Israel

3.5 A Later Map of Roberto Bachi's which compares graduated circles to GRPs

3.6 An annotated screenshot of Jerusalem from the Israeli Central Bureau of Statistics (CBS) online interactive map of 1995 Israeli census data

3.71 A map showing the extent of the development of an Israeli national GIS database as of 1996

3.72 A screenshot which gives the extent of Google Street View in Palestine and Israel as of August 2013.

3.81 A map of hotels inside the Tel Aviv-Jaffa municipal boundary

3.82 A map that shows a convex hull (line) around hotels in the Tel Aviv-Jaffa municipal boundary

4.1 A detail of a 1:250,000 scale British map of Jerusalem with 100 hand-drawn border overlay, said to be the original map where the Green Line boundary of the West Bank was drawn in wax 
pencil during ceasefire negotiations in 1949

4.2 A UN map of the West Bank which indicates Areas A and B, which are under full or partial Palestinian control, combined in light brown, and Israeli-controlled Area $\mathrm{C}$ in dark brown

4.3 A picture of ruins in the former Palestinian town of Lifta, near 107 Jerusalem

4.4 A picture of a professional NGO cartographer who is explaining the process of digitizing an aerial photograph

4.51 A broad scale British map of Jerusalem from 1945

4.52 A fine scale British map of Jerusalem from 1937

4.61 A map showing the extent of the completion of British topographical maps of historic Palestine as of 1945

4.62 A map showing the extent of the completion of British cadastral maps of historic Palestine as of 1945

4.7 A Palestinian Authority (PA) map of Nablus from 1997

4.8. A PA map of major roads in the full West Bank from 1997124

4.91 Two details of Nablus from a 1940 British Road Map made by 125 the Survey of Palestine

4.92 Two details of Nablus from the 1998 PA Road Map (Figure 4.8) 125

5.11 A map of the British triangulation network in historic Palestine in the late $1940 \mathrm{~s}$

5.12 A map of the Israeli triangulation network as of 2009

5.21 A photograph taken by an Applied Research Institute Jerusalem (ARIJ) field worker which shows a view of the Palestinian town of Taqu'a from within

5.22 A photograph taken from the window of the ARIJ offices which shows the Israeli settlement of Har Homa from without

5.23 A picture taken by the Peace Now Settlement Watch which shows the E-1 Israeli settlement area from within

5.31 An ARIJ map of the E1 settlement expansion plan and the Israeli settlement of Ma'ale Adumim

5.32 A Peace Now map of the E1 settlement expansion plan and the 
Israeli settlement of Ma'ale Adumim

5.4 An aerial image of Mishor Adumim which shows buildings and roads at the reported site of an Israeli military base

5.51 Detail of a Peace Now settlement map (Figure 5.22), showing Mishor Adumim, but without a military base

5.52 Detail of an ARIJ settlement map (Figure 5.21), showing Mishor Adumim and a military base

5.53 Detail of a B'Tselem and Eyal Weizman settlement map, showing Mishor Adumim and a military base

5.54 Detail of a UNOCHA settlement map, showing a military base but omitting much of Mishor Adumim

5.61 A detail of a Palestinian Land Use/Land Cover (LULC) map which indicates Israeli settlements, from 2008

5.62 A detail of a Peace Now map of Israeli settlements in the West bank from 2011. The map combines data from the Palestinian Central Bureau of Statistics (PCBS) and the Israeli CBS.

5.7 A photograph said to be of Palestinian teenagers climbing the Wall to go to Friday prayers in the Old City of Jerusalem during Ramadan in 2013. 



\section{List of Abbreviations}

\begin{tabular}{|c|c|}
\hline ARIJ & Applied Research Institute Jerusalem \\
\hline CBS & (Israeli) Central Bureau of Statistics \\
\hline GIS & Geographic Information Science \\
\hline GRP & Graphical Rational Patterns \\
\hline IDF & Israeli Defense Forces (military) \\
\hline LULC & Land Use/Land Cover map \\
\hline $\begin{array}{l}\text { MOP } \\
\text { (MOPIC) }\end{array}$ & $\begin{array}{l}\text { PA Ministry of Planning, formerly Ministry of Planning and } \\
\text { International Cooperation }\end{array}$ \\
\hline NGO & Non-Governmental Organization \\
\hline OPT & $\begin{array}{l}\text { Occupied Palestinian Territories } \\
\text { (West Bank, East Jerusalem, Gaza Strip) }\end{array}$ \\
\hline PA & Palestinian Authority \\
\hline PACBI & $\begin{array}{l}\text { Palestinian Campaign for the Academic and Cultural Boycott of } \\
\text { Israel }\end{array}$ \\
\hline PCBS & Palestinian Central Bureau of Statistics \\
\hline PLO & Palestinian Liberation Organization \\
\hline PPIB & Physical Planning and Institution Building \\
\hline SOI & Survey of Israel \\
\hline STS & Science and Technology Studies \\
\hline UNOCHA-OPT & $\begin{array}{l}\text { United Nations (UN) Office for the Coordination of } \\
\text { Humanitarian Affairs in the OPT }\end{array}$ \\
\hline UNRWA & $\begin{array}{l}\text { United Nations (UN) Relief and Works Agency for Palestinian } \\
\text { Refugees in the Middle East }\end{array}$ \\
\hline
\end{tabular}





\section{Dates Mentioned in the Text}

1920-1948

1948

1948-1949

1949-1967

1967

1987

1993-1995

1995

2000

2008
British Mandate (occupation) in Palestine

UN Partition Resolution 181 leads to civil war and the exodus of substantial numbers of Palestinians, an event known in Arabic as the Nakba or 'catastrophe'.

The State of Israel is declared on the day before the British Mandate expires.

War breaks out between Jewish and broader Arab forces in the region.

During the ceasefire negotiations, the boundaries (Green Line) of the West Bank and Gaza Strip are first created, and they are put under respective Jordanian and Egyptian control. Jerusalem is divided.

After a war between Israel and Arab forces, Israel begins its occupation of the West Bank, East Jerusalem, and Gaza Strip. A census is conducted, and Israeli settlers begin moving to the West Bank.

The First Intifada, a major Palestinian uprising against Israeli rule, begins.

The Oslo Accords are signed, leading to the founding of the PA with limited rule in the Gaza Strip and West Bank. East Jerusalem remains annexed to Israel.

The CBS conducts the first Israeli census to make extensive use of GIS maps.

The Second Intifada begins. Israel starts constructing the separation Wall.

The Hamas party wins the Palestinian elections and assumes control of the Gaza Strip. After a struggle, Fatah remains in control of the PA in the West Bank 



\section{Acknowledgements}

I began this book by redefining my own geographical boundaries to include Maastricht. Sally Wyatt and Bas van Heur, my co-promoters, were supportive from the very first email, even as they challenged me to specify and extend my ideas. In this, they were joined by my colleagues in the Technology and Society Department at Maastricht University, many of whom have read chapters from this book in draft form at departmental seminars and the annual Summer Harvest. Matthijs Kouw and Bas van Heur played an important role in helping me to get settled both intellectually and personally, as did numerous colleagues and friends who enriched my time there, including Gili Yaron, Alexandra Supper, Koen Beumer, Eefje Cleophas, Anna Harris, Thomas Fuller, Jessica Mesman, and Veronica Davidov. Maastricht was an ideal place to undertake a Ph.D., allowing for both the freedom and support necessary to bring this research into being. My conception of how theory informs the process of research has been thoroughly shaped by the chair and coordinators of the Netherlands Graduate Research School of Science, Technology, and Modern Culture (WTMC). They include Willem Halffman and Teun Zuiderent-Jerak, as well as the many other Ph.D.'s, and the anchor teachers Geoffrey Bowker and Helen Verran. The WTMC also helped to support the printing of this book.

My fieldwork was made possible through the generosity of many in Palestine and Israel who shared their time and expertise. Jaad Isaac and the colleagues of the Applied Research Institute, Jerusalem (ARIJ) provided invaluable assistance and hospitality. Riham Dweib answered endless questions and made me feel incredibly welcome. Many others did so as well, including Ahmad, Issa, Sari, Ayman, Laila, Raed, and Suhail, as well as Stefan Ziegler and the staff of the Border Monitoring Unit at the United Nation Refugee and Works Association (UNRWA). Numerous cartographers in Palestine and Israel explained their work to me with great patience. Many of them guided my dumbstruck self back and forth across hills, checkpoints, walls, and innumerable borders-Riham in mini-buses and taxis, Hagit Ofran in her truck, and Sahar and Rotem on foot. In addition, Khaldun, Lilach, Lika, Tammy, Shelby, Zuzanna, Dan, and Katie regularly invited me to events and welcomed me into their homes.

A number of scholars drank coffee with me, even when I could offer nothing but questions and more questions, including Khalil Tufakji, Anat Leibler, Dov Gavish, Oren Yiftachel, Omar Salamanca, and Irma van der Ploeg. Christine Leuenberger ensured that this research got off to a rapid start and helped to keep it productive throughout. Faculty at Birzeit University and Tel Aviv University spoke at length about their work. With Riham's help, at Birzeit they also saved a place for me in the bus for field workshops and graduate seminars. The staff in numerous archives were invaluable, helping in the name of research even when they were not entirely 
sure of my academic motives. They include Oded Fluss at the National Library of Israel and Hana Pinshow at the Ben Gurion Research Institute, as well as staff at the ARIJ Library, the GIS Unit at the Central Bureau of Statistics, and the Tel Aviv University Map Library.

In my current position as a Postdoctoral Fellow in the Monitoring Modernities group at Erasmus University of Rotterdam, I have the privilege of continuing to work on the key concerns that motivate this book, albeit on the new topic of financial regulation. Willem Schinkel has been truly welcoming, and he has assembled a unique group, including Maja Hertogs, Sanne Boersma, Rogier van Reekum, and external members such as Irene van Oorschot. I am grateful to be part of it. It was a luxury to finish my dissertation with the knowledge that I would soon begin a new project in such a stimulating environment. Bethany Hipple Walters, with the help of Carey and Tinneke, helped to make the transition a smooth one. (Thank you for not letting me drop the precious washing machine down the stairs.) Thomas Pablo Sciarone designed the cover precisely to my wishes-but far better than I could have-and Wytske Versteeg did an expert job of writing the Dutch translation of my rather dense English summary, both of which appear at the back of this book.

On a personal level, this project really began when I studied in Cairo in the fall of 2000, if not before. However, academically, it dates to my time at the City University of New York (CUNY). At CUNY, Marianna Pavlovskaya was instrumental to my development as a writer, always pushing me to take arguments one step further. Cindi Katz, Neil Smith, and Joseph Massad provided invaluable feedback. William Tutol and Elinore Pedro helped me to survive our evening classes, making sure I always had dinner.

My family has always been incredibly supportive. My parents never said 'no' to buying me a book, and often went to great lengths to find specific ones that I requested, my mother combing stacks at local libraries, and my father scouring bookstores during his travels. My brothers Ben and Ethan-as well as Sandy, Rachel, Lucas, Carter, Natalie, Oliver, Declan, and Baby B.--kept me honest, forcing me to occasionally put down the books, to focus on the world around us. Our extended family in California and New Jersey made sure I got into enough trouble to keep things interesting, but never too much that it wasn't possible to get out of it again.

Jayne DeBattista has enriched my life more than I can say, in ways that improved my writing and researching beyond measure. Her impact goes far beyond this book, and she read every word. Amy Hay Howard has long indulged my love of obscure technical details, and thanks to her I've gotten to know Andy and Sasha. Claude the cat always kept my writing warm by sleeping soundly on top of the keyboard, whether I was using it or not. Over the years, many friends have contributed to the process of cooking, laughing, and forever playing with new ideas, including Alejandra Gonzalez, Amira Mittermaier, and Samantha Severin. Lastly, the writing of my dissertation coincided with the devastating loss of my young nephew Oliver, when he was still a baby, to a rare form of brain cancer. This book is dedicated to him, because more than ever, his death reminds me of the importance of every life. 


\section{CHAPTER 1}

\section{Where Cartographies Collide}

\section{On the Variegated Use of Maps}

"We don't use maps in Palestine," a colleague told me soon after my return to the region in 2011 to conduct the fieldwork that would lead to this book, "It's a small country. We know where we're going." He was mostly joking, but it was a refrain that I was to hear many times during interviews: maps make interesting decorations to put on a wall, or useful tools for political negotiations, but they're not necessary for getting around. This attitude stemmed in part from the fact that maps of the region, even though there are a plethora of them, are often misleading. As recently as 2010, Google Maps misplaced the Western Wall, one of the most famous religious sites in the world, putting it almost 1 kilometer off target on the edge of East Jerusalem, the Palestinian part of the city (Figure 1.1); its location has since been updated.

Sometimes the process of using maps can be confusing due to constant changes in the landscape. In the context of the ongoing Israeli Occupation of East Jerusalem, the West Bank, and the Gaza Strip since 1967, intermittent Israeli military roadblocks and checkpoints are regularly enforced, and the calculated unpredictability of such obstructions has made many maps, such as the UN closure maps (UNOCHA 2008), obsolete as travel tools before they were even printed. Where travel maps of the West Bank do exist, they are produced primarily for Christian pilgrims from elsewhere. The vice-president of a local map company noted that the "street map and the tourist map, they are both the same for us, because it's all for tourists." He stopped to add that occasionally local corporations do commission wall maps to be given out as gifts (Interview 2, cartographer in private Palestinian geoinformatics firm). The bemusement which sometimes greeted my constant questions about maps is broadly reminiscent of Latour's discussion, in Science in Action, of the Chinese navigators encountered by the French explorer Lapérouse. The Navigators, Latour writes, "were not all that interested in maps and inscriptions-not because 
they are unable to draw them (on the contrary their abilities surprise Lapérouse very much) but simply because the inscriptions are not the final goal of their travel" (Latour 1987, 218, emphasis in original). As with the navigators, many whom I spoke to, like the colleague I quote above, emphasized the importance of interpersonal relationships over paper printouts of a map-particularly when the maps were so often limited in their usefulness. ${ }^{1}$ By contrast, in Israel the use of maps is more common as part of everyday life, but it doesn't exclude other means of finding one's way. Even the spread of digital cartographic technology, intended in part to make maps more accessible, has not precluded recourse to navigation methods that don't involve maps. One commenter on the website of Ha'aretz, Israel's well-known

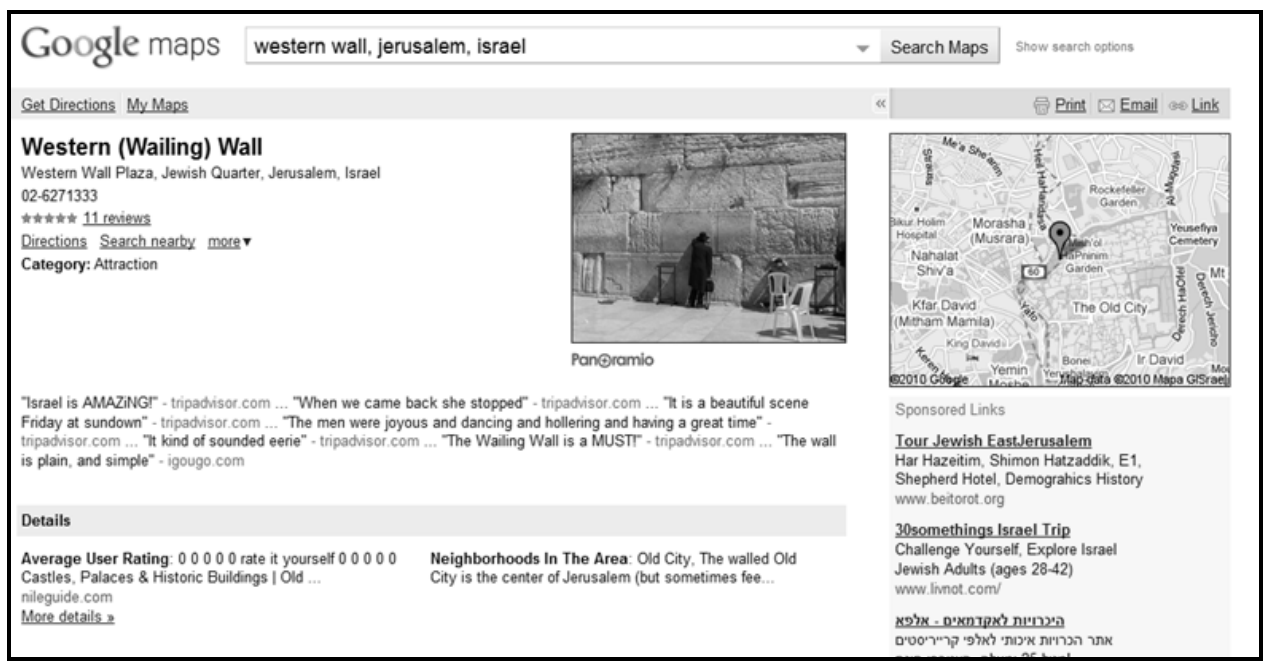

Figure 1.1. A Google Maps Screenshot from 29 June, 2010, showing the Western Wall placed on the edge of East Jerusalem, north of the Old City, instead of by the Temple Mount in the Old City's southeast corner.

\footnotetext{
${ }^{1}$ See the Appendix for a numbered list of interviews cited, as well as a complete list of organizations where I conducted interviews, participant-observation, and followed additional field tours. I only quote those interviews and meetings for which an audio recording or, in rare cases, verbatim notes exist. All translations are my own, except where indicated. When transliterating Arabic and Hebrew terms, I used accepted English spellings for geographic features, titles of textual sources, and some common words, in cases where they exist. I also omitted diacritics for purposes of readability, given that most of the terms are in widespread use. In cases where particular individuals have preferred transliterations of their own names, I use these. Otherwise I follow the American Library Association-Library of Congress transliteration system, with only minor additional variations for readability, depending on the context.
} 
newspaper, criticized the Israeli government's unsuccessful legal battle to prevent Google Street View, which allows internet users to view pictures of streets taken at ground level, from coming to Israel. Opponents of Street View worried that, if it were allowed, then it would make it possible to find sensitive sites like the Israeli prime minister's mansion (Hasson 2012a; Yaron 2012; Yaron 2011; Zrahiya 2011). However, the commenter responded that such locations can be easily found without any map, "Thousands of Israelis demonstrate at the [prime minister's] residence. Terrorists can just ask a cab driver or anyone in Jerusalem" (Hasson 2012a). The comment appeals to powers of observation, which are assumed to be equally accessible to everyone in the landscape. It also dispels some of the paranoia with respect to maps as secret repositories of classified information-an attitude which, by restricting access to data, contributes to their limited effectiveness in contested areas. Maps, however central to political debates, are not absolutely necessary for finding the way; "terrorists" can simply ask for directions to find landmarks that "anyone" can see.

The non-use (Wyatt 2008b; Wyatt 2003) of maps as a way to find a destination doesn't prevent maps of Palestine and Israel from being made. Quite the contrary, they are produced every day, and Jerusalem has been one of the most regularly mapped places on Earth, with early images dating from the $6^{\text {th }}$-century Madaba mosaic in Jordan. However, the maps are often highly selective, in terms of both which features, and which areas, they display. Furthermore, they are often created as part of the struggle over facts in political disputes, and this highlights the international dimension of cartography in the region. Many of the maps are intended for audiences abroad at least as much as for local ones, and until the mid- $20^{\text {th }}$ century, maps of Palestine and Israel also have generally been made by people who originated, or were trained, elsewhere.

The introduction of computer mapmaking has reshaped the international bent of many maps in the region. The use of digital cartographic technology such as Geographic Information Science (GIS) map-making software, much of which is sold by corporations which are based in Europe and North America, has partially tightened the international hold on cartography in Palestine and Israel. In addition, in the context of political struggles, international viewers remain a central audience for Palestinian and Israeli maps (see Chapter 5). However, as GIS was brought into the region in the latter $20^{\text {th }}$ century and further developed there, it was intended to help broaden the pool of cartographers, in part by reducing the initial costs necessary to begin making maps. While nonetheless still expensive, the use of GIS software-in combination with the increasing availability of free online mapmaking tools-has led to the further incorporation of locally-trained Palestinians and Israelis from diverse backgrounds. In the process, the use of GIS has also helped to instantiate what is not just a different computer program, but a digital paradigm for traveling through space and viewing the world.

Early $21^{\text {st }}$ century cartography includes a range of practices in Jerusalem and the West Bank, from adaptations of decommissioned spy satellite images to a road 
map made by Palestinian students who tracked their own movements on their mobile phones. Yet GIS and the practices of cartography more broadly have also changed through their wider incorporation in the region, in part through the heavily segregated geographic landscapes of the Israeli Occupation, which the cartographers must move through and live within, in order to produce their maps. Such physical boundaries reflect, and reverberate across, political divisions, shaping and separating communities of cartographers on either side, thereby allowing for the creation of divergent methodologies and standards of practice. While there is no reason to contend that this paradigm might be more or less effective in Palestine and Israel than anywhere else (See Mitchell's paraphrase of Chakrabarty in T. Mitchell 2002, 7) the specific influence of the regional landscapes of Palestine and Israel highlight central issues in the use of GIS which are of interest everywhere where digital cartographic technology is used.

How have these geographies - including both the occupied landscapes of Palestine and the international landscapes of science and technology-affected cartographic practice across space and time? The ways that cartography becomes embedded in landscapes which are at once material and social is the subject of this book. Through three representative cases on publicly-available population, governance, and urban maps, I attempt to answer this question by analyzing how specific aspects of these segregated landscapes have shaped the process of making maps, and thus geographic knowledge, of Jerusalem and the West Bank from 1967to the present. $^{2}$ While technology is often believed to provide an objective perspective, here I investigate how all knowledge is embedded in specific times, places, and cultures-including international cultures of technoscience. Therefore, I critique the notion that technology functions as an impartial arbiter in disputes that are said to hinge on empirical observations on the ground.

The work is structured symmetrically between (self-defined) Palestinian and Israeli accounts, but rather than suggesting that Palestinians and Israelis are treated equally, I employ symmetry precisely to highlight imbalances of power among Palestinian and Israeli cartographers, although both come from technical elites. I use symmetry in a different sense than that included in the call by the Palestinian Campaign for the Academic and Cultural Boycott of Israel (PACBI), which states that "supporters are asked to refrain from participating in any event that morally or politically equates the oppressor and oppressed, and presents the relationship

\footnotetext{
${ }^{2}$ I was prevented from studying currently classified maps for the simple reason that I had no access to them whatsoever. However, since my interest was primarily in how maps are produced to influence public scientific and political debates, a lack of access to secret maps was less of a hindrance than might be expected. Thus this book only addresses military cartographic technologies and maps in cases where they have been adapted for unclassified use. For an attempt to grapple with the liminal character of classified knowledges, see Rappert (2009). For an analysis of the impact of censorship and classified knowledge upon academia in Israel, see Forte (2003).
} 
between Palestinians and Israelis as symmetrical" (PACBI 2011; PACBI 2009). ${ }^{3}$ As with the wider effort to achieve symmetry in STS (Wyatt 2008a) which I discuss in more detail in Chapter 2, here I use symmetry precisely to bring such imbalances of power into starker relief. Focusing across boundaries in this way allows for an analysis of how group divisions are reinforced through scientific practices in local and regional landscapes, one that also incorporates the ways that such imbalances reverberate across international hierarchies which differently affect Palestinians and Israelis, thereby serving to reproduce systemic injustice.

\section{The Significance of Segregated Landscapes}

Maps are central to debates over the future of Palestine and Israel, and this has only intensified since the advent of digital cartography led to increasingly minute surveillance and control (Abujidi 2011; Weizman 2007). Summarizing critical boundary theory, Janice E. Thompson notes that while "there is a marked tendency to accept boundaries as given, permanent, and even natural [....] On the contrary, they are arbitrary, contested, and ever-changing" (Thomson 1996,13). While Thompson is referring to the implementation of boundaries on the ground, a similar argument could be made for the boundaries displayed on maps, which are influenced by the cartographers' own positions in relation to the contested borders they draw. Intended to display objective facts, empirical maps often inspire tense discussions, with participants exhibiting a variety of observational frames that cannot be divorced from their unequal positions within the very terrains that they seek to portray. However, my purpose here is not to investigate the veracity of particular claims, but to consider how knowledge is materially situated in ways that go beyond a dichotomy between truth and falsity (Harley 2001; Swedenburg 1995). By elaborating on the ways that knowledge is geographically, as well as socially and culturally, produced, this book contributes to fields like Science and Technology Studies (STS), Geography, and Anthropology. Furthermore, by exploring how borders have shaped the mobility of cartographers in a region that has become an "iconic model of geopolitical spatial dilemmas" (Abujidi 2011, 313), this book is

\footnotetext{
3 The boycott is increasingly felt in international academic circles. In addition to numerous calls against participation in academic conferences in Israel. This was seen, for example in the extensive discussion on the Critical Geography listserv regarding whether international academics should attend the 2010 International Geographical Union (IGU) annual conference, which was in Tel Aviv. It is also filtering into academic publishing. For example, when Zone Books issued a recent edited volume, The Power of Inclusive Exclusion, with a thin slip of printer paper in the front cover noting that, "although the research group which was the genesis of this publication was funded by the [Israeli] Van Leer Jerusalem Institute [...] the publisher of this volume [...] received no funding or other support from the Van Leer Jerusalem Institute, nor is Zone Books in any way associated with that institution" (Ophir, Givoni, and Hanafi 2009).
} 
relevant to a growing body of literature on the roles of technology and academic knowledge in entrenching the Occupation in space (Abu El-Haj 2001; Aouragh 2011; Leibler and Breslau 2005; Ophir, Givoni, and Hanafi 2009; Weizman 2007; Zureik, Lyon, and Abu-Laban 2011) as well as a broad variety of studies of the intersections of power and expertise (Foucault 1986; Haraway 1988; T. Mitchell 2002).

This book is organized chronologically, moving from the mid-20th century's broad-scale attempts at mapping rigidly defined territories to the increasingly compartmentalized contemporary efforts that have followed the establishment of the Palestinian Authority (PA) in the mid-1990s - and the intensification of microscale conflicts over sovereignty in the West Bank. In Chapter 2, I argue for the benefits of studying the geographic production of technology, which requires a combination of literature in geography with STS research. I begin by exploring geographical studies of cartography and empire in combination with literature on the production of urban landscapes. Next, I bring together STS literature with work in the emerging field of Critical GIS, in order to explore the symmetrical framework of my overall analysis of GIS practice. Throughout the chapter, I develop these claims through an investigation of how the landscape of Palestine and Israel was developed after 1948 in ways that privileged narrow forms of rationality above all other concerns-and which, paradoxically, led to a contemporary landscape whose affects often appear to be irrational.

In Chapter 3, I study official Israeli population cartography. The Israeli census is conducted by the Central Bureau of Statistics (CBS), which periodically carries out a direct count of the total number of inhabitants of Israel and collects statistical information related to population. As such, the census has played a central role in a conflict where demographic fears are paramount. Population maps, traditionally one of the only forms of professional maps which displayed people (instead of geographic features like tracts of land), make heavy use of statistical methods and were one of the first types of maps to be made on a computer. With this in mind, I analyze the alternating inclusion and exclusion of Palestinians on Israeli census maps, 1967-1995, in order to show how even the most abstract facts are conditioned by the landscapes where they are produced. Through an exploration of the geostatistical methods developed by Roberto Bachi, long the head of the CBS, I show how the types of mathematics that Bachi used were altered by his attempts to make maps that were scientifically accurate while at the same time avoiding indicating local Palestinian populations. So even though Palestinians do not always appear on Bachi's maps, the fact that there were significant numbers of Palestinians living in the landscapes that Bachi was mapping in turn affected the types of maps that Bachi made.

In Chapter 4, I examine more recent official Palestinian cartography. I investigate how past and present colonial legacies circumscribe the scale and extent of PA cartography amid attempts to practice sumud, or steadfastness against the Occupation, in the post-Oslo period (Allen 2008). While studies of the Occupation since the 
year 2000 have often focused on the restriction of mobility, I argue that stasis, or the ability to stay in place, is also central focus of Palestinian efforts. Curtailed mobilities indeed hamper PA cartographers working in the West Bank, but equally important are restrictions on their ability to stay reliably within portions of the landscape, without experiencing aggression from the military or the settlers, in order to set up surveying equipment and take more extended readings of the land. This combines with ongoing raids against PA infrastructure and databases by the Israeli military, as well as a shift in the locations of institutions and organizations away from Jerusalem due in part to the building of the Wall and restrictive permit regimes. These current challenges to PA stasis combine with legacies of British cartography in the region in ways that intrinsically shape the content of PA maps in ways that are not visible simply by analyzing the final map.

In Chapter 5, I build on the two earlier cases of state cartography through an exploration of alternative urban maps made by non-governmental organizations (NGOs). I compare recent maps of Israeli West Bank settlements made by one Palestinian and one Israeli NGO in order to demonstrate how intricately segregation affects the process of collecting the geographic data that is used to make maps. Segregated landscapes not only separate populations based on preconceived definitions of group belonging, but they also serve to reify mutually exclusive forms of identity and reproduce disjunct observations among cartographers who map areas, and use technologies, that ostensibly are the same. Geographic facts and statistics on settlement expansion are based on observations on the ground of the extent of urban areas. These in turn are determined by observing the locations of particular buildings, roads, and fences which cartographers, for their own safety, may only be able to view from a distance. Thus the empirical nature of data collection is still central to digital cartography. Furthermore, while Israeli efforts take place largely within Israeli settlements, thereby depicting Palestinian areas from without, for Palestinians it is the opposite. Palestinians work within the Palestinian West Bank, but must map the same settlement from without. In theory, this difference should not affect the data collected, but which in practice has a profound effect on the resulting maps. Overall then, this book represents an attempt to intervene in debates over the Occupation by demonstrating that no single group-including Israeli, Palestinian, and international-has a monopoly on the decision of which scientific facts should be accepted as true.

To better understand how earnest work to rationalize and simplify a complex political landscape might instead lead to further complexity, it is necessary to investigate the impact that landscapes, including those of 1948 and 1967, have differently affected the lives of both cartographers and their maps. With this in mind, in this introductory chapter I next provide a brief account of cartography in the changing landscapes of Palestine and Israel after 1948, and then illustrate my arguments about the significance of landscapes through a retelling of the stories of two re- 
markably similar, yet at the same time vastly different, cartographers: Sami Hadawi and David Amiran. 4

Hadawi and Amiran were rough contemporaries-their lives each spanning nearly the whole of the 20th century-but changing imbalances of power followed them throughout their lives. Hadawi, a Palestinian scholar, spent his time documenting the land and people of Jerusalem and the surrounding regions from afar after 1948, while Amiran, a Jewish academic who fled the rise of the Nazis in Germany, would go on to become one of the preeminent Israeli geographers of the post-war period, noted for his wide-ranging travels in the local region. However, although both Amiran and Hadawi were refugees, Amiran's local travels were only made possible by the exclusion of Palestinians, including Hadawi and his wife. Bringing Hadawi's and Amiran's lives together not only permits an exploration of how unequal landscapes shaped their work, but also makes it possible to turn the argument around and better understand how the local, national, and international scales themselves were produced as unequal hierarchies (Bank and Van Heur 2007; N. Smith 1992) -albeit without falling into the blunt "macroconcerns" of broad approaches (Latour and Woolgar 1986, 17). The analysis of Hadawi and Amiran thereby provides a fitting introduction to the following sections of this chapter. In those sections, I discuss the method of traveling ethnography, which I developed in the course of writing this book, and which takes into account the ways that such imbalances in the material trajectories of scholars' lives-including my own-affect the resulting research.

\section{The Production of Cartographic Knowledge in Palestine and Israel}

The territories that comprise contemporary Palestine and Israel have been mapped and re-mapped countless times, and the long history of cartography in the area provides a rich basis for comparison between historical and contemporary practices (Figure 1.2). To give just a few examples, in addition to a host of Biblicallyinspired maps of the Holy Land, as well as any number of maps drawn independently by travelers to the region in recent centuries, several major cartographic projects were undertaken in the region beginning in the late $18^{\text {th }}$ century. After the topographic maps made by the French military during Napoleon's 1799 invasion, the first large-scale maps were produced under the Ottoman authorities in 1887 in connection with public works in the Hulah Valley (Gavish and Ben-Porath 2003). In the same decade, the British-led Palestine Exploration Fund produced detailed maps to aid pilgrims and authorities (Levin 2006). These were extended with systematic land ownership surveys of the territory covered by the British Mandate (1920-1948), which represented the last major state map-making project in the region before the establishment of the state of Israel (Gavish 2005).

\footnotetext{
${ }^{4}$ Both Hadawi and Amiran are said with short $a$ sounds, as in the word $a h$, and long $i$ sounds, as in we.
} 
Soon after Israel's declaration of statehood on May 14, 1948, cartographers set to work developing Israeli state cartography. Barely one year later, Ben-Gurion, the first prime minister, appointed a Governmental Names committee, including key members of the pre-existing Jewish Palestine Exploration Society, to determine Hebrew names for all of the villages, rivers, lakes, roads, mountains, and other geographical features. This initiative was part of an overall process whereby Arabic names were actively erased, names which were defined as foreign in the context of the Bible, which provided an almost 2,000 year-old description of the geography of the region. Almost overnight, the toponymy was transformed, with the overall effect that by the 1960s a standardized national geography of Israel could be said to have emerged through close collaboration among diverse groups of public andprivate sector cartographers (Abu El-Haj 2002; Srebro 2009), and this simulta-

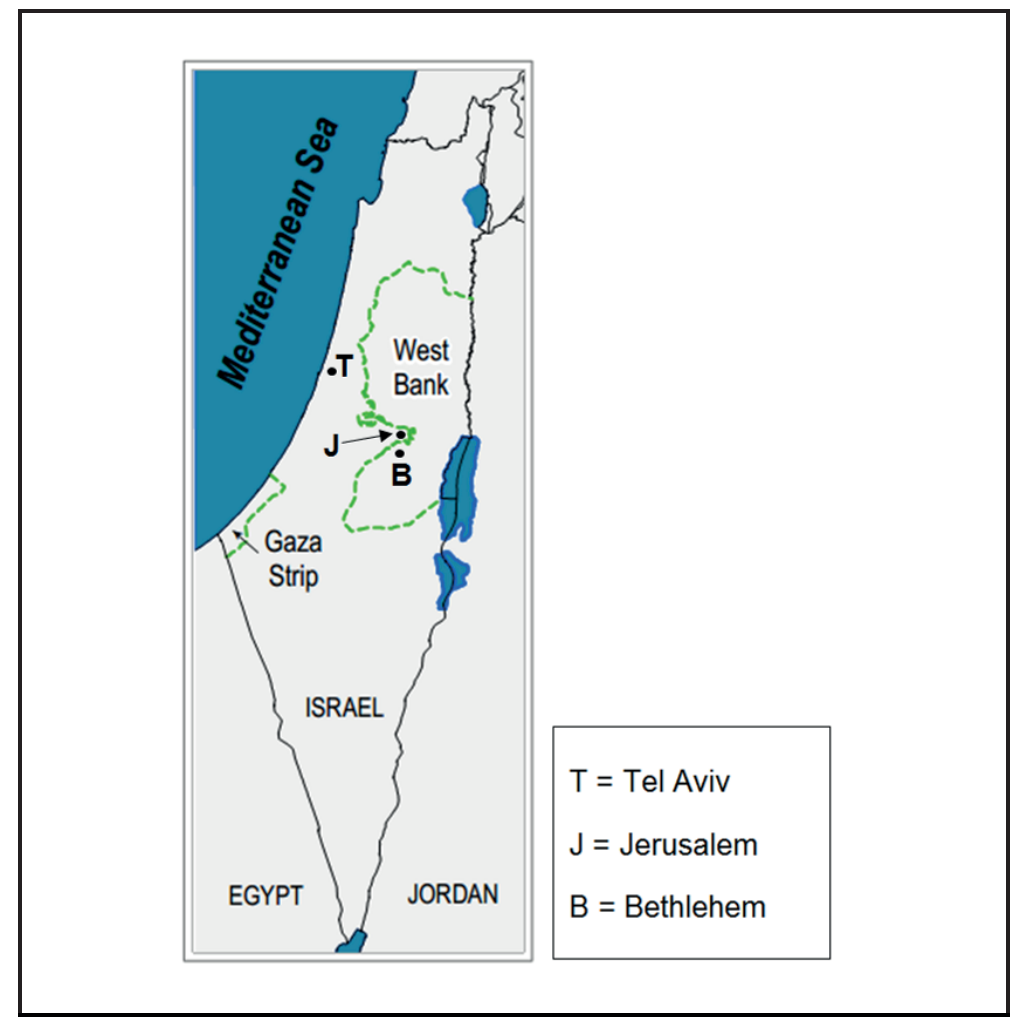

Figure 1.2: A base map showing Israel and the Palestinian Territories, including the West Bank and Gaza Strip, as well as select major cities. Politically, East Jerusalem is also considered part of the Palestinian Territories, but in practice it is largely severed from the West Bank. The city annotations, whose locations are approximate, have been added by the author. Ramallah (not shown) is north of Jerusalem. Detail from (UNOCHA 2010a). 
neously led to a feeling of loss even for those Palestinians who were able to remain on the land, due to its sudden unfamiliarity (Scham 2003, 75).

Israel's victory during the six-day war of 1967 drastically expanded the territory under Israeli control. In addition to capturing the Sinai Peninsula and portions of the previously Syrian-controlled Golan Heights, the Israeli military occupied East Jerusalem and the West Bank, as well as the Gaza Strip, territories that previously had been under (respectively) Jordanian and Egyptian administration. The West Bank and the Gaza Strip in particular, viewed as the potential core of a future Palestinian state, would become the focus of political negotiations and international humanitarian aid to the Palestinians. Following 1967, the Israeli government argued that the West Bank and Gaza Strip were part of Israel, and no longer showed their borders on Israeli maps. The 1967 war thus did more than reinscribe political realities, it also brought into question the nature of Israeli state borders themselves. From being an avowedly homogeneous state-albeit one that was made so through the exclusion of Palestinian refugees - whose contested areas were located outside of Israel proper, after 1967 the Israeli military managed both the Gaza Strip and the West Bank, although with the exception of East Jerusalem, the Territories have yet to be formally annexed to the state.

Until the adoption of the disengagement plan in 2004, the Israeli Civil Administration-the Israeli government's term for the Occupation authorities-took an active role in the daily management of the Occupied Territories. Yet, after the Oslo Accords in the mid-1990s, the newly-created Palestinian Authority was granted jurisdiction over large cities and population areas within the Territories. The result was a proliferation of territories of varying degrees of official local and international control. These, through their geographical relationships with and resulting access to surrounding zones, amounted to multiple ambiguous forms of sovereignty, all within territory that was ostensibly part of the Israeli state-despite the official illegality of the Israeli Occupation under international law (Weizman 2007). Throughout this period, the mapping of these densely fragmented territories would become a central focus of cartographers working in Palestine and Israel The complexity of changes in the landscape-a proliferation of borders of multiple sovereignties in relation to the borders of the nation of Israel-evolved in concert with emerging GIS mapmaking practices which allowed for increasingly detailed depictions of ever more minuscule parcels of land. At least since the late 1970s, Palestine and Israel have been considered a key region for the emergence of high-tech industries, including geospatial technologies such as remote sensing and computer cartography. Far from being part of a unidirectional technology transfer from the West to the Middle East, Palestinian and Israeli cartographic practices made early contributions to the broader transition from the hand-made paper maps of traditional cartography to the data-rich maps now in wide use through internet sites such as Open Street Map and Google Maps. Digital map-making in Palestine and Israel can be seen as both a response to the need to administer contested lands and an ena- 
bling mechanism which allowed for maps to be made at much greater resolution at ever finer scales, thereby providing for wider options and increasingly minute maneuvering in the political definitions of land (Weizman 2007).

Although GIS has been employed as a conflict resolution tool, the increased level of detail and alleged accuracy has led neither to a lessening of the importance of territory (Newman 2001) nor to a straightforward resolution of political debates. Despite the advent of computer cartography, cartographers regularly make competing factual claims regarding Jerusalem, and it is therefore a key area to study the production of scientific knowledge. This is particularly apparent in light of the fact that GIS and digital cartography were developed within the context of the advent of computers in the late 20th century, and which shaped such systems-that allegedly allow anywhere to be mapped from anywhere-in specific ways. Rather than solely emphasizing the methodological break initiated through the development of computers, however, such research must include a better understanding of how computer cartography connects with prior practices, as I discuss in Chapter $2 .{ }^{5}$ With this in mind, I now turn to an analysis of two quantitative cartographers who would help to lay the groundwork for the later incorporation of GIS technology. Although their stories are by no means wholly commensurable, nonetheless they allow me to explore the combined material and social conditions of their lives-including where they were allowed to live and travel-while also simultaneously highlighting the related empirical paradigms in which they worked.

\section{A Nation of Scattered Documents: Traveling Cartographers, Traveling Ethnography}

The son of a Palestinian mother and Iraqi father, Sami Hadawi was born in Jerusalem in 1904, and he spent part of his childhood in Jordan after his father was killed while fighting for the Ottomans in World War I. He worked as a translator there before returning to Mandate Palestine to serve under the British, who were conducting a survey of the land in order to document claims to land ownership. In 1948, Hadawi became a refugee together with his wife, losing the home they had built in the Jerusalem suburb of Katamon along with most of their belongings. From 1948 until his death in 2004, Hadawi worked tirelessly, to produce facts about the people of Palestine, this time focusing on property that had been confiscated by the newly created state of Israel. With this in mind, perhaps it is not surprising that Hadawi ended up in New York, as the Land Specialist for the UN Conciliation Commission for Palestine in 1952.

\footnotetext{
${ }^{5}$ Part of the challenge of studying quantitative cartographers from the mid- to late- $20^{\text {th }}$ century is that they often do not speak at length on their methods, as such things were expected to be entirely clear and apparent, and so not worthy of discussion.
} 
At the UN, Hadawi attempted to combine all of the diverse property records relating to Palestinian land ownership in one place, in the hope that compensation one day might be granted. Much of his time was spent collecting and shipping key documents across borders-borders that were international by definition given that the state of Palestine had yet to be recognized - in the hope of finding them a stable and accessible home. It was an attempt to change the international system from within, by appealing to the same international laws and decrees that had overseen the Palestinians' dispersal. In the words of Izzat Tannous, the director of the Palestine Arab Refugee Office in New York, where Hadawi worked after he left the UN, their shared goal was to "place before the American people, the Government [sic], and the United Nations, the true facts about the situation in Palestine" (Tannous in Hadawi 1957, n.p.).

Out of necessity, then, Hadawi became a collector of documents, sending representatives to Jerusalem from the supposedly neutral territory of New York, fighting for the right to copy or obtain records that had been seized by the Israelis. In so doing, he also struggled against inequalities in access. The Israeli state was given copies of many British records which were not in their possession in the immediate aftermath of 1948 (Gavish 2005), yet the same achievement took a consistent effort over twenty years by individuals like Hadawi, and representatives of governments in the Arab world. Documents were even the reason why Hadawi ended up a refugee rather than an Israeli citizen. At the time of the ceasefire, he was in East Jerusalem delivering a group of Palestinian land records to the Arab High Committee, the main political body on the Arab side. If instead he had been in West Jerusalem, where his home was, and had transferred the documents to a central depot as per British orders, then Hadawi would have been made an Israeli citizen after the ceasefire, and the documents would have ended up in the hands of the Zionist forces (Fischbach 2003, 213-14).

\section{Building the Lab, Clearing the Field}

Amiran was born in Berlin in 1910, making him just six years older than Hadawi. He too became a refugee when, after leaving Germany to work as part of a scientific survey in Moscow, the rise of the Nazis made it difficult for him, as a Jewish person, to return. He thereby narrowly escaped the Holocaust, moving first to Switzerland, where he completed his $\mathrm{PhD}$, and then to Israel. Amiran arrived in Jerusalem in 1935, and he lived the rest of his life in the Jerusalem and its environs. He enlisted in the Mapping Unit of the British Army during the Second World War, serving the allied effort in Egypt. He then served in the Israeli Defense Forces (IDF) in 1948, becoming the deputy commander of the Mapping and Aerial Photos unit before helping to found the Geography Department of the Hebrew University in Jerusalem (Bar-Gal 2013). In this capacity he served as a bridge between the military, academia, and the state, simultaneously furthering his scientific research and his institution 
building efforts as a means of, in his view, helping Israel to prosper both locally and internationally.

After 1948, Amiran worked to construct Israeli academia as a national system which snugly fit into, and yet struggled to participate as an equal member within, international scientific communities. In the process, he became a noted expert on arid regions, arguing against those who claimed that Israel was a desert, meaning that it was unfit for modern development. He sought to prove them wrong, discursively by arguing that Israel was a desert only as a result of past Arab mismanagement (Amiran 1987), and materially by helping to redevelop Israel's landscapes. Both projects required extensive travel within Europe, North America, and even the USSR in order to obtain support and funding for his research. Amiran's trips in turn were financed, and made politically possible, by the economic reshaping of the Israeli landscape along lines which fit Western conceptions of modern development, as I will discuss in Chapter 2.

Amiran also traveled locally to collect data and measurements of the natural landscape, yet his local travel was made possible by the continued measures taken to prevent Palestinian refugees from returning to their homes inside what was now Israel. Prior to 1948, Jewish and international travelers in Mandate Palestine made extensive accounts of the villages there and their inhabitants; the British cartographic surveys were only accomplished through extensive fieldwork in concert with local Palestinians to determine names of towns and geographic features (Abu El-Haj 2001). Amiran's ability to travel through what became Israel and view it primarily as a natural landscape, extensively documenting temperatures, the heights of hills and mountains, and the location of rivers and springs, was only possible after 1948, once a majority of its Palestinian population was excluded from the landscape.

\section{Two Incomparable Exiles}

Both Hadawi and Amiran were forcibly pushed out of the places of their birth, and both traveled extensively throughout their lives. Moreover, professionally both scholars saw themselves as empirical observers of the geographic landscape, and they had similar ways of framing their methods and goals. Yet they continued to be divided by their access to a state, ${ }^{6}$ a disparity which reveals the power imbalances at work throughout their lives. These are evident in the ways that Hadawi and

\footnotetext{
${ }^{6}$ As I discuss in Chapter 4, access to a state also impacts the possibilities for producing knowledge. For example, see Rashid Khalidi's discussion of how the exodus of Palestinians between 1947 and 1949, and the continued absence of an internationally-recognized Palestinian state, has affected the archival records that are available for historic Palestine; Khalidi notes, the "basic asymmetry with respect to archives is a reflection of the asymmetry between the two sides" of the conflict (R. Khalidi 2006, xxxvxxxvi). Also see Tamari and Zureik (2001) on efforts to collect and digitize the scattered archives for Palestinian Refugees.
} 
Amiran were affected by landscape economically, through their ability to shape the landscapes in which they traveled, and socially, in terms of how they were treated on an international level. While Hadawi spent his time attempting to convince the UN to restore Palestinian property which had been lost, Amiran traveled to obtain funds to support modern development in Israel. At the same time, he consistently benefited from the control that came with establishing new state institutions, with the help of international aid, thereby instituting the disciplinary and economic infrastructure that would allow Israeli scientists to set up future funding bodies of their own. In addition, the wholesale rationalization and modernization of a landscape that rapidly became Israeli after 1948 was also enabled by high levels of foreign aid and loans (Razin 1993), in combination with the economic assets obtained through the seizure of Palestinian land, including fruit orchards, arable fields, urban built-up areas, beaches and archaeological sites which double as tourist destinations. $^{7}$

In contrast, although Hadawi was also funded primarily through international assistance, albeit as an employee of humanitarian agencies, the funding for Hadawi's projects came not as personal assets, loans, or aid among nations, which have comparatively fewer restrictions, but as aid from international bodies like the UN, which ultimately controlled the money's direction and flow. In keeping with these more nebulous funds that were available to him, the institutions which he founded in exile were more transitory both in terms of location and duration, and this despite the best efforts of Hadawi and his associates. Partly as a result, Hadawi was often on the move as well, living in Lebanon and the United States, among other countries, before settling permanently in Canada (Bland 2004; Safieddine 2004). ${ }^{8}$

Rather than being recognized for his effectiveness, Hadawi was forced to resign from his position at the UN in 1955, on the grounds of a conflict of interest after he asked formally for economic restitution for the home that had been taken from him in 1948 - thus due to a perceived incompatibility between his identity as an international observer and a Palestinian refugee who believed he had a right to compensation under international law (Fischbach 2003, 252-58). ${ }^{9}$ In contrast, Amiran was

\footnotetext{
7 Thus in the 1950s Don Perez argued that "Abandoned property [i.e. property left behind by Palestinian refugees who were not allowed to return] was one of the greatest contributions toward making Israel a viable state" (cf. Hadawi 1957, 31).

${ }^{8}$ Hadawi would never see Jerusalem again, passing away in Toronto in 2004 at the age of 100 . Hadawi was a British citizen, and so he had the option of visiting Palestine and Israel, but he refused to do so out of protest (Fischbach 2003).

${ }^{9}$ Fischbach suggests that the request for restitution was simply an excuse, and that political considerations were in fact behind Hadawi's forced resignation. These would have included outright political opposition to having a Palestinian on the team; it is likely that Hadawi did not foresee even the perception of a conflict of interest or else he would not have submitted the request.
} 
widely recognized and celebrated for his work, as his identity as a Jewish Israeli and as an international scholar were widely believed to be fully compatible. Amiran increasingly was received as an equal among international power centers, whereas Hadawi's contributions to history were only recognized decades later. Thus, the practical effects of statehood on the ground served as the fulcrum of the imbalance of power between the two scholars, an instance which will be seen time and again, albeit in differing guises, in the chapters which follow.

\section{From Traveling Theory to Traveling Ethnography}

Just as Hadawi and Amiran were influenced by the times and places in which they worked, my own research is inevitably a product of my position as an international scholar. This book is grounded in over six months of ethnographic fieldwork and archival research in Palestine and Israel, as well one additional month of archival research internationally. These periods include five months of participantobservation at the Applied Research Institute Jerusalem (ARIJ), ${ }^{10}$ one of the premiere Palestinian cartographic NGOs in the West Bank, as well as 54 semi-structured interviews with cartographers, urban planners, and civil engineers. During my fieldwork, I participated in more than 30 field visits with cartographers throughout the West Bank, and I took upwards of 10,000 photographs of maps and documents in related archival collections in the West Bank, Israel, and the UK. ${ }^{11}$ My methodology consisted of a combination of semi-structured interviews, participantobservation, archival research, and document and data analysis. Interviews were recorded and were conducted for the most part in English, although with interjections in Arabic and Hebrew. During the participant-observation I took part in meetings and tours that were conducted alternately in Arabic, Hebrew, or English. I sought a representative sample of interviewees who work for the dominant cartographic institutions and organizations in the region, which was possible due to the relatively small geographic area to cover-Palestine and Israel combined are roughly the size of the US state of Vermont (Hadawi 1957), or about one-half the area of the Netherlands. The combination of textual and ethnographic sources enabled me to explore the influences which shaped the entire process of making maps, from the initial setting of the grid and data collection, meaning both the gathering of existing sources and new observations on the ground, to the ultimate design of a particular map.

During my fieldwork, I was repeatedly reminded of how my position as an international scholar opened specific routes, as groups were giving in terms of time

\footnotetext{
${ }^{10} \mathrm{ARIJ}$ is said as a word rather than an acronym. The $i$ sound is long as in the word we, and the $j$ sound is pronounced as in the word jeans.
}

${ }^{11}$ See Appendix C for a list of archival collections consulted. 
and expertise in the hopes of bringing their work to a wider audience, while foreclosing others. My US citizenship made it possible for me to work both in central Israel and the West Bank, which is significant given that many Palestinians experience routine discrimination when traveling between the two, even when their visas permit it, and Israeli citizens are formally barred by the Israeli government from traveling to the Territories without special permission, although small groups of activists continue to do so. However also as an international, my stay in the region was dependent upon me leaving every three months, and I could be refused reentry each time I entered or returned. ${ }^{12}$ So my somewhat extensive range of movement was also precarious, since it could be prohibited at any moment, at any checkpoint, the granting of which was also largely dependent on factors of race, gender, and class, as determined by my appearance. My ability even to conduct research full time for an extended period was dependent upon a generous research position at Maastricht University, which both made my visit intellectually and financially possible yet also lead to me building a life and set of responsibilities in the Netherlands.

This book represents an attempt to mobilize the privilege just described to conduct rigorous research. To do so, I sought to follow Edward Said's notion of traveling theory to its logical conclusion, by conducting a traveling ethnography. Said famously proposed traveling theory as the study of "what happens to a theory when it moves from one place to another" (Said 1983, 161). In his critique of the totalizing aspects of Foucault's theory of power, Said proposes an analysis that might provide "attractive alternatives" to any theory that "left to its own specialists" would tend "to have walls erected around itself." These alternatives make prolific use of geographic metaphors:

To measure the distance between theory then and now, there and here...to move skeptically in the broader political world where such things as the humanities or the great classics ought to be seen as small provinces of the human venture, to map the territory covered by all the techniques of dissemination, communication and interpretation....

(1983, 177-78, my emphasis)

Said's examples borrow from graphical conceptions of space which implies a recognition that theories also have a material form which is affected when those theories move and change. This emphasis thereby prefigures later conceptions of

\footnotetext{
12 Such a refusal of entry is routinely enforced without warning upon Palestinians who are also Israeli citizens, as well as North American and European scholars of Arab heritage, but also at times on teachers and interns in international NGOs, despite the privileges conveyed by their US passports (Abdel Fattah 2013; ARIJ 2013b; Miller 2013). During this research I was not refused entry, in no small part likely because of my outward appearance.
} 
translation in Actor Network Theory (ANT) as the way that actors must transform in order to be incorporated into a network (Latour 1999, 15-16). Yet to study such transformations, it is also necessary to pay heed to the negations and omissions, to feel out the paths of greatest resistance-the places where theory fears to tread, so to speak-thereby widening Trouillot's (1994) study of the "silences of history" to include the silences of geography. For theory makes and unmakes places and passages through its movement. To feel out these simultaneous affirmations and negations in ways that also took into account their materiality, I conducted the better part of my research on the road-although I also routinely strayed off the road, both literally and metaphorically. I thereby attempted to materialize my attempts at scholarly reflexivity, to better understand how the study of traveling theory alters the subjectivity of the traveling scholar in ways that might further nuance the resulting research.

So I began this traveling ethnography with the simple notion that to study traveling theory it is necessary to travel with it. As a traveling ethnographer, I made daily trips back and forth across the many boundaries which encircle the West Bank, using as many forms of transportation as possible, including the segregated Palestinian and, alternately, Israeli buses and mini-buses, taxis, UN jeeps, private cars, bikes, extensive hiking, and at one point, a small gasoline-powered scooter. I sought out alternate routes, taking Israeli public buses into settlements, and then walking across to adjacent Palestinian towns, to come back through checkpoints on foot. I hiked through the ruins of demolished Palestinian villages that are buried beneath the 'green belt' of forests-planted in part to surreptitiously hide those same ruins and secure Israeli government ownership of their land-that line the highway that runs from Tel Aviv to Jerusalem (Cohen 1993, 109). I traveled north to the Lebanon border and south to a Bedouin town in the Negev desert which at the time of writing has been demolished 49 times (Kestler-DAmours 2013). I made regular trips along the segregated road, newly built with US funding, for Palestinians that takes perhaps the longest route possible between Bethlehem, south of Jerusalem, and Ramallah, to Jerusalem's north. The road runs on steep inclines and descends through the aptly named Valley of Fire, taking between one and two hours to go between two cities that are no more than twenty minutes apart if they could be traveled by a direct route. I walked along the Wall, part of the broader Israeli Separation Barrier which consists, in places, of barbed-wire fences surrounded by trenches and a broad exclusion area on either side, and in others, of an 8-meter high concrete wall. Overall the Barrier is built with brutal efficiency within the populated areas of the West Bank, on top of a crisscross of streets, homes, and fields - a route that is alternately eerily tranquil and, during protests, full of teargas clouds.

Throughout, my travel was shaped by my privilege as a white international academic. With this in mind, the hope was that by crisscrossing the boundaries in such innumerable ways, I might come to a more embodied understanding, in my own way as an international, of how societies can be so intricately interwoven, and 
also thoroughly disjointed. ${ }^{13}$ Yet this privileged mobile life was itself circumscribed by the near-moratorium on internationals traveling to Gaza, and as such, it too was geographically circumscribed in ways that have reverberated throughout my research. The choice to circulate across and through the margins required giving up on becoming fully immersed in any one place. At times I became thoroughly disoriented, not sure which language I was supposed to be speaking, or to whom. Yet it certainly did achieve its aim of opening up an awareness, albeit in a highly advantaged fashion, of border issues in Palestine and Israel, of living between societies in a small specific way, despite the practical difficulties and theoretical challenges of doing so. While such an approach certainly is not appropriate for all studies of the region, and the potential forms which alternative travel takes are vast and have varying political and social implications, ${ }^{14}$ I hope that this account demonstrates that work that is physically conducted on the margins is a necessary part of wider projects to study the impact of landscapes of occupation which are at once social and material, and which depend on the enforcement of strict yet ambiguous boundaries. ${ }^{15}$ In this introduction, I have attempted to illustrate such divisions through a retelling of the lives and work of Amiran and Hadawi. In the next chapter, I turn to the theoretical literature which makes such a study possible, before presenting three rich examples of mapmaking.

13 Thus while sympathetic to the elevation of nomadism in recent critical theory (for example, Braidotti $2013,57)$, I also question whether at times it might reproduce the historic misconceptions of nomadism as simply aimless mobility, a form of wandering around through undefined landscapes.

14 See the emerging literature on alternative tourism in Palestine and Israel (Barnard 2013; Stein 1998). In addition, several alternative travel guides have recently been released (Jubras, Nasser, and Yahya 2008; Natour and Abu Ta'ah 2000; Shahin 2005; Szepesi 2012).

15 Of course, the ways researchers move about are also central due to the potentially negative impacts of academics in boundary communities. For example, the continued influx of (temporary) international researchers into Palestinian refugee camps may have actually increased distrust. Moe Ali Nyel (2013) relates one incident where a female resident, Um Muhammad, asked an American professor if he could help her seriously injured son, only to have the male professor reply that "'We will include your son's story in part of the study we are doing, and it will be published by Harvard.' Then, the professor asked me [Nyel] to tell anxious Um Muhammad that Harvard is an important university and when the report was published many people would read it." So, while traveling complements existing studies where scholars embed themselves in particular communities, travel alone is not sufficient and suffers from its own set of pitfalls. On issues facing over-researched communities, see Sukarieh and Tannock (2012). 


\section{Chapter 2}

\section{The Materiality of Theory}

Maps have been an intrinsic part of political struggles over historic Palestine at least since some of the first topographic maps of the area were produced by Pierre Jacotin, a senior officer in Napoleon's army, who followed the general's trail of battlefields during his failed invasion (Godlewska 1999, 77-78). Jacotin's results were inconsistent, however, because they were only able to work in those sites where Napoleon's forces had won (Khatib 2003, 211). The tight coupling between cartography and expanding control over land persists in modified form in contemporary Israel, as is evident in a recent text by Haim Srebro, the director of Israel's state mapping agency the Survey of Israel (SOI). In the Preface to a recent volume on the SOI, Srebro depicts cartographic surveyors are "pioneers": "[Surveyors] are the first to be in the field [....] the first to thrust a stake in the ground. When they arrive [...] the field is usually bare, often unapproachable" (Srebro, Adler, and Gavish 2009, 7). Srebro's words evoke images of unmapped land as both empty and inhospitable, a depiction which would have seemed familiar in Jacotin's day.

The persistence of such pioneer metaphors points to the need to better understand how ongoing legacies of colonialism and empire shape digital cartography in Palestine and Israel. The intertwined histories of maps and struggles for territorial control also are broadly relevant to a better understanding of the spatialities of knowledge. Recently, authors in a variety of disciplines have begun to refer to a "spatial turn", and metaphors of mapping are widely used in social theory to refer to textured understandings of complex social phenomena (Law and Mol 2001; Warf and Arias 2009). Nonetheless to date beyond specific subdisciplines of geography and, with quite different implications, certain branches of mathematics, where functions are referred to as maps, there has been little critical interrogation of mapping practices.

In order to contextualize maps more fully, this chapter provides an analysis of cartography as both a political and scientific practice. Told through a narrative of 
how cartography has been embedded in the landscapes of Palestine and Israel since the founding of Israel in 1948, it has two main goals. First, I aim to demonstrate how studies of Palestine and Israel (Abowd 2007; Abu El-Haj 2001), and resources on the political impacts of technology, can benefit from using a postcolonial frame. ${ }^{16}$ Second, I argue that critical theory cannot afford to bracket science and technology, but instead must delve into both their material and theoretical details. Material landscapes help to define the contours of what it is possible to know through direct observation, and therefore they shape the production of knowledge. While overall in this book I contribute an analysis of how colonial legacies of knowledge are affected by the changing political, social, and economic landscapes of Palestine and Israel, in this chapter I examine how those landscapes themselves are reshaped through land management practices that are also interwoven with cartography.

The body of this chapter is divided into three main sections. In the first, I analyze research in geography that deals with the relationships between cartography and empire as well as with the production of space and related conceptions of landscape. In the second section, I turn to earlier attempts to rationalize the landscape of the state of Israel 1948-67, as well as related efforts in the West Bank under Jordanian rule. Ideologies of modernization were closely connected with colonial discourses about the alleged inferiority of local populations, and these were also deployed in modified forms by Israeli planners whose development efforts were increasingly effected through statistical, and ultimately digital, maps. With this in mind, in the third section, I analyze research in Critical GIS, whose authors examine the changing materialities of technology during the transition to digital cartography which took place in the mid- and latter-20th century. In addition, I argue for an expansion of the notion of symmetry in STS, to include geographic symmetriessuch as the one in this book between Palestinian and Israeli maps-that can be employed strategically to highlight imbalances of power. Overall in this chapter, I demonstrate how refashioned material landscapes can serve to both alter and perpetuate colonial knowledge legacies, including a narrow conception of rationality that has been legitimized through the use of digital technology, at times with bewildering results.

\section{Irrationality in the Landscapes of Palestine and Israel}

Despite how they are sometimes represented in the media, the ongoing conflict between Israel and the Occupied Palestinian Territories did not arise out of an illogical sectarian quarrel, but instead as a result of internationalized methods of developing and analyzing the land which privileged specific forms of rationality and

16 That is, as Timothy Mitchell (2002) has noted, a frame which permits an exploration of persistent colonial legacies, rather than one which implies that colonialism is solely a process of the past. 
quantification. After the beginning of the 1967 Israeli Occupation of the West Bank and Gaza Strip, their landscapes were irrationalized, or made irrational, to the extent that the increasingly intricate and obscurantist governance procedures often contradict one another. This is partly the result of conscious effort on the part of the leadership of Israel to solidify their position on the ground by creating conditions which encourage Palestinians to emigrate, but it also has had unexpected resultsnot least the entrenchment of Palestinian resistance. Pre-1967 efforts at defining distinct and separate spaces for Palestinians and Israelis were followed after 1967 by attempts to enforce a single state in both Israel and the Territories while at the same time refusing to annex the Territories fully to Israel (A. Barak 2005). Eyal Weizman $(2007,4)$ has described the ambiguity which results:

Against the geography of stable, static places, and the balance across linear and fixed sovereign borders, frontiers are deep, shifting, fragmented and elastic territories. Temporary lines of engagement, marked by makeshift boundaries, are not limited to the edges of political space but exist throughout its depth. Distinctions between the 'inside' and 'outside' cannot be clearly marked. In fact, the straighter, more geometrical and abstract official colonial borders across the 'New Worlds' tended to be, the more the territories of effective control were fragmented and dynamic and thus unchartable by any conventional mapping technique.

While his claim that there is a direct relationship between the abstraction of a border and its complexity perhaps depends on poetic license, Weizman rightly highlights the simultaneous inclusion and exclusion of the West bank in relation to Israel (Ophir, Givoni, and Hanafi 2009). This results in a condition that Meir Margalit has called, "permanent temporariness" (Margalit 2010, 23) and which has also been analyzed through Agamben's notion of the state of exception (Shenhav and Berda 2009).

The proliferation of borders within the West Bank means that, in practice, there is incredible difficulty for anyone to demarcate precisely where the boundaries between such multiplicitous areas fall on the ground. The results would be comical if they were not so destructive, because Palestinians can be tried for crossing borders that are invisible and whose location, for 'security' reasons, they aren't officially permitted to know. For example, Diana Kurd, a Palestinian widow from Anata, was divested of her pension, despite paying Israeli taxes for years, because her deceased husband had slept on the side of their bed that lay outside the Jerusalem city boundary, according to the Israeli authorities' maps (Hasson 2011).

The borders that intrude into the bedroom also cut towns in half, and sever them from their surrounding regions. The construction of the infamous Wallalternatively called the "segregation wall" or the "separation barrier", among other names-within the West Bank has created enclaves in Barta'a and western Bethlehem, leaving Palestinian towns on the Israeli side of the wall, literally moving the 
border around them (UNICEF 2008). ${ }^{17}$ As a result, the inhabitants are trapped: unable physically to enter the West Bank, and unable legally to enter Israel. However the Wall's apparent irrationalities appear to be the intended result of deliberate policy. Wendy Brown has argued that despite its uniqueness, there are continuities of intent, if difference in design, both between earlier straight boundary lines and the current barrier (Brown 2010, 30) in their attempts to claim land and micromanage populations. Thus apparent irrationality may also result from shifting rationalities. Helga Tawil-Souri (2012) has argued that over time, the Occupation authorities have shifted from attempts to control specific pockets of space, to efforts to track specific individuals through a multifaceted regime of ID cards which allow varying degrees of access, as discrimination is obscured through a proliferation of ID categories. ${ }^{18}$ This segregation by individual rather than by territory, parallels a shift in GIS, analyzed more fully in Chapter 3, from the mapping of territories towards the modeling and analysis of large datasets for the location and movement of populations of individuals (Longley and Batty 2003).In this context, it is no surprise that some of the 'clearest' maps of East Jerusalem alone show over a dozen relevant borders (Figure 2.1). To better understand how the drive for rationality has led to the present situation, it is necessary to explore how rationality and land control have been intertwined more broadly. Thus, I now first investigate the literature which draws links between historic forms of cartography and empire.

\section{Making Empires, Making Maps}

Maps have long been considered to be scientific representations of territory, but recently geographers have begun to question whether either of these characterizations is entirely deserved-whether as a purely scientific object or as a representation of land (Kitchin and Dodge 2007; e.g. Latour and Hermant 1998). Jeremy Crampton has outlined how the view of maps which predominated in professional cartography since the 1950s was predicated on "a clear separation between the cartographer and the user" - a separation that, it was believed, could be bridged by maps, which function as communicative intermediaries (Crampton 2001, 693). However this communication model implies that maps themselves are not part of the material world. In contrast, more recent critical scholars have claimed that maps and the material world-including maps, users, and the land itself-are fully imbricated. Crampton and Krygier summarized the updated view of maps as a

17 On the effects of the Wall on dividing communities, also see Heruti-Sover (2012) and Hammerman (2011).

18 Also see Tawil-Souri (2011a) and Halabi (2011) on recent surveillance in Palestine, as well as TawilSouri (2011b) on the role of technology in the enclosure of the Gaza Strip. 


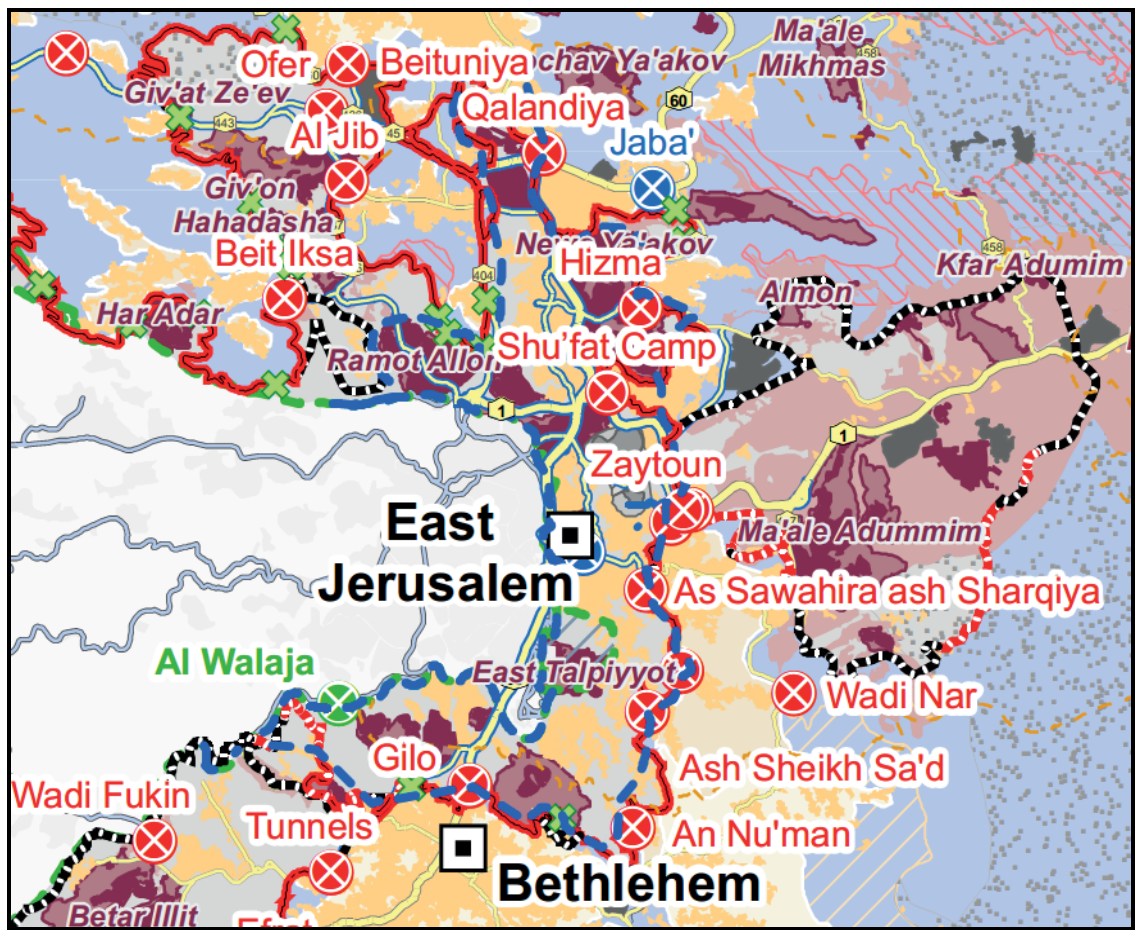

Figure 2.1: The intricacy of the geopolitical situation can be seen in this detail from a United Nations (UN) map of East Jerusalem, which lists over one dozen borders and barrier types for this region alone (UNOCHA 2012a, S2). The full map can be viewed at http://www.ochaopt.org/documents/ocha_opt_ humaitarian_atlas_dec_2012_web.pdf.

recognition that a "map is a specific set of power-knowledge claims" which itself has a specific material form (Crampton and Krygier 2006, 12; Dodge, Kitchin, and Perkins 2009). Yet the claims inherent in maps do not need to represent the Earth as it currently is, but instead are often suggestive of what it could be-as in the case of Israeli state maps printed in the 1960s, where Palestinian villages were depicted as ruins, in anticipation that the Israeli government would continue to prohibit Palestinians from reinhabiting them (e.g. SOI 1964). Thus, critical scholars argue, scientific maps represented a useful means to describe the Earth precisely because the Earth was remade in their image-not the other way around (Harley 2001; Pickles 2004; Pickles 1995). John Pickles summarized the implications of the predictive capacity of maps when he claimed that "mapping, even as it claimed to represent the world, produced it" (Pickles 2004, 93).

The view that "maps make space as much as they record space" (Crampton 2010 , 48) first emerged in the literature on Critical Cartography, which dates its antecedents to the years after World War II and the work of J.K. Wright (Crampton and Krygier 2006; Edney 2005; Pickles 2004) and which gained salience in the late 
1970s. ${ }^{19}$ A key subarea of critical research involved the detailed exploration of the historical and geographic role cartographers played in making European empires from the 15th to 19th centuries, demonstrating the confluence of political and scientific designs. Centuries later, imperial ideologies would transform into the modernizing discourses that were employed during the wholesale transformation of the landscape of Israel after 1948. With this in mind, in this section I first analyze Critical Cartography literature on the intertwined legacies of maps and empire. I then turn to literature which seeks to analyze how such modern landscapes are produced, as well as related conceptions of landscape.

\section{Cartographies of Empire and Empirical Cartography}

Matthew Edney famously highlighted the connection between cartography and imperialism when he claimed that "the empire exists because it can be mapped" (Edney 1997, 2; cf. Pickles 2004). Similarly, Timothy Mitchell has noted that "In recent years the production of maps has often been taken to epitomize the character of colonial power, and by extension the power of the modern state" (T. Mitchell 2002, 9). Over the years, Critical Cartographers have conducted extensive historical studies of how cartographers came to impose mathematical order upon the earth, thereby helping to legitimize claims to land (Livingstone 1992). For example, Winichakul (1994) notes how troops from the Kingdom of Siam advanced in tandem with British surveyors in an 1885 conquest, leapfrogging one another across the land in the initial consolidation of what is now Thailand: "Sometimes, mapping advanced one step ahead of the troops. Then the military followed, making the mapping proposal of the areas come true." Winichakul argues that only the military "could provide the authority under which mapping could be executed. In a sense, map anticipated the space; force executed it; map again vindicated it" (1994, 8082).

Cartography was able to vindicate conquest in part because it was increasingly viewed as an empirical science with practical import to the state. Cartographers were empirical in the sense that they gathered evidence through observation, increasingly relying on field surveys to observe local conditions as a means of producing knowledge which was believed to stretch beyond those conditions (Latour 1987; Turnbull 2000). In his analysis of cadastral maps in Europe, James C. Scott stresses the geographic importance of this striving for universality in contexts where outsiders sought territorial control. Scott argues that the map's value "lies in its abstraction and universality. In principle, at least, the same objective standard can be applied throughout the nation, regardless of local context." Overall, land

19 The geographical subdisciplines of Critical Cartography includes both historical studies of cartography and empire, analyzed in this section, as well as contemporary work on GIS and digital maps more broadly. I discuss the latter topic, collected under the heading of Critical GIS, below. 
maps "are designed to make the local situation legible to an outsider. For purely local purposes, a cadastral map was redundant. Everyone knows who held, say, the meadow by the river" (J. C. Scott 1998, 44-45).

Despite attempts at standardization and universality, however, Edney notes that, "the European knowledge of each empire is accordingly far more incomplete and nuanced than has often been recognized" (Edney 1997, 17). In the case of the British Empire in India, due to the practical concerns of operating in the landscape "the British could never implement the technological ideal" of triangulated surveys, leaving them instead to combine different surveys within a single grid in an attempt to construct a general map. However, this apparently did little to dampen the drive to depict territories as if they were distinct, unchanging, and internally consistent entities (Edney 1997; Winichakul 1994). Indeed, Edney has argued that the attempt to universalize cartography was so influential, despite its shortcomings in practice, that there were no substantial differences in appearance between maps of nation states and maps of empire. Nations and empires were viewed as being part and parcel of overall territories of rule (Edney 2009). This was also the case under British rule in Mandate Palestine prior to 1948, when the region was viewed as a core part of the British Empire more broadly (El-Eini 2006). Indeed, the legacy of the attempts to standardize the British ordinance survey in the UK (Hewitt 2010) are clear in the British emphasis on a consistent triangulated survey over 'all' of historic Palestine (Gavish 2005).

Just as European cartographic methods were variable over space, they also were never solely European methods. The history of Western cartography includes recurring contributions from people around the world (Macleod and Kumar 1995; Raj 2007). To this end, David Turnbull has argued that all scientific knowledge is local knowledge (Turnbull 2000; Turnbull 1996), and Raj has pointed out the pitfalls of the 'diffusion model', whereby cartography solely spread out from a central metropole to the colonies (Craib 2009; Raj 2007). Many such contributions to geographic knowledge were uncredited and undervalued, as colonial and national maps often served to erase the presence of indigenous groups, who were often left off of maps and instead relegated to the realm of ethnographies and travel accounts (Safier 2009). Yet this was not always the case. At times, imperial cartography even sought to map indigenous groups, albeit often with ulterior motives, as in the case of Syria and Lebanon, where French cartographers presented groups according to religious subdivisions as a means of dividing and fragmenting the Arab majority (Gratien 2013), as well as in Siberia, where indigenous communities were depicted as a way of highlighting Russian superiority by contrast (Kivelson 2009). In some cases, official cartography explicitly incorporated indigenous practices, as in the Qing Empire in Manchu, China (Hostetler 2009).

Critical cartographers thus generally agree that maps have their roots in empire while acknowledging that even dominant cartographic knowledge is far more heterogeneous than was first understood. Despite this, however, there are ongoing disagreements between scholars over the best way to conceptualize these geogra- 
phies of cartographic practice. In recent studies of maps and empire, there is a tension between scholars influenced by French poststructuralist theory who analyze maps as discourses (Harley 2001; Wood 2010)—or more appropriately, images (Cosgrove 2008) - to be interpreted, and researchers who draw on British and North American Marxist work in geography to analyze the practices, institutions, and power regimes which frame a map even before a single line is drawn (Cosgrove 2007). This is parallel to debates in the history of capitalism and expertise more broadly. For example, Robert Jessop and Timothy Mitchell disagree as to the value of, alternately, producing broader evolutionary narratives which "seek to explain why only some economic imaginaries" are institutionalized at the expense of others (Jessop and Oosterlynck 2008, 115-16) and the perhaps more localized project of "tracing the specific history of a movement [...] the sites of economic knowledge it brings into being, the kinds of representation it makes possible" (T. Mitchell 2008, 1120). While a search for evolutionary patterns may obscure other modes of change, conceiving of knowledge solely in terms of sites or localities can obscure attempts to maintain systematic power hierarchies. However, as the study of how to conceptualize territorial variation, cartography is uniquely suited to contribute to debates which are central to broader social science. Research on the geographies of knowledge allows scholars to overcome dichotomies between structuralist and poststructuralist accounts. Despite their theoretical differences, at times such accounts overlap in terms of aligning broad-scale narratives with definite power structures, while also placing it in a simplistic opposition to local knowledge, which is conceived of solely in terms of contingent forms of agency. In the next section, I present literature on landscape as one way to move beyond the implicit theoretical binary between local particularity and global patterns and to get at the nuanced and many-scaled spatialities at play in the geographic production of knowledge (Martino Martin 2011).20

\footnotetext{
20 Two conceptions of geographic scale run throughout this book. First, I follow Neil Smith's (1992) call to avoid taking for granted the existence of particular scales, such as the national or local scale. Instead, Smith urged scholars to study how specific geographic scales were produced as natural or given levels for the study of society, a process which is further explored by many scholars, notably Marston (2000), Paasi (2004), and Swyngedouw (2004). This is precisely what I aim to do here in my analysis of specific landscapes which may or may not fall within the territory of one (or more, in the case of the military Occupation) nations. Second, I build upon the work of recent scholars who critique the binary between local and global scales and argue that multiple scales (including the international, national, and local) can be implicit in any particular place and time (e.g. Gibson-Graham 2002; see also Herod and Wright 2002). This simultaneity of many scales in turn frames my analysis of how international systems of power, which often have diffuse spatialities, might co-exist with colonial methods of control that focus on defining specific geographic areas.
} 


\section{Producing Landscapes for Traveling Cartographers}

The study of cartography cannot be divorced from an analysis of landscape. Empirical observation involving a detached observer, has been long contrasted with memories of and emotional attachment to the land. Yet knowledge and empire are intricately interwoven with the production of the land which is being both produced and observed. Far from being a system that was simply imposed upon a preexisting territory, cartographies were developed through territory as part of a recursive process. Maps not only served to define particular territories, by depicting them in particular ways, but the redefinition of those territories in turn reshaped the practice of cartography. Imperial maps made by early scouts and explorers laid out routes of travel and trade, thereby facilitating colonization (H. V. Scott 2006), and this led to maps of newly-established forts and tracts of private property (Akerman 2006). The towns that were then established in turn provided bases for further travel to collect data for yet more maps. ${ }^{21}$

The ways that the landscapes were experienced and altered by colonial systems for the management of land and population thus afforded the conditions of possibility for later forms of empirical cartography. In Colonising Egypt, Timothy Mitchell describes one early such transformation in Egypt in the 1860s: the addition of Boulevard Muhammad Ali in Cairo, which was "ploughed diagonally through" hundreds of houses as well as "mosques, mills, bakeries and bath-houses". He cites a British commenter who likened the resulting destruction to "a city that has recently been shelled" $(1991,65){ }^{22}$

Practices of land management would be reconfigured over the course of the 20 th century, which saw both the persistence of empire-and the Middle East ${ }^{23}$ is one central area of debate over current imperial trends-combined with the transformation, but not excision, of imperial legacies under resource management plans in postcolonial states. The latter was effected through modern geographical knowledge which built upon colonial-era innovations with the aim of creating visible national landscapes (Bhabha 2004; T. Mitchell 1991, 67). Shiv Visvanathan em-

21 In Mandate Palestine, while the British argued that they furthered geopolitical and humanitarian goals, their focus on standardizing land ownership belies their (at times conflicting and variable) colonial motives (El-Eini 2006; Gavish 2005) - even though, in this case, they focused on the settlement of Jews rather than British citizens, as a form of proxy colonialism.

22 Mitchell argues that the boulevards resulted from a wider belief in structure, rather than indicating that cities are naturally structured according to universal rules. Nonetheless, the reshaping of cities would also facilitate later mapping and surveillance on the part of the state, thereby reinforcing their apparent effectiveness and necessity. Thus, even if a belief in structure led to the construction of structured landscapes, those produced landscapes can affect knowledge production in ways which exceed that founding belief.

${ }^{23}$ For a deconstruction of the concept of the Middle East using maps, see Culcasi $(2012 ; 2010 ; 2008)$. 
phasizes the situated visuality of the connection between modernism and colonial science, claiming that "modernity was a vision of conquest" (Visvanathan 1988, 264, emphasis added). Building upon the work of Henri Lefebvre (2002) on the production of space, literature on the production of landscape provides one possibility to investigate the ways that geographic knowledge which privileges observation in the collection of empirical data is situated in material landscapes (Massey 2005; Massey 1994). ${ }^{24}$ In recent decades, scholars in critical urban planning, development studies, geography, and anthropology have emphasized the ways that land is shaped and reshaped (e.g. Domosh 1996). Neil Smith has noted the resulting unity of concepts and material, albeit from a standpoint that privileges the material aspects: "While the emphasis [...] is on the direct physical production of space, the production of space also implies the production of the meaning, concepts, and consciousness" (N. Smith 2008, 79). Making a similar point, albeit from a different theoretical perspective, Timothy Mitchell has argued that, for social science, "the distinction between the material world and its representation is not something we can take as a starting point" (T. Mitchell 2002, 6).

Research on landscape encompasses a number of analytics, from the work of Carl Sauer (1925) and his students on historical landscapes in North America, to Cindi Katz's more recent call $(2001,1229)$ for studying countertopography, as a way to "imagine a politics that maintains the distinctness of a place while recognizing that it is connected analytically to other places along contour lines that represent not elevation but particular relations to a process" such as globalization. Sharon Zukin has called landscape "the cultural product of our time" $(1991,22)$. In Palestine and Israel, Eyal Weizman has analyzed the "folded terrain" of the West Bank (Weizman 2002), in order to demonstrate his argument that "the conflict manifests itself most clearly in the adaptation, construction and obliteration of landscape and built environment." 25 Stressing production, the work of Zukin and related scholars in geography (Domosh 1996; D. Harvey 2006; D. Harvey 2005; D. Harvey 1997; C. Katz 2006; N. Smith 2008; Soja 2000; Soja 1996) echoes Barbara Bender's call, based in literature in archaeology and architecture on contested landscapes and divided cities (Misselwitz and Rieniets 2006; Pullan and Baillie 2013; Sorkin 2002), to study the ways that landscapes are "tensioned, always in movement, always in

${ }^{24}$ For the relationship of Lefebvre's work to other French research on science and social space in the context of aerial photography, see Haffner (2013) and Merrifield (Merrifield 2000). Mitchell's claim (T. Mitchell 2002, 79) that Lefebvre assumes a distinction between social and material neglects more recent work in geography which adapts Lefebvre's views to the production of nature (C. Katz and Kirby 1991; N. Smith 2008; Swyngedouw 2006).

25 Also See Weizman's co-edited volume, together with Rafi Segal and David Tartakover, entitled A Civilian Occupation (2003a). The book's first edition was censored by the Israeli Architects' Association, (Segal and Weizman 2003b) and attempts were made to halt the construction of the new Israeli National library, designed by Rafi Segal, in relation to his continued support for the book (Rosenblum 2012). 
the making" (Bender and Winer 2001, 3). Similarly, Mitch Rose and John Wylie (2006) have argued against the 'flattening' trend in recent social science research, which has seen a shift, including the work of Bruno Latour (1993) and Giorgio Agamben (2005; 1998), away from landscape towards topology, the relatable study of space which is mutable and changing-yet which, in its geometric echoes, at times reproduces the idea that space is an empty, gridded three-dimensional container. Instead, this study follows Rose and Wylie's call for the study of landscape as a form of "dynamic materiality", a "tension of presence" and absence, which "reintroduces perspective and contour; texture and feeling; perception and imagination" (M. Rose and Wylie 2006, 477).26

Even though landscape is a central term in geography, it primarily has been defined implicitly, through its use in a variety of analyses both within geography and beyond (Cosgrove 2008). This has resulted in heterogeneous meanings which traditionally privilege observation from above. However, as Dorrian and Rose have argued, landscape may also be productively mobilized as an oppositional term. This is true particularly to the extent that landscape has the potential to encompass and, therefore allow for an exploration of, tensions between the material and the subjective, the inside and the outside, the past and present, and the representable and non-representable-albeit an exploration which is itself performative, rather than predicated on an a priori belief in any specific dichotomy (Dorrian and Rose 2003, 16-17). For as recent scholarship has shown, such dichotomies are partly effects of colonial geographical legacies (Keane 2007; T. Mitchell 2002; N. Smith 2008). In her account of imperial travelers, Mary Louise Pratt refers to the "textual apartheid that separates landscape from people, accounts of inhabitants from accounts of their habitats" $(2007,61)$. Pratt therefore views landscape as an effect of colonial attempts to divorce, or deterritorialize, indigenous human subjects from the lands in which they lived-which didn't preclude romanticizing them as connected to the land.

By analyzing cartographic practice through conceptions of landscape, then, I am not attempting to reinstate strict divisions between people and land, subjects and objects. Instead I aim to reterritorialize science and technology, allowing for greater attention to the varying spatialities of the geographical production of scientific knowledge. Thereby, this book is part of a disparate movement within STS, geography, and postcolonial theory which "locates these problems of colonialism, global expansion, and translation within the history and practice of science, rather than outside it" (T. Mitchell 2002, 7). However, this book does not stop there, for in conducting my investigations into the geographies of digital cartography, I am also questioning the varying implementation of such spatialized notions as the geo-

${ }^{26}$ In a related vein, Clark, Massey, and Sarre $(2008,2)$ pair the study of land with mobility, arguing for combined analyses of territory and flow, which I explore more fully in Chapter 4. 
graphic inside and outside of scientific practice (For example, see the analysis in Chapter 5 of settlement cartography from within and without).

Through their focus on the reworking of land, studies of the production of landscape can provide a significant complement to work in STS, where authors have explored how the pristine laboratory was only made possible by the exclusion of the rest of the landscape as the messy, unpredictable, field (Latour 1988; Latour and Woolgar 1986). However, in STS research, often the focus has been on the lab, as scholars have emphasized how labs were created as unique spaces for experimentation (Kavornen and Van Heur Forthcoming). To give just two examples, Latour and Woolgar, who have focused extensively on the constitution of scientific objects, nonetheless note that "an object [of scientific study] is simply a signal distinct from the background of the field and the noise of the instruments" $(1986,127)$, thereby simultaneously paraphrasing a particular scientific worldview and also reinforcing the notion of space as an insignificant backdrop of science. Likewise, Karin Knorr Cetina has analyzed materiality, space, and broader patterns of knowledge production $(1999 ; 1981)$, yet she too tends to focus on materiality only within the laboratory, while analyzing broader patterns primarily in terms of social organization. Thus her assertion that "tools and resources are the capital without which a lab could not maintain its place in the field" $(1999,85)$ is intended to refer to a scientific field, but it could productively be applied to the upkeep of related lands, buildings and infrastructure.

The focus on the laboratory at the expense of the field in science studies is partly a result of the privileging of laboratory sciences more broadly during the 20th century; Robert E. Kohler (2002) provides a detailed analysis of how field biologists responded to the increased attention to the laboratory and experimentation in the early 1900 s in the US by developing notions of "nature's experiments". In recent years, researchers have increasingly sought to blur (Kohler 2002) and mediate dichotomies between the lab and the field, for example through studies of 'urban laboratories' which specifically challenge conceptions of the laboratory as a separate sterile space (Kavornen and Van Heur Forthcoming). This has led to more detailed attention to place-making in scientific practice (Gieryn 2006; 2000), as well as a broader interest in how the field itself is also produced. More recently, Sekhsaria $(2013 ; 2011)$ has explored how scientific instrument-building can take place in geographic contexts, and mobilize material practices and knowledges, which exceed narrow definitions of a laboratory. This book thereby builds upon and broadens ongoing studies of the materiality of technology in recent STS (Wyatt 2008b) and geographical (Clark, Massey, and Sarre 2008) research.

Although they have not yet made concerted use of production of landscape literature, scholars working in Palestine and Israel have extensively analyzed the relationship between ideology and the reworking of the land. Meron Benvenisti has pointed to the destructive consequences of the implicit valuation of rational knowledge in Israel. He notes how the ultimate destruction of Palestinian villages after 1948 was made possible precisely because they did not fit into the rational 
patterns that the Zionists expected from a developed landscape. He states that, to members of the Jewish communities, the Palestinian communities were "white patches-terra incognita [....] These towns, villages, and neighborhoods had no place in the Jews' perception of the homeland's landscape. They were just a formless, random collection of three-dimensional entities" $(2000,56)$. Thus Benvenisti equates the Palestinian towns' perceived lack of form-that is, of rational pattern and organization-with their eventual near-erasure, which is conceptualized as omission from both the map and, ultimately, the landscape itself.

Nonetheless, they would also benefit from greater attention to STS critiques of rationality and scientific knowledge. ${ }^{27}$ Often nostalgia for (common sense) rationality pervades work on maps and landscape in Palestine and Israel. While Sari Hanafi has termed the urban policies of the Occupation as spaciocide (2009), Weizman refers to them as the "politics of verticality" (2007; 2002). However, the use of verticality reinforces the Cartesian framing of discussions of landscape as something reducible to three separate numerical axes. Similarly, Denis Wood's (2010) recent discussion of "nonreactionary" maps—-such as the Atlas of Palestine 1948 (Abu Sitta 2004) and the UN closure map (UNOCHA 2008) - is only partly ironic. While allowing that facts can be selected according to specific ideologies, Wood notes "each chosen fact is as factual as can be. None has invented data. None is a fantasy. You can go there ... and check it out" (2010, 246-47). ${ }^{28}$

Despite Woods' slightly humorous appeal to common sense efforts to 'check it out', this diverts attention from the ways that different individuals and groups may make different scientific observations based upon both their physical position in a particular (produced) landscape, as well as the geographic shaping of subjectivities more broadly, themes which Wood treats in his analysis of artistic maps (2010). For it is not simply that, as Weizman claims, "planning decisions are often made not according to criteria of economic sustainability, ecology or efficiency of services, but to serve strategic and national agendas" (Weizman 2002, n.p.). Rather, an analysis of the production of space precisely allows for an exploration of how criteria of sustainability, ecology, efficiency, and strategic agendas are all fully enmeshed. Thus, the very constitution of the data is shaped by landscapes in ways that are far more fundamental, and also more diverse, than any purposeful invention of facts might suggest. In the next section, I build upon the production of space literature to analyze attempts to rationalize the landscape of Israel and Palestine after 1948-

\footnotetext{
27 Two exceptions of work on colonial knowledges which incorporate geographical and STS critiques are Abu El-Haj's (2001) study of the building of Israeli archaeology as a field science, as well as Gary Fields' (2012; 2010) comparisons of land enclosure movements in the historical US and UK with land grabs in contemporary Palestine.
}

28 Wood also explores the implications of artistic atlases. These include the (Shoshan 2010), which combines empirical maps and design, the Subjective Atlas of Palestine (de Vet 2007), and the recent exhibit catalogue Imaginary Coordinates (Rosen 2008). 
attempts whose legacies would ultimately enable the sometimes absurd regimes outlined earlier in this chapter.

\section{The Rational Landscape of Palestine and Israel}

Over the course of the $20^{\text {th }}$ century, cartography's imperial legacies would uniquely influence efforts to reshape the landscapes of Palestine and Israel. In Israel in particular, efforts to fit the land to meet the map have dominated the landscape since before the state's inception in 1948. The Governmental Names Committee's efforts to Hebraize place names after Israel's founding lead to extreme toponymic transformations. However, throughout this was accompanied by the wholesale reworking of the land in order to rationalize it - that is, to make it legible, measurable, and quantifiable. No sooner had the 1949 armistice been signed than work began on the initial stages of the National Water Carrier, a series of interconnected pipes, pumps, tunnels and canals which were designed in part by engineers from the US, and which aimed to divert water from the Sea of Galilee towards the coast of Israel, bypassing the West Bank (Alatout 2009; U. Davis, Maks, and Richardson 1980, 7-9; Fischhendler 2008). The importance of water infrastructure is evident in the fact that one of the first actions of the Palestine Liberation Organization (PLO) was an attempt to sabotage the National Water Carrier in 1964 (Wolf and Ross 1992, 93137). Yet the National Water Carrier is only one example from an entire host of similar projects, many of them funded from abroad. Across Israel in the middle and later decades of the 20th century, masses of highways, forests, and large agriculture irrigation installations were wrought from infilled marshlands, dynamited hills, and the rubble of demolished Palestinian towns.

These projects arguably helped to stabilize the young Israeli economy while also providing international legitimacy. Many of them also led to environmental degradation, and some initiatives, such as the draining of the Hula Valley, have since been reversed (Inbar 2002; Levin, Elron, and Gasith 2009; Watzman 1993). Yet concerns about the impact of modern development-for example, Efrat's (1994) caution in terms of the impact of the construction of highway 6 on Palestinian agricultural lands-have not halted construction. This suggests that a constructed sense of inevitability continues to prevail in Israeli development circles despite ongoing opposition (Garb 2004).

The Israelis were not alone. Between the 1949 cease-fire which ended the war that followed the declaration of the state of Israel, and the beginning of the Occupation of the Palestinian Territories in 1967, the West Bank and Gaza Strip were under respective Jordanian and Egyptian control. Both the Jordanian and Egyptian governments undertook related modernization efforts in the Territories that were newly under their jurisdiction. The Jordanians, for example, attempted to demonstrate their legitimacy in Jerusalem by conserving and opening Christian religious 
sites to high-profile visitors such as the Pope (K. Katz 2003). However, after 1967, large-scale investment was increasingly stunted in the Territories through a lack of investment on the part of the Israeli authorities, who now controlled them, coupled with an impenetrable regime of building permits which are required for even the smallest modifications (Coon 1990; IPCC 2009; Tamari 2001; UNOCHA 2011b). ${ }^{29}$

Throughout these transformations, national, international and colonial (particularly British Mandate) modernizing discourses were all thoroughly intertwined (Gasteyer and Butler Flora 2000) - as were financial and nationalist motives (Levinson 2007). In Israel, the specific lineaments were combined in a fashion that was relatively unique to Zionist discourse (Goldshleger, Amit-Cohen, and Shoshany 2006; Shohat 1992; cf. Gorney 2007), with the emphasis on "making the desert bloom" or, in the words of Hadawi, turning it into a "rose garden" (Hadawi 1957, 7). In Jordan as well as in nearby states like Syria, many were likewise influenced by, and innovated upon, international discourses, drawing on complex admixtures of modernist, nationalist, and colonial tropes, thereby leading to what Lisa Taraki has called a "uniquely Arab expression of modernity" $(2008,63) .30$

In contrast to a broader postcolonial emphasis on self-sufficiency, however, in Israel the discourses which accompanied such large-scale modernizing processes fed into Orientalist and colonial tropes ${ }^{31}$ in ways that uniquely appealed to power brokers in Europe and North America. Zionist land management efforts traced their immediate roots to before the establishment of Israel, particularly to the efforts of Zionist agencies in the 1920s to drain swamps thereby, it was claimed, healing a landscape that was sick from both malaria and economic neglect. This was accomplished without any reference to the fact that many areas were already actively managed by Palestinians (Gorney 2007, 267; Hirsch 2009; Sufian 2007, 138-44). Building upon pre-state discourses which alternated between presenting Palestinians as a part of the landscape, and arguing that they were "completely absent" (Nassar 2003, 150), after 1948 Israeli geographers increasingly positioned themselves as cultural Europeans, casting local populations as unfit for development. In so doing, they bought into the Western perception of development as a linear process with defined goals that were exemplified in the societies of Europe and North

29 The challenges faced by the PA are dealt with in Chapter 4. For an example of an attempt to combine modernizing with environmental sustainability, see Saleh (2008).

30 See Alkhalili (2012) on differences in the treatment of refugees and non-refugees in the urban planning of Ramallah. See Coignet (2009) on development and public space in Amman, Jordan, and Van Heur and Abbas (2013), as well as Zawawi, Corijn, and Van Heur (2013) on gender and public space in the Occupied Palestinian Territories.

31 See Adas's seminal work (1989) for a further elaboration on specific European colonial tropes with respect to development and technology in the global South. 
America. ${ }^{32}$ In the words of Moshe Brawer, Israelis alone in the region accomplished "rapid and extensive urban and rural development, and provision of the modern efficient services and infrastructure of an advanced state." Such achievements were juxtaposed to those of neighboring states, for example by claiming "the West bank had suffered from neglect, stagnation, and partial depopulation during its 19 years under the Jordanian Kingdom (1948-67)" in an attempt to paint the 1967 Occupation as if it were of benefit to the local population (2008, 153-54, emphasis added).

However, such colonial arguments were not solely relegated to the early and middle decades of the 1900s. Prominent Israeli developers and academics have consistently presented themselves as modernizers (Interview 3, Israeli geography professor; Interview 4, Brawer), often at the expense of the Palestinian population. Srebro's characterization at the beginning of this chapter, of un-surveyed land as both bare and unapproachable implies that Palestinians failed to develop the land, while also cluttering it up (i.e. with their presence) in ways that prevented it from being accessible to the real developers-the Israeli authorities (Srebro, Adler, and Gavish 2009). Such discourse leads to a continued effacement of Palestinians, including alternative methods of treating the land. Elia Zureik has called the attitude of Baruch Kimmerling-a prominent Israeli scholar who himself critiqued the Israeli state-towards Palestinians as one of "conceptual neglect" (Zureik 2001, 222). It also encourages misconceptions based in ideas of Western exceptionalism. Tal Golan has suggested that it was solely the overwhelming support for science and technology in Israel that enabled Israel, among other nations founded after World War II, to be "the only country that reached a per capita income level approaching that of the long-independent Western nations" — even as he implies that this wealth has also enabled an escapist academic culture which has largely ignored the history of Israeli science and technology (Golan 2004, iv).

Modernizing discourses were not external to land management practices. Instead, the broader reworking of the land was in part an attempt to make it easier to map, and to make the maps legible for those reading them. Bruno Latour has brought attention to the need for the landscape to adapt to the map:

When we use a map, we rarely compare what is written on the map with the landscape-to be capable of such a feat you would need to be yourselves a well-

\footnotetext{
${ }^{32}$ Linear conceptions of societal development can be traced in part to the work of the $14^{\text {th }}$-century historian Ibn Khaldun, whose work was widely influential, including in the Arab world and, by the $18^{\text {th }}$ and $19^{\text {th }}$ centuries, in Europe. In the Introduction to his Muqaddimah, Ibn Khaldun argued that a breakdown in social cohesion could lead a society to be overtaken by outsiders from its geographic periphery. As of the time of writing, an English translation of the Muqaddimah (Ibn Khaldun 1967) is available at http://www.muslimphilosophy.com/ik/Muqaddimah/. However, although it can be interpreted as supporting linear development of history, Khaldun's processual view is more in keeping with that advocated by Thomas Kuhn (1996), who famously argued that science consists of a non-linear succession of different paradigms vying for legitimacy based upon collective support and belief.
} 
trained topographer, that is, to be closer to the profession of geographer. No, we most often compare the readings on the map with the road signs written in the same language. The outside world is fit for an application of the map only when all its relevant features have themselves been written and marked by beacons, landmarks, boards, arrows, street names and so on. (Latour 1987, 254, emphasis in original)

Claiming that in order to match map and land, rather than map and signs, one would need to be a topographer, Latour highlights the fact that the need for cartographers is almost as great when remaking the land as it is when making a map. Indeed, cartographers were an intrinsic part of Israeli efforts to recondition the landscape, and they took part in furthering the modernist development discourses of geographers more broadly. In the 1980s, David Amiran (See Chapter 1) used Israeli land management methods to justify their hold on the land. ${ }^{33}$ He characterized the entire eleven-hundred year period, from the 7th-century Arab conquest to the founding of modern Israel, as "centuries of decay when the land of Israel turned into an impoverished, malaria-stricken country, suffering both from maladministration and from a backward population." In contrast, Israeli developers, Amiran argues, created newfound wealth "with enterprise and modern agricultural techniques" in an era when "large-scale projects reclaimed the land which had deteriorated throughout centuries" $(1987,311)$. He states:

Israel is an outstanding example illustrating that the same earth-the same natural resources-are put to different uses by different people, employing different technologies. Israel illustrates that land of great value to one population was entirely useless to another one. $(1987,309)$

Amiran thereby implies that Palestinians had no right to the land of Palestine, because they "had neither the means nor the initiative to cultivate it" (1987, 299300). More recently, Raja Shehadeh has argued that the spread of natsh, a local weed, has been exploited by settlers in legal settings to expropriate land since 1967. Paraphrasing their arguments, Shehadeh writes, "The land is full of natsh. I saw it with my own eyes.' Meaning: What more proof could anyone want that the land was uncultivated and therefore public land that the Israeli settlers could use as their own?" (2007, 52-53).

However, this practice of alleging mismanagement in order to seize land is not unique to Israel. Instead it is evocative of urban renewal practices that were then dominant in Europe and North America during the 20 th century (Carmon 1999),

${ }^{33}$ Also see Lowdermilk (1960). 
which likewise built upon colonial tropes. ${ }^{34}$ For example, efforts to carve out large gaps into the Jerusalem hills to allow for a gently sloping highway are reminiscent of Rudolph Mrázek's description of road-building efforts over one hundred years, and over eight thousand kilometers, distant in Dutch Indonesia: "the newness, the hardness, the cleanliness-it was the roads' modernity" $(2002,8)$.

This emphasis on cleanliness carried over to urban renewal efforts within Israel as well. Soon after Israeli troops marched into the Old City of Jerusalem in 1967, the Maghrebi quarter, a historic Palestinian neighborhood that stood adjacent to the Western Wall in the Old City, was demolished and cleared. The act was represented as a "cleaning up process"-one which resulted in several deaths of residents who were crushed by bulldozers (Abowd 2000, 9). Planners viewed the houses, including a mosque from the middle ages (Hasson 2012b), as decaying and cluttered ruins (Ricca 2007, 6) and justified demolishing the centuries-old homes, which were fully inhabited, on the grounds that it was for public use (Abowd 2000). They thereby echoed the claims of Eminent Domain in the United States. Eminent Domain is the ability of the state to buy or take over areas on the grounds of public good. In practice, it is often justified by arguing that the areas are "blighted" and not being put to adequate use. The implication, that land must be used for tenants to retain ownership or usage rights, echoes the later arguments in use in Israel. Such international influence that is not surprising, given that many Israeli geographers and planners were trained in the US in the early decades of the modern state of Israel (Carmon 1999).

The transformation of the landscape continues to be fully imbricated with attempts to frame Israelis as representatives of modernity in the region. ${ }^{35}$ Throughout the 20th century up to the present day, authorities have dammed streams, rerouted springs, and demolished ancient cisterns-tanks for collecting rainwaterin the name of a narrowly-defined modernity which favored visibility, quantification, and clarity. Pine forests have been planted over the ruins of villages to make the scrub vegetation more productive-that is, more like the situation in Europe (Cohen 2002; 2000; 1994; 1993). Large tracts, particularly in areas inhabited by Bedouins in the Negev, have been seized amid accusations that the Bedouin failed

${ }^{34}$ In turn, American colonial tropes were themselves built upon forms of Orientalism, based on the denigration of Muslims and Jews alike, that were originally brought over with Christopher Columbus during his conquest (Shohat 2002). In recent years, Orientalism has likewise been mobilized in attempts to enforce strict dichotomies between East and West, North and South, upon Israeli and Palestinian academics living in the US and Europe, although in many cases their lives do not conform to such facile divisions (Shohat 2004).

35 At times colonial development discourses persist with surprisingly little variability. To provide a recent example: In August 2013 on the progressive Jewish Mondoweiss blog, one commenter criticized an article against Israeli settlements by claiming, apparently without irony, that "Israel is a developed nation in a sea of economic backwardness" (Robbins and Weiss 2013). 
to develop the landscape, ${ }^{36}$ despite the fact that their long inhabitation there had resulted in less-damaging transformations than the enormous undertakings of the comparatively short history of modern Israel (Adalah 2013; Falah 1989; 1985; Human Rights Watch 2008; Shamir 1996). These efforts are both due to political motives and because traditional forms of use, such as the maintenance of olive groves, were not recognized as true agriculture, thereby ultimately creating a political opposition between olive trees and pine (Braverman 2009).

Too often development has occurred at the expense of Palestinians. Even as buildings and roads were carved out of the land, as swamps were filled and forests planted, exclusionary notions of which types of farming and cultivating counted as agriculture and industry increasingly-once many Palestinian populations were forcibly removed-came to replace the intertwined forms of modern and indigenous knowledge by which the land was previously shaped and known. If those Palestinians who remained attempted to enter the lands claimed by the recentlyestablished government - for example, to pick herbs for cooking their dinnerthey could be arrested and charged with trespass on the grounds of security (Gurvitz 2011). ${ }^{37}$ These movement restrictions in turn enable the demolition of Palestinian homes and seizure of agricultural lands in the West Bank on the grounds that the lands-even those where local Palestinians are prohibited from entering-are not being (properly) used.

Neglecting the effects of the Occupation, some scholars have argued that Israeli methods should be exported elsewhere in the developing world, such as Doerr, Koling, and Kerr's $(1970,337)$ claim that the "lessons as the Israelis have learned [in agriculture and development] must be employed with swift and sure efficiency in the world's developing areas". This in turn ignores not only the political situation, but also the immense level of foreign funding that was granted to the Israeli state and private enterprise (Dattel 2013; Nitzan and Bichler 2002), a level of funding that was much higher and freer of restrictions than the support offered to other postcolonial states in the region, and which, until the 1990s, was often tied to broader geopolitical considerations in the context of the Cold War (Hecht 2011). However, the specific forms of the development of the landscape are crucial for the impact that they can have on future attempts to redevelop specific areas-an issue

\footnotetext{
${ }^{36}$ At times, academics in the US such as Goering (1979), although sympathetic to the impacts on bedouin communities of the changes wrought after the founding of Israel, nonetheless perpetuates colonial tropes of time (Fabian 2002) by presenting the bedouin as timeless and unchanging.

37 Variations on such arguments about security and technology are not confined to contemporary Israel. Schivelbusch (1987) has demonstrated that safety was historically used in Paris to legitimate the introduction of street lighting, at a time when street lamps were routinely smashed by offended members of the public who feared the greater police surveillance they made possible.
} 
that is especially relevant in countries with that are smaller geographically and already intensively developed (Hommels 2005). ${ }^{38}$

\section{GIS and Landscapes of Technological Practice}

The strong inter-relationships between land and map have altered, but not attenuated, with the onset of computer cartography in the region in the latter half of the $20^{\text {th }}$ century. Indeed, far from signaling a break with cartographic methods grounded in conquest and empire, digital cartographers have built upon colonial technological legacies. The efforts of the Israeli authorities to modernize the landscapes formally annexed to the state were explicitly connected to an ongoing attempt to promote technological and scientific knowledge. Indeed it is no accident that the oldest university in Israel, established in 1912 when the area was under Ottoman Rule, is the Technion-also known as the Israel Institute of Technology. In the early years of the state, technological knowledge helped to make possible the transformations of the landscape just discussed. In time, however, the relative financial security enabled by this wholesale modernization would further enable the development of technology and human capital in the context of limited natural resources, with Tel Aviv becoming a "Silicon Wadi" (2011), 39 a counterpart to California's Silicon Valley. Israel hosts branches of companies such as Intel, Motorola, IBM, Microsoft, and HP, to name only a few (Rashi Foundation 2012). ${ }^{40}$ As in the US, the technology developed in Israel has often been first designed and used for military purposes, and there is ongoing cooperation between universities and the military in high-tech research-a relationship that has been "widely-discussed" in Israel (Sheizaf 2013). Given the historic relation between geography and the military

\footnotetext{
${ }^{38}$ Not unlike contemporary Palestinian efforts, Israeli developers didn't neglect the natural environment entirely, but instead sought to achieve some unity of local (natural) conditions and rationalized construction. In recent years, environmental movements have arisen in the region which seek to mitigate the detrimental effects of the rationalization of the land, but these groups largely conform to the nationalist divisions of the conflict (Cohen 2002; 1994; 1993). For example, sustainability has become a loaded term. To the PA, sustainability is used to refer to attempts to prevent destruction of Palestinian areas in the West Bank under the Occupation, in combination with programs to undo the negative impacts of past modernization efforts. In contrast, among some environmental groups in Israel, sustainability is used in the context of maintaining an explicitly Jewish presence on the land (Cohen 2002; 1994; 1993). Thus environmental conservationism and nationalist efforts which draw on modernizing ideologies may also overlap. On the use of national parks for political ends, also see Hasson (2013) and Zonszein (2013b).

${ }^{39}$ Not coincidentally, wadi, a term for a type of river-flooded valley, comes to Modern Hebrew from Arabic. Also from Arabic, it survives in Spanish in the prefix guadal-, as in Guadalcanal, which comes from the Arabic name Wadi al-Qanal, meaning "valley of the stalls".

40 The hype that once surrounded large-scale industry and agriculture in Israel has transferred to hightech companies. See Senor and Singer (2009).
} 
(Livingstone 1992), perhaps it is not surprising, as Cindi Katz has noted, that those in power are infatuated with maps. Katz referred to it as going "map-crazy" and hypothesized that it was "no more than a form of 'gun-crazy' once removed" (1994, 1215).

The connections between development and cartography thus beg further investigation. However, any examination of how this technological focus has been affected by the refashioned landscapes of Palestine and Israel also requires a thorough consideration of the ways that technology is developed and used. This can be achieved by combining literature on cartography and technology—work which is influenced by STS, with its focus on how broader social contexts influence the inner workings of specific technologies-with research in critical GIS, an emerging theme in geography, whose proponents analyze the use and implications of GIS in particular. While geographic scholarship on cartography and empire often focuses primarily upon the political effects of maps once they are completed (e.g. Anderson 1991; Harley 1989), STS and critical GIS research enable a more textured understanding of specific practices by emphasizing the fact that cartography is an extended process which needs to be conceptualized holistically, from the process of collecting the initial data, on through choices of how data are categorized and displayedmost of which labor is not readily visible in the resulting map. With this in mind, I first describe the use of GIS cartography before turning to a more detailed exploration of these two bodies of literature.

\section{Maps as Interactive Visual Databases}

Far more complex than an image file, a GIS program is a way of visualizing and analyzing multiple databases at once. Although there are multiple interpretations of the range and goals of GIS, the adoption of GIS has coincided with an increasing emphasis in cartography on quantitative analysis as a goal (Longley and Batty 2003). ArcGIS Desktop, produced by Esri, is currently one of the most widespread GIS software packages in use. Similar to a blank Word document, a new GIS map document often simply consists of a white window on the screen. After creating it, the first thing a user does is add layers to the map. There might be one layer for roads, another for rivers, and a third for buildings, for example. These are stored as separate files, added in turn to the current document, and then viewed and modified together to make a final map. ${ }^{41}$

The kinds of layers that are loaded into map files are themselves datasets that can be linked to tables that include any number of related attributes, such as length, density, and textual labels, among others. The result is that the map becomes interactive. Users not only see the location of a dot indicating a city, for example, but by clicking on that dot with the mouse, they can bring up tables of information for that

${ }^{41}$ For an example of a GIS map, see Figure 3.8. 
city, including its name, population, etc.-provided that the map has been designed accordingly. However, large datasets might cause the program to crash unexpectedly, or can lead to long processing times.

Once the desired layers are visible and the map layout is set, printing or saving the file as an image becomes almost an afterthought. As November, CamachoHübner, and Latour note, rather than emphasizing the printed map, digital cartography has: "rematerialized the whole chain of [map] production. Today it is impossible to ignore that, whenever a printed map is available, there requires people, skills, energy, software, and institutions and on which the constantly changing quality of the data always depends" $(2010,584)$. The interactive, yet ephemeral, GIS maps on a computer screen, with their multitude of cartographers stretching from the user to the graphic designer, to the one who manages the database, back to the initial fieldworker with a GPS unit, stand in stark contrast to the fixity of paper maps. Although paper maps too had their legions of support teams, most of who did work, such as data management, that was never visible on the paper map, nonetheless the finality of the printed product differed substantially from the constant feedback involved in making digital maps (November, Camacho-Hübner, and Latour 2010). Once a paper map was completed, it could be difficult to modify or update, and it was easier to add new features in addition to older ones than it was to remove existing features. For this reason, the features on paper maps tended to be fixed into place, and the updates were clearly visible. In contrast, GIS maps are much more susceptible to alteration as circumstances change. However, despite these changes, digital cartography also exhibits strong continuities with paper mapmaking, as I explore in the next section.

\section{Critical GIS: The Work of Making Maps}

Just as the relationships between cartography and empire have been extensively critiqued, the role of GIS maps in furthering mechanisms of colonial control have increasingly come under scrutiny. In particular, scholars have pointed to some of the continuities between digital cartography and previous methods of making maps. If the introduction of computer maps represented an increase in the malleability of maps, in the respect that they can be changed more readily and updated more frequently, it has also reinforced some of the fixities associated with paper cartography. Chief among these is the privileging of particular forms of mathematics and quantification. In keeping with trends in other disciplines, the increasing importance of computers in cartography has made it ever more attractive for cartographers to quantify every aspect of the land, to attempt to analyze it solely in terms of attribute tables described above. At times, maps of landscape that might have included elements like memory, sensory impressions, stories, and extensive textual description were reduced instead to a process of counting trees, people, buildings, and other visible objects and inserting them into tables of data; the re- 
sults therefore derived from a narrow conception of which types of experience and observation are fit to be the basis of empirical knowledge.

This particular narrow use of GIS has also been subject to extensive critique from its early stages. In direct opposition to the sometimes euphoric reactions of GIS users, human geographers' first assessments of GIS in the 1990s consisted of strongly-worded condemnations of a technology that was viewed as taking over the discipline of geography; leading to a sometimes acrimonious debate which Fisher and Unwin have referred to as the "GI wars" $(2005,3)$. Particularly notable are the extensive critiques of John Pickles' edited book, Ground Truth (1995). In the context of these debates, Peter Taylor famously referred to GIS as a new form of imperialism (Taylor 1990; cf. Fisher and Unwin 2005, 1).

Although their concerns have at times proven to be fully justified, many of the early criticisms were made by scholars without a background in using GIS technology, and at times, the reactions against GIS and positivism in general have gone so far as to characterize all quantitative methods as clear, monolithic, and unchanging (Wyly 2011). In the ensuing decades, newer generations of scholars with expertise in both GIS and critical theory have developed the subdiscipline of Critical GIS, which is associated with both Critical Cartography and GIS analysis (Crampton and Krygier 2006). Critical GIS researchers, in keeping with other critical cartographers, argue that even the most scientific or natural maps are subjective in very specific visual and textual ways, given that all forms of cartographic truth are conditioned by historical and geographical systems of power (Dodge, Kitchin, and Perkins 2009; Massey 1994; Piper 2002). As a result, maps never simply convey information in a direct unmediated manner, but instead, they are invested with the power to incorporate specific forms of information while omitting others (Dodge, Kitchin, and Perkins 2009; Monmonier 1991). ${ }^{42}$

As a result of-or perhaps leading to-their interdisciplinary position, Critical GIS scholars also tend to be concerned with addressing the "rift" between critical social theory and largely quantitative spatial analysis in geography (Kwan 2004). Thus while Timothy Mitchell, as a postcolonial theorist, argues for a better understanding the nuances of quantitative methods in particular contexts (2002), nonetheless he stops short of allowing such an analysis to influence his own methods. 43 In contrast, Critical GIS scholars argue against privileging textual critique, which has long been favored in critical theory, over other scholarly methods and theories, such as work which adapts structuralist theory to contemporary debates using

\footnotetext{
${ }^{42}$ See Chapter 5 on the alternate highlighting and omission of the location of Israeli military bases on maps.

${ }^{43}$ Mitchell even appears to be suggesting an evolutionary narrative of academic development when he groups together studies at the "structural level" with those that use "hypothetico-deductive" (i.e. positivist) methods under the rubric of "the systematizing social sciences" and proceeds to refer to them as "the older kinds of social science" (2002, 2, emphasis added).
} 
visualization or quantitative analysis. ${ }^{44}$ So unlike in other areas of critical cartography, the emphasis in critical GIS is upon achieving a better understanding of how cartography is situated in relation to societies and academic practices that are overwhelmingly heterogeneous; caution is called for, however, against the tendency to overvalue GIS in ways that can marginalize other geographical methods (St. Martin and Wing 2007). Nonetheless, the focus on interrelationships allows for more diverse conceptions of the possibilities and consequences of cartography on the whole. Such conceptions include empirical maps as only one of myriad types, including schematic visualizations, artistic representations, and cognitive maps, while incorporating a variety of technologies, from pen and paper, to GPS and surveying equipment, to name just a few examples (Crampton and Krygier 2006; M. E. Pavlovskaya 2006).

The data-focused capabilities of GIS apparently have the potential to reduce all spatial questions to mathematical models and formulae, so it is perhaps not surprising that much Critical GIS research focuses on the role of quantification in geography. Pavlovskaya has argued that the apparent divide between quantitative and qualitative research is actually a spectrum, rendering the two fully compatible in spatial analysis using GIS, which she characterizes as "neither a quantitative nor qualitative tool" $(2006,3)$. Any table used in connection with a GIS map might equally contain numbers or letters, meaning at the very least there is greater qualitative and descriptive capacity than first imagined, despite its focus on classification through the use of tables. Joanne P. Sharp has noted the colonial routes of the privileging of quantification in GIS, arguing that central to governance in many European colonial regimes was "the commodification and bureaucratization of everyday life, namely making space mathematical and ordered (challenging the indigenous ordering of space) in such a way as to render the colony most efficiently known and governable" $(2009,64)$.

In this vein, Critical GIS scholars have been quick to point out that GIS is not static. Reconfigurations can occur on many levels, from alterations of hardware and software such as the development of online cartographic visualization services such as Ushahidi, Mapbox and CartoDB, to the creative use of existing techniques (e.g. Ahlqvist (2005) on fuzzy boundaries), to the expansion of communities of cartographers, both in person in Participatory GIS (Scholten, Velde, and Manen 2009, 3) and through social media, which is integrated with services like Google Earth (Farman 2010). Thus Curry's (1998) early emphasis on the limitations of GIS, as a technology that underscores scientific values such as universalism, disinterestedness, and skepticism, may become less relevant over time. To date, however, it is difficult

${ }^{44}$ Definitions of writing are also being expanded to include phenomenological and material aspects of the act of writing. Noy (2008) has argued as much in the case of the ideology of commemoration in Israeli historical sites. 
to tell; a more detailed history of the social development of GIS as a technology, as opposed to digital cartography more generally, is lacking (O'Sullivan 2006).

However, since its advent, one major reconfiguration of digital cartography is apparent. Computer mapmaking has seen the relative democratization of cartography as selections of professional datasets and software become available freely online. GIS techniques have begun to be combined with social media data and open source tools (Elwood 2009; Farman 2010) even as geographical services begin to be incorporated into technologies far beyond cartography (Scholten, Velde, and Manen 2009). ${ }^{45}$ At the same time, GIS software is far from inexpensive and many sophisticated datasets-including everything from updated higher-resolution aerial photographs to data describing underground infrastructure such as plumbing pipes and ICT cables-remain under the exclusive control of national governments and private corporations (Dodge, Kitchin, and Perkins 2009). ${ }^{46}$

Critical GIS is only beginning to incorporate and build on postcolonial theory, and the focus of Critical GIS case studies are still largely within Europe and North America. In the Global south, Participatory GIS efforts have included projects to incorporate indigenous groups in making maps of the lands where they live (e.g. InfoAmazonia 2013). The aim is to attenuate exclusionary mapping, for example, in the construction of parks and conservation areas (Harris and Hazen 2006); however, the further incorporation of indigenous groups into unequal political and economic systems can also pigeonhole them. For example, once any particular group is 'given' land on a map, they may have difficulties accessing places outside of that official area. Likewise, the incredible variety of everyday spatial practices have yet to be fully incorporated into alternative GIS, although PPGIS researchers continue to innovate in terms of how indigenous conceptions of space might further inform

\footnotetext{
45 In Palestine and Israel, alternative cartographic methods are expanding. Many of these involve transnational social media networks. One example includes Engineers Without Borders (EWB) Palestine's efforts to map West Bank roads using mobile phones, which was assisted by international EWB cartographers. EWB also explores alternative engineering more broadly, including making solar coffee makers (repurposed TV satellite dishes) for bedouin families in unrecognized villages, and developing mobile homes which can be moved at a moment's notice, for Palestinian communities under threat of home demolition (Interview 12, Palestinian civil engineer). Another related project is the ongoing effort to map Israeli protest marches from above, to demonstrate the extent of internal dissent, which might be downplayed in mainstream news outlets. As part of a growing transnational movement in alternative cartography, cartographers tape digital cameras to kites and helium balloons, which allows them to create their own aerial photos at minimal expense (Interview 21, Freelance Israeli NGO cartographer). Unfortunately, many such projects are short-lived.
}

46 The Open Source movement is gaining currency in cartography, allowing for wider access to geographic technology. Open Street Map, a Google Maps alternative, also is available for public editing within and beyond the region at http://www.openstreetmap.org. Only minimal training and no software downloads are necessary for those who are familiar with computers. 
academic theory and GIS practice (Moore 2007). ${ }^{47}$ At times, the expansion of GIS internationally can lead to the entrenchment of technocratic elites who only reinforce existing power hierarchies (Dunne et al. 1999), and the resilience of state mapping organizations can steamroll alternative cartographic efforts, no matter how successful (Duncan 2006; Radcliffe 2009). This points to the necessity of further studies, such as those found in this book, to better understand how GIS technology is itself situated within asymmetrical colonial legacies of knowledge. Perhaps paradoxically, a symmetrical framework is a uniquely effective way to study such asymmetrical legacies. With this in mind, I now turn to an analysis of the related conception of symmetry which is a central focus of STS research.

\section{Asymmetrical Violence and the Violence of Symmetry}

As with the critical GIS literature, work in STS provides distinct methods for analyzing the relationships between empire, maps, and digital technology. Chief among these is the notion of symmetry, which involves artificially constructing a comparison among diverse entities in order to highlight ways that their very constitutions are incommensurable. Yet before further analyzing various conceptions of symmetry, it is important to first situate them within the unique context of STS research. STS is distinct from critical GIS, although the two share similar concerns (Schuurman 2000; 1999). At its formation, STS continued the legacy of the Strong Programme (B. Barnes, Bloor, and Henry 1996, 19; Bloor 1976) by analyzing the ways in which specific forms of technology are culturally and historically contingent (Bijker 1995) while drawing increasing attention to the importance of qualitative, ethnographic methods in the critical study of science and technology. This has led to a body of literature that tends to focus on interdisciplinary case studies of technological practice, although scholars are increasingly moving to link case study research with broader political, economic, and social systems (Bank and Van Heur 2007; Wyatt and Balmer 2007). Related research has also considered the influence of economic and political systems on the development of professional networks (MacKenzie and Wajcman 1999; Van Heur 2009), as well as the 'boundary work' necessary to demarcate between areas of knowledge (Gieryn 1999; Halffman 2003; Henke and Gieryn 2008; Jasanoff 2004). While research on boundary work in particular focuses on the formation of divisions between disciplines, as well as between experts and policy makers, Halffman has argued that "the resilience and

\footnotetext{
${ }^{47}$ More broadly, research on indigenous spatialities includes anthropological studies such as Elizabeth Povinelli's (2006) work on geontology, which picks up on debates in ANT and the vast literature on the relationships between people and land in geography to analyze Australian aboriginal conceptions of the subject which seamlessly incorporate both the Earth and the human body; however, Povinelli focuses on specific instances of placemaking more thoroughly than on the relationship between such aboriginal conceptions and the materially situated methods that she herself uses as an international researcher producing textual knowledge- the latter of which is the focus of PPGIS research.
} 
dynamic of boundaries of science cannot be found in language alone" (Halffman $2003,57)$ and contended that "boundaries can even be embedded in the structure of an organization" (Halffman 2003, 71). This points to the need for a more substantial critique of landscapes of science, like that undertaken here, as it implies that a conception of science as a seamless enterprise only occasionally marred by boundaries does not deal seriously enough with the impact of boundaries on scientific practice.

Building on Halffman's simultaneous analysis of discourse and materialization, I take up Gieryn and Henke's related call to study how "legitimate knowledge requires legitimizing places" (Henke and Gieryn 2008, 359). For Gieryn and Henke, such research includes the study of how the geographic distribution of the branches of an institution, as well as between institutions, both reflects and affects the constitution of knowledge. However, a fuller analysis of the geographic distribution of science also requires an exploration of power, including the role of imperialism, in manifesting particular clusters while scattering others. Furthermore, by way of focusing my arguments for the importance of geographic landscapes, I follow Beaulieu, de Rijcke, and Van Heur $(2013,29)$, who emphasize the interaction between institutions and infrastructure in knowledge production, particularly in terms of "how new actors come to be involved", "how empirical material is legitimized", and "how knowledge claims are validated in relation to existing and emergent forms of order" $(2013,26)$. A consideration of how these processes are situated in geographic landscapes can only enrich the resulting analysis.

Cartography has not been considered yet at length in STS literature. Although Bruno Latour e has argued that maps circulated as standardized knowledge tools which enabled decision-making across vast distances, the cartographic 'black box' is only occasionally opened in STS research (exceptions include Handel 2009; Leuenberger 2012; Leuenberger and Schnell 2010; and J. C. Scott 1998). However, given the concern in STS for the specificity of technology, including geographical specificity, the need for a study of digital cartography is especially pressing. Although geography can provide STS with detailed conceptions of social and material space, STS also can contribute the conception of symmetry to geography (Coutard and Guy 2007). In a context where technologies were said to be successful because they were useful, or "worked" (and vice versa), Bijker and Pinch (Pinch and Bijker 1989) use symmetry to avoid taking for granted the success of a particular technology by providing accounts which symmetrically outlined the reasons both for its failure and success. Wyatt (2008a) explores how symmetry was soon expanded to include alternative configurations, from perhaps most famously attempts to be symmetrical to an actor being human or nonhuman (Callon and Latour 1992), to Wyatt's own work (2008a; 1998) which actively incorporates concepts introduced by actors, as well as by the analysts or researchers themselves. As a constructed measure for exploring the complexity of power imbalances, symmetry can be incredibly useful in terms of finding ways to incorporate reflexivity into research design. Symmetry is particularly helpful for attempts to avoid reverting to domi- 
nant narratives in subjects where particular types of accounts have traditionally been alternately ignored, obviated, or stifled.

Symmetry also dovetails with work on speech and binary oppositions in critical theory. Gayatri Spivak has argued that attempts to produce socially just forms of knowledge are not only hindered by the fact that particular voices go unheard, but that power imbalances affect the constitution of voices themselves (Spivak 1999; Spivak 1988). Likewise, Derrida (1981) has noted that, when power imbalances are effected, it involves not only dealing with two sides that are in an unequal relationship, but rather the contrast between a produced whole and a dissipated nothingness. Although he is referring to philosophical hierarchies, Derrida's analysis seems prescient for the study of the Occupation, as he outlines an opposition between one group which is recognized, defined, and dominant, and a second group which is inconsistently defined, if at all. In his view, oppositions are not "peaceful coexistence" but "violent hierarchy": "One of the two terms governs the other (axiologically, logically, etc.), or has the upper hand" $(1981,41)$. As a form of strategic play that was formulated independently from Derrida's critique, symmetry shares with deconstruction an attempt to account for the negation particular groups by actively incorporating formerly negated or disregarded experiences in the analysis.

Symmetry has its own pitfalls, because the efforts to incorporate alternative accounts nonetheless involves defining those accounts-first of all as accounts, and second of all in a way that makes it possible to place them into an opposition to a more dominant version. While elegant and effective in its simplicity, this can be problematic in cases where there are not two unequal opposing sides, but instead one more dominant view which stands in opposition to a plethora of other options. However, the constructed nature of a symmetrical axis means that its proponents can draw attention to the imbalances created by particular historic hierarchies, and the resulting problems of group definition and analysis, without entirely reinforcing the categories thereby imposed.

Symmetry is particularly relevant in the context of the Israeli Occupation. Those familiar with the politics of the Occupation are often suspicious of attempts to bring together Palestinians and Israelis precisely because they represent the conflict as a result of a "perhaps tragic, but certainly rectifiable, psychological misunderstanding" (Said 1995, 36), that thereby does little to address more systemic material inequalities among those involved. However, such critiques were precisely the motivation for the symmetrical structure of this book. My account is intended to counter facile attempts at commensurability by highlighting the fact that, as Thomas Abowd has noted, although there is a "parity of desire" for Jerusalem and related areas among Palestinians and Israelis, so far "there has been no parity of power" (2007, 243). Furthermore, by building my symmetrical account I have focused on the work of professional elites precisely to analyze specific instances where Palestinian cartographers have attempted to build a voice in a modern sense, to function as international scientific observers through their maps. As an analytical practice, 
symmetry is a uniquely effective method of highlighting the discrepancies that exist even in such a 'best case' scenario.

In addition, the technique of symmetry, as it is used here, also allows for an investigation of the exclusionary effects of the ways that segregated landscapes serve to excise identities such as Palestinian and Israeli from one another, reinforcing their dichotomous construction due to segregated regimes which discount and attempt to negate the point of view of those who identify (or are identified by others) as Palestinians (See Chapter 5). For the categories of Palestinian and Israeli are also socially produced, and they often overlap. Moreover, the type of overlap varies depending on the circumstances, as can be seen in the differences among groups and individuals who do not neatly fit into any particular group. ${ }^{48}$ Overall, through a combination of STS and critical GIS research, of work on landscape production and studies of cartography and empire, the connections between colonial legacies and the intricate details of digital cartographic software can be studied more thoroughly. This is precisely what I have set out to do in this book.

\section{Conclusion: Postcolonial GIS}

Throughout this chapter I have argued for a combination of geographic literature on cartography and empire with research in STS and critical cartography which analyzes the specific materialities of technology, including GIS. Such an interdisciplinary dialogue might make it possible to move towards a postcolonial analysis and use of GIS, in keeping with a fuller awareness of the legacies and materialities of GIS technologies and their related practices, while at the same time expanding literature on colonialism and technology by including considerations of how material landscapes affect digital knowledge in ways that crystallize forms of control within particular geographic scales, at the expense of other people and regions.

In the following chapters, I turn to a symmetrical analysis of how geographic landscapes interact with cartography in Palestine and Israel in complex ways that can have unexpected results. On the one hand, ArcGIS is a software package like many others. It is a sometimes clunky way of combining tables of data and graphing them in many different colors, a way of composing into a single screen the vast amounts of information collected at different resolutions and under varying conditions. As a cartographic technology with colonial roots, GIS more broadly allows representations of land to be seemingly divorced from the landscapes in which they

\footnotetext{
${ }^{48}$ For example, there are marked historical differences between Palestinian citizens of Israel-who formed over twenty percent of Israel's population in 2012 (CBS 2012) - and those of mixed Palestinian and/or Israeli heritage, who may or may not be Israeli citizens, as well as Mizrahi Jews, or Jews of Middle Eastern origin who are often citizens of Israel yet discriminated against in a culture long dominated by European, Ashkenazi Jews. These groups also overlap.
} 
were created, although they continue to be fully imbricated within them. On the other hand, ArcGIS is an advanced multidimensional interface which permits ever more detailed studies of the intricate facets of the surface of the earth in ways that, although they consist of existing methods and technological components, nonetheless are innovative in combination-and which therefore enable ever more detailed disputes. 


\title{
Chapter 3
}

\section{Subtracting Palestinians and Remaking Borders: Israeli Population Maps after 1967}

\author{
"Making these experiments sometimes made me feel like a kindergarten boy \\ playing with colored papers, and afforded boundless amusement for my grand- \\ children." (Bachi 1968, 3)
}

"It was decided to carry out the enumeration from house to house under curfew [.... The enumerator marked the doors of the houses enumerated with chalk to ensure an orderly and complete coverage." (CBS 1967)

\section{The Methodology of Curfew}

The quotations above serve to illustrate the intimate ties between population control and the development of statistical cartography. They date from the beginning of the Israeli Occupation of the West Bank and Gaza Strip in 1967; the census described in the second quote began only a little over two months after Jordanian and Israeli troops had ceased fighting street by street through the Old City of Jerusalem. The author of the first quotation, Roberto Bachi, was the head of the Israeli Central Bureau of Statistics (CBS), which was in charge of the enumeration, and he was at the height of his career. Bachi remained a key architect of the Israeli census for over twenty years, and he was praised in diverse corners of the international scientific community for his innovative research in statistical cartography and geostatistics ("In Memory of Roberto Bachi" 1996, 13-14). The quotation captures Bachi's romantic depiction of his academic research into his method of "Graphical Rational 
Patterns" (GRPs), which were a new symbology or visual code for depicting numbers in a precise way on maps (see Figures 3.1 and 3.2). The 'colored papers' he refers to were transparent stickers or transfers that, at the time, were applied when making a particular map so that the cartographer didn't have to draw every symbol by hand. The second quotation comes from the official report of the 1967 census of these newly-occupied Palestinian Territories, carried out by the Central Bureau of Statistics (CBS), which Bachi both founded and directed. ${ }^{49}$ It describes the curfew imposed upon the Palestinians, who were forced into their homes, or the home they happened to be closest to at the moment, their doors and walls marked with chalk, so that the count might be considered 'orderly and complete'.

There is a clear symbiosis between the colored papers and the curfew. In the first instance, Bachi depicts himself cutting into colored papers or transparency sheets, using glue to stick them into place on maps; in the second, Bachi is at the head of an army of enumerators - supported by the actual military (CBS 1967, III)-who physically marched through the streets, metaphorically cutting up groups of people and sending them back inside, fixing them in place in order to obtain a clear picture, but this time using chalk to do so.

This relationship between methods of state control and academic research has often been conceived in terms of the influence of representation in the interplay of representation and materiality in shaping the landscape (D. Harvey 2005; Low and Lawrence-Zúñiga 2003; N. Smith 2008), but in practice the focus has been primarily on representation (e.g. Mitchell 1991). In this chapter, instead of emphasizing the ways that conceptions or representations of space shape the landscape, I will investigate how the landscape that was constructed through the Israeli census in turn influenced Bachi's academic work. More specifically, I will analyze the ways that the continued physical presence of subjugated populations in the landscape of the Israeli census - a presence which was acknowledged through the need to conduct a census in the first place-influenced Bachi's theoretical research in statistical cartography. Although he claimed his work was scientific, and he focused not on political issues but on obtaining an objective, quantitative view of Israel and the Territories, nonetheless even Bachi's most abstruse equations were fully embedded in the cultural and material landscapes in which he worked.

\section{The Census as Western Science}

Bachi himself grew up and became a successful professor of statistics in Italy before the Fascist government's racial purity laws forced him to flee to Israel before World War II. Over the course of his career, Bachi was active whether in government, academia, or independent research, throughout nearly every major political transition

49 Joel Perlmann has made the 1967 census data for the Territories available online at http://www.levyinstitute.org/palestinian-census/. 


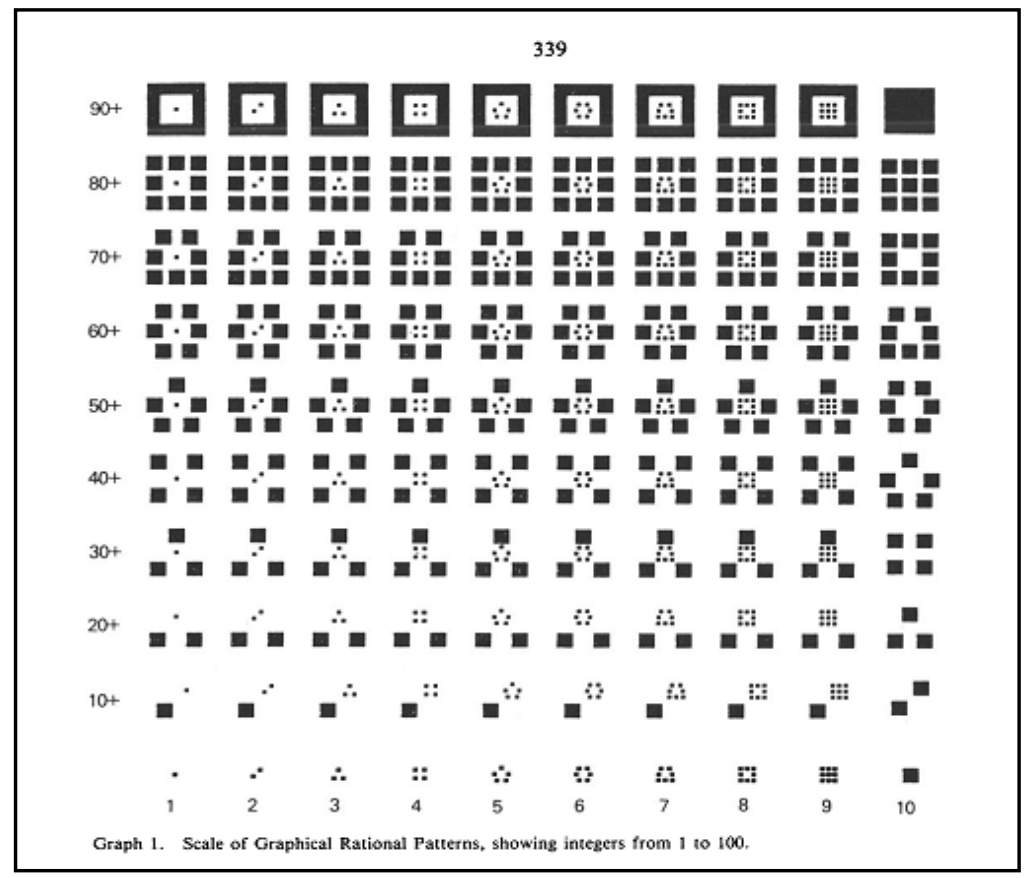

Figure 3.1. An example of Roberto Bachi's GRPs: A Chart of the Symbols for the numbers from 1 to 100 (Bachi 1989, 339).

in the region during the second half of the 20th Century, from before the founding of the state of Israel until the just before the signing of the second Oslo Accords. From the beginning, Bachi insisted that the Israeli census be conceived as an enterprise that was firmly rooted in Western science. As far back as the 1948 census, carried out while the war that followed the founding of Israel was still raging around them, Bachi insisted that the census would be conducted according to rigorous and objective statistical principles (Bachi et al. 1955; Leibler and Breslau 2005). Later, as the director of the Israeli Central Bureau of Statistics, he continuously argued that military concerns should not be allowed to dominate over scientific rigor (Bachi 1981; Leibler and Breslau 2005). Throughout, he looked to Europe and North America for models for his scientific work. In the planning stages of the Israeli censuses of the 1950s and 1960s, Bachi and his colleagues requested numerous census documents from countries such as Canada, France, and Spain-and, coincidentally, from Iran, which at that time was still under the control of the Shah, who was politically supported by governments in Europe and North America (CBS 1969b). He was a main contributor to both the Statistical Atlas of Italy (Bachi 1999) and the Atlas of Israel (SOI 1970) and spoke at innumerable international conferences (For example Bachi 1989; Bachi 1975; Bachi 1974a; Bachi 1962a; Bachi 1962b; Bachi 1955). 
Bachi's repeated attempts to present his work as objective and neutral are evidenced by the fact that under his leadership the CBS fought to compile data "solely according to professional considerations, without interference from political quarters" (Schmelz and Gad 1986, xii). But despite this, Bachi's more politicized work counting and managing Palestinian populations nonetheless exerted a strong influence on his abstract research in ways that were not wholly incompatible with his aim of developing statistical cartography as a science. Indeed, even the academic context of his research was the outcome of his governmental efforts. In addition to running the census, Bachi also founded the Department of Statistics at the Hebrew University of Israel, thereby further linking academic statistics to Israeli state objectives. In addition, his two major academic books were published in tandem with major census milestones: the first, in 1968, immediately after the census of the Occupied Territories discussed above, and the second, after his death in 1995, following the first census in Israel to fully incorporate automated statistical mapmaking of the kind which Bachi had fought hard to develop (Bachi 1999, ix; "In Memory of Roberto Bachi" 1996, 13-14; Schmelz and Gad 1986, xi-xiv). As I discuss in detail below, both books address key issues of the census and develop methodologies first implemented in the census in order to enumerate populations in the Occupied Palestinian Territories. Thus the theoretical, academic, and governmental areas of his professional career were thoroughly interlinked; furthermore, far from contradicting, they mutually reinforced one another throughout.

The relationship between Bachi's governmental and his theoretical work was also influenced by the advent of digital cartographic technology. Throughout his career, Bachi took part in the fundamental technological transition in cartography as it morphed from a trade reliant on hand drafting skills into a quantified, mechanized science that became heavily dependent on computers. Bachi himself was trained and largely active within a modernist tradition of statistical cartography in Italy; indeed, he was instrumental in bringing the paradigm to the nascent Israeli state, where it was further developed in part due to his personal efforts (Schmelz and Gad 1986). However, as I will demonstrate, his later methods enabled the detailed management of piecemeal territories, a type of complexity which is considered a hallmark of late modern governance.

\section{Late Modernism and the Influence of Landscape}

Instead of illustrating an abrupt late 20th-century disjuncture between the modern and the post-modern, the developments in Bachi's work serve to demonstrate the specificity of a digital transition in a particular context, as Bachi chose to further key modernist goals in formulating cartographic knowledge, such as accuracy and the continuity of borders, while actively rejecting others, like completeness and the consistency of space. While his later work arguably is evidence of a new form of modernism, nevertheless it is one that still would be accepted among international 
scientific communities-and this despite the fact that, as just noted, it simultaneously challenged two fundamental goals of statistics.

Bachi's work demonstrates how, in the context of processes of modernization and their related conflicts, the landscapes that are produced often transform the initial goals themselves. As the efforts to enforce a single set of national borders for Israel on the ground instead spiraled into the construction of tightly-linked networks of bounded settlements in the West Bank, the very process of determining these borders would transform the aims and purpose of Bachi's theoretical work. To the extent that Bachi cooperated with broader efforts to expunge Palestinians, by name at least, from the statistical landscape, nonetheless he could not extricate himself from the social and material connections that their relative physical proximity afforded. ${ }^{50}$ As a result, years of struggle and Occupation ultimately fed back into statistical cartography, shaping both Bachi's research trajectory and, through him, the very fabric of the digital canvas upon which Palestinian and Israeli population statistics continue to be mapped.

In order to explore these and related issues, in this chapter I analyze key cartographic methodologies that Bachi developed, with a focus on his two major theoretical books on statistical visualization which appeared in 1968 and 1999-the latter posthumously from work completed in 1995. My aim is to show how each book was influenced at even its most quantitative and theoretical level by the very presence of Palestinian populations in the landscape, who did not necessarily see themselves as forming part of Israel. This influence was felt through the concerns which arose while preparing to count populations in the West Bank in the course of the Israeli census. Furthermore, it was inflected through key political arguments of each book's respective era: first, in 1968, through the claim that Palestinians did not exist, and second, in 1995, by way of the ongoing debates that came to be known as the Demographic War. In what follows, I first introduce each book and the census which predated it (in 1967 and 1995, respectively) in the context, respectively, of one of these two major political debates, and then delineate the development of Bachi's theoretical claims in relation to relevant census methodologies. I proceed by analyzing each book in the context of his work as a whole, pinpointing Bachi's simultaneous retention of cartographic ideals such as accuracy and continuity, and his rejection of others, such as completeness and consistency (Haraway 1988; Livingstone 1992; Monmonier 1991). In the conclusion to this chapter, I return to the role of computerization in his efforts to innovate while maintaining Western scientific standards.

By analyzing Bachi's work in the theory of statistical maps in 1967 and 1995, this chapter encompasses the entire period of direct and full Israeli control of the West Bank and Gaza Strip until the beginning of limited management on the part of the Palestinian Authority-a period which coincides with what might be called the

${ }^{50}$ It became increasingly less proximate over time, as I will discuss in later chapters. 
pre-history and early history of the development and eventual spread of digital cartography. During these decades, even as Bachi sought to cement the transformation of statistical cartography into an international computational science, he himself was influenced by the process of mapping local and regional landscapes.

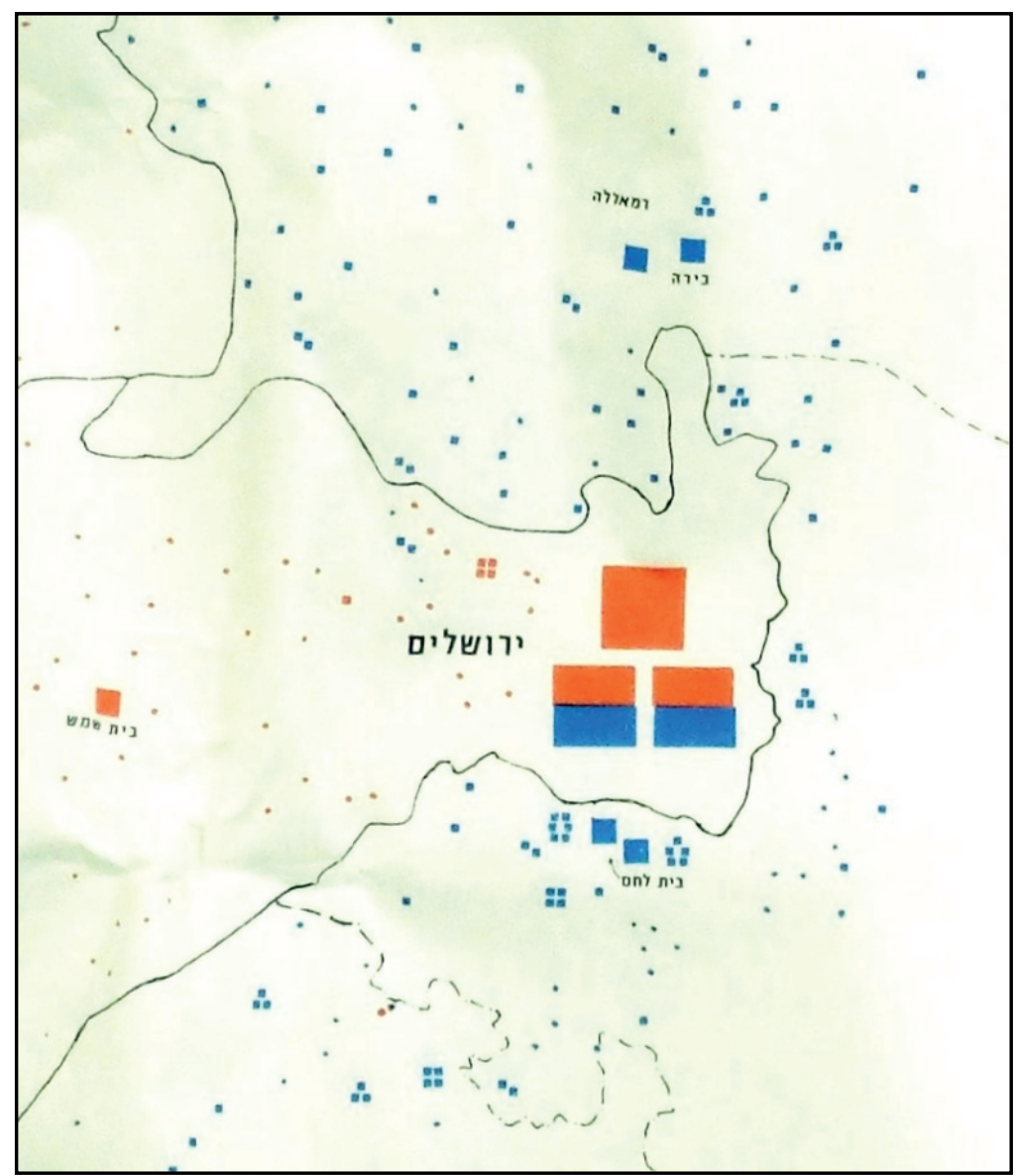

Figure 3.2. Example of a Map Made Using GRPs: Detail of Jerusalem population from an Israeli state population map. Jewish population is shown in red and non-Jewish population is in blue. The fact that the Green Line boundary of the West Bank (the black line which snakes through the image), is shown indicates that this map was only intended for internal, government use. The sources for the data are not given. The GRP symbology used is similar to the one given in Figure 3.1. (CBS 1969a) 


\section{The Critical Cartography of Census History}

As the prime means by which state bureaucrats collect quantitative information about the people under their jurisdiction, national censuses-a process of counting the resident population-have played an important role in linking the production of academic knowledge to the spatial management and control of human mobility in Palestine and Israel (Zureik 2001), and census statistics generally comprise a more expansive and inclusive form of data than other measures that are also in common use, such as voter turnout (Hannah 2001). Geography and cartography are central to the census as a tool for surveillance and control (Crampton 2003), as the census doesn't simply take place within pre-determined national borders, but which represents part of the work of constituting the nation on the ground (Anderson 1991; Leibler 2007; Leibler 2004; Leibler and Breslau 2005; Zureik 2001). Recently, Foucault's call to study geographies of power has sparked a body of research into the ways that colonial geographies were integral to the power systems of Modernism's core (Stoler 1995), yet his work has only just begun to be applied to the study of quantitative geographic knowledge (Crampton and Elden 2007).

While the central role of census mapmaking is often acknowledged in academic literature (Anderson 1991; Crampton 2003; Edney 1997), statistical cartography's technical aspects have less often been treated in detail (Exceptions include Hannah 2009; Hannah 2001; Mood 1946; M. Pavlovskaya and Bier 2012). In studies of the census in postcolonial contexts, geography and modern conceptions of space have taken more of a central role due to the well-documented relationship between cartography and imperialism (Cosgrove 2008; Edney 1997; Godlewska and Smith 1994; Gregory 1994; Harley 1989; Kalpagam 2000; Stone 1988; Turnbull 2000; Winichakul 1994), as well as the attested links between the geographic spread of technologies and bureaucratic systems in the context of managing colonial and postcolonial populations (Bektas 2000; Feldman 2008; Hull 2003; Leibler and Breslau 2005; Mrázek 2002; Zureik, Lyon, and Abu-Laban 2011). To date, however, less critical attention has been paid to methods for conceptualizing census boundaries, and the spatial epistemologies that are implicit in such definitions, with the notable exceptions of literature on gerrymandering in statistical districts more broadly (Bunge 1966; Cranor, Crawley, and Scheele 1989; Mood 1946; Sauer 1918; Sherstyuk 1998), and Elia Zureik's analysis of how borders have been shaped by "a Palestinian-Israeli dialectic of state construction" framed by asymmetrical power relations-although Zureik emphasizes continuities in contestation on the ground over transformations in maps $(2001,227)$.

\section{International Hierarchies of Scientific Knowledge}

Just as those in power have attempted to define and manage populations through the census, their own subjectivities have also been shaped in the multiple geo- 
graphic scales in which they operate. Bachi certainly served as a privileged denizen of dominant statistical discourse in Israel, yet his role internationally was much more complex. For Bachi did not only benefit from international hierarchies. As a Jewish scientist from a small nation like Israel, he was also constrained by them. International hierarchies of science would serve to shape the ways that Bachi could innovate within this interdisciplinary framework while still being accepted as a scientist-that is, while still being viewed as a worthy theorist whose methods were credible and whose findings about the nature of statistical space, therefore, could be accepted as objectively true. ${ }^{51}$ With this in mind, Bachi's insistence that the census be scientific-namely, that it be conducted not according to dictates of politics, but rather in line with the requirements of rationality (Leibler and Breslau 2005) - was not only the outcome of personal preference or beliefs. It can also be viewed as part of an attempt to fit within an international hierarchy within particular disciplines, and among academia more generally, whose members often had rigid, if implicit, notions of belonging based on strict logical principles (Porter and Ross 2003; Wagner 2001). For, although in Bachi's case he appears to have embraced the dominant paradigms in demographics whole-heartedly, his and other Israeli academics' attempts to demonstrate their scientific legitimacy are also the logical outcome of the widespread belief that there is only one true way to do science (M. R. Smith and Marx 1984; Wyatt 2008a).

The belief in the unity of science has important implications in terms of the international landscapes of science, because it includes an assumption that the 'right' way to do science is that practiced in Europe and North America. So if there is one way to do science, and the right version is the one practiced in the West, then any developments that do not seem, in the main, identical to Western science are themselves taken to be unscientific by definition. For this reason, it would be imperative for Bachi and other Israeli academics to demonstrate their willingness to meet the methodological restrictions in order to gain the international legitimacy conveyed by broader recognition that their work is indeed scientific. Thus, even as he used methods that were recognized as Western science to assist the government in managing Palestinian populations through restrictions on mobility and other measures, the fact that Bachi was not working solely in the West would have set limits upon the scope of his potential innovations.

\section{The Quantitative Revolution: Geography as a Statistical Science}

This begs the question: what was this interdisciplinary paradigm to which Bachi was expected to adhere? Bachi's role as an early adapter of digital mapmaking, who sought to computerize his cartographic methods as early as the 1960 s, stood in stark contrast to the situation at the turn of the 20th Century when geography,

${ }^{51}$ In Chapters 4 and 5 I explore the implications of knowledge hierarchies for Palestinian cartographers. 
including its sub-discipline of cartography, was considered a field comparable to history. While attempts had been made previously to re-establish geography as a science (Godlewska 1999), human geographers, it was widely believed, gave descriptive, analytical accounts of particular landscapes (Livingstone 1992). This would change after WWII, as young geographers sought to transform geography into a statistical science, a movement that became known as the 'quantitative revolution' (T. J. Barnes 2001). As a result of their efforts, by the 1960s mapmaking was no longer viewed as a descriptive spatial record of territories, but instead as a scientific method for using a Cartesian grid for the display of statistical variability, which was achieved largely through the use of thematic maps (Godlewska 1999; Livingstone 1992). ${ }^{52}$ Although Bachi himself was quite sensitive to the specifics of geographic mapmaking, he tellingly uses the words graph and map almost interchangeably.

The quantitative revolution allowed Bachi to make seamless transitions back and forth between population statistics and geostatistical theory, to put mathematics to work, via technology, in the name of modern empirical science. In Bachi's case, the stress on clarity and transparency is apparent in his exhortation that GRPs would make graphing 'quick and easy', and would avoid types of mapmaking which are 'inaccurate or even misleading' (Bachi 1968, 1-2). By framing his work in this way, Bachi helped early on to bring the insights of geography's quantitative revolution to Israel, and to serve as a link between Israel and international networks of science. But he was an innovator as well as a transmitter of this new quantitative methodology, and his work challenges the assumption that the quantitative revolution, or indeed the concomitant development of GIS, took place primarily in Europe and North America. As early as the 1960s, while the revolution was ongoing in Europe and the US, Bachi was already pursuing similar avenues of research in Israel (e.g. Bachi 1956). Although he might not have been able to challenge the paradigm wholesale, Bachi nonetheless was able to innovate within its bounds. He therefore navigated the alternating process of conformity to international dictates and change, so that existing statistical methods might become practically useful in the contexts, like the census, in which he worked. The process of doing so would transform Bachi as well. Through the ultimate ambivalence in Bachi's depictions of statistics for Palestinians in the Territories, the Palestinian struggle for selfdetermination would also leave its mark on his research.

\footnotetext{
52 Godlewska (1999) has pointed out how in the Middle Ages geography was also viewed as a science, but that since it was founded on accurate descriptions, rather than hypothesis testing, it lost this status as a science during the Renaissance, only to regain it in the 20th Century. She also convincingly investigates exceptions to the broad trends described here-the explorer and cartographer Alexander von Humboldt foremost among them.
} 


\section{Locating Existence under Occupation, 1968}

The outcome of conflict between two parties does not usually hinge on a debate over whether or not one of those parties exists. But this is precisely the way that some Zionist groups have attempted to frame debates over the right of Palestinians to live in and visit Israel and the Occupied Territories. Prime Minister Golda Meir's famous proclamation in 1969 that, "There never was such a thing as Palestinians...They did not exist," ("Golda Meir Scorns Soviets" 1969) has been reiterated over countless election cycles both within Israel and abroad. ${ }^{53}$ Meir's and other's challenges to Palestinian identity have been skillfully rebutted at length in academic and broader literature (Bishara 2003; Kanaaneh and Nusair 2010; R. Khalidi 2010; 2006; Massad 2006; 2003; 2001; Seikaly 1995). Yet, in the longer piece from which this quotation is taken, Meir bases her argument on principles of statehood, claiming, "When was there an independent Palestinian people with a Palestinian state?" Although few today would join her in claiming that nationhood is what brings people into existence, nonetheless by tying a group's physical existence to the (social-geographical) definition of a nation, Meir implicitly claims that social and material are forever interlinked-an implication that is quite in keeping with the work of poststructuralist scholars who have sought to deconstruct the dichotomy between the social and the material, as discussed in more detail in Chapter 2 (Callon and Latour 1992; Keane 2007; T. Mitchell 2002). ${ }^{54}$ With this in mind, for the sake of this chapter, I will focus strategically on the more (if not fully) material aspects of the Palestinian presence in the landscape and their influence on Bachi's research—and, through Bachi, on Israeli population maps more broadly.

\section{Palestinian Existence and the Israeli Census}

Irrespective of any claims to Palestinian nonexistence, from the perspective of the Israeli military administrators who took over the management of the Territories in 1967, the Palestinians needed to be counted. The presence of significant popula-

\footnotetext{
53 That this position is still relevant today can be seen from the claims to this effect by several candidates in the 2012 US Republican primary as well as numerous online articles such as Farah (2002). For example, the site http://www.mapofpalestine.com directs viewers to a page that says, "No such thing! Palestine does not exist" ("Map of Palestine" 2013).

${ }^{54}$ Meir's words also contrast with a well-known quote from Angela Davis, writing from prison just two years after Meir spoke, albeit in the somewhat different context of the US Black Panther struggle: "Human beings cannot be willed and molded into nonexistence" (1971).Viewed one way, Davis's quote seems to insist upon an essentialist materialism where physical presence cannot be manipulated or constructed through social means. However, her statement could also be read pragmatically-that is, to suggest that human beings will not often allow themselves to be willed into nonexistence. In this respect, Davis's words highlight how attempts like Meir's can actually be counterproductive, because they often generate the types of obdurate resistance they seek to foreclose.
} 
tions would have immediately indicated the need to control them, given that they would have been perceived as a security concern. The first step in carrying out these tasks was to count them and note their precise locations-and this is precisely what the CBS set out to do. But if the need to conduct a census after the 1967 war demonstrates a tacit acknowledgement of the Territories' and Palestinians' existence, the census also aimed to limit the number of Palestinians who were allowed to remain. As Anat Leibler has shown (2007; 2004; Leibler and Breslau 2005), one of the primary motivations for conducting the census so quickly was to prevent those who had fled during the conflict from being included, because the census was the basis for issuing identity cards allowing their bearers to reside permanently in the Territories, if not to become citizens. In this way, the census could be said to have two potentially conflicting priorities-on the one hand, to gain an accurate count of the populations now under Israeli control, while on the other, excluding as many people as possible so that fewer Palestinians could claim residency.

Despite this, or perhaps because of the potential that they could be charged with undercounting, the census authorities stress the extreme lengths to which census enumerators went to obtain accurate counts. Their report notes that, "despite the use of special vehicles (and even donkeys), the enumerators could not reach isolated houses or distant localities (especially nomads' tents), because of difficulties of access or danger of mines" (CBS 1967, XXX). In so doing, they also highlight the fact that, as a result of 1948's enduring political realities as well as the outcome of war, some of the ways that the hinterland of the West Bank, for example, actually became practically inaccessible to the Israelis in the immediate aftermath of the war. So, just as the very presence of Palestinians made the 1967 census necessary, in the eyes of Israeli officials, the enduring geographical impacts of the political events of 1948 and 1967 circumscribed their ability to conduct that census. And the census in turn would affect the types of maps that Bachi used and advocated in his 1968 book.

\section{Bachi's 1968 Book: From Choropleths to Graduated Circles}

Bachi's name appears on the official report both as the 'director of the census' and the 'government statistician' (CBS 1967), and he played a key role in the way the 1967 census was conducted. In the process, however, Bachi contradicted one of his own judgments in 1948. In the 1948 census, against members of the Israeli military who had wanted to count Palestinians separately and by different methods than Israelis, Bachi argued forcefully that the methodology should remain the same for both groups so that the results could be seen to be statistically rigorous (Leibler and Breslau 2005). The 1948 Census Reports also described the hesitancy to enumerate Jews via a curfew, given that this method had been widely used by the British during their occupation after World War I, and it would thereby have brought back traumatic memories for the inhabitants (Bachi et al. 1955). Yet by 1967, under Bachi's direction, the census did precisely this for the Palestinians in the Territo- 
ries-a process undertaken for the Territories alone. He oversaw the one-day curfew on the Palestinians in the Territories, with the stated reasoning that indiscriminately confining people to their homes would improve the chances of counting as many people as possible.

Thus the curfew was justified using arguments for accuracy, despite the fact that it would have imposed its own sources of error upon the statistics. ${ }^{55}$ The resulting presence of the census data for the Territories likely would have proposed a logical conundrum for Roberto Bachi. As someone who considered himself a scientist, to Bachi the Palestinian census data likely would have seemed less than rigorous-seeing as how it was collected under restrictive conditions which made it only partially comparable to census data for the fully-annexed areas of the state of Israel. Yet, also as a scientist, he could not completely ignore that the data existed-for example, by following common practice and placing labels that read 'no data available' on relevant areas of his maps of Israel. After all, he spearheaded the operation which collected the data in the first place. So, on scientific maps, the question for Bachi would have become: How to map Israel while neither denying that data exist for Palestinians, nor actually including that (only semi-rigorous) census data on the map?

This difficulty of how and to what extent to acknowledge the existence of data for Palestinians was compounded by the presence of the Green Line boundary between Israel and the newly-Occupied Palestinian Territories. The Green Line was created during cease-fire agreements in 1949, and in places between 1949 and 1967 it served as a highly militarized border between central Israel and the (Jordanian-controlled) West Bank. While Jerusalem was rigidly divided, in other areas the separation was inconsistent, and border areas were quickly filled in with Israeli settlements. As a result, as late as the 1950s, Sami Hadawi could claim that "the Armistice Lines have not until this date been demarcated on the ground" (Hadawi 1957, 1). From 1967 onwards, however, even the official policy of enforcing the border was reversed. The agencies of the state of Israel claimed that the Green Line was no longer a valid border. Instead of referring to the military Occupation of the Territories, academics and government agents euphemistically proposed that Israel and the Territories had been 'reunited'. In keeping with this claim, the Green Line between Israel and the Territories no longer appeared on most state maps (Benvenisti 1984; Gorenberg 2012; Shehadeh 2007, 178). In a related effort, PLO and other Palestinian maps did not show the Green Line even before 1967 (e.g. Hadawi 1957), although as with Israeli maps this practice has mitigated somewhat

\footnotetext{
55 The curfew introduced notable irregularities not only in terms of excluding the refugees who were missing or away from home due to the war, as well as those who no longer had homes in cases where these had been taken over or destroyed during the fighting. But it also, by the census takers' own omission, had the effect of creating "differences between the locality in which [inhabitants] were registered and the permanent places of residence"(CBS 1967, xxx-xxxii).
} 
over time. The official omission was in contrast to the situation on the ground however. Given that the Territories to date have not been formally annexed by the state - with the notable exception of East Jerusalem - the administrative, military, and economic policy discrepancies between annexed Israel and the Territories were and are extreme (Benvenisti 2000). Such ambiguities of segregation are emblematized in the separate-and-unequal policies of the 1967 census of the Territories. As a result of the Palestinians' existence and ongoing struggle, it was the Green Line, and not the official state line that bounded all of Israel and the Territories, which served as the physical boundary which circumscribed the collection of data for the majority of the Israeli population.

The resulting inconsistencies in mapping the Green Line are born out in Bachi's 1968 book, Graphical Rational Patterns. The aim of his book was to introduce the eponymous GRPs, which as noted consisted of a standardized set of symbols for displaying numbers on maps. While maps often indicate numerical values with circles of varying sizes, and whose differences can be difficult to judge, by constructing his elaborate symbology of GRPs, it was Bachi's hope that anyone familiar with GRPs would be able to tell the exact number the cartographer sought to display (See Figures 3.1 and 3.2). However, in the process Bachi also begins to move away from rigid notions of consistency, which would have required him to display all internal borders, including the Green Line, in favor of greater accuracy of a few selected points. Perhaps not surprisingly, the points he selected to display most often represented Jewish Israelis. In fact, despite directing and overseeing the census of the Territories, Bachi rarely if ever used the data from that census in his work.

In order to achieve this in the context of the possibly not wholly reliable 1967 census data, Bachi increasingly began using one very specific type of map from among two commonly-available options. As is evident in his 1968 book, for mapping census data collected from 1967-onwards, Bachi uses graduated circles more and more, becoming increasingly critical of the shaded area technique called choropleth which was and continues to be more commonly used. Choropleths (See figure 3.31) are maps in which districts, states, or regions are shaded in progressively darker or lighter shades in order to represent increased percentages of some particular characteristic, such as the average number of people in each household (figure 3.31) for the respective areas. Choropleths are convenient because they allow cartographers to indicate statistical data without an abundance of symbols. However, they can also be very misleading, and there are several problems which arise particularly with choropleth maps. For instance, because different regions are shaded in, those with larger geographic areas often stand out and appear more significant than they would seem to be if judged by the statistics alone-and this is only one of multiple layers of complexity.

In contrast to choropleths, graduated circle maps (See figure 3.32) use shapes, generally circles, of different sizes to represent a particular statistic-for example, the population of Jewish residents, in Figure 3.32. The difference between 
choropleths and graduated circles are not obvious at first, and both are widely used. But graduated circle maps have one particular advantage relevant to Bachi's work, which is that instead of shading an entire area or sub-region, the graduated circle is located with respect to one single point on the map. This allows for greater precision in depicting-or choosing arbitrarily, since the most populous city or even a completely random point could be used-the precise locations of populations within national boundaries. The result, however, is that in graduated circle maps, the actual boundaries of those districts do not have to be included on the map, even though standard practice is still to indicate major boundaries. In contrast, on choropleths, if each district is shaded in, then the edges of those shaded regions-their boundaries-must be implicitly indicated (Figure 3.4). So, using graduated circle maps gives Bachi the option to omit certain boundaries, including the Green Line.

The trend can be seen progressively through the course of Bachi's work; as he moved increasingly to graduated circles over time, the Green Line appears less frequently on his maps. In the 1968 book in particular, several maps of other regions, or of earlier data, indicate the internal boundaries of the area being mapped (Bachi 1968, 196-97, 227, Plates VIII and X). This stands in contrast to his later maps; nearly every single map of the region which depicts data collected in 1967 or later uses graduated symbols instead of choropleths (e.g. Bachi 1999). And although prior to 1967 Bachi's graduated circle maps rigorously display the Green Line (e.g. Bachi 1962b), in the first years following 1967 the boundary was irregularly omitted and displayed, seemingly without respect to whether the data displayed included data for the West Bank or not (Bachi 1974b).

The increasingly frequent omission of the Green Line was coupled with the disappearance from his work of maps that show broader views of Palestine and Israel. Over time Bachi moved towards only mapping Israel and Palestine at a finer scale, with a focus on Jerusalem. Throughout the 1970s, Bachi would expand his use of choropleths of Italy and the US to substitute for the absent maps of broader Israel and Palestine (e.g. Bachi 1975). But over time these too would turn into graduated circle maps, with the result that even the internal borders of Italy and the US also would come to be alternately included and excluded from Bachi's maps (e.g. Bachi 1999). Thus the issues he faced mapping Palestinians extensively affected Bachi's cartographic work.

In his 1968 book Bachi still advocates the use of choropleths in combination with GRPs and describes several methods of doing so, thereby showing that his methodology was not technically or rationally incompatible with his new methodology (Bachi 1968, 198-216). However, nonetheless Bachi criticizes choropleths in the same work, claiming that, when using choropleths to represent percentages of population by sub-regions or provinces, "The distortion resulting from this method may be extremely dangerous" (Bachi 1968, 205). Later, comparing a choropleth and graduated circle map with GRPs for the same areas, he notes that "the visual impression obtained by the two graphs [maps] is completely different and almost 
opposite," and that the graduated circle map "enables us to receive the correct impression" while the choropleth "may thus fail almost completely to convey an accurate view of the distribution under survey; Moreover, comparison of data for each region and of the national average may create an impression of discrepancy." This discrepancy is not present in graduated circle maps that use GRPs (Bachi 1968, 210-13, emphasis added). The practical result of these convictions was that Bachi's maps were both increasingly accurate, by pinpointing values via graduated circles and GRP symbols, yet they were also increasingly inconsistent in terms of his depiction of the Green Line.

In his 1999 book, the Green Line is absent from every one of Bachi's relevant maps-including both his multiplicitous maps of the Jerusalem metropolitan area (which straddles the Green Line), as well as his sparse maps of Palestine and Israel more broadly (Bachi 1999, 46, 104, 149, Plates 2 and 3). But even when the Green Line is not indicated, due to its influence on the spread of Jewish towns, its ghost can be seen where areas of high Palestinian concentration, depicted as blank areas, in effect sketch out the boundary as a type of palimpsest (See Figure 3.5). Choropleths were not entirely absent from Israeli census publications after 1967; in contrast, although the Green Line was often left off their maps, the CBS did continue to use choropleths sparingly on maps showing census boundaries and which were intended for internal use or the use of the Israeli public or in the Jewish Diaspora (Figure 3.4) (Bachi 1974b; CBS 1985b; 1969b). Yet, unlike his earlier work (Bachi et al. 1955) by the late 1970s Bachi was no longer routinely using CBS choropleths, even though technically such maps were available.

Over time, as Bachi came to prefer not to indicate the Green Line on his statistical maps, this would have also limited his options-limitations which he justified on scientific grounds as discussed above, perhaps showing some uneasiness with the omission, but which also conveniently fit the practice among state Israeli cartographers of no longer depicting that border after 1967 (Benvenisti 2000). Instead of having two common options available to him for mapmaking, both choropleth and graduated circle maps, Bachi was instead restricted to using only graduated circle maps. This might seem an inconsequential detail, but it has significant statistical implications which dictate which statistics might subsequently be used. Moreover, it affected the entire course of Bachi's subsequent research: it is perhaps not surprising then that his GRP symbology consists precisely of an innovation almost exclusively in the area of graduated circle cartography.

If by creating GRPs, Bachi was attempting to construct a more refined system of statistical visualization, it was obtained at the price of the consistency in the representation of regional territorial borders. In addition to addressing contemporary concerns with the representation of statistical data, by grappling with the Green Line Bachi's work is also representative of how the existence of the Palestinians, and the Occupation more broadly, shaped the key methodological issues that Israeli census cartographers faced in the unique post-1967 context. But Bachi's work with graduated circles and points didn't mean that he would give up mapping borders 


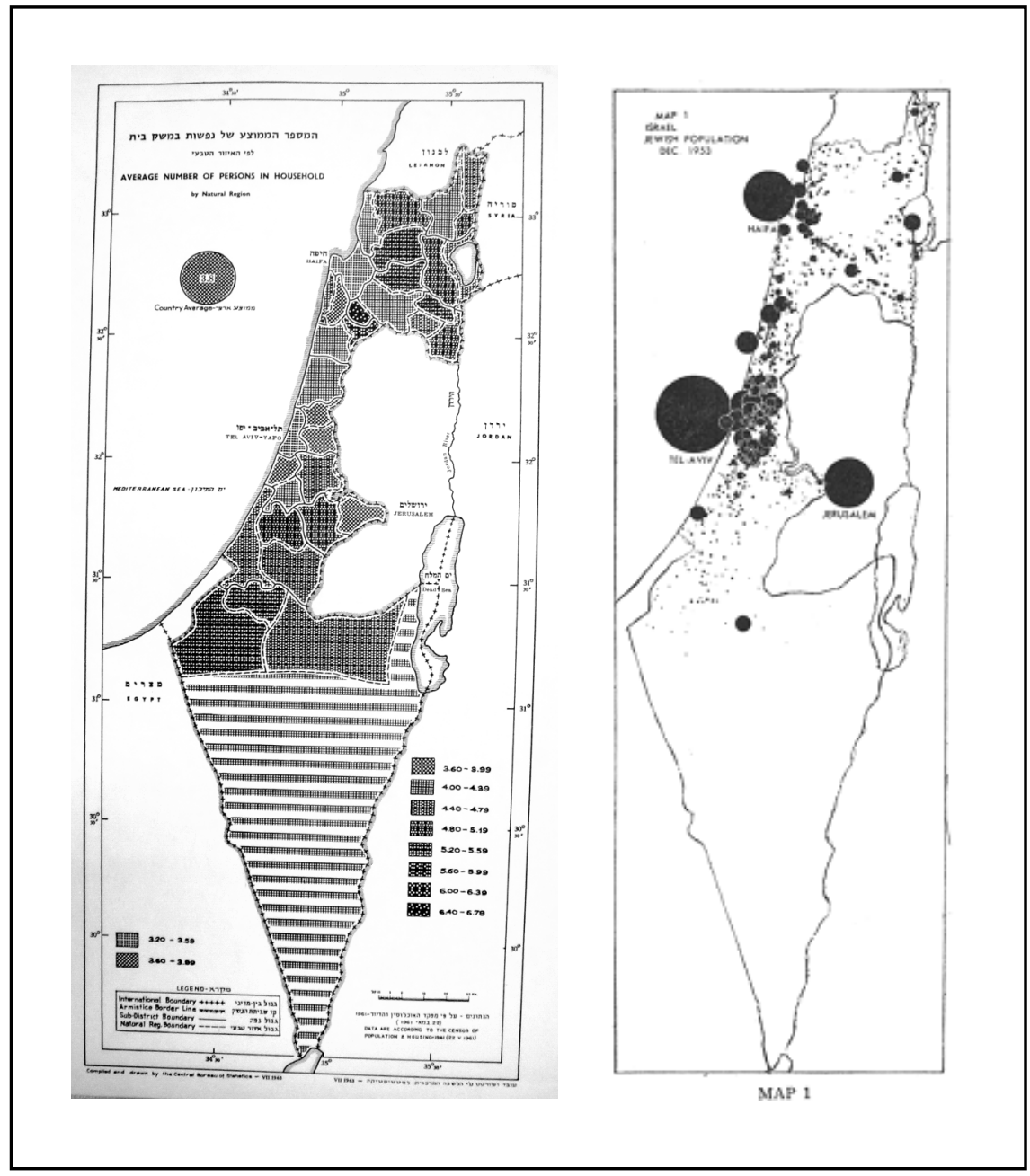

Figures 3.31 and 3.32. Figure 3.31 is a sample choropleth map from the 1961 Israeli census. Figure 3.32 (Bachi 1962b, 101) is an example of a Graduated Circle Map, showing Jewish population of Israel in 1953, where Bachi displays the boundaries of the West Bank and Gaza Strip. The Green Line is again indicated in black. In Figure 3.31 (CBS 1963), the shaded areas indicate the average number of people in each household in that subdistrict, called a "natural region", as defined by the CBS. Because it was made prior to 1967, data for the West Bank and Gaza Strip are not included.

Bachi extensively critiqued choropleth maps like this one. Notice how the use of shading requires the cartographer to display some internal boundaries - at the very least, between areas which are different shades. Here the Green Line is the boundary of the West Bank and Gaza Strip, in black. Yet even if the Green Line were not indicated here, the boundaries of the Israeli districts shown fall along the Green Line, and thereby simply shading those districts gives and impression of the Green Line (See Figure 3.4). 


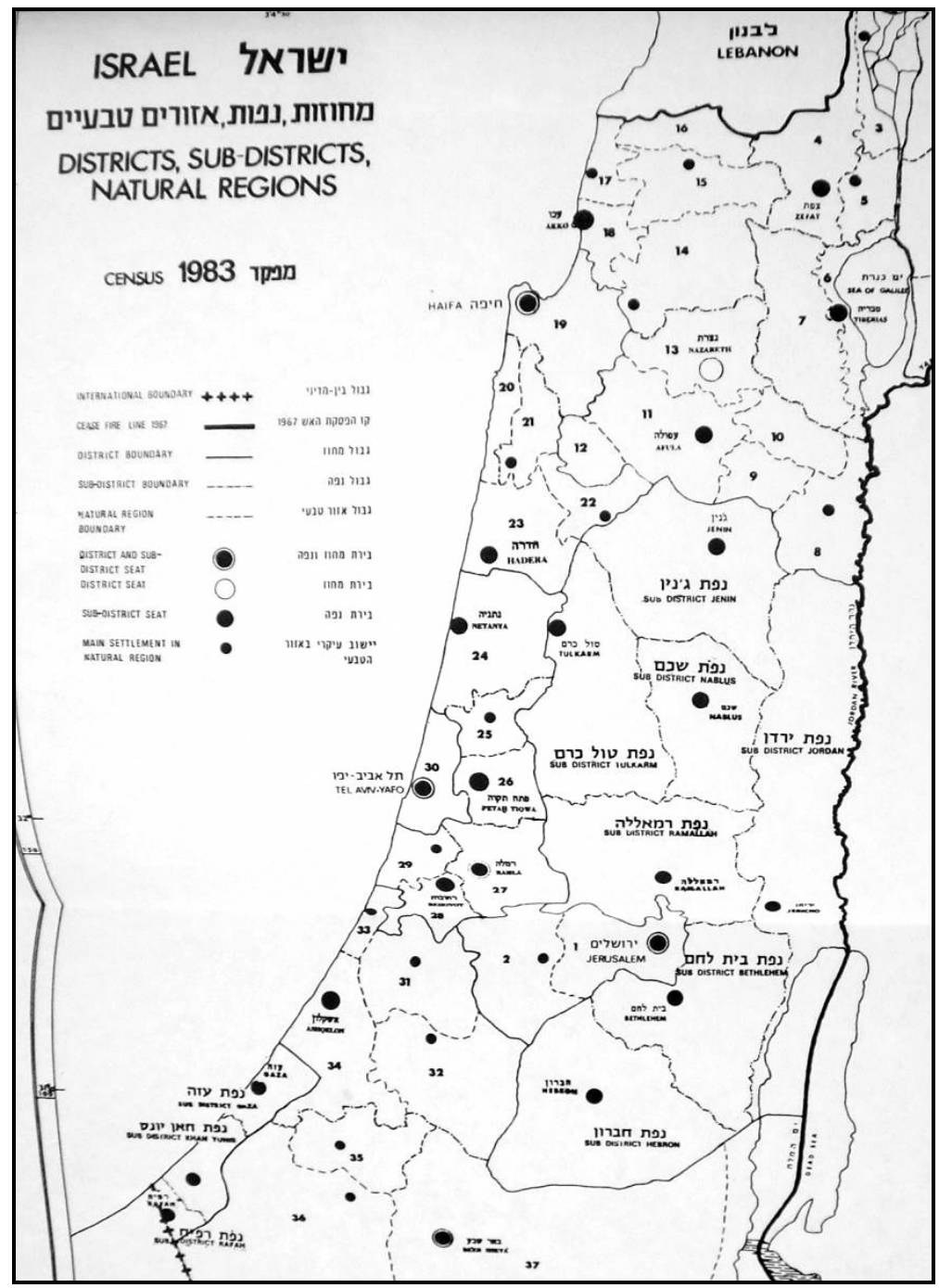

Figure 3.4. A 1983 map (CBS 1985a) showing subdistricts of Israel, intended for internal CBS use, as well as international academic use. Notice how the Green Line is traceable from among the boundaries. Because the district and boundaries follow the Green Line, any map which indicates district boundaries, as this one does, or shades in those districts within their boundaries, as choropleths do, also makes the Green Line visible. Thus choropleth maps could not be used without showing the Green Line. 
altogether. Instead, by 1999, amid large-scale Israeli settlement construction in the context of what is known as the "Demographic War", Bachi would begin using points to construct new boundaries of his own.

\section{The War of Scattered Boundaries, 1999}

If the 1967 census represented tacit acknowledgement of the existence of significant populations in the newly-occupied territories, the 1995 census showed the persistence of the ongoing struggle that has come to be known as the demographic war. The demographic war has been a form of ongoing competition in Palestine and Israel, whereby leaders from many different political persuasions encouraged their populations to have more children in order to secure the demographic majority that they hoped would give them political power and legitimacy (Courbage 1999; Kanaaneh 2002). On the Israeli side, its proponents primarily peddle fears that Palestinians outnumber Israelis, but also compile evidence suggesting that European-origin Israelis were in fact a minority, which frightens those concerned with maintaining Israel's status as a Europeanized nation, thereby highlighting the currents of racism and discourses of racial purity in the conflict (Massad 2003).

Bachi himself was a central actor in demographic debates, and he is credited as being one of the earliest scholars to warn of impending Jewish population decline around the world ("In Memory of Roberto Bachi" 1996; Schmelz and Gad 1986). A consideration of Bachi's later work, in light of the 1995 census's attempts to quantify what in some ways was the outcome of almost 30 years of demographic debates, provides a fitting counterpart of the analysis of the claim of Palestinian nonexistence performed above. From one perspective, the demographic war is the flipside of the claim that Palestinians did not exist historically. Because while the existence claims mistakenly suggest that there were no groups present who (legitimately) identified as Palestinians, often the rhetoric in the demographic war argues that Palestinian numbers are so high that they threaten to 'engulf' (non-Palestinian) Israelis, with Netanyahu even referring to a "demographic bomb" (Munayyer 2012). Seen from another perspective, however, the demographic war and the existence claims have much in common. For, in statistical terms the question of whether a group exists is often translated to a question of whether that group has a high enough population to be considered statistically significant. And in many places the most comprehensive population counts are issued by the national census-which is also the major state agency producing the kinds of authoritative information that informs debates over demographic trends.

\section{Israeli Settlements in the 1995 Census}

As with the existence claims, then, what is striking about the demographic debates 

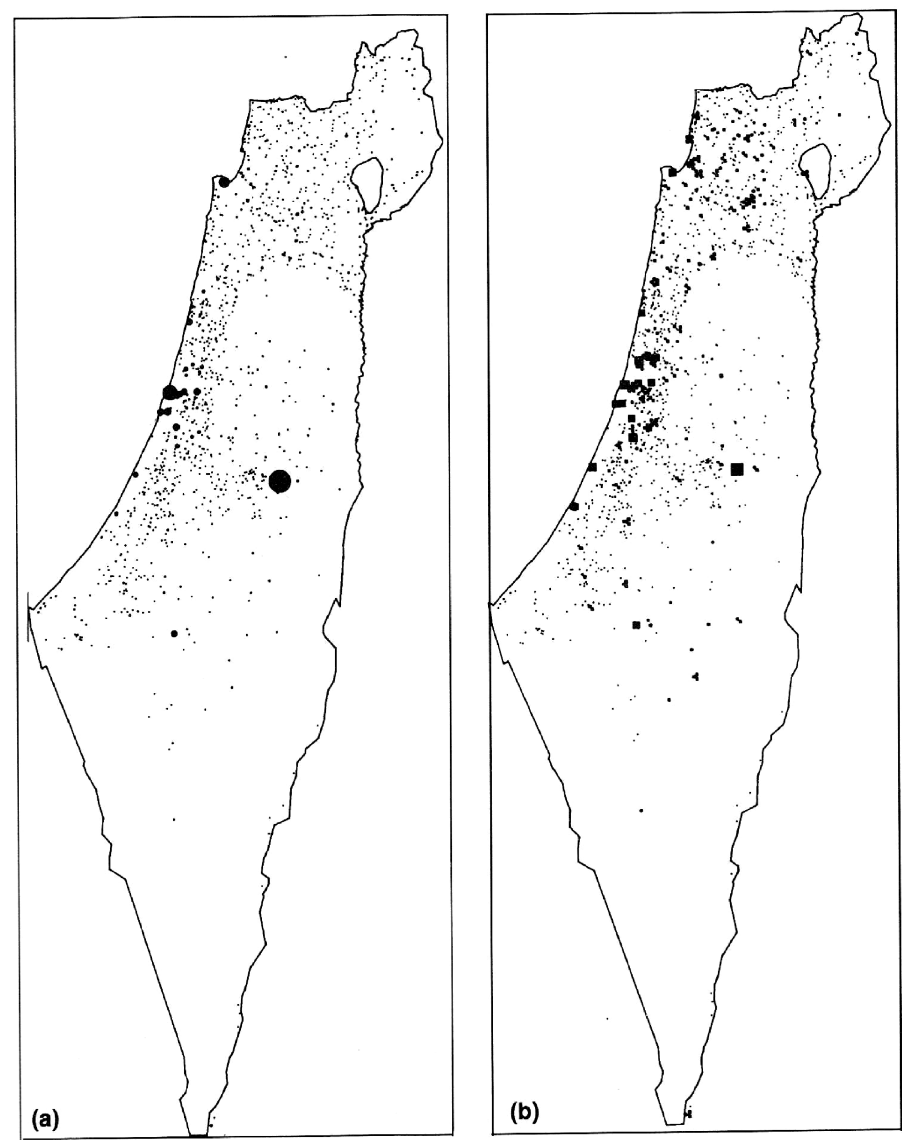

Figure 6.26. Israel. Total population by 1055 settlements and cities, 1992: (a) map based on circles: $.1011 \cdot 134,700 \cdot 249,800 \cdot 356,900-556,500$; (b) map based on GRP: $1011 \cdot 10,118$ 19,224 $50,590 \quad 556,500+$ (Source of data: List of Locations, Israel Central Bureau of Statistics, 1993).

Figure 3.5. A Later Map of Bachi's, comparing graduated circles (left) to GRPs (right). The Green Line and any indication of the Palestinian Authority are omitted, but since Palestinian cities and towns are not shown, a blurry outline of the West Bank can still be seen in the areas of comparatively lower Israeli settlement. (cf. Bachi 1999, 165)

are the interlinkages between political discourse and the material bodies of a population. For although Golda Meir's statement that Palestinians didn't exist, noted at the beginning of this chapter, was framed in historical terms, it could also be considered an exercise in prophecy. It is only possible to claim that Palestinians didn't exist in a situation where so many of those Palestinians who could attest to their own existence had been violently expunged from the landscape due to the wars of 
1948 and 1967. Thus, to turn it around, Meir's claim about Palestinians nonexistence in the past is more a prediction that she would neither let them reside in Israel, nor build a nation of Palestine, in the future.

In this light, after World War II the best way to make it true that Palestinians didn't exist as a significant population in the land of historic Palestine seemed to be to make sure that those who fled during the 1948 war weren't allowed to return (Leibler and Breslau 2005; Morris 2004). Simultaneously, the best way, in the estimation of the Zionist leaders, to counter the claim that Jews themselves did not comprise a significantly large population was to bring in Jewish families; this is precisely what they did, encouraging emigration to Israel around the world while also helping to transport large numbers of Jewish families to Israel from elsewhere in the Middle East in the 1950s, in the context of a broader regional uproar and anti-Semitism that erupted in turn over the founding of Israel (Meir-Glitzenstein 2011). 56

This would be coupled, after 1967, with coordinated attempts to bolster the Jewish population in the Territories, thereby witnessing the expansion of the settlement movement, which was inspired by fears that the significant Palestinian population of the Territories in 1967-including large numbers of families that had been made refugees in 1948 and had subsequently resettled in the territorieswould result in Israel losing its hold over them. As a response, in 1967, Israeli settlers began moving to segregated enclaves in East Jerusalem and the Territories. The aim was to complicate any future geographical division, to obfuscate what until 1967 had been a starkly segregated landscape, by building a small and diffuse, but tightly-linked network of settlements in the Territories at multiple scales (Weizman 2007). 57

As a reaction to fears of Palestinian expansion, the settlements therefore also represent a tacit acknowledgement of Palestinians' existence. However, although the settlements were created as an effort to make the material world conform to claims made upon it, and specifically to confound traditional methods at drawing

\footnotetext{
56 The incoming Jewish refugees from the Middle East became known as Mizrahi Jews. Most of them spoke Arabic as their primary language, and their descendents now make up over half of the Jewish population of Israel (Loolwa 2013). Yet they also experienced discrimination in a country where European Ashkenazi Jews were privileged. This led to the 1970s founding of the Israeli Black Panther movement, modeled in part on the Black Panther movement in the United States, as part of the struggle among Mizrahi Jews for social justice in Israel (Ettinger 2007). An archive for the Israeli Black Panthers is available at http://israeli-left-archive.org/cgi-bin/library?site=localhost\&a=p\&p=about\&c=blackpan $\& \mathrm{l}=\mathrm{en} \& \mathrm{w}=\mathrm{utf}-8$.

${ }^{57}$ In Hebrew the word settlement (yishuv) is most often used in its general sense to refer to all places of steady human habitation. So, throughout the CBS and other state maps, Israeli settlement throughout Israel and Palestine; no internal borders are shown, no Palestinian towns in the Territories are shown, and there is no distinction between cities in Israel (which are also referred to as settlements) and illegal settlements in the Territories.
} 
boundaries between national groups, the resulting changes to the population landscapes would also influence maps of Israel. For the settlements would influence the CBS and Bachi to develop methods that would allow them to draw borders around complex small population clusters. Likewise, Bachi's innovations in his later work lie precisely in his ability to separate what was meant to be inseparable, to draw out the intentionally imbricated Israeli settlers from their distributed points across the territory of the Gaza Strip and the West Bank.

It was not a foregone conclusion that the settlement populations would be counted in the Israeli census, given that they were located on disputed territory. However, the need for the CBS to give the state legitimacy by demonstrating the numerical strength of Israelis dovetailed (unsurprisingly) with state efforts to claim the settlements as being an integral part of Israel. ${ }^{58}$ In the context of the demographic war, the 1995 census marked a push forward for increased accuracy on the part of the CBS methodology. Although the CBS conducted censuses roughly every decade after 1967, the 1995 census was a methodological watershed of sorts. For starters, it was the first census to comprehensively use GIS mapmaking in an attempt to record the precise location of 'every' dwelling-and thereby, in theory, every person in Israel (Lasman 1997), building upon the groundwork in the Survey of Israel (SOI), which had begun converting its paper maps to a Geographic Information Science (GIS) framework in the late 1980s (Peled 1996). Moreover, rather than incorporating digital maps on the side, instead the census shifted wholesale towards conducting the census through the means of GIS. Districts were redrawn, enumeration methods were mechanized by using GIS to determine and print maps for each enumerator to follow while conducting the counts, and a national database was developed to store census data for the foreseeable future (Bahat 1997; D. Barak 1997; Ben-Moshe 1997a; 1997b; 1997c; Blum 1997; Calvo 1997; Kagan 1997; Lasman 1997; Peled 1996; Stier 1997).

Distinct parallels can be drawn from the methodology of the 1995 census and Bachi's later work. Bachi himself did not have a direct hand in the 1995 census because he had retired from the CBS, although he remained professionally active until he passed away in 1995 ("In Memory of Roberto Bachi" 1996). But in many ways the 1995 census represents the culmination of the methodology that Bachi

58 In contrast, the publicly-available Israeli counts of Palestinian populations were left deliberately vague. After 1967, the CBS did not attempt to count Palestinians in the Territories (aside from those residing in areas annexed to Israel, such as East Jerusalem) again in a public form, instead relying on estimates of population growth (e.g. see MOD 1973, 98). Moreover, after the 1994 signing of the Oslo accords, Palestinians gained some limited sovereignty, and the duty of counting Palestinians was transferred to the newly-formed Palestinian Authority. For this reason alone, the 1995 Israeli census was unique; it was the first census after 1967 that was conducted in the expectation that the Palestinians would also conduct their own census, focusing on Palestinian-controlled areas of the Territories as well as East Jerusalem, at roughly the same time. The Palestinian census was in fact completed in 1997 (PCBS 2008). 
developed over the course of his career. The early turn to computerization in Israel, ${ }^{59}$ coupled with the emphasis on international scientific standards, as well as on pinpointing exact locations to obtain a 'snapshot' of Israel in the census (Leibler 2007; Leibler 2004), all demonstrate Bachi's influence. ${ }^{60}$ While Bachi's 1999 book was only published posthumously with the help of his granddaughter and former colleagues (Bachi 1999), much of the material was written by Bachi himself precisely during the years that the 1995 census was also in development.

\section{Bachi's 1999 Book: Convex Hulls from Point Features}

Given that the settlements were built in the context of the Demographic War-and therefore in no small part as a response to the continued Palestinian presence in the Occupied Territories - and the CBS's interest was to count as many Israeli Jews as possible, then the question would have become not whether, but how to include the settlements in the census? In the end, an attempt was made to seamlessly incorporate the post-1967 settlements into the new computerized regions.

In the 1995 census, each settlement is defined as one or more census tracks, and they appear throughout the CBS's publications, including in lists of 'towns in Israel', and collections of maps of the 'urban areas of Israel' (CBS 2000b), without reference to their unique status as settlements within Palestinian Territory (Figure 3.6). Similarly, the lands of Israeli settlements in the West Bank are registered with the Israel Land Authority, rather than the administration of the Palestinian Territories. This indicates that, legally and economically, they are considered Israeli land (Shehadeh 2007, 83). More recently, Google Street View has also begun to collect data for the Israeli settlements, presumably to include the settlements in its Street View map of Israel (Sheizaf 2012), although Street View has not been extended to the Palestinian Territories more broadly as of the time of writing (Figures 3.71 and 3.72). The 1995 census indicates a shift in conceptions of sovereignty, from one which seamlessly incorporated all of the West Bank (Figure 3.71) to one which omitted Palestinian-controlled areas but nonetheless retained the incorporation of the settlements (Figure 3.72). Thus, whereas Palestinian populations, in the 1967 census, were treated entirely separately by the census, using distinct definitions

\footnotetext{
${ }^{59}$ For comparison, although the US census had been developing computer cartography for the purposes of census enumeration since the late 1960s, the first GIS files were only created for the 1990 census, a mere five years before Israel fully computerized its population counts. For more on the early history of GIS use in the US census, see http://www.ncgia.buffalo.edu/gishist/DIME.html.

60 The 'snapshot' metaphor was also built upon the census methods under the British occupation. For example, Sami Hadawi argues that the 1931 census "enumerated all the persons present in Palestine at midnight on November $18^{\text {th }}, 1931$, irrespective of whether they were residents of the country or not." Similarly, according to Hadawi, residents who were not in Palestine at the time were not enumerated, and this held for further estimates, based on the census, right up to $1946(1957,8)$.
} 
and methodology of enumeration, in 1995 the groups of Israelis in the same land are fully incorporated, despite the fact that they lie beyond the Green Line. Furthermore, while the Green Line still was not often displayed explicitly, the settlement boundaries were being redeveloped and reinstated with increasing sophistication. The definition of these settlement boundaries was a lengthy and detailed process (Calvo 1997) that required new methods of the sort that Bachi just happened to be developing at the time.

In his 1999 book, the culmination of his life's work, Bachi avoided choropleths altogether. But this does not mean that Bachi avoided focusing on boundaries. Instead, although he continues to eschew political boundaries, statistical borders are the main focus of the book, and Bachi centers his arguments primarily on methods for drawing variegated and complex borders around existing small population groups. These are precisely the sort of methods that would have perfectly fit the needs of the Israeli census to demonstrate that, statistically, the settlements fit within the natural statistical area defined by the Israeli population.

One of Bachi's methods is particularly useful in this context: his work on convex hulls, a common graphing method. If the problem the census faced was how to define the national area in light of population groups like the settlements, which were not geographically contiguous with mainland Israel, convex hulls represent possible solutions. The convex hull is a mathematical term for a boundary that fits tightly around all of the points of a particular set (See figures 3.81 and 3.82). Finding a convex hull would be particularly useful, for example, in determining the areas that are defined by close networks of Palestinian towns-and thereby determining the leftover packets of space which might be settled by Israelis. It also parallels the redrawing of political boundaries after 1967, most notably including the expanded boundary of 'Greater Jerusalem' which allowed for the annexation of East Jerusalem, as well as large areas of the West Bank that immediately surrounding the city, to Israel. Placing redistricting in the context of the Demographic War, Meron Benvenisti has claimed, "The annexation boundaries did not determine the city's demographic ration. Rather, the 'optimal demographic ration' has created the city's boundaries" (Benvenisti 1999; cf. Zureik 2001).

This method is also useful for estimating the geographical size of settlements and statistically appending their areas to the total inhabited areas of the Israeli state. For, although settlements have official extents, they often expand quickly, especially in the early stages, and claim outside lands for defense walls and other security structures (Weizman 2007). This indicates that the populated area of any particular settlement, which is of interest to a census concerned with mapping every habitable building, could easily fall outside the municipal area. Instead of using one solid boundary, whether for nations or cities, the use of convex hulls therefore would allow for a more textured and complex rendering of the scattered populations that are typical of Israeli settlements in the Occupied Territories.

So, after omitting internal boundaries and moving from points to areas in his early work, Bachi then begins to constitute new borders based on only those points 


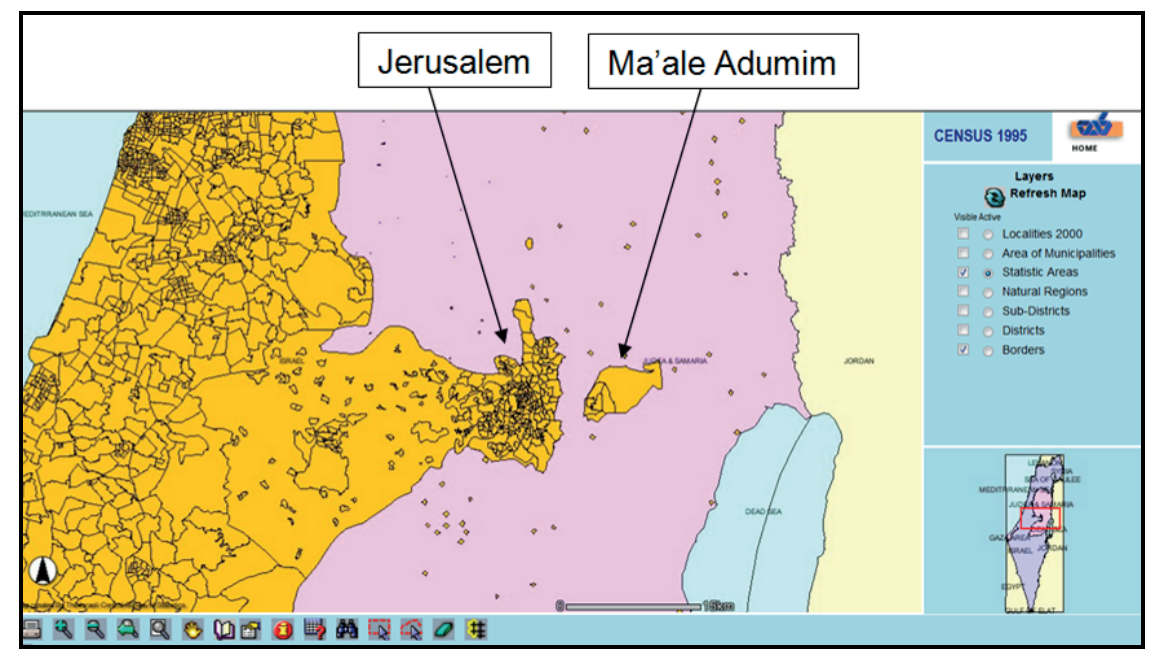

Figure 3.6, An annotated screenshot of Jerusalem (center) from the CBS online interactive map of 1995 Israeli census data. As this map was made just after the Oslo Accords, the Green Line is drawn clearly and prominently through the center of the map, surrounding the (Israeli-defined) Jerusalem metropolitan area and dividing the annexed areas of Israel on the left from the West Bank on the right. However the West Bank is referred to using the adapted Biblical name of "Judea and Samaria".

The map shows the borders of statistical areas, revealing how Israeli settlements in the West Bank (smaller pockmark areas at right), are incorporated as Israeli municipalities for the purposes of the census. The largest of these areas, just to the East (right) of Jerusalem, is the settlement of Ma'ale Adumim. The attempt to incorporate Israeli West Bank settlements into the census has meant giving up on the contiguity of Israeli territory. Here, Israeli territory includes all of the complex areas towards the left, as well as the settlements, which appear as small but numerous islands of Israeli sovereignty within the West Bank-although the map, from data made in the mid-1990s, does not show more recent settlement expansion. Annotations by the author (CBS 2000a).

that he has selected as being significant to the state. In so doing, Bachi is again adapting and innovating upon Westernized statistics in order to meet key realities of the Israeli census. However, in this case he rejects a traditional focus on the consistency of national territory in order to retain the continuity of borders around the now-fragmented territories, including the settlements, claimed by the state. His methods therefore would allow for an enlargement of the total area of Israel that is inhabited by Israelis. Moreover, they can do so in a way that statistically naturalizes the settlements. In addition, when using the convex hull, the total area of a particular settlement could be determined based upon the furthest points of construction of habitation rather than its official municipal boundaries, which might take longer to catch up to the pace of construction; any private Palestinian areas that happened to fall between two outlying points would simply be incorporated into Israeli territory. In combination with GIS software, the geographic database that was developed in the course of the 1995 census enabled the cartographers to calculate convex hulls for hundreds of thousands of individual points at ever finer scales, includ- 

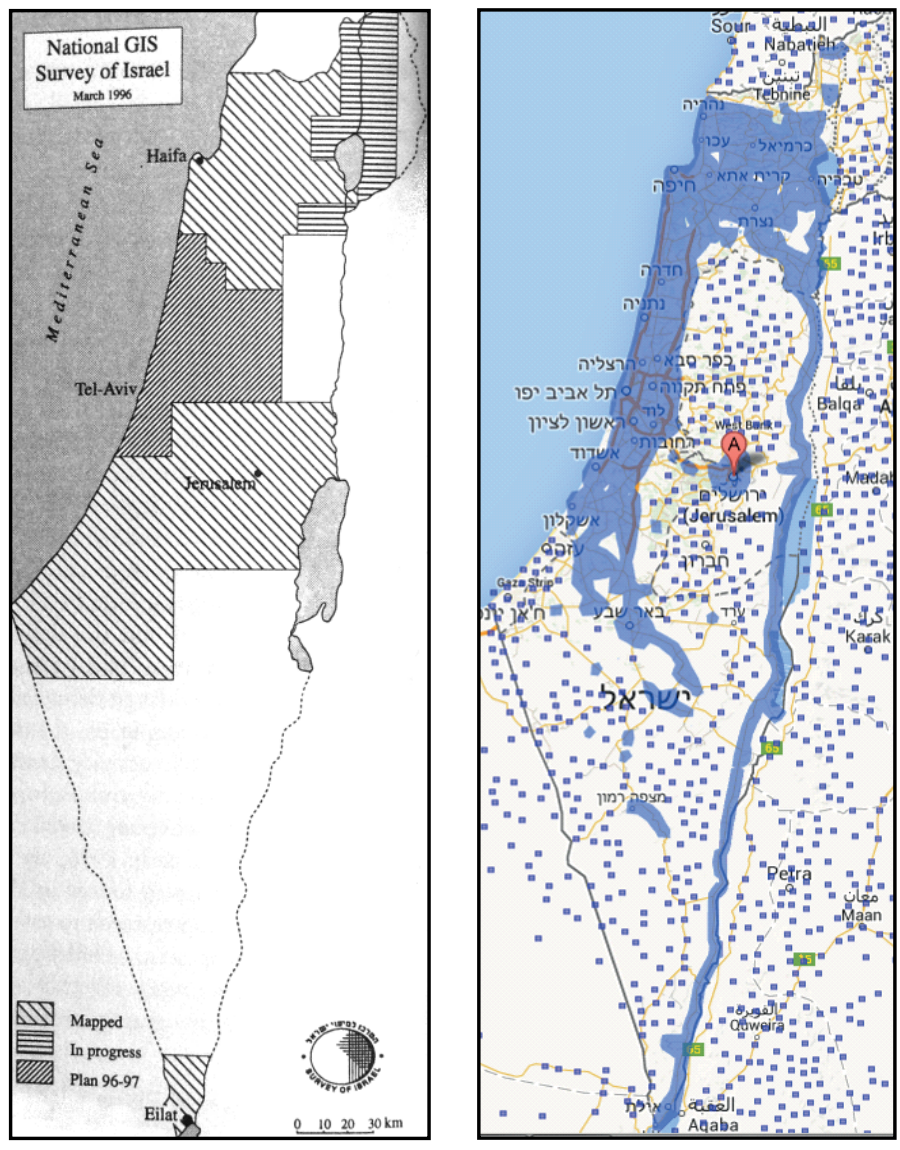

Figures 3.71 and 3.72. Figure 3.72 is a screenshot which gives the extent of Google Street View in Palestine and Israel as of August 2013. In contrast, Figure 3.71 indicates the extent of the development of an Israeli national GIS database as of 1996. Shaded regions indicate those areas where digital map data existed or was in progress as of 1996. The SOI appears to have prioritized the West Bank and Gaza Strip, which both fall under the "Mapped" category, which shows those areas that were converted first to GIS from paper maps. In Figure 3.72, the purple overlay areas are the areas where Street View is available. The dots indicate regions which only have discrete photographs at particular locations. Neither the West Bank nor Gaza is included in the shaded area, although particular Israeli highways in the West Bank are included and reports suggest that Street View also will soon begin to include the Israeli settlements there (Sheizaf 2012). The marker with a letter A indicates Jerusalem.

Figure 3.71 demonstrates that the GIS data were developed from an overhead view which seamlessly incorporated all of the Palestinian Territories into Israel (Peled 1996). This was likely accomplished precisely with the expectation that Israel would lose the ability to collect data consistently throughout the entire Territories due to the handover of some sovereignty to the Palestinians following the Oslo Accords, which were taking place at the time. 
ing individual buildings, thereby defining and quantifying a set of ever more multiplicitous borders. ${ }^{61}$

\section{Conclusion: The Continuity of Computer Cartography}

In his later years, Bachi largely abandoned his attempts to rectify GRPs with choropleth maps and had turned instead to drawing boundaries around statistical data. The convex hull method, which he treats extensively, sacrifices predetermined political borders and national contiguity in order to maintain strict, if increasingly numerous, borders. In 1968, Bachi's attempts to make graphing and statistical mapmaking more readily available served to place him in the vanguard of statisticians. In so doing, Bachi retained the continuity of borders while rejecting the consistency of space. In the end, rather than representing a radical departure from previous cartographic methods (November, Camacho-Hübner, and Latour 2010), computers and GIS were useful in justifying Bachi's position. While the public use of Bachi's GRP symbols was fast outpaced by computer graphics capabilities-even to the extent that they appear less frequently in his own later work (Bachi 1999)-Bachi's contributions to core concerns of geographic and demographic statistics, and their application in statistical cartography, continue to be influential (Louder, Bisson, and La Rochelle 1974; Shea and McMaster 1989; Edward J. and Carr, Daniel B. 1993).

In contrast to computers, which represented the triumph of, rather than a challenge to, the theoretical foundations of Bachi's work, the physical existence of Palestinians influenced the main directions of his theoretical research. In 1967, the very presence of Palestinians on the newly-occupied lands meant that the census cartographers, including Bachi, had to rush to count and manage them. The policy of omitting the Green Line, in the context of the existence of large numbers of Palestinians in the landscape, presented a challenge to Bachi's attempt to construct a cartographic image of the homogenous nation of Israel. In 1999, the ongoing conflict, and the settler movement which was conceived of as a response to the continued Palestinian presence, meant that the census now had to include disparate and non-contiguous settlements in tabulations of Jewish population. Consequently, Bachi would move from developing ways of mapping which obviated the need for borders, to finding ways to draw continuous boundaries around non-contiguous spaces.

In formulating the GRPs, Bachi thus shifted away from choropleths, which until then had been the norm, and moved towards graduated circles, which he represented with greater numerical accuracy at specific locations or points, using his

${ }^{61}$ However, the fact that there were more borders did not mean that they became more open or less guarded; quite the contrary. 


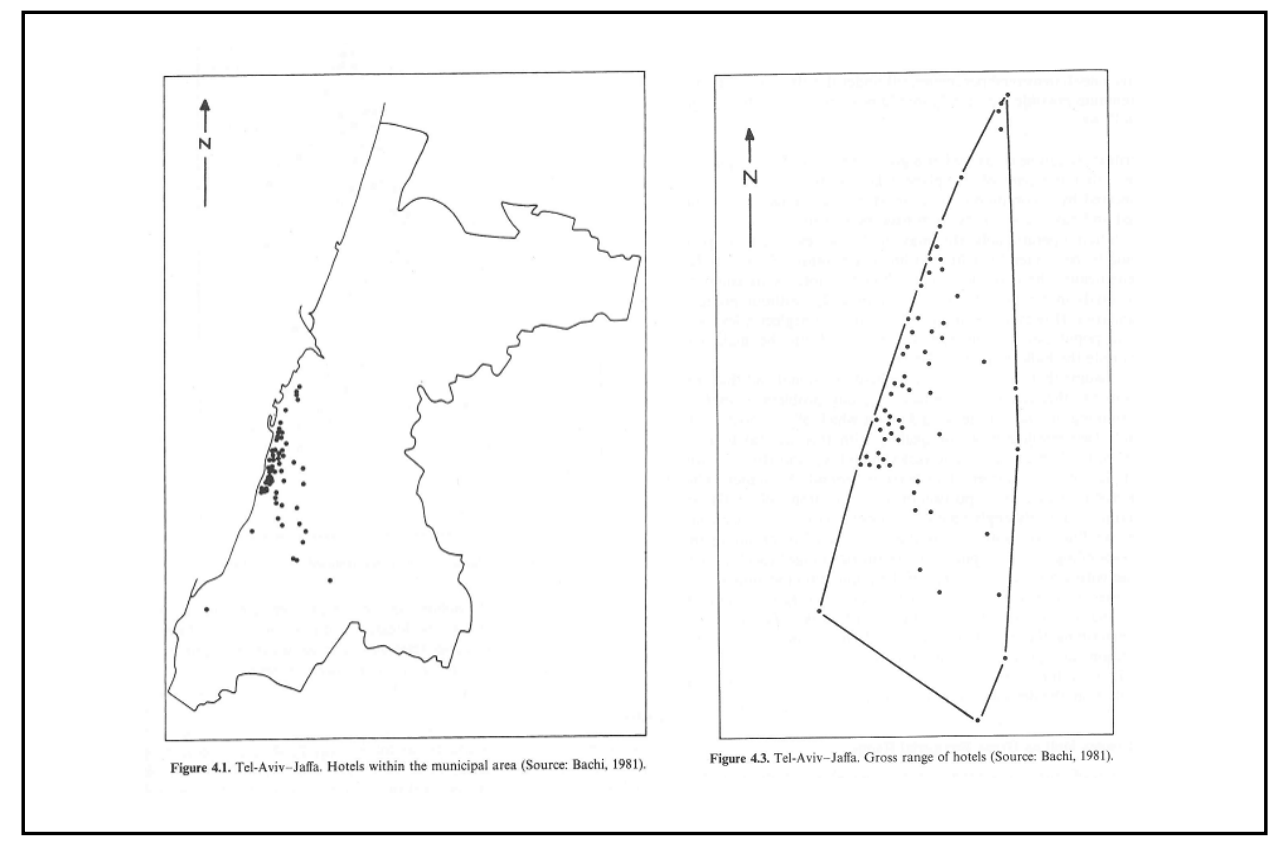

Figures 3.81 and 3.82. Figure 3.81 (left) shows hotels (points) inside the Tel Aviv-Jaffa municipal boundary (line). Figure 3.82 (right) shows a convex hull (line) around that same set of hotels (points) in Tel Aviv, at a slightly finer scale. These figures demonstrate that point or circle maps obviate the need to show political boundaries; none are given in the map at right. In addition, it illustrates how Bachi begins with data and then constructs (statistical) boundaries - in this case, a convex hull consisting of the straight lines connecting the most distant points.

Thus, the Palestinian city of Jaffa, which falls within the broader Tel Aviv-Jaffa municipal boundary as seen in the Southern area (at bottom) inside the boundary of the map on the left, is cut off from the map at right. This is accomplished through the act of drawing the convex hull, thereby transferring the background area of the hotels from the municipal (political) boundary, to the statistical (convex hull) one. The resulting boundaries are entirely dependent on the accuracy of the statistical dataset that is used. In addition, two outlier hotels (including one in Jaffa) appear to have been deleted before drawing the convex hull. Bachi defines the convex hull as the "gross [territorial] range", yet here it serves precisely to leave out the Palestinian residents (Bachi 1999, 91, 94; 1981, 1018).

GRP symbology. By increasingly omitting internal boundaries altogether, Bachi could include Israeli data without making plain the fact that data for the Palestinian Territories was either not being collected-or, in the case of the census, not being indicated on the map. In his 1999 book, Bachi builds upon the shift from areas to points, but in this case he is using points to reconstruct areas by drawing new statistical borders using convex hulls. Both GRPs and convex hulls were useful in constructing facts which would be useful in the context of the Demographic War. Ironically, however, in order to reconstruct a total national area that includes the settlements, the 1995 census first had to extricate the settlements from their sur- 
roundings-namely, the numerous Palestinian towns of the West Bank and Gaza Strip.

Bachi's research is thus both internationally scientific and thoroughly influenced by local landscapes. Despite his best efforts to position himself otherwise (Bachi 1980), the landscape of Palestine and Israel shaped even the most abstract levels of Bachi's research. However, his choices were also circumscribed by the hierarchies of international science-whereby his legitimacy depended on his ability to present his work as objective and exact. Computers lent credence to this goal, but nonetheless the tension between maintaining supposed empirical rigor-an aim which ironically lead to the maps being practically useless due to the lack of internal geographic detail-and adapting his methodology to the people and landscapes at hand, so that they might further the practical goals of the Israeli government, is one that continued through the advent and spread of the GIS technology in the region. These tensions played out in different ways in the nascent Palestinian Authority, which is the subject of the next chapter. 


\section{Chapter 4}

\section{The Colonizer in the Computer: International Influence in Palestinian Authority Maps}

\section{The Steadfast Colonial Legacy}

In this chapter, I investigate two international influences which have shaped the Palestinian Authority's efforts to establish a distinctly Palestinian form of empirical knowledge in the West Bank. Drawing on the concept of sumud, ${ }^{62}$ or steadfastness, I argue that the material legacies of colonialism, past and present, have served to circumscribe cartographers' attempts to develop stasis, which I define as the ability to remain in place. In the late 1990s, Palestinian Authority (PA) cartographers developed a highly sophisticated system for making maps using Geographic Information Science (GIS) cartographic software, with the goal of developing a Palestinian national mapping program, thereby helping to build the nascent Palestinian state in keeping with nationalist ideals (Tesli 2008). Yet their work took place in the context of a continued international presence in the region over the course of centuries. As such, it interacted in complex ways with the legacy of British imperialism and the ongoing Israeli Occupation of the West Bank and Gaza Strip.

In what follows, I analyze the implications of stasis for knowledge practices in Palestinian regimes in an attempt to broaden and deepen both the mobility studies literature and studies of technology in Palestine and Israel. I first focus on the stasis of maps from the British Mandate period in order to demonstrate how the PA's extensive use of British colonial maps as sources of geographic information in turn

62 Sumud is pronounced with two long vowel sounds similar to the 'oo' in the English word food. It is alternately transliterated as soumoud. 
affected the scale and resolution of early PA maps. I analyze maps made in the period 1994-2000, from the founding of the PA to the start of the Second Intifada or uprising against the Occupation. In particular, I show how the use of British maps led to broad depictions of the West Bank that were less useful for daily governance. Second, I turn to the techniques that PA cartographers and institutions have used to build stasis in the period 2000-present. While the connections between maps and nationalism are well known, and they have recently been explored in relation to Palestine and Israel (Leuenberger 2012), there is a necessity to follow the specific cartographic methodologies in their unique contexts. The PA also attempts to produce knowledge as a way of countering the Israeli Occupation (Romani 2008; Zureik 2001, 227). Despite the changes which followed the 2006 election of Hamas, the Occupation continues to limit the scope and extent of places where the PA can collect data, thereby leading to the continued erasure of rural areas from the map. By focusing on the PA cartographers, rather than the people and areas being erased, I indicate the difficulties of even privileged attempts to expand the purview of dominant forms of knowledge. This provides an interesting counterpoint to the observation of Wouters et. al. (Wouters et al. 2013, 2) that there is a "cyclical feedback loop" between new forms of knowledge and new infrastructure, for in the West Bank the restrictions, and at times direct attacks, upon infrastructure have furthered the persistence of existing processes for the production of knowledge.

While British Mandate maps have been hailed as an empirical triumph (Gavish 2005), nonetheless the British colonial authorities' emphasis on defining territories with hard boundaries-from attempts to control private ownership by marking out land parcels, to proposals to divide the region into two separate states-have been criticized as contributing to the beginnings of conflict in the region (Fischbach 2011; Weizman 2007, 14-15). The legacy of hard boundaries is evident even in the text of the 1994 peace treaty which allows for the establishment of "permanent, secure, and recognized" borders between Israel and Jordan "without prejudice to the status of any territories that came under Israeli military government control in 1967" (i.e. after the start of the Israeli Occupation of the West Bank and Gaza Strip) - and this despite the allowances that were built into the treaty in order to account for the fact that this particular border follows the ever- mutating course of the Jordan river (Hashemite Kingdom of Jordan and State of Israel 1998). So there is a certain irony in the fact, often noted by the cartographers during our conversations, that this legacy of colonialism has led the PA to strive to end the Occupation by making use of the very maps that may have helped to start it in the first place.

\section{Building Stasis and Sumud}

If PA cartography must be viewed in the contexts of British and Zionist colonialism, then it also takes place in the context of efforts to build sumud, or steadfastness, among Palestinians in the region. The concept and practice of sumud, which Lori Allen refers to as a "nationalistically inflected form of stoicism" (Allen 2008, 156), 
have come to play a key role in anti-Occupation struggles, not least because they provide a 'third way' between hatred and acquiescence (Shehadeh 1982, viii). First coined at the 1978 Arab League Summit in Baghdad, and intended primarily as a means of raising funds to support Palestinian communities, in time sumud came to draw attention to the frustration felt by many in the absence of political gains. It did so by highlighting the work that is necessary for Palestinians to remain in place on the land, both pragmatically and metaphorically. Following the writings of Rajah Shehadeh (1982), sumud currently refers to a spectrum of activities that promote steadfastness in the Palestinian Territories and beyond. Contemporary examples of sumud range widely, from the ongoing act of persisting as a group in the face of efforts to deport, assassinate, or otherwise remove the Palestinians, to active support for the health, education, and related infrastructure that makes survival possible (van Teeffelen, Toine and Giacaman, Fuad 2008), including through efforts such as the Sumud Story House in Bethlehem. ${ }^{63}$

Building upon sumud, here I explore one very specific aspect of it: the sense of staying put, of working to sustain a presence in a particular landscape. In order to distinguish my concept from sumud's more multifarious connotations, I call it stasis. Stasis is in no way unique to the work of PA cartographers, but its specific expression in the context of the Occupation has a marked currency that makes its production explicit in ways that might otherwise lie dormant. While mobilities scholars have considered stillness and immobilities (Cresswell 2011; 1999; Söderström et al. 2013), stasis is not simply equivalent to either stillness nor immobility, for often those who are not granted the ability to move at will are also denied the opportunity to remain-a logically impossible position which affects countless refugees. Likewise, stasis is not simply equivalent to the absence of movement, but rather it can result from the tension between equal but opposing forces. Thus, while Sheller and Urry (Sheller and Urry 2006; cf. Söderström et al. 2013, 10) have noted that mobilities are predicated on "often highly embedded and immobile infrastructure" and conceptualize them as "multiple fixities or moorings", this can be further enriched by the long tradition of urban geographical analyses of how infrastructures are produced and institutionalized. In this vein, Van Heur has emphasized the interaction of obduracy and processual change, allowing that the city is always "becoming but also being, movement as well as stasis, circulation as well as sedimentation" (Van Heur 2010, 125). ${ }^{64}$

Attention to the city as a site of production also indicates the benefit of expanding mobilities studies to not only discuss the movements of particularized individuals, but also to further include an analysis of the effect of particular geographic landscapes and political regimes on both stasis and mobility. While mobility is often

\footnotetext{
${ }^{63}$ See https://twitter.com/SumudHouse.

${ }^{64}$ On urban obduracy, see Hommels (2005).
} 
presumed to occur on top of spaces which are presented as a neutral background to movement, 65 PA cartographers don't simply travel in pre-existing landscapes. Rather, they move through spaces which themselves change, and are changed by, their movements. ${ }^{66}$ Thus, stasis is not a reference to a Cartesian grid; rather it requires ongoing work in changing circumstances. As Allen notes in reference to sumud, in "conditions where the routine and assumptions of daily life are physically disrupted [...] everyday life in Palestine-in its everydayness-is itself partly the result of concerted, collective production" $(2008,156)$. Noting the connection between the home and conceptions of homeland among Palestinians in Jerusalem, Amahl Bishara $(2003,144)$, draws on the work of Arjun Appadurai to indicate the challenges of dominant categorizations which "leave some people trapped, and others placeless altogether." Thus both mobility and fixity can lead to disempowerment, which contrasts with the potential for stasis as a way of achieving empowerment through the production of place. Rather than indicating an absence of movement, then, stasis draws attention to the maintenance work that is required, including everything from political negotiations to the literal upkeep of buildings, to remain in place in social and material landscapes, all while helping to construct that place as being the same, as existing continually over time.

\section{The Shortest Distance between Ramallah and Oslo}

Discussions about the role of sumud were reinvigorated after the 1994 Oslo Accords provided an international legal mandate to found the Palestinian Authority with a limited jurisdiction in the West Bank and the Gaza Strip. Although they led directly to the establishment of an administrative body for the Palestinians, and therefore represented a concrete step towards self-government, the Oslo Accords came to be viewed as at least a partial betrayal of the struggle for sumud, both in terms of the concessions granted to the Israelis, and due to the jockeying among different PLO factions at the expense of concrete gains (Parker 1999; Said 2001). ${ }^{67}$

Framed as interim agreements, the first Oslo accords in 1993 and the second agreement in 1995 were intended to set the stage for full Palestinian sovereignty in the occupied territories, with the final boundaries and possible land swaps to be set by a final status agreement-one which has yet to materialize despite several

65 On Palestinian immobility and the Internet, see Aouragh (2011). For an analysis of the role of NorthSouth hierarchies on the movement of technology and a critique of simplistic notions of technology transfer, see Shamsavari (2007) and Edgerton (2007).

66 This material feedback contrasts with Ian Hacking's e notion that material objects do not react to the categories attributed to them.

${ }^{67}$ For example, see Edward Said on Raja Shehadeh's ultimate rejection of a PLO post due to dominance of the Tunis faction $(2001,151-2)$. 
rounds of negotiations, including the failed Camp David and Taba talks of 2000 and 2001, respectively. Yet, after the election of the Islamist party, Hamas, in 2003, the members of the more pro-Western and economically liberal Fatah party, which was in charge of the PA, refused to step down. This succession crisis resulted in a split between Fatah and Hamas, evidenced most starkly in the PA's closure of the parliamentary body, the Palestinian Legislative Council. As a result, the PA continues to rule by decree in the West Bank (UNOCHA 2010b), while Hamas maintains a parallel government in the Gaza Strip.

Despite the varied critiques of their impact, the Oslo Accords have also come to be accepted as marking the founding of PA cartography, and this highlights both the internationalism of the PA, as well as the fact that official Palestinian mapmaking was founded in the service of a specific pragmatic goal: to influence political negotiations. Although the influence of Ottoman and Arab regimes have been downplayed or even actively erased in Palestine (Tamari 2009), empirical mapmaking efforts which involved Palestinians go back at least one hundred years, from the Ottoman efforts of the 19th and 20th centuries (Foster 2013; Gavish and BenPorath 2003), to the Egyptian maps of the 1950s (Gavish 1996), to the Jordanian program of land registration (Jordanian Department of Lands and Surveys 1966).

Maps were hand drawn in the service of the Palestinian national cause at least as far back as the 1940s. The Palestinian Liberation Organization (PLO) in the 1980s (Gavish 1996) made similar efforts-which generally omitted reference to Israel just as Israeli maps often failed to show the Palestinian Territories, as discussed in Chapter 3-not to mention numerous attempts to document the locations of demolished Palestinian villages and cultural geography (Hadawi 1970; W. Khalidi 1992). However, it was not until the 1990s that the Negotiations Support Unit (NSU) of the PLO for the first time began developing its own maps to counter the Israeli maps then in joint use by the negotiating parties-maps which, not surprisingly, had been uniquely suited to defending the official Israeli position (Interview 6, former PPIB cartographer). Thus, the Oslo negotiations are routinely cited as the first time that the Palestinian representatives brought their own maps to the negotiating table (Interview 6, former PPIB cartographer). Palestinian contributions to cartography multiplied in the ensuing years, and extended into digital topographical modeling (Weizman 2011, 68).

After Oslo, many of the NSU cartographers would go on to work for the PA in various mapmaking capacities (Tesli 2008), but their role in negotiations does not mean that empirical efforts were not addressed in early NSU maps. Quite the contrary, as the Israelis had long demonstrated, the way to gain political clout internationally was by producing maps which attempted to represent objective truths. Therefore, NSU cartographers attempted to demonstrate their legitimacy in the eyes of international monitors, by advancing empirical evidence as to the nature and location of particular Israeli claims to land (Sayegh 2000).

From the beginning, NSU cartography also aimed to be fully digital (Sayegh 2000; Tesli 2008; Interview 6, former PPIB cartographer), an ambitious goal that 
was in keeping with the simultaneous trend to computerization in the Israeli state. This was in part due to the well-known difficulties that arise from the use of paper maps to determine boundaries (Interview 6, former PPIB cartographer). One example is the often-retold story of the birth of the Green Line boundary of the West Bank in 1949 during negotiations between Jordan and Israel. The border was drawn by hand onto a paper map, and on that paper map it seemed thin and detailed, but when administrators later tried to mark the now-militarized boundary on the ground, they found that large areas of the landscape lay entirely inside the line of the boundary, whose thickness on the ground at its most refined was equivalent to 250 meters, or the width of several buildings (Figure 4.1) (Cameron 2011; Blake 1995; Brawer 1990); for this reason, more recent treaties often use lists of coordinates instead of maps as the definitive indications of contested borders (e.g. Hashemite Kingdom of Jordan and State of Israel 1998). This created a challenging situation for villages that fell within the borders. Sami Hadawi has argued that the area of such villages "could not be calculated accurately because the Arab military authorities would not permit, for security reasons, either the government surveyors or the villagers to approach within 500 yards" (Hadawi 1957, 25). During interviews (Interview 6, former PPIB cartographer; Interview 1, Tufakji), this story was

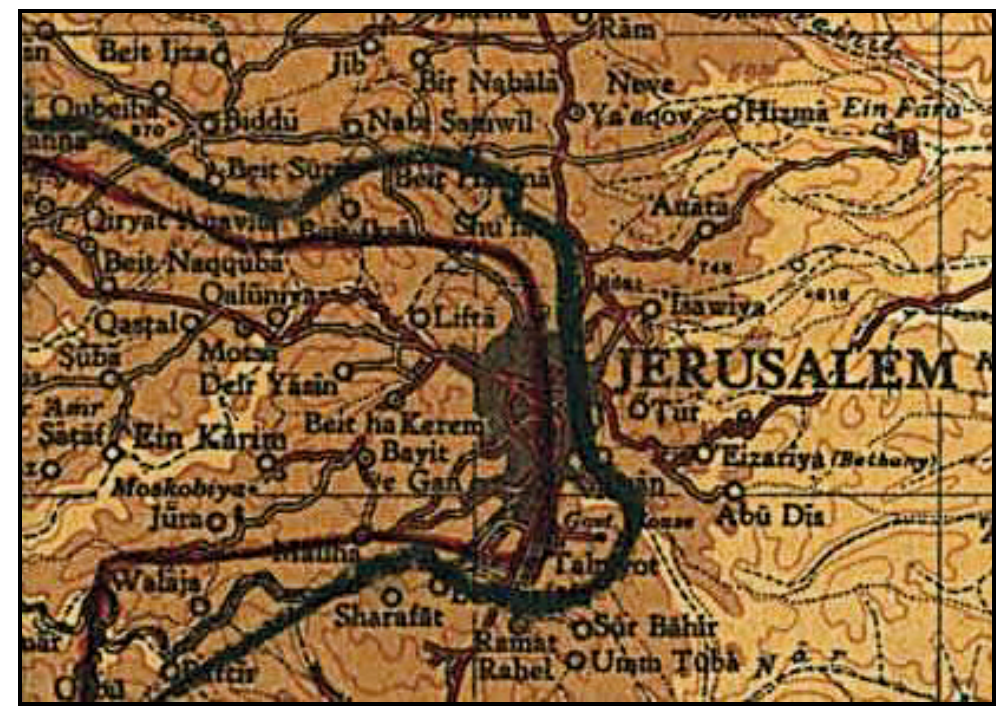

Figure 4.1. A detail of a 1:250,000 scale British map of Jerusalem with hand-drawn border overlay, said to be the original map where the Green Line boundary of the West Bank was drawn in wax pencil during ceasefire negotiations in 1949. This map well illustrates the perils of paper maps. Here the Green Line is the thick black line which begins near the top left corner, then heads vertically through Jerusalem before leaving the frame at the bottom left. The line varies considerably, crossing roads and villages at will, and it covers the eastern side of Jerusalem almost completely (SOP 1937). 
used to indicate the inherent error, as it is argued, of paper maps. If viewers zoom in on a paper map, or on a fixed image of one, the details quickly become blurry. In contrast, digital maps like Google Maps redraw in greater detail with ever finer zooming-although there is still an upper limit.

The inconsistencies found in paper maps did not disappear with the advent of digital cartography; instead they were transformed in ways that, while arguably more accurate, did not necessarily lead to greater power or control. After the Oslo Accords, Palestinian cartography continued apace and the use of GIS mapmaking began to spread through the higher echelons of the PA, as evidenced by the success of the Palestinian Geographic Information Center (PALGRIC), the first major PA GIS agency (Abdullah 2005). Following PALGRIC, there was one additional project which lasted much longer than PALGRIC, however, and which was thereby essential to the process of bringing GIS to the Palestinian State. This was the Physical Planning and Institution Building (PPIB) project which was funded by the Norwegian Agency for Development Cooperation (NORAD) with the aim of building long-term cartographic infrastructure, including servers, modems and digital storage, in the West Bank (Tesli 2008). The PPIB project is central to the history of the PA's efforts in Palestine because it was later integrated with the Ministry of Planning (MOP), and it thereby became one of the main mapmaking initiatives whose work is currently in use in daily governance in the West Bank. Historically it is also significant given that it lasted from 1995-2008 (Tesli 2008), including the period immediately following the Oslo Accords, on through the second Intifada and the split between Fatah and Hamas; it thus provides a central site to analyze the stasis and mobility throughout the early period of the PA.

The PPIB also provides a unique opportunity to study of the role of international agencies in the PA's daily functioning. Ironically, rather than simply representing a failure of Western democracy, and thus a push away from the West, instead the PA's maneuvers to oust the democratically-elected Hamas have brought it closer to the European and American powers. The fact that PA cartography was made possible by an international accord, and then sustained by the backers of that accord as the PA overthrew the laws which brought it into existence, then, makes it all the more urgent to investigate the ways that international landscapes influenced and helped to maintain specific forms development and spatial knowledge. For, although international political and economic development in Palestine is sometimes taken to work in opposition to the Israeli Occupation, this is not necessarily the case. In the context of $20^{\text {th }}$ century South Africa, Peris Sean Jones demonstrates that apartheid advocates supported, rather than opposed, calls to (separately) economically develop segregated Bantustans as a way of legitimizing the young states in concert with, rather than in opposition to, the apartheid regime (Jones 2002). Thus, any critique of either the PA or the Israeli Occupation must include a closer examination of the role of variegated Western knowledge forms in helping to shape the trajectory of authoritarian rule in the West Bank. 
The PPIB is also significant in light of debates in the history and sociology of science. For the efforts to produce stasis in the PA, this can be seen as an inversion of the historical process described by Shapin and Shaffer, whereby "the naturalization of experimental knowledge depended upon the institutionalization of experimental conventions" (Shapin 1985, 79). In the PA, in contrast, naturalized forms of knowledge have supported efforts to establish particular conventions and institutions that become legitimized by referencing that knowledge. However, the power of international interests should not be overstated, for even as academic theory can be used to analyze social practices, PA cartographic practices also theoretically could have the power to shift conceptions of technoscience internationally by how they demonstrate the heterogeneous composition of even the most dominant and supposedly monolithic conceptions of science.

\section{Moving Mountains of Data: Mobilities Studies under Occupation}

In the early stages of the project, the PPIB leaders struggled to implement their goals during an era when historic restrictions on the movement of Palestinians in the West Bank crystallized into an increasingly complex system of control. Whereas in the decades between the 1967 war and the 1994 Oslo accords, Israeli forces focused upon erasing the vestiges of the Green Line border from the land in order to cement the government's claim over the recently occupied territories (Brawer 1990), in the post-Oslo period the focus turned towards regulation of Palestinian population movements between the jumble of newly-defined areas within the West Bank that were given to Palestinian management (Figure 4.2).

In light of their fragmentary design, and because Israel retained control over what became known as Area C-the majority of the West Bank, which fully surrounds Areas A and B, which respectively were placed under full and partial Palestinian control-the number of Israeli checkpoints mushroomed throughout the West Bank and Gaza Strip. Trips which once had taken thirty minutes instead stretched to hours and required Palestinians to pass through dozens of checkpoints where they were routinely detained, often indefinitely and without charge (Amnesty International 2003; B'Tselem 2004; UNOCHA 2012b; 2009). In addition, as the Second Intifada accelerated and attacks and counter-attacks began anew, the Israeli forces used Palestinian suicide bombings of Israeli civilians as a justification for attacks on civilian Palestinian populations in combination with harsh closures of the Occupied Territories as a unit. ${ }^{68}$ Workers from Eastern Africa and Southeast

\footnotetext{
${ }^{68}$ For example, a recent report analyzes the severe impact that the near-total closure of Gaza has had on academia in the Gaza Strip (Gisha 2012; Nagra 2013). At times, the Israeli authorities also withhold funds from the PA in reaction to political developments, such as their 2012 bid to become part of the UN, which can lead to closures at West Bank universities (Guarnieri 2013).
} 
Asia were increasingly brought to Israel to substitute for the labor of Palestinians from the territories, who previously had formed a central subset of labor in Israel, particularly in construction, and Palestinians from the Territories were increasingly prevented from entering Israel (Stamatopoulou-Robbins 2011, 60).

For these reasons, in the Occupied Territories the recognition of mobility as an aspect of social justice to some extent predates the recent turn in social theory towards the study of mobility. Nonetheless, mobility studies has subsequently proven quite useful to researchers attempting to highlight the discriminatory and often debilitating effects of the amorphous and itself somewhat mobile network of Israeli checkpoints and surveillance upon the rhythms of everyday life (Hanafi 2009; Zureik, Lyon, and Abu-Laban 2011). ${ }^{69}$ Mobility studies not only questions the assumption that pre-defined nations or societies should be the natural unit of analysis for social inquiry (Cresswell 2011; Hannam, Sheller, and Urry 2006), but also highlights the production of related immobilities and stillness (Cresswell 1999; Söderström et al. 2013; Urry 2002) and question whether a high degree of mobility is always desirable (Vannini 2011). Mobilities researchers have opened up new methodologies, such as mobile ethnographies (Urry 2002) and sites of inquiry, focusing on mobile places and the cultures of circulation of both people and goods (Lee and LiPuma 2002). Mobility studies scholars also critique static conceptions of social theory in ways that parallel analyses of professional cartography, which is arguably far better suited towards mapping static political territories than mobile populations (Crampton 2010; 2001; Crampton and Krygier 2006). In addition, mobility studies also parallels STS literature, which increasingly has focused on the movement, adaptation, and differing uses of technologies across space (Aouragh 2011; Todd 1995) in an effort to bridge the more specific case studies that to date have characterized the discipline (Sismondo 2010).

Despite its advantages, the experiences of those involved in the PPIB project highlight two issues concerning how an analysis of stasis can contribute to mobilities and related literatures. First, if mobility is to be taken as the strategic foundation for critical inquiry, then a central question arises as to how the production of stasis occurs. Stasis is not simply immobility or the opposite of mobility, because the ability to stay in place-and the work thereby necessary to produce the ongoing presence of people in particular places-is not always identical to the work it takes to be accorded the ability to move. So mobility and stasis do not necessarily form a dialectic. Likewise, stasis is not identical to stability or durability, given that forms of mobility can also be stable or unstable, durable or mutable.

Second, the concept of stasis calls into question the production of particular places, as well as people and objects, as static in the first place. With this in mind, I envision stasis not as referring to a single point or area which is timeless and un-

69 On Palestinian Authority surveillance, see Parsons (2011). 


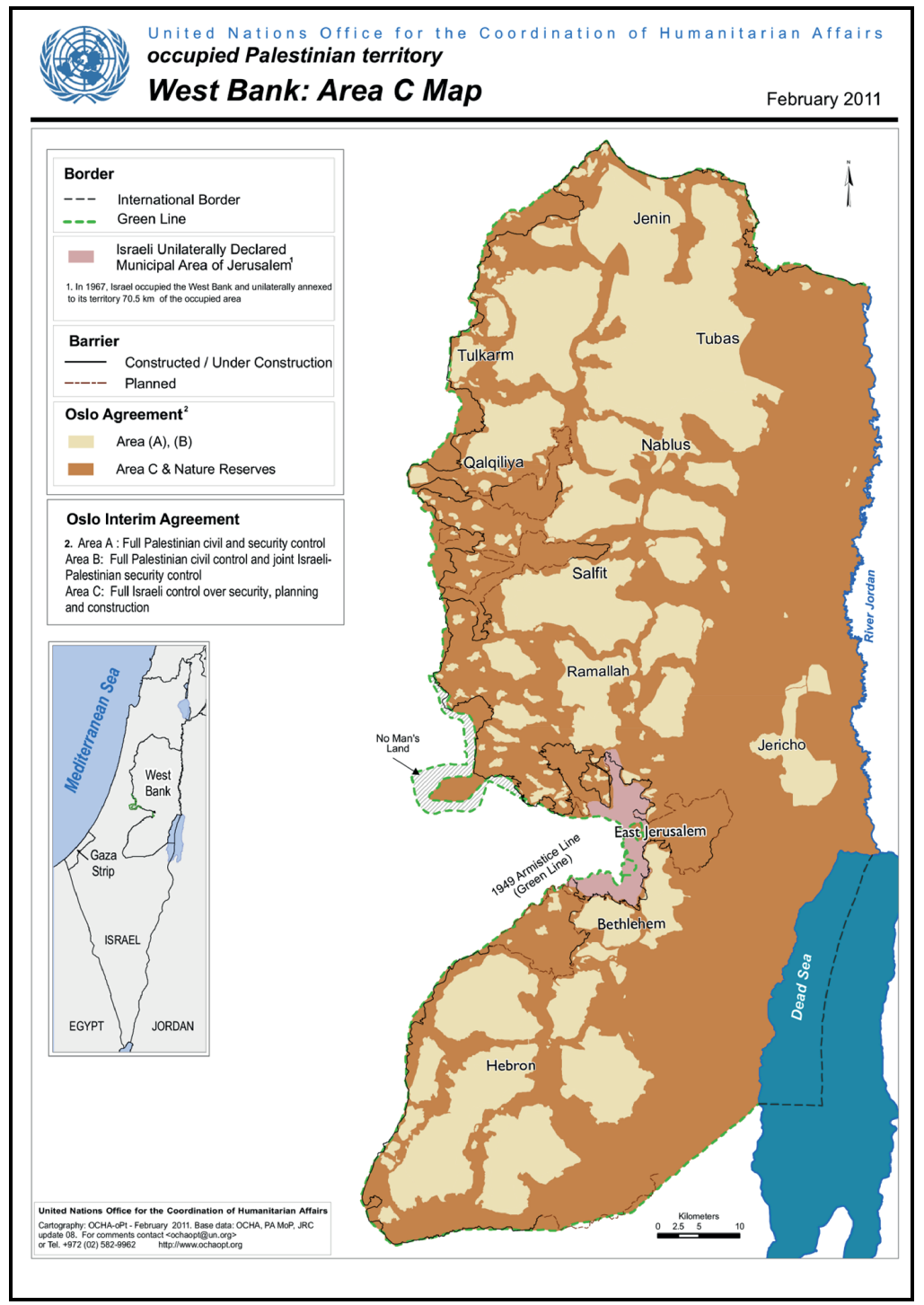

Figure 4.2. A UN map of the West Bank which indicates Areas A and B, which are under full or partial Palestinian control, combined in light brown, and Israeli-controlled Area C in dark brown (UNOCHA 2011a).

ending, but rather as one aspect of the production of landscape-namely, of the entire complex of ideas and actions which are necessary to produce and maintain particular places as being the same. This includes the production of geographical areas or scales (including the national scale (Balibar 1990) as enduring entities 
(N. Smith 1992), and to attempts to maintain a recognized correspondence between those areas and the people who inhabit them. ${ }^{70}$

\section{Palestinian Authority Stasis: Anything But Fixed in Place and Time}

The stasis of many Palestinians could thus be seen as something of an inversion of dichotomous thinking, which imposes colonial fixity upon indigenous populations while simultaneously viewing the postcolonial movement of labor in terms of freedom (Clifford 2003, 57; 2001; Fabian 2002). This contrasts sharply with the more positive connotations which are often implied in discussions of postcolonial mobilities-and this despite the fact that during this same era many have been required to move vast distances to find work. In contrast to other groups, many Palestinians moved into diaspora believing they were but temporary refugees, and yet have so far been denied the option of returning. So rather than being afforded a right of movement to counter a past of colonial entrapment in place, Palestinians have since the early 20 th century been forced to move and been denied the ability to return or remain.

In this context of enforced mobility, the attempts on the part of the Palestinian Authority to build Palestinian cartography, and thereby to increase the stasis of their institutions and data, requires them to reshape, and be shaped by, material landscapes of science and international aid that have actively omitted Palestinians in the past (R. Khalidi 2010; Kreimer 2007; Massad 2006). Yet such efforts have occasionally been characterized as a misguided attempt to reproduce outmoded forms of nationalism, as a result of what in Marxist terms would be called 'false consciousness', or the unreflexive internalization of colonial norms (Fanon 2008). While this critique is certainly relevant at times, at others such a response treats modernity as a monolithic entity and therefore denies the complexity of attempts to produce empirical claims. Despite their ongoing awareness of the paradoxes of their position under current circumstances, PA cartographers do not always have the luxury of openly questioning the paradigms which they are active within, when their very legitimacy depends upon their ability to demonstrate an understanding of those paradigmatic norms. Nonetheless this hardly means that their participation in international knowledge arenas is somehow given or predetermined; instead, cartographers routinely find ways to modify and implicitly question prevailing paradigms, at times through their very insistence on stasis as professionals participating in scientific practices and debates.

\footnotetext{
${ }^{70}$ For example, stasis might refer to a small business owners' ability to maintain a particular store or stand-including the work of, for example, paying the rent or mortgage, obtaining permits, updating the interior and exterior, ordering and inventorying goods, and perhaps defending the area from violent attacks. But it could also refer to efforts to maintain a particular neighborhood or region in the face of indiscriminate developers, industrial pollution, or military conflict.
} 
In the analysis which follows, I focus on the efforts of the PPIB staff prior to 2008, as well as the related work of the Ministry of Planning staff and supporting non-governmental organizations (NGOs) who inherited the PPIB project from 2008 onwards, to produce maps that would support daily governance efforts. While the PA has been criticized for silencing dissent and a failure to meet its goals (e.g. Hass 2012), here I sidestep such debates in order to focus on the challenges that are faced by even the most conscientious members of the West Bank elite. I therefore refrain from outward judgment of PA cartographers as either brainwashed adopters of Western values or, alternately, heroic reshapers of contemporary forms of modernist cartography. Instead I follow Saba Mahmood (2005) by attempting to move beyond a dialectic of accommodation and resistance.

However, to the literature on practices of self-making (e.g. Hirschkind 2006) I contribute an analysis of the ways that landscapes shape knowledge practices beyond a dialectical frame. In so doing, I attempt to take seriously the PA cartographers' use of contemporary technologies, without presuming either wholesale acceptance of liberal scientific ideals or a purely instrumental manipulation of them for political ends (Swedenburg 1995). Doing so moves away from oversimplified dichotomies to draw attention to the ways that PA cartographers enact an awareness of the politics of particular epistemes (e.g. Sayegh 2000). In addition, it highlights their theoretical and material innovations in terms of building stasis, a process which of necessity requires them to reshape professional landscapes that have, often quite physically, excluded them.

\section{All the Data that Remains: The Stasis of British Mandate Maps}

"There are people who would have burned them." This is how Aziz Shihadeh described his efforts, at the Israeli National Library, to preserve and catalog the books of Palestinians which the Israelis had seized after the 1948 war that followed the establishment of the state of Israel (Amit 2008 n. 19). Speaking to Israeli researcher Gish Amit, Shihadeh goes on to relate how some 30,000 books were taken and diligently added to the newly-founded National Library's collections (Amit 2008; Bekker 2013; Mermelstein 2011). Reading his words, I was struck by the ways that the combined theft and preservation of the lost books highlights the selective nature of what was destroyed in 1948 and what was allowed to remain. Scores of Palestinian villages were demolished in what were exceptionally tumultuous times. Some were intentionally dynamited (W. Khalidi 1988; Morris 2004; Pappé 1992), some were allowed to go to ruin (Figure 4.3), and still others were inhabited by Jewish residents, with the result that original tile work can still be seen while walking the streets of West Jerusalem. Throughout the landscape, village ruins poke out of the landscape almost everywhere I looked, from terrace walls to pointed arches to piles of pockmarked rubble overgrown with weeds (Benvenisti 2000). In this 
context, the laborious preservation of thousands of Palestinians' books is at the very least more charitable than some of the alternatives. However, it pales in comparison with another act of preservation: the detailed conservation of British Mandate Maps.

The British relinquished their League of Nations Mandate in Palestine in 1948-a mandate which, seeing as how it was bestowed by the League of Nations, the predecessor of the UN, represented both the coming to the fore of international governing bodies as well as the ways that colonial dependencies were reshaped in the name of world peace. As the British, and by extension the League of Nations, gave up their control, the very same building that housed the Survey of Palestine was rechristened the Survey of Israel, and it continues to be the seat of Israeli state cartography (Gavish 2006; Gavish and Adler 1999). During my fieldwork in large map collections like that of Tel Aviv University, British maps and documents spilled over onto the floor. In every pocket of space above, below, and beside the library shelves, I found overflowing boxes of books of colonial regulations with handwritten annotations, file cabinets full of detailed village surveys, and portfolio folders of British field maps with purple Arabic overlay, to name just a few examples. The sources included the index of a list of regulations for riding the railroad, apparently

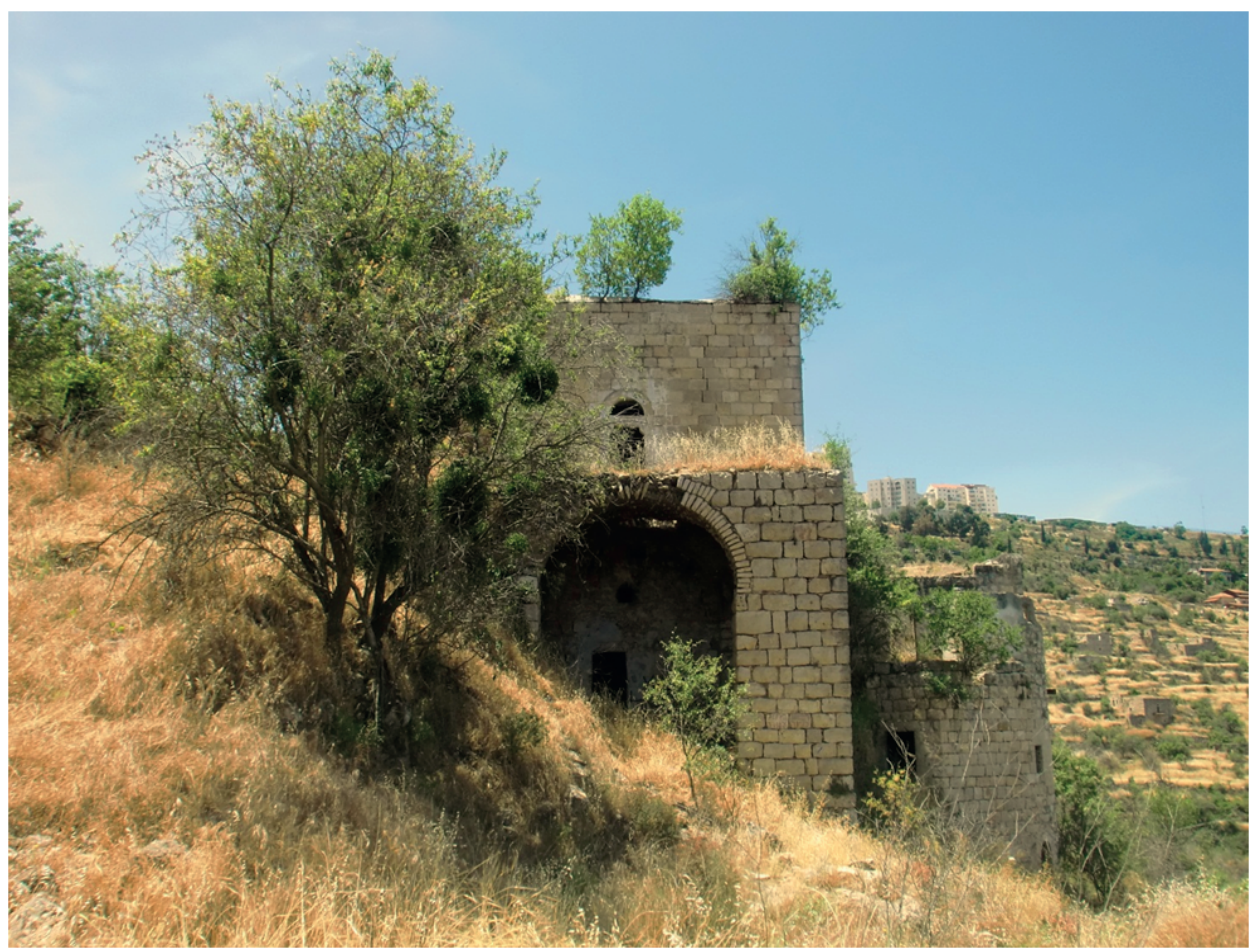

Figure 4.3. A picture of ruins in the former Palestinian town of Lifta, near Jerusalem. Photo by the author. 
also in use in Mandate Palestine, from the 1920s. It included guidelines for people traveling with everything from barrel organs and bath chairs to automatic lung testing machines. They also included rules for transporting large quantities of ham-with no little irony in a region where many follow Halal and Kosher restrictions on the consumption of pork (Government of the United Kingdom 1924). Everywhere I stepped, it seemed, I had to avoid tripping over British documents.

So the villages were destroyed but the maps remain. This outcome was by no means assured, given that both Palestinian and Jewish forces violently opposed the British prior to $1948 .^{71}$ Even after 1948, reams of British papers were sold in bulk for scrap (Amit 2008), and as late as the 1980s some documents may have been incinerated due to a lack of space, a common concern in archival collections the world over (Interview 13, Israeli geography professor). Yet in the end thousands upon thousands of maps were kept and catalogued, and they have turned out to exhibit greater stasis than the very territory they map. ${ }^{72}$ Many Palestinian villages, on the other hand, were destroyed or left unpreserved, partly because those who had the knowledge to maintain them were not allowed to inhabit them (Benvenisti 2000; SOP 1945, 4).

However, in addition to the fact that British colonial maps have greater stasis than Palestinian villages and knowledge forms on the whole, they also exhibit greater mobility. British maps of historic Palestine, including the bulk of what are now Israel and the Palestinian Territories, are widely available both through online retailers and antique dealers internationally. Throughout the interviews I conducted with academics, cartographers, and Palestinian Authority officials, they uniformly explained that the easiest part of the process was actually buying originals or detailed copies of British Mandate maps. As one PA official put it, in terms of information, "If you have the means, if you can pay, then by the end of the day you can get it" (Interview 6, former PPIB cartographer). The Survey of Israel (SOI) itself

\footnotetext{
71 Jewish opposition extended to the theft of British maps. Before the 1948 war, the British vainly attempted to divide the existing maps, field notebooks, and related documents along UN partition lines. They hoped to give Arab leaders in the city of Ramla the maps of areas that were slated to fall under their control; they likewise planned to do the same for the Jewish leaders in Tel Aviv. One British report from 1948 recalled the failed efforts to deliver the maps in this manner: "As soon as the removal began the office was twice raided by Jewish extremists who took away a large quantity of printed maps, office machines, instruments, etc. The Army was therefore called in to remove immediately the Arab records under escort. Subsequently there were further thefts." The report also notes that "Arab raiders" stole documents and maps from the Ramla station-likely without realizing that they were slated to fall into their hands-as well as from offices in Haifa and Nazareth. The same report points out that cartographic fieldwork "was less seriously affected as most of the surveyors were Arabs and working in Arab areas"although the survey efforts were eventually abandoned due to the onset of war (A. P. Mitchell 1948). Ramla, including the maps intended for the Arab administrators, was eventually taken over by the Jewish forces and today lies in central Israel.
}

72 Similarly, Latour and Hermant note (1998) a 1930s engraved panorama in the Samaritaine department store in Paris. 
sells copies of British maps online, and it has offered a number of historical maps through mail order for many years. Numerous libraries, including Israeli libraries, work to maintain public access to SOI maps, at least for those who are allowed to visit Israel. One Palestinian professor who had worked with the PPIB project noted that the cartographers who could enter Israel would work on maps housed in the Hebrew University, while others would travel to libraries in Jordan and Istanbul in order to obtain and digitize British maps (Interview 5, Palestinian geography professor). Copyright law also would have made it more practical to use British maps. In contrast to recent SOI maps, many of which remain confidential, the British maps are not only declassified, but they are effectively in the public domain, given that they were originally copyrighted by the Mandate government (SOP 1945, 4), which no longer exists. ${ }^{73}$ While the colonial maps are available, the amount of work needed to acquire maps should not be overlooked; nonetheless, for those with money and ingenuity they can reach the Palestinian Territories and around the world.

In recent years, the preservation and circulation of British maps have come to have a concerted effect on attempts to make maps for the nascent Palestinian state. The PA would draw time and again on British sources, in part simply because they were there, and relatively easily available. To some extent, then, the value of the maps' scientific and technological knowledge is assured through a self-fulfilling prophecy: knowledge forms are preserved, because they are assumed to be valuable, and then they become valuable precisely because they were preserved. It is therefore essential to better understand how the colonial legacies materialized through such acts of preservation continue to impact the production of knowledge. ${ }^{74}$

\section{A Digitized Mandate}

To begin to see the impact of British Mandate maps, however, it is necessary to examine the specific digital methods that were used to incorporate them into recent cartography. From the beginning, the PPIB project was intended to be fully digital (Tesli 2008; Sayegh 2000), and one of the first tasks the cartographers undertook was to scan the British maps into digital image files. However, scanning

\footnotetext{
73 To my knowledge there has been no effort by any party to enforce a copyright on British maps in Palestine and Israel, and they are widely available for purchase on the internet. However, in Britain access to such maps is often filtered through the restrictions of the holding institution, such as the British Library or the Palestine Exploration Fund archives.

${ }^{74}$ Speaking of the development of digital cartography, Laura Kurgan (2013, 17-18) has noted a similar process of the increasing "'coordination' of physical space with digital space" which parallels to some extent the self-fulfilling prophecy described here. However while Kurgan emphasizes the newness of digital technology and builds her argument by opposing "digital and physical globes" which subsequently interact, as she demonstrates, in complex ways, here I am concerned with the ways historical legacies continue to shape the ways that digital and physical landscapes are fully imbricated.
} 
was not sufficient to produce digital maps. First the PA employees needed to digitize them, a technique that involved using the mouse to trace over the relevant portions of the scanned image so that the ArcGIS program could record the length, position, and direction of every small curve or area that was traced (Figure 4.4). A cartographer might open an image of a road map, for example, and then laboriously trace the lines that indicate roads one by one, drawing on top of the scanned map and thereby incorporating its information into the computer. Digitization was a time consuming and labor intensive process. One cartographer who had worked with the PA noted that "We started from zero [....] We had two employees spending eight months working 24 hours a day to digitize the contour lines of the British 1936 maps" (Interview 6, former PPIB cartographer). Thus the PA's high-tech mapping industry began with professionally trained cartographers laboriously tracing colonial maps. While it is not unusual for cartographers to draw on existing maps using digitization, the extent of the use of British maps was far greater due to the restrictions imposed by the Israeli Occupation. This contrasts with the development

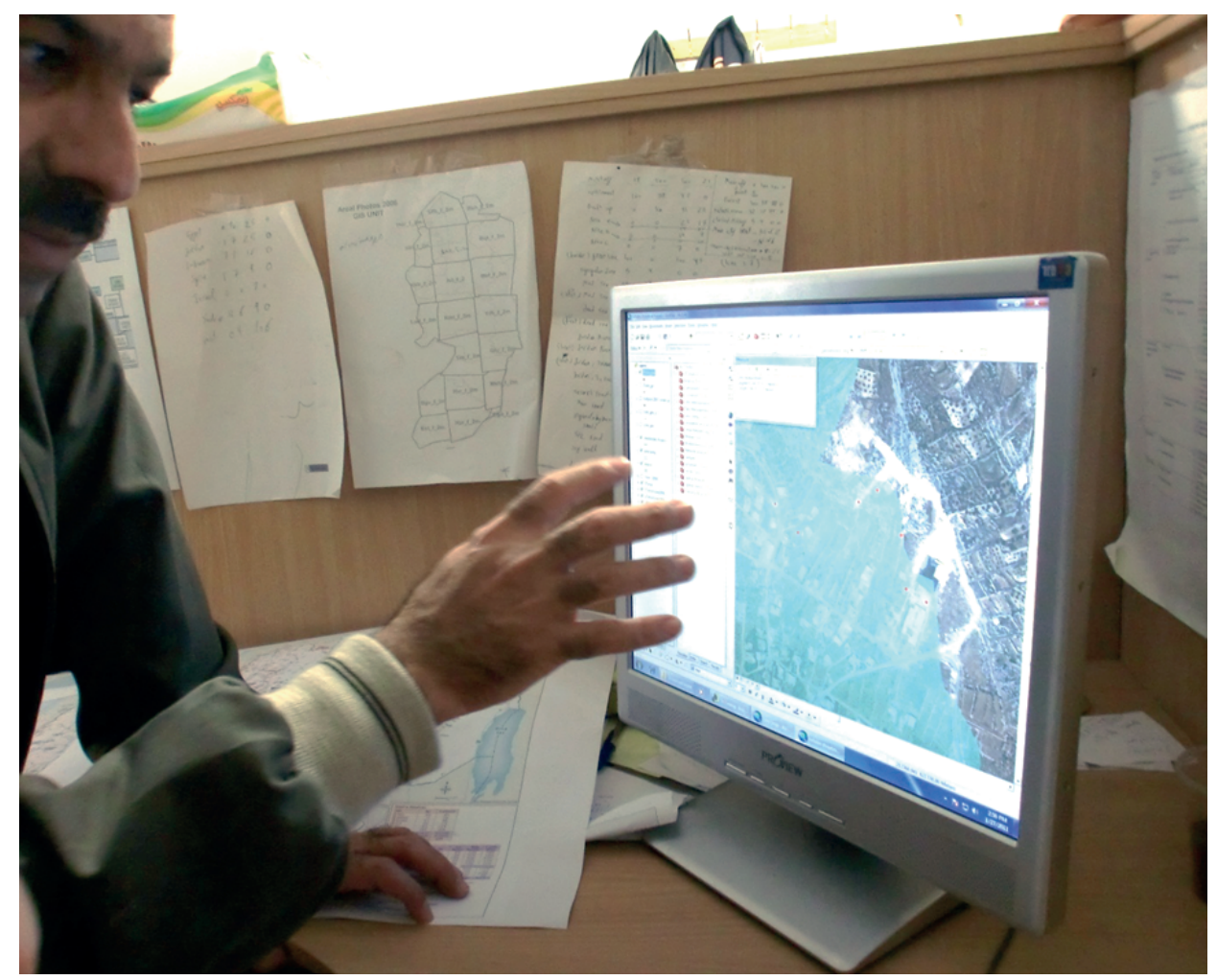

Figure 4.4. A picture of a professional NGO cartographer who is explaining the process of digitizing an aerial photograph. The green shaded area is the digitized layer which has been traced over the image. Photo by the author. 
of GIS in Israel in the mid-1980s and early 1990s, when data from existing maps were routinely verified by field surveys using handheld GPS, a privilege afforded to Israeli cartographers even within the Palestinian Territories at the time that was likewise in the context of the Occupation (Peled 1996, 492). Furthermore, in addition to being time consuming, digitization also selectively shaped the digital files that were produced-not least because the user decided which parts of each map to include and which to omit. However it is not possible to digitize layers which are not present on the original map. So the type of map that was used also conditioned the data that resulted. In the case of the PPIB, colonial maps shaped the digitized data in part through the specific set of geographic scales that were originally used by the British to make their maps.

Geographic scales are integral to the resolution, or amount of detail, that is contained in a particular map. A finer scale map shows a higher level of detail over a small area, such as a neighborhood, while a broader scale map would show little detail but could depict a much larger area, such as an entire continent. However, a scale is not incidental. Map data are collected at a particular resolution or level of detail, and as such, every data file has a particular geographic scale built into it. In digital maps, like Google Maps, it is possible to change between scales-literally zooming in and out, from one scale to another. ${ }^{75}$ In contrast, for a paper map, the scale at which the map was originally made represents the highest level of detail of the data it contains, so that boundaries and features become chunky and blurry when zoomed in much closer than that range.

Because they were tracing paper maps made at fixed scales, the PA maps were restricted to the same fixed scales that those paper maps used. Digitization did not preclude the PPIB from using other types of historical maps as sources. Indeed, as the project progressed they would have particularly made use of Israeli maps; however these also drew on British maps as data sources, particularly in the West Bank where much of the Israeli data was classified, so the use of Israeli maps would only have helped to cement the British influence. ${ }^{76}$ So through digitization alone,

\footnotetext{
75 However, computers can only make the transition appear seamless when in fact, to achieve the zooming effect, it is necessary to cobble together a patchwork of different maps and data sets that are often collected at different scales, different times, and under different conditions.

${ }^{76}$ Other types of maps that could have been used were US, French, German, Russian, and Ottoman maps, to name a few, as well as aerial photographs. However, in addition to generally being more expensive, in some cases more likely to be under copyright, and harder to find, such maps alternately focused in only on Jerusalem, or depicted the entire territory of historic Palestine at the broadest scale possible. They thus were made at even more restricted sets of scales than the British maps, in addition to themselves drawing on British data. Even many of the extant aerial photographs - at least those that were declassified by the late 1990s - were in fact taken by British military recognizance missions during World War I, conducted in conjunction with the British mapping surveys, and which themselves would have served as sources for the British maps (Gavish 2006; 2005; 1996; Srebro, Adler, and Gavish 2009). For examples of both historic and more contemporary aerial photographs of the region, see Kedar (1999).
} 
the PA cartographers could not improve on the scale of the British data; they couldn't make more detailed features appear if they weren't there in the original paper map. Instead they could simply try to trace the British maps as accurately as possible (Figures 4.51 and 4.52).

The British controlled a territory much larger than the PA does, so only the finest of the common British scales was detailed enough to show the West Bank in any detail. Thus the PA's extensive use of British data meant that it would be quite difficult for PA cartographers to make maps at any scale that was finer than the entire West Bank. Indeed, early PA maps replicated precisely the finest British scale and no finer (MOPIC 1998; 1996). As a result, their early maps were useful for symbolic political purposes, but were less helpful in terms of daily governance. The persistence of the British scales, even in digital form, contrasts sharply with the irregular levels of stasis for PA institutions, as I explain in the following section.
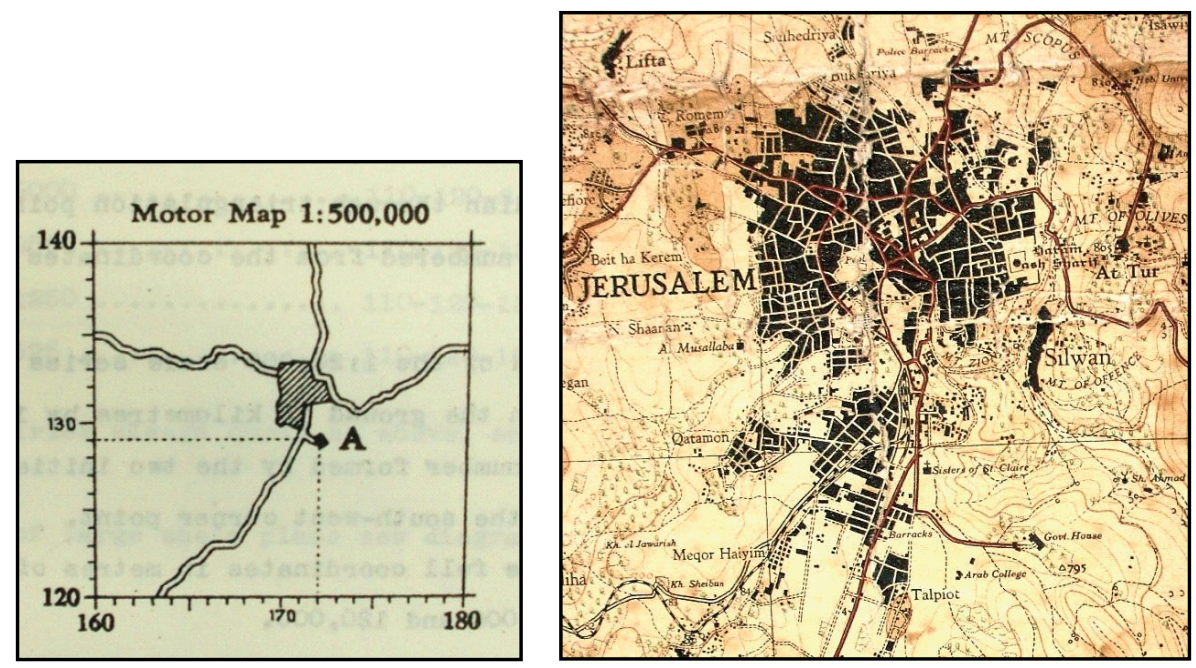

Figures 4.51 and 4.52. Two British maps of Jerusalem at different scales. Zooming in on Figure 4.51 (left) might enlarge the shaded area, but it cannot increase the level of detail (SOP 1945). In contrast, Figure 4.52 (right) is taken from a much finer scale British map; however, such detailed maps were never completed for the area that would become the West Bank (SOP 1937).

\section{Staying Put in Palestine: Palestinian Authority Stasis}

At 11:30pm on the night of December 5, 2001, the office of Dr. Hassan Abu-Libdeh released a statement which began as follows: "The Israeli military forces have just occupied the premises of the Palestinian Central Bureau of Statistics (PCBS). Scores of heavily armed soldiers have entered the building by force" (Abu-Libdeh 2001a). 
The raid lasted for six hours. Local security personnel and others in the building were interrogated (Abu-Libdeh 2001d; Claudet 2001). Such disruptions appeared to be secondary to the main goal of the raid, which was to gather knowledge. AbuLibdeh, then the head of the PCBS, the PA department which produces the Palestinian census, noted that "What I fear most is the magnitude of the data that were stolen." He worried that Israel would continue raiding offices to gain access to the geographic and population data the PA collects while, at the same time, destroying their means of storing it, preserving it, and turning it into maps (Abu-Libdeh 2001a; 2001b; 2001c; Claudet 2001). By preventing them from fulfilling their mandate, the raid could thus be seen as an attempt to disrupt the stasis of the PCBS not only during the raid itself, but also in the future. ${ }^{77}$

Israeli seizure of Palestinian knowledge centers was not a new phenomenon at the time. Since 1967, Palestinian knowledge repositories have repeatedly been subject to challenges to their institutional stasis. The Palestine Research Center, affiliated with the PLO, had been seized and subject to forced closure as far back as 1982 (Jiryis and Qallab 1985; Orient House 2001a). Zureik $(2001,212)$ notes that after the Israeli invasion of Lebanon in 1982, the documentary records of the PLO were transported wholesale to Israel, although some of it was later returned, presumably after the Israelis had made copies of it. However in 2001 raids began in earnest, in the context of the attacks on civilians during the second Intifada. In May 2001, the Israeli Defense Forces (IDF) had taken over the Orient House, which had long served as the de facto PLO headquarters and which, in this capacity, had been producing maps without GIS since the 1980s (Interview 1, Tufakji; Orient House 2005; Tufakji n.d.). The staff claimed that their entire archival collection was impounded, as were dozens of computers (Orient House 2001a; 2001b; 2001c; 2001d; 2001e). ${ }^{78}$

The PPIB was also affected, although they managed to preserve much of their geographic data, and thus further the stasis of their project, by decentralizing their collections and moving them to undisclosed locations. As with the PCBS and the Orient House, the MOP, which would come to house the products of the PPIB project, was also raided by the military (Interview 6, former PPIB cartographer).However, a PPIB employee noted that they had altered their method of data storage after the PCBS raid, and the military found little to no data in the MOP offices. "When the attacks [on PA ministries] started, we took all of the data, all of the data, and we disappeared." In this context, former participants and associates of the PPIB project routinely mentioned fears that their amassing of data might be in vain

\footnotetext{
${ }^{77}$ Hassan Abu-Libdeh has since been brought up on corruption charges-charges, however, which appear to be unrelated to his time as the director of the PCBS, and which he claims are politically motivated ("Palestinian Economy Minister Charged with Embezzlement, Insider Trading" 2011).

78 The 25,000 volumes of the Palestine Research Center were returned two years later, whereupon it moved to Cyprus (Jiryis and Qallab 1985). At the time of writing, the Orient House remains closed.
} 
(Interview 1, Tufakji; Interview 6, former PPIB cartographer), and this fear appears to have encouraged decentralization, instead encouraging individual PA offices to manage their own servers - a decision which, by increasing the power of local and regional PA branches, would in theory have the potential to ultimately affect the stasis of the PA central offices.

Since 2008, the raids on institutions (e.g. Matar 2012; Nusseibeh 2012) and attacks on data infrastructure (Tawil-Souri 2011c) have continued; thus the physical integrity of Palestinian knowledge centers, and their ability to increase their level of stasis, is far from assured. This complicates earlier debates over the relevance of local scientific practices to broader institutional systems (e.g. Lynch 1993, 112), as the institutional practices are also localized-in this case in relation to their repeated destruction. Their stasis is not only shaped by direct incursions, but it is also affected by the very constitution of knowledge landscapes. In the absence of a fully-recognized state, local and international businesses (Bouillon 2004) and, more central to knowledge production networks, NGOs have come to the fore, and they continue to perform many of the functions that would be expected of a national government, including the production and preservation of maps (Ibrahim 2011; Jensen, Abed, and Tellefsen 1997). Yet NGOs are often highly transitory, subject to outside control, and their future depends upon fleeting international aid cycles and grants (Hanafi and Tabar 2003). This creates difficulties conducting research, as Zureik, Lyon, and Abu-Laban note in their recent study on information society in Palestine: "It is an understatement to admit that researching an emergent country like Palestine is not an easy task, particularly when the data [...] are hard to come by" $(2011,1) .{ }^{79}$ At the inception of the PPIB, the effects of Israeli military control combined with the prevalence of NGOs at least partly as a result of the Occupation, to ensure that the PA had no local map archive at its disposal. ${ }^{80}$ Referring to the "almost total lack of basic data" - in no small part because such data were "considered to be military secrets by the Israelis"—one consultant notes simply, "There were no maps" (Tesli 2008, 23). ${ }^{81}$

\footnotetext{
${ }^{79}$ Also see Daoud (2000) on the impact of political events on development funding in Palestine.
}

80 The difficulties of maintaining archives in colonial and postcolonial contexts has led Buckely and Wasiuta to advocate privatizing archives (2013), although as I show here, the particularization and dispersal of sources, while they might solve some problems, simultaneously introduce an entirely new set of concerns. There have been some efforts to institutionalize research in the absence of a recognized state, including the creation of the Palestine Academy for Science and Technology. However, this is not to paint too rosy a picture of the strength of institutions in Europe. For example, Bijker, Bal and Hendriks (2009) have referred to the "paradox" of the trend in the Netherlands towards increasing authority of scientific advice at the same time as institutions of science are being eroded. With thanks to Elena Glasberg for bringing Buckley and Wasiuta's work to my attention.

81 The withholding of data on the part of the Israeli authorities, as well as the classification of many maps and related documents, also led to the creation of the PA mapmaking projects for reasons dealing both 


\section{Immobile Elites: NGOs on the Move}

This enforced transitory character of Palestinian institutions interacts in complex ways with the stasis and mobility of the cartographers who have built and rebuilt those same institutions over time. This in turn impacts their ability to conduct surveys or otherwise collect data on the ground. It thereby serves to restrict the extent of the new data that they can produce, with the end result that, on PA maps, some areas are depicted in much greater detail than others. By analyzing the stasis and mobility of PA cartographers and institutions in relation to their cartographic efforts in the context of the Israeli Occupation, it is possible to see the varied effects on the resulting extent of their data.

While discussions of Palestinian mobility tend to focus on local or regional movement (e.g. B'Tselem 2004), the mobility and stasis of PA cartographers and institutions must be viewed across geographic scales, including at the international scale. The fact that many NGOs and PA ministries receive international aid with the precise aim of building stable state institutions, led the noted Israeli journalist Amira Hass (Hass 2001) to point out the fact that, in its raid on the PCBS, the Israeli military was effectively destroying millions of Euros of taxpayer money. Was the IDF, in citing security and intelligence concerns as the reason behind the raid, Hass asks, accusing Norway, Switzerland, and Germany of terrorism? ${ }^{82}$

Hass's question points to the ironies of PA internationalism, which can also be seen in the generally high international mobilities of Palestinian elites. Many of those I worked with had studied for advanced degrees internationally, including in Canada, the Netherlands, Russia, and the United States, to name only a small sample. However, the process of travel was often fraught with uncertainties. In addition to the discrimination commonly found at checkpoints and airports-as well as the ongoing prohibition against Palestinians operating their own planes without Israeli approval (which is rarely forthcoming) (PLO and State of Israel 1995), and attempts to build an Israeli settlement on the existing airport at Atarot (Houk 2008)-many Palestinians have no ability to obtain a passport from any nation. Unlike passports, permits and visas can easily be revoked, as in the case of Palestinian Fulbright fellows who were given research grants but were never granted visas which would

with the content and availability of data. Classification creates high levels of uncertainty, although sometimes the differing levels of security across multiple collections (for example, in Israeli versus British collections, or libraries versus online retailers) allow for a more complete picture of the maps produced. Raja Shehadeh (2013) has suggested that PA authorities and academics may also become discouraged due to the high personal and economic costs of attempting to do research.

82 The funding provided by supranational organizations, like the EU, and donor countries also significantly shaped the PA cartography in ways that, while perhaps not as crucial as the British and Israeli influence, are certainly deserving of further study. For example, NORAD provided high levels of funding to the PPIB, but the sometimes minute monitoring of those funds could also be seen as a form of imperial control. 
have allowed them to go to the US to receive the awards (Bronner 2008). ${ }^{83}$ Students and academics, among others, are systematically prevented from traveling from Gaza to the West Bank (Hass 2011b). Furthermore, travel is not always a privilege, given that many Palestinians must go abroad to find work or visit family who themselves cannot enter the Territories. Thus extensive international mobility can be a symptom of, rather than a remedy to, challenges to Palestinian stasis within the West Bank. 84

The relatively higher international mobility, for those Palestinians who can afford it, stands in contrast to the well-known difficulties that Palestinians can experience when traveling within the West Bank. ${ }^{85}$ While the Gaza Strip has been virtually closed off to international as well as local visitors since the rise of Hamas, the West Bank experiences periods of relative quiet where internal travel restrictions are eased somewhat. At other times, extensive mobile checkpoints may be set up without warning, curfews imposed, and Israeli incursions, such as those in 2003 to give just one example, and attacks or infighting may halt mobility almost entirely. The common practice of detaining Palestinians, including academics and technicians, further affects their mobility. Many who I spoke with noted that they regularly used their detailed knowledge of local streets and neighborhoods to help them find alternative routes in the case of road closures. ${ }^{86}$ Yet the very need for such knowledge points to the difficulties imposed by the Occupation forces.

Such challenges can be seen further in the shifting locations of cartographic offices in the Jerusalem area and its resulting impact on their ability to update British data. The location of PA offices primarily in Ramallah, as an implicit future capital of a Palestinian state, is symbolic of the broader move to force Palestinians out of Jerusalem. Over the past decade, a variety of factors, including the ongoing raids, have combined to push Palestinian organizations ever further from the city. Several

\footnotetext{
${ }^{83}$ Although not a Fulbright fellow, one student from Gaza did make it to Oxford, her education paid for in part by fellow students at the university by building up a fund through numerous small donations of about 4.50 Euros each ("Student's Journey from Gaza to Oxford" 2013).
}

84 The Israeli administration also imposes movement restrictions that target specific cartographers. For example, see the international travel ban on noted cartographer Khalil Tufakji (MIFTAH 2010; Interview 1, Tufakji).

85 It also contrasts with efforts to expand the already high mobility of Israeli elites. Locally, these include both the construction of transportation infrastructure to service settlements in the West Bank ("Israel Unveils Controversial Plan for West Bank Rail Network" 2013). Internationally there are efforts such as the attempts on the part of US senators to lobby the US government for a visa waiver exemption for Israelis who travel to the US even though, contrary to standard policy, the Israeli government is not prepared to offer parallel waivers to US citizens traveling to Israel (Coogan 2013).

${ }^{86}$ In a similar vein, at the first TEDx Ramallah, Laila Atshan, a counselor based in Ramallah, noted her admiration for Palestinian taxi drivers to spontaneous and raucous applause (2011, 1:40). 
of the NGOs I worked with were originally located there, but following the outbreak of the Second Intifada, Jerusalem was increasingly closed to Palestinians from the West Bank, and many cartographic NGOs moved east into the outskirts of the city so that all of their employees could continue their work. Once construction on the Separation Wall began, with the aim of separating the majority of the West Bank from Israel, the NGOs moved again from the immediate vicinity of the wall, which became the site of checkpoints and abandoned shop fronts, towards prominent cities like Ramallah and Bethlehem.

Yet the move to the West Bank side of the Wall would also impact their ability to collect information concerning those who remained on the Jerusalem side. Khalil Tufakji, the former director of the Orient House Maps and Survey Department, had begun painstakingly rebuilding a collection after the maps were confiscated, although he no longer advertised his location (Interview 1, Tufakji; Orient House 2001a). Given that each move would require a tremendous effort and outlay of funds, even those organizations that persisted under the Occupation were made mobile in ways that, rather than acting as a privilege, came to diminish their institutional stasis. The impacts of their specific forms of stasis and mobility experienced by the PA cartographers, both in institutional and operational terms, thereby serve to restrict the extent of the data which were produced, yet as I discuss below, the scope and geography of precisely how their data are restricted are themselves quite varied.

\section{In the Field, Stuck in the Car}

The fact that their offices were ever on the move would serve to affect how geographic data was collected in the field, even after the 2008 handover of the PPIB to the relatively more stable PA Ministry of Planning. Cartographic field surveys are one major way that it might be possible to update British map data, and they involve using tools such as handheld Global Positioning System (GPS) unitsextended versions of the mapping applications available on many mobile phonesto record precise locations for sometimes dozens or hundreds of buildings, roads, crops, and other features. Mobility is central to surveying, and while it was one obvious factor that affected their ability to collect data, the cartographers I spoke with repeatedly mentioned that, in many cases the challenge was not simply accessing different areas. At one time or another, it was possible to reach many parts of the West Bank, with the obvious exception of the settlements and closed military zones (Ingham 2013; Interview 7, PA transport cartographer; Interview 8, PA transport engineer). However, they faced tremendous difficulties in the field when attempting to stay in one place reliably without the intervention of settlers or the military. It takes time to observe and record data, and field surveys can require dozens of technicians, sometimes with heavy equipment. So in order to survey an 
area in the way it is most commonly carried out, cartographers had not only to travel there, but also to remain. ${ }^{87}$

Yet reliable stasis still is not often achieved, especially given that the West Bank is divided into a complex quilt of Areas A, B, and C. Particularly in Areas B and C, those under partial or full Israeli control, cartographers spoke of beginning to draw attention to themselves, of the Israeli military appearing spontaneously at times if they spent too much time in one location. Hanging around in the possession of expensive-looking instruments often aroused suspicion. One cartographer noted, "We can move in Area C, but if we have equipment, it is very dangerous for us. If we have cameras or GPS, and if the soldiers stop us, they can arrest us. Two years ago, they arrested me and [my colleague] because they caught us in Area C [...taking] photos of demolished houses and GPS points" (Interview 9, Palestinian NGO cartographer).

Many of those I worked with had been arrested at one time or another simply for carrying out their (officially legal) work. Another pair of cartographers mentioned that although their survey was restricted to Areas A and B, the fact that these areas are non-contiguous and surrounded by Area $\mathrm{C}$ meant that while traveling they were often detained at Israeli checkpoints and would need to hide their GPS units and cameras to avoid confiscation. The advent of small GPS units made their jobs easier, one engineer noted, because they 'look like mobile phones', although sometimes phones were also confiscated (Interview 7, PA transport cartographer; Interview 8, PA transport engineer).

For these reasons, in recent years PA and NGO cartographers have begun to develop the technique of mobile surveying, using handheld GPS units and conducted fully within a car or taxi. One mentioned that although his groups work in Area C, "We are very careful. Like when we use GPS, we [take it] in the car and drive the car without anyone seeing anything" (Interview 9, Palestinian NGO cartographer; Interview 12, Palestinian civil engineer). Rather than visiting a single location one time to take a detailed reading, the use of cars allowed them to visit several times, for short periods, to take quick readings of different aspects of the landscape that could then be combined. So, just as their computer labs were gutted from within by the IDF, PA cartographers in the field were confined to their cars, which became circulating cartographic laboratories (Lee and LiPuma 2002). Thus their stasis and their mobility were intertwined in ways that broke down divisions between the lab and the field, and they achieved stasis not by rendering themselves immobile, but by being constantly on the move.

\footnotetext{
87 To a lesser extent, such challenges have also been faced by Israelis seeking to carry out alternative cartographic fieldwork in the West Bank, even before the increased restrictions on travel outside of settlements. In the 1980s, Meron Benvenisti and Shlomo Khayat could assert, in the introduction to the West Bank and Gaza Atlas (1988, n.p.), that "we have done the best we could, given our very limited resources and less than satisfactory cooperation rendered by the [Israeli] authorities."
} 
There is a complex relationship between the extent of the area where data could be collected and the extent where cartographers were able to move and remain. For example, even in a car, PA cartographers cannot conduct surveys throughout Area $C$, but this does not mean that they never enter it, given that the boundaries between Areas A, B, and C are often not visible on the ground; settlements and settler roads, by contrast, are well-marked. Indeed, the Israeli authorities only provide boundary information for the broadest scale maps of the West Bank, so they are difficult for even most cartographic agencies to determine at finer scales, and cartographers themselves might travel to Area $\mathrm{C}$ without realizing it (Interview 5, Palestinian geography professor; Interview 9, Palestinian NGO cartographer). ${ }^{88}$ Under such ambiguous circumstances, and given that the method of doing surveys by cars is especially perilous in zones that are formally under full Israeli control, those I spoke with generally limit the extent of their data collection to Areas A and B alone, as much as that can be determined.

\section{Measuring the Extent of the Occupation}

Despite such limits on their mobility and stasis, PA cartographers are still expected to provide updated maps of the 'full' West Bank, including places like Israeli settlements, which they cannot visit in person (Interview 10, PA urban planner). This results in a situation where the partial stasis of PA cartographers in the field serves to reinforce the changeable stasis of Palestinian towns and villages. The cycle can be seen by examining the grid that is often visible in the background of maps (e.g. Figures 4.1 and 4.52). In addition to aiding navigation, each square of the map is assumed to be depicted at the same level of detail as every other square. This creates tension in PA maps, however, given that Areas A, B, and C cut across different squares of the grid, and are surveyed in different levels of detail, but must be displayed together on a single map. The seamless transition between the data for each of the three areas obscures the lack of detail for Israeli-controlled Area C, whose blank areas appear to the viewer not as an omission on the map, but as empty space on the ground. This thereby serves to erase dozens of rural towns and innumerable features which would be apparent with a consistent survey. Such erasures can be self-perpetuating, because it is easier for Israeli authorities to justify moving or demolishing communities if they are quite literally left off of even Palestinian maps.

The relegation of Areas B and C to the negative white space of PPIB maps is compounded by the fact that the limited extent of British cadastral maps (see Fig-

\footnotetext{
${ }^{88}$ During my participant-observation, at least one call per day would come in from landowners who wished to know whether their homes fell within area A, B, C, or some combination of these. Even if a home was on the border with only one a backyard in an Israeli-controlled district, this was considered grounds for demolition by the Israeli authorities (ARIJ 2006a; Interview 9, Palestinian NGO cartographer).
} 
ures 4.61 and 4.62) may have contributed to the ultimate omission of Area $C$ from the PA's jurisdiction. By using British maps, the PA cartographers were not only influenced by the rigid system of relatively broad (in comparison to the West Bank) scales in use by the Mandate forces, as noted above. They also were affected by the fact that, to the extent that the British did map higher resolution data for land ownership, this almost never occurred in the area that would become the West Bank.

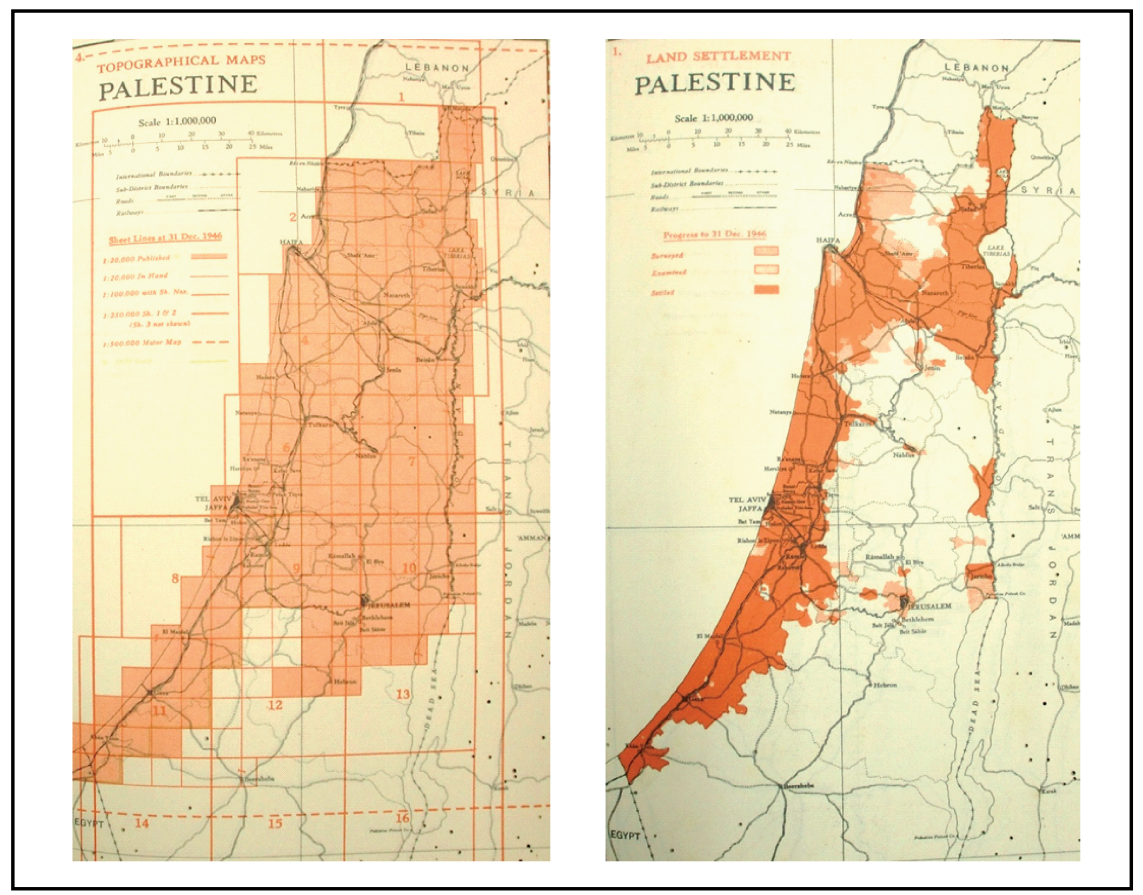

Figures 4.61 and 4.62. Two maps showing the extent of the completion of British maps of historic Palestine as of 1945. Figure 4.61 (left) shows areas (orange overlay) where the British had completed broad and mid-scale topographical mapping. The topography in the north is entirely mapped, in detail. In contrast, Figure 4.62 (right) indicates those areas (orange) where the British had completed the much finer scale cadastral mapping. With the exception of a small selection of larger towns, the West Bank area was not cadastrally mapped (SOP 1948).

For, even as the data favored a broader scale, this was compounded by the fact that they also concentrated almost entirely on more populated areas that, at the time the British were in power, lay mainly along the coast. During their tenure, the British cartographers produced two main types of maps: topo-graphical, with a focus on indicating elevation and land contours at a broader scale, and cadastral, maps at much finer scales which primarily indicate the boundaries of individual land parcels. The topographical maps were completed for the full British Mandate 
area, including the West Bank, by the time of the handover of power in 1948, and their influence can clearly be seen in the maps produced by the PPIB as it still represents some of the highest resolution data available (for example, see the contour lines in Figure 4.7). ${ }^{89}$ Yet the cadastral mapping was not completed for the hilly region which would become the West Bank, likely partly because the lands were not regularly the subject of disputes since the Jewish population in the area was minimal compared with their presence in population centers along the coast, like as Tel Aviv (Gavish 2005).

The limitations of the British maps are self-reinforcing in the context of lack of PA stasis due to the Occupation. Given that detailed land ownership in the West Bank was not mapped by the British, the populations of its rural regions went largely unrecognized. It would have been simple for the Israeli negotiators to claim that Area $C$ in particular was entirely unpopulated, thereby making those regions more fully available to Israeli control. So the British choice to avoid mapping land ownership in the West Bank meant that its lesser-populated areas (Area C) dropped off the cadastral maps entirely; subsequently, the fact that these areas were blank on the cadastral maps meant that the PA were less likely to be given jurisdiction over them; and then the lack of Palestinian sovereignty there continues to limit their ability to fill in those same negative spaces. In this way, the constricted extent of the British cadastral maps resulted in administrative boundaries (Area C) which themselves contribute to the functional omission of Area $\mathrm{C}$ from future maps (see Figures 4.8, 4.91, and 4.92). Thus the locations of boundaries on broad-scale maps, influenced by British data, serve to restrict the extent of cartographers' surveys, and this in turn substantiates the apparent fixity of those same boundaries by enabling the demolition of villages in areas that appear blank on the map.

\section{Preservation in Pieces: The Dispersal of Palestinian Data}

Despite the vast differences between the British and Israeli colonial regimes, both have combined to circumscribe the possibilities for the scale and extent of PA maps,

\footnotetext{
89 The coast was also long the focus of Palestinian memories of loss after 1948, as Scham notes (2003, 75). Despite their broad scale, the British topographical maps still are invaluable repositories of information on the number and location of Palestinian villages before 1948. They continue to be referred to as factual sources-for example, in a recent Facebook post by the anti-Occupation group, Ta'ayush. The author of the post uses images of pre-1948 British maps to argue that the Israeli military "cannot be persuaded with the facts". In this case, the facts are taken to be the existence of villages in an area where the authorities seek to make a military firing Zone, which requires forcibly emptying it of (Palestinian) civilians: https://www.facebook.com/photo.php?fbid=10151551881596986\&set=a.196756516985.

138990.170738066985\&type=1\&relevant_count=1\&ref=nf.
} 


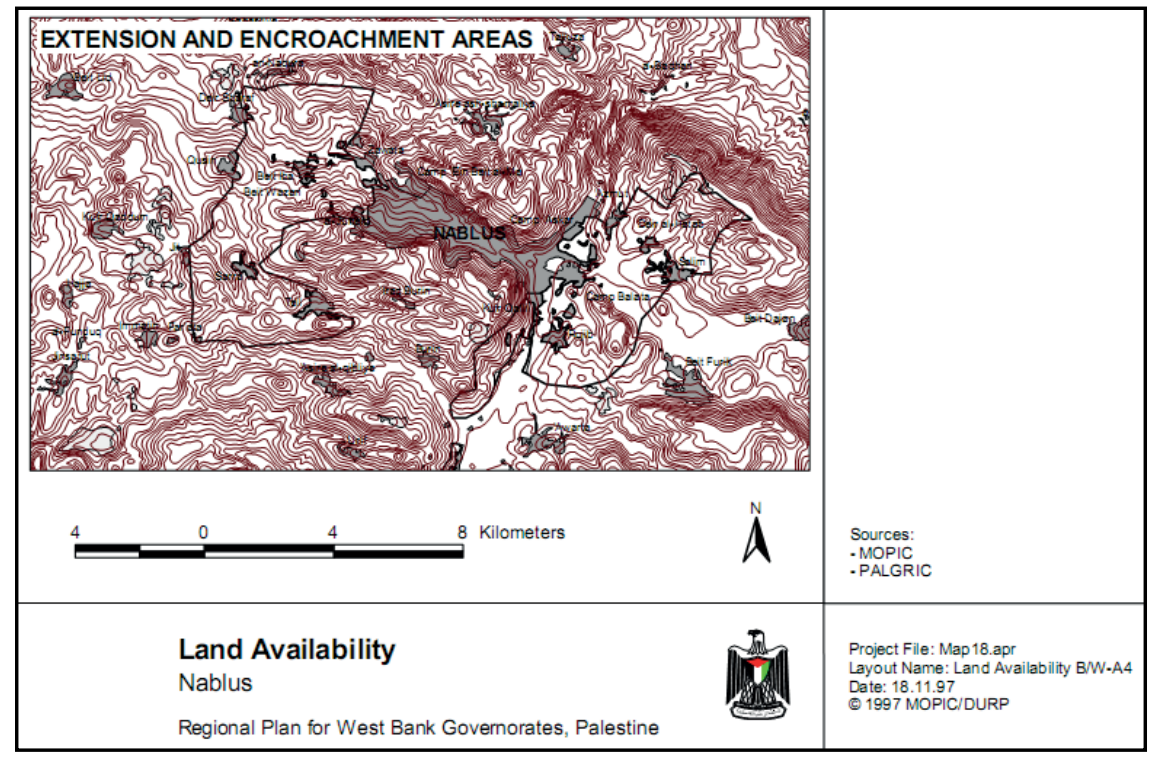

Figure 4.7. A PA map of Nablus from 1997 (MOPIC 1998, 55-6). The curved contour lines that form the background of this map would have been digitized directly from the contour lines in the 1937 1:50,000 series of British colonial maps-precisely the same series as the map in Figure 4.52. At the time this represented the finest level of detail available to the PA. (Interview 6, former PPIB cartographer)

thereby resulting in broader, largely symbolic, maps. The effects were felt particularly strongly during the early 1995-2008 period, although the process has continued in a modified fashion after 2008. The enduring stasis of British data when compared to that of PA cartographers not only shaped the PA staff's work to build stasis for Palestinian institutions and forms of knowledge, they also affected the stasis and mobility of PA maps themselves.

On the one hand, the PPIB maps were incorporated into a series of reports which were published, often in color, in multiple languages to assist in their circulation (MOPIC 1998; 1996). On the other hand, however, the fact that they were expected to plan for anticipated political realities-which, in the aftermath of Oslo, were expected to include the handover of Area C by 2005 (MOPIC 1998, 13)meant that the durable, confident proclamations the reports contained were often obsolete due to political considerations before the reports themselves were even printed. This made the reports less useful, and less likely to be preserved in the long term. The complete absence of a national Palestinian library, commonly part of an established state, means that there is not yet any institution to collect these publications for longer preservation to ensure their long-term stasis, nor to send them overseas to ensure that they are represented among international libraries' collections. Rather, documents are carefully preserved in PA offices such as the MOP and the local ministry in Hebron, NGO offices such as the Applied Research Institute 
Jerusalem (ARIJ) and the Arab Studies Society, and personal files of academics at universities such as Birzeit, Al-Quds, and An-Najah. Their very dispersal among a variety of largely local offices both means that one particular confiscation, whether of an office or a home, is less likely to wipe out all of the PA publications, but it also means that their stasis is partial as it is often determined at an individual or organizational level.

The commodification of data certainly plays a role as well in limiting the stasis of PA maps. Given the large amount of time and expertise which are required to produce datasets, even those adapted more or less directly from British maps, geographic data is incredibly expensive. And in an area where the economy, the mobility of goods and labor are highly restricted by the Occupation authorities, valuable commodities are well-guarded. Palestinian industry and private corporations largely began to develop in earnest only after the initial development of the PA (Spinner 2012), and they did so in the context of a large influx of foreign aid, which was input largely into NGOs and state-building projects like the PPIB.

Although foreign aid helped to set up the foundations for capitalist investment, for better or worse, the higher salaries and operational budgets of the NGOs have raised the salary structure for professionals overall, making things more difficult for new companies, and therefore creating an economic landscape which favors the (often, but certainly not always, international) NGOs. The dampened private economy, therefore, results in a situation where NGOs and state endeavors are among the few producers or 'factories' of economic value, often in the form of data or other knowledge products. This combined with the at times uneven flow of international aid, due to political factors, means that data is safely guarded against future uncertainty-uncertainty which is in part an intended result of Occupation policies (Handel 2011). ${ }^{90}$ But the hording of data reduces the number of maps that are made, and makes the data more vulnerable to being misplaced, unused, or deleted, while also limiting the number of users. This also lowers the level of stasis for cartographic data in Palestine overall.

The reliance on British Mandate data, combined with the stasis and mobility of PPIB cartographers, also has affected the PPIB maps' mobility. One of the recurring issues which came up in interviews was the absence of reliable data sharing between PA ministries and Palestinian NGOs. While certain memorandums of under-

${ }^{90}$ For a fuller account of the impact of uncertainty upon specific visualizations and digital models, see Moody, Kouw, and Bekkers $(2013,89)$. 


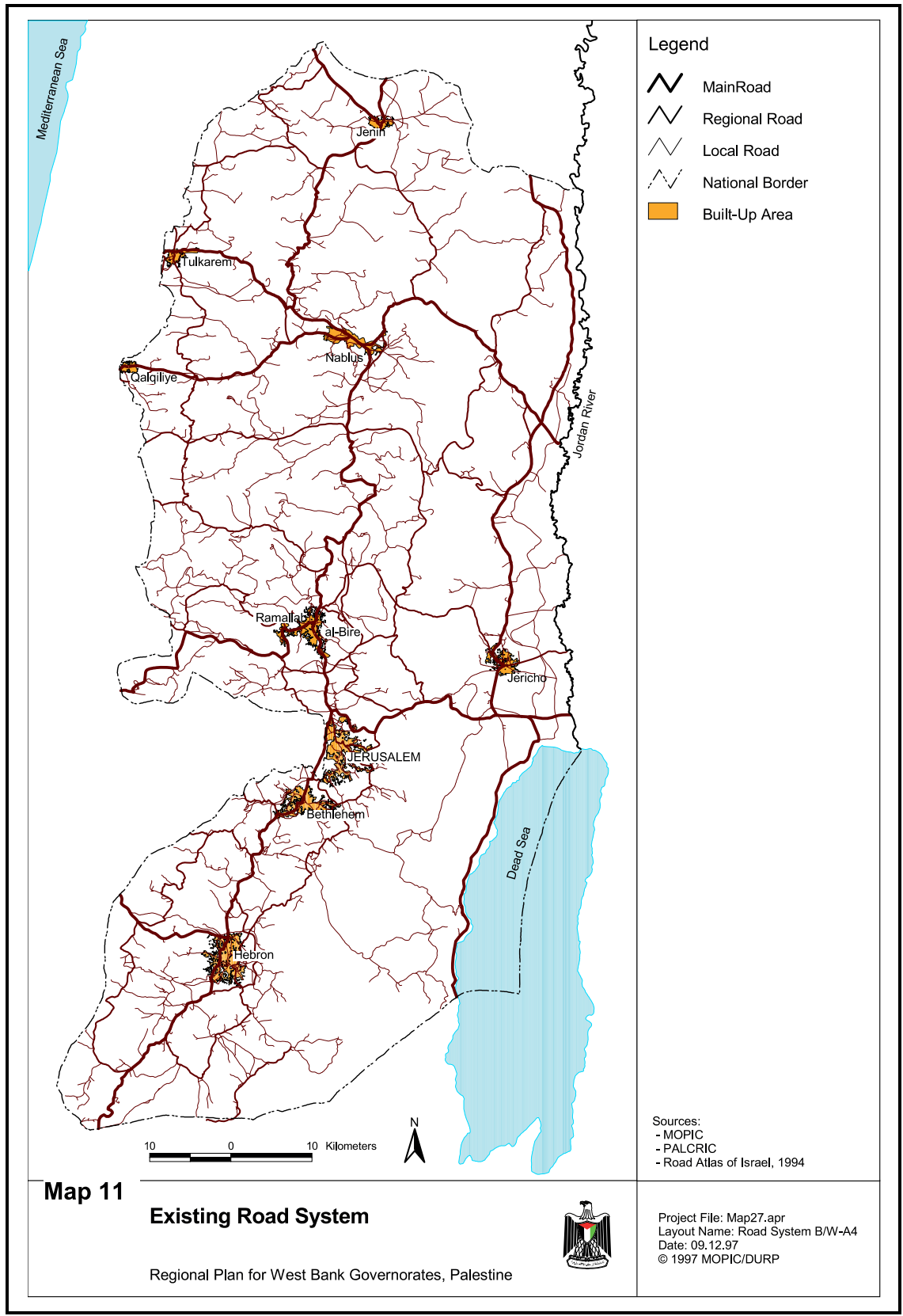

Figure 4.8. A PA map of major roads in the full West Bank from 1997(MOPIC 1998, 85-7). Although this map is based largely on data that originally came from British colonial maps, the information has been updated. However, the updates only appear for major cities in Area A, whereas inhabited areas in Areas B and $\mathrm{C}$ are not indicated, a result of the difficulties in conducting ground surveys due to the Occupation. (Interview 6, former PPIB cartographer) 

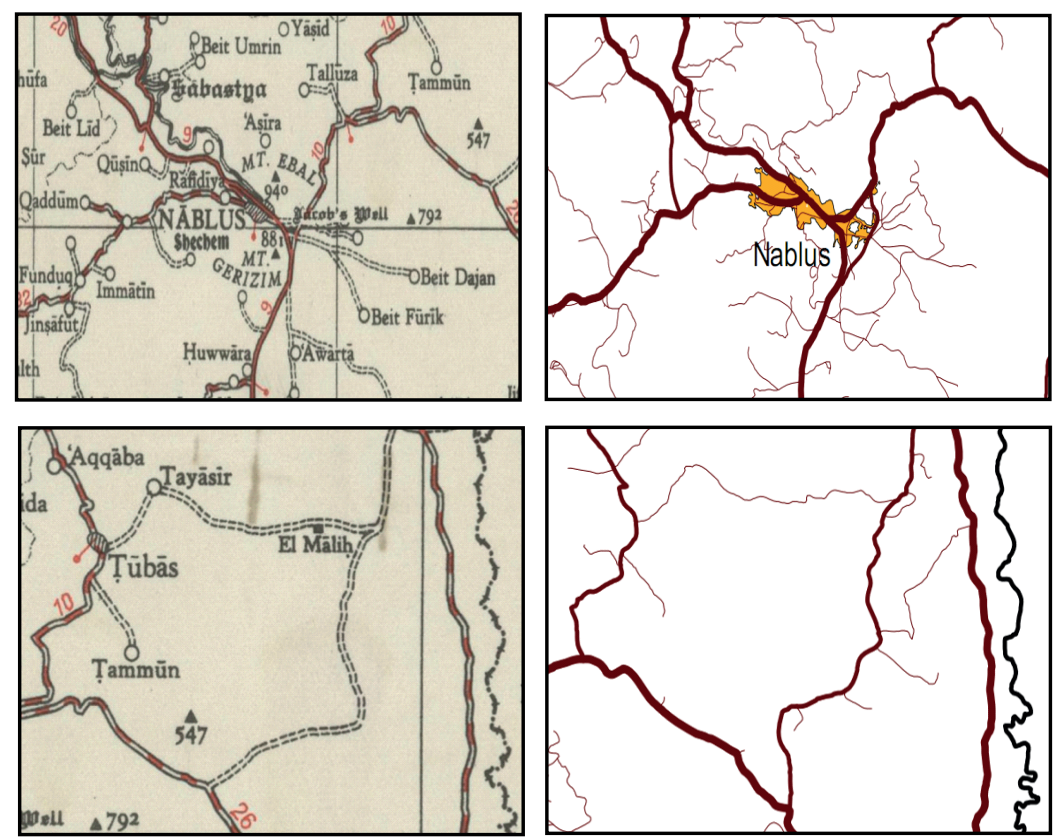

Figures 4.91 and 4.92. Figure 4.91 (left, top and bottom) consists of two details of Nablus from a 1940 British Road Map made by the Survey of Palestine (SOP 1941)

Figure 4.92 (right, top and bottom) provides two details of Nablus from the 1998 PA Road Map in Figure 4.8. The lines indicating roads follow nearly identical courses in the PA map details as they do in the corresponding British map details. Because Nablus is a major city, parts of the 1998 map that depict Area A have been updated (top right), including the orange shaded region indicating the extent of the built up area. In addition, several major roads constructed by the Israelis for settler use have been added. Otherwise the Palestinian and British data are nearly identical.

In rural areas in Area C, such as those east of Tubas which lies just outside Nablus (bottom right), these early PA maps contain only the most minor updates from British data, despite the PA cartographers' best efforts. In contrast to the areas that became Israel, many of the smaller towns in the West Bank, which are indicated on the British maps at left, do still exist and indeed have grown considerably. Although the towns do not happen to be indicated in these particular images, they do appear on other PA maps. In contrast, the map of Nablus in Google Maps (not shown) shows an entirely different set of roads.

standing had been written and some data was widely shared for specific purposes, at least among PA ministries, the absence of a clearly defined hierarchy as well as competition among the PA and NGOs, in combination with data's status as a valuable commodity, all served to restrict the unpaid exchange of data among different organizations. The PPIB itself was intended to collect geographic data from NGOs rather than to create it themselves, I was told (Interview 6, former PPIB cartographer), but the unwillingness of others to share the data that had already been produced was one of the inspirations that lead them to embark on such an extensive digitization process (Interview 6, former PPIB cartographer; Tesli 2008). This is not 
solely to criticize the cartographers who are concerned primarily with the stasis of their own institutions in extreme circumstances where their stability is regularly in question; rather, it is to delineate the ways that the Occupation, in part through the its control over ever-changing regimes of mobility and stasis which so affect cartographers daily lives, feeds into restrictions on data sharing more broadly.

\section{Passages of Palestinian Authority Data}

PPIB cartography was formed in landscapes which already had defined passagesstable but "never fixed" pathways of least resistance (Peters, Kloppenburg, and Wyatt 2010, 354-55) - for both the stasis and mobility of data. British maps were preserved, and thus digitizing them represented the easiest or most obvious passage for the PPIB cartographers to follow. In order to build a national cartographic infrastructure, the PPIB cartographers, both Palestinian and international, had to redirect existing passages in order to build new forms of mobility and stasis for Palestinian cartographers with the aim of increasing their control over their own maps. The need to which redirecting existing pathways serve to influence the outcome of geographic knowledge production is acknowledged in the summary report of the PPIB, where the author (Tesli 2008) acknowledged the difficulties of producing new or alternative forms of data when the very fact of a Palestinian governing body making its own maps, in the late 1990s, was unique. Their ability to produce reliable maps despite the uncertainties, especially during the Second Intifada, when political conditions repeatedly were invoked to account for lost time (Tesli 2008), is in part a testament to the extent to which PA cartographers have been able to collect and piece together British data, finding ways to preserve their collections despite repeated raids. As such it demonstrates the theoretical innovation, with respect to passages of mobility and stasis, that is involved in the material reconfigurations that are necessary to make their maps. This innovation requires taking seriously their motives as well as the produced material realities in which they work.

To some extent, then, the PA was successful in developing new passages for knowledge in the West Bank. However, the very limits on Palestinian cartographers' mobility and stasis which lead them to rely heavily on colonial maps nonetheless have also restricted their ability to control the very scale and extent of the maps which they have produced. The effects of the Occupation, such that even PA government officials must be careful when collecting data in the field, served to reinforce the presence of British Mandate maps, and the apparent seamlessness of PPIB maps (such as Figures 4.7, 4.8, 4.91, and 4.92) belie the very complexity of the area under their jurisdictions in which they are produced. This was partly the outcome of the difficult period of the second intifada, and the methods for surveillance and control that emerged in the context of the Israeli Occupation. However it is still in effect in recent periods, which are at times-though not always-more stable on the ground. 
Currently the differences between Areas A, B, and C are more pronounced than ever in terms of the geographic knowledges which are produced. The very certainty of pinpointing exact locations was founded on practical expertise developed towards increasing the PA's institutional stasis, by working through political uncertainties, military attacks, checkpoints, and confiscations. If nothing else, by springboarding off of the stasis of the British data, PPIB cartographers have pushed the landscape one step further towards accommodating passages which allow for greater Palestinian control over knowledge production in ways that are more ontologically and epistemologically diverse. However, even as these passages are formed, their course is influenced by the very prevalence of the colonial knowledges that they seek to overcome. 



\section{Chapter 5}

\section{Validating Segregated Observers: Mapping West Bank Settlements from without and within}

\section{On the Appropriation of Empirical Facts}

In October 2006, the Israeli organization Peace Now published a report entitled Breaking the Law: One Violation Leads to Another. The report consisted of an examination of Israeli settlements in the occupied West Bank. Through maps of land ownership, Dror Etkes and Hagit Ofran aimed to demonstrate that upwards of 30\% of the settlements were held on land that would be considered stolen-even according to the regulations of the Israeli government. The report thus was incriminating for the settlement project, as it appeared to counter assertions that the Israeli West Bank settlements had been built in areas that were either unoccupied or owned by the state.

Although the Israeli press were chastised (Benziman 2006) for downplaying the implications of the findings-allegedly in the hopes of burying them-the internet lit up with commentators who alternately praised and lambasted the report. The intensity of the response only increased once an updated report was issued in March 2007. "Peace Now's Blunder: Erred on Ma'ale Adumim Land by 15,900 Percent" was the headline of one critical reply (Safian 2007), made in response to changes in the Peace Now data between the two versions. ${ }^{91}$ Yet, rather than indicating a retraction of their previous claims, the changes that Peace Now made in the

\footnotetext{
${ }^{91}$ Such assertions of error were widely reported on pro-settlement websites and even filtered, without citation, into a handbook for the Israel lobby in the US (International Business Publications 2011, 1:32). Also, this doesn't even begin to include those who argue solely using Biblical sources for land ownership, e.g. ("Who's [sic] Land Is It Anyway?" n.d.).
} 
updated report instead reflected newly available information. The data for the 2006 report came from a source inside the government, who anonymously leaked it to Peace Now (Chadwick 2006). However, a few months after publication, the Israeli government released an official dataset to Peace Now, in response to their numerous Freedom of Information Act requests. That revised official data was the source for the new March 2007 report. ${ }^{92}$ For their part, the Israeli government issued no explanation as to why the new data differed from the previous set.

The changes between the two versions of the reports provide a cogent illustration of the unique position of Israeli non-governmental organizations (NGOs) in the landscapes of Palestine and Israel. Overall, Peace Now is privileged in terms of being able to enter Israeli government offices to submit formal requests for government data, like that contained in the report, which would otherwise remain classified. However, their use of the official sources also means that Peace Now is vulnerable to the government's ability to control and change that data.

Peace Now's position contrasts sharply with that of a related Palestinian organization, the Applied Research Institute, Jerusalem (ARIJ). While Peace Now was critiqued in the context of its access to official data, ARIJ has been criticized precisely for conducting observations in Palestinian areas, where Jewish Israelis are not legally allowed to go. Such a critique is evident in the response to an online ARIJ report entitled Ecocide in [Taqu'a] Town, which built upon an earlier ARIJ report (2004a; 2004b). ${ }^{93}$ The updated report states that "the Israeli Army randomly dispensed flyers on the farmers' lands informing [them] of the Army's intention to clear all trees (mostly olive) existing along the Israeli bypass roads." In one response, Zev Wolfson of NGO Monitor (2005) claims to disprove the ARIJ report using methods of direct observation. Wolfson notes: "a visit to the area demonstrates that no trees have been uprooted from the area around Taqu'a."

In making this assertion, however, Wolfson neglects the differing access that the (Israeli and international) NGO Monitor reporters would have when compared with ARIJ's (primarily Palestinian) observers. ${ }^{94}$ NGO Monitor's efforts to view the area from the Israeli road, which would be partially or fully restricted to Palestinians, would differ from the view of ARIJ's workers from Palestinian farmers' fields

\footnotetext{
${ }^{92}$ Mathematically, $86.4 \%$ and $0.54 \%$ are already percentages, so it would be common to simply use the error rather than the percent error. To find the error, one would simply subtract: $86.4 \%-0.54 \%=$ $85.86 \%$ (error). Instead, the author determines the percent error: $(86.4 \%-0.54 \%) / 0.54 \% * 100=$ $15,900 \%$ (percent error). Although both are technically correct, in comparison with $85.86 \%$, the figure $15,900 \%$ has a far more dramatic rhetorical effect.

93 In Arabic, Taqu'a is written تقوع. Tekoa, a nearby Israeli settlement, is the Hebrew version of the same name, and is written תקוע. When transliterated, the name may be spelled several different ways, including Tequ' and Tuqua, among others.

94 Wolfson also omits to mention one key detail of the ARIJ report: the report asserts that the military said it would begin clearing the trees, not that it had already done so.
} 
(Figure 5.21). Thus, Wolfson would find it particularly challenging to address ARIJ's claim, elsewhere in the same report (2004a), that fields were burned and farmers chased away in areas-out of sight of the road-which might be largely inaccessible to Israeli settlers and their supporters. ${ }^{95}$ Furthermore, even if the NGO Monitor staff were able to visit all of the areas mentioned in the ARIJ report, it is quite possible that they might see different things based on the varying forms of information at their disposal. ARIJ maintains extensive contacts locally, and would be able to draw on eyewitness accounts unavailable to NGO Monitor staff in the context of the Israeli Occupation.

\section{Where Are the Settlements Now?}

The Peace Now and ARIJ reports are examples of the multifaceted ways that landscapes can affect the very constitution of knowledge. In order to further investigate how differing geographic positions might shape the production of facts, this chapter compares and contrasts the maps of Israeli settlement expansion that are produced by these two organizations. Israeli settlement expansion is a timely issue where empirical facts are hotly contested. Israeli towns in the West Bank are considered illegal under international law. They have been constructed precisely to cement the hold of the Israeli government on areas that are believed to be destined for a future Palestinian state. However, to date there is little agreement as to the extent and location of these settlements. Rather than using facts to support political arguments, actors often argue over the intrinsic composition of the facts themselves. ${ }^{96}$ Yet calls to confirm facts through observation rarely lead to consensus.

The challenges of validating observations in the context of the Occupation stem not only from open disagreements, but also from the ways that facts are firmly, and often oppositionally, rooted in social worlds borne out of experience (Radder 2006). The advancement of the settler movements, and the resistance which results, has led the Occupation administration to impose extreme forms of segrega-

\footnotetext{
95 Equally interesting, the moment when NGO monitor strayed from such allegedly impartial empirical criticisms was the precise moment when they broke Israeli libel laws. In 2007, after claiming that ARIJ 'emphasize external issues including the justification of violence', ARIJ and several partner NGOs sued NGO Monitor for libel in Israeli courts and won, forcing Professor Gerald Steinberg, the executive director of NGO Monitor, to issue an apology (Silverstein 2010).

96 The debates over facts spill over into social media in ways that can be surprisingly self-referential. This can be seen in the following quote from the Wikipedia page for NGO Monitor ("NGO Monitor" 2013): "According to Ha'aretz, Arnie Draiman, a social-media employee of NGO Monitor, edited under the username Soosim, Wikipedia articles related to the Israeli-Palestinian conflict and was subsequently topic-banned for a conflict of interest. The editor in question is reported to have promoted the company's agenda in his editing, particularly with regard to NGO monitor's Wikipedia page." These assertions were present only in the English version of the site. They were entirely absent from the Hebrew version of the same page.
} 
tion in the West Bank. Jewish Israelis are formally allowed only within the settlements, whereas most Palestinians with West Bank visas can only travel within Palestinian areas that lie outside the settlement fences and walls. Such segregation fosters diverging sets of experiences among Palestinians, Israelis, and internationals. It can result in sometimes widely differing observations of places and events, even when they occupy spaces that are allegedly the same. ${ }^{97}$ Segregation therefore has complex consequences in terms of shaping empirical knowledge of the Occupation, consequences which I explore in this chapter.

\section{A View of Har Homa, The View from Har Homa}

ARIJ and Peace Now's positions within the landscapes of the West Bank reflect power imbalances between Palestinians and Israelis internationally. In contrast to the wider reception of Israeli accounts, until recently, Palestinian perspectives were not widely represented in Europe and North America. Even on the occasions when Palestinian intellectuals and activists discussed the conflict with a (non-Arabicspeaking) international audience, their experiences were often downplayed in part because they didn't fit the dominant conception of what a voice would need to be in order to be considered credible (Spivak 1999; 1988).

Lori Allen has noted that "the problem of how to make themselves audible and visible has been a central stumbling block" for Palestinians, citing how, in the middle $20^{\text {th }}$ century, "Palestinians were without any territory or institutional platform to express their national aspirations" $(2013,35) .{ }^{98}$ This political and geographical context made "establishing the credibility of the testimony takers just as important as that of the testimony" (Allen 2013, 50). This has additional implications in terms of eyewitness accounts of the Occupation. Because the Occupation by definition affects 'only' Palestinians, those who relate experiences of Occupation internationally must risk speaking a private language (Wittgenstein 2001). As a result, Palestinian advocates must not only produce facts, but they also must develop a community of Palestinian observers, whose accounts are verifiable within the community, as part of a legitimizing process to help convince international observers.

The power imbalances between Palestinians and Israelis more broadly also conditions the reception of scholarly research, both locally and internationally. For example, Moshe Brawer, one of the founders of geography as a discipline in Israel, draws on Orientalist stereotypes of inconsistent, irrational Palestinians (Elia 2005; 2004) in his review of the edited atlas by Walid Khalidi (1992), an equally esteemed

\footnotetext{
97 For an example of a Palestinian journey which would be manifestly different for non-Palestinian Israelis or internationals, see Yousef (2011). On the effects of segregation among Palestinians from different areas, see for example, Ghussein and Robbins (2013).

${ }^{98}$ See also Jordan (2002) on the difficulties of advocating a positive image for Palestinians internationally, particularly in the US.
} 
Palestinian geographer working in the UK. ${ }^{99}$ Brawer (1994) criticizes Khalidi's fieldwork methods in particular, noting that it: "leaves so much to be desired-in systematic and consistent description of geographical features, in accuracy, and in scholarly observations" (1994, 337-38). ${ }^{100}$ What Brawer does not mention when questioning the scholarly character of Khalidi's work, however, is how Khalidi's position as a Palestinian academic might lead to challenges in his access to sources and field sites-and thus to potential difficulties conducting the types of extensive, standardized observations that Brawer expects. ${ }^{101}$

Such portrayals also affect research completed in government or NGO capacities. Reacting to negative characterizations of their work, one cartographer in a Palestinian NGO related that:

The first thing when you go to conferences is, what's your sources? [....] In the early days, it was all about emotions [.... but soon enough they ask you, 'What's your source?' [.... In the early days, we'd say, 'What source? I'm telling you,' and they would go, 'It's your word against theirs. What facts do you have?' (Interview 11, Palestinian NG0 cartographer)

His words point to a two-fold labor on the part of Palestinian organizations and academics. On the one hand, it is necessary to be recognized as a credible observer, in a political game which depends upon such recognition (Markell 2003). On the other, it is necessary to formulate claims precisely in a way that will be heard-to produce a community capable of putting forward the allegedly objective facts which serve as a metaphorical entrance fee to the debates. ${ }^{102}$

${ }^{99}$ See Davis (2011) on Palestinian village histories, which are often accompanied by village atlases such as Abu Raya (2010) and Abu Sitta (2007). For an example of an online interactive map of destroyed villages, see ACA (n.d.). Contemporary Palestinian atlases include ARIJ (2009a) and PalMap (2011), and Israeli atlases include Carta (2005) and SOI (2009).

100 In the same review, Brawer also criticizes Hadawi and Khalidi in tandem, as does Karsh $(2000,12$, n.6). Brawer himself has investigated the negative impacts of border segregation on Palestinians (Brawer 1990), albeit in a context where the Israeli Occupation was alleged to preventing the segregation that might be introduced as a result of Palestinian self-rule. In practice, however, the Occupation has resulted in far more extreme segregation than might be necessary between two sovereign nations.

${ }^{101}$ Israeli scientists have been relatively more successful in terms of presenting themselves as credible observers-partly as a result of the legitimacy afforded by the state of Israel (see Chapter 3). However, anti-Semitism continues to affect the broader reception of work by Jewish researchers.

102 Discursive power inequalities are inflected throughout legal, economic, (etc.) imbalances. The legal imbalances are especially apparent: Even though all West Bank inhabitants are officially under military law, in practice this only affects Palestinians. Instead, the more lenient civilian law is routinely applied to Jewish residents (MCW 2013). 
Throughout its history, ARIJ ${ }^{103}$ has worked to establish just such a community. Initially started as an environmental group to further sustainable development methods for Palestinian agriculture, in time, ARIJ has become a major producer of civil maps of the Territories both for local use and to participate in international debates. Founded in Jerusalem in 1990, ARIJ predates the founding of the PA, and so it was one of the first organizations in the Territories to begin making digital maps using Geographic Information Science (GIS) software.

ARIJ has been headed since its inception by Jad Isaac, a Bethlehem native who holds a Ph.D. in Agriculture from East Anglia University. Currently, ARIJ includes over 50 employees, with the Geo-Informatics Department (the primary GIS unit), and the Urbanization Monitoring Departments (which includes settlement monitoring) together employing 10-12 of those staff. Funded in part by international donors, including the European Union, ARIJ nonetheless primarily employs Palestinian cartographers from a variety of backgrounds, mostly from the West Bank, but also East Jerusalem, as well as a revolving group of international fieldworkers, like myself. 104

As an organization which combines nonviolent nationalism and empirical methods, Peace Now functions as an Israeli counterpart to ARIJ. A pro-peace Zionist organization. Peace Now emerged as a mass movement in 1982, when Israel invaded Lebanon with the aim of expelling the Palestinian Liberation Organization (PLO), which was then stationed there. After the largely nonviolent First Intifada began in 1987, Peace Now came out in favor of negotiations, and they were active supporters of the 1993 Oslo Accords. Their support was challenged during the Second Intifada, when violence escalated, yet they continue to support an end to the Occupation as a strategy both to enable a viable Palestinian state while, in their view, strengthening Israel.

Currently, headquartered in West Jerusalem with about twelve employees, Peace Now is one of the largest and most well-known Israeli peace organizations. Together with its US sister organization, Americans for Peace Now, Peace Now's advocates have undertaken one of the longest lasting and most expansive settlement mapping projects. Their work builds upon earlier geographic surveys of the West Bank by Israeli NGOs, such as that conducted by Meron Benvenisti in the 1980s (Benvenisti and Khayat 1988). Begun in 2002 by Dror Etkes, since 2007 the Settlement Watch division, the main cartographic arm of the organization, has been taken over by Hagit Ofran. It was with Ofran that I first entered a West Bank settle-

\footnotetext{
103 ARIJ's Arabic name is Ma'ahad al-Abhath al-Tatbiqiyat al-Quds (Areej). Peace Now's Hebrew name is Shalom Achshav. For both organizations, the English names are direct translations.

104 This chapter is the result of five months of participant-observation in the GIS Unit at ARIJ in the spring of 2011, as well as extensive interviews and participant-observation, during that same period, at Peace Now. Please see Chapter 1 for a more extensive elaboration of my methodology.
} 
ment, and I was dumbstruck by the sheer suburban banality of what, to that point, I had only seen from the other side of the electrified fences and desiccated fields.

\section{The Power of Observation}

Latour has described how digital cartographic technology breaks down the assumed divide between the material world and the map, by bringing the map outside on devices and through GPS while simultaneously bringing data traces into the lab (November, Camacho-Hübner, and Latour 2010, 585-87). In this chapter, I build upon this insight to analyze how produced material dichotomies, such as the division between Palestinian and Israeli areas in the West Bank, can nonetheless be built back into the map. ${ }^{105}$ In what follows, I first explore feminist Standpoint Theory, through the concept of triangulation, whereby a particular observation is made three times, from differing positions in the landscape, as a means of finding one 'true' value. Second, I turn to the settlements, to analyze how ARIJ's position without, and Peace Now's within, Israeli areas in the West Bank, in turn affect each NGO's resulting maps. Hagit Ofran travels regularly on fact-finding trips within the settlements, and this, combined with her increased access to data within Israel, affects the maps which she produces for Peace Now. However, this positioning also has nuanced effects, particularly in terms of the display of Israeli military bases, and related changes in settlement boundaries, which I explore through four maps of the settlement industrial area Mishor Adumim.

Third, I turn to an analysis of Palestinian communities in the West Bank, in order to investigate how ARIJ's position within, and Peace Now's position without, Palestinian areas differently impacts the cartographic methods that they use. In order to get at the complexity of the power imbalances between the two organizations, I analyze ARIJ's Land Use/Land Cover (LULC) cartography, which seeks to rectify the blank Palestinian areas on many maps of the West Bank. I demonstrate how ARIJ cartographers' ability to adapt international LULC classification systems to fit the areas around them in fact depends upon their everyday experiences in Palestinian landscapes. Furthermore, through a network of Palestinian observers in both the West Bank and Gaza Strip, ARIJ has early knowledge of the military orders for land confiscation which are distributed to Palestinian farmers. In contrast, Peace Now fieldworkers' maps of Palestinian areas are far less detailed than those at ARIJ, and their position viewing Palestinian areas from without in fact divorces

105 Even when power imbalances are less significant, different methods of observation can lead to varying results, as seen in the controversy over whether Mount McKinley, in Alaska, had shrunk-a dispute which stemmed in part from differences in average height measurements taken by plane, and point measurements attained by scaling McKinley's highest peak (Vergano 2013). However, differences in measurement methods cannot be separated from the broader contexts in which those methods are used. 
them from communities of cartographers, like those at ARIJ, that might otherwise be potentially supportive of Peace Now's work.

\section{Triangulating Standpoints: Paradigms are Made in Landscapes}

Observations of landscapes are themselves made in landscapes. This point is not lost on applied cartographic surveyors. So it is with some irony that triangulation, once the dominant scientific method for surveying and mapping landscapes, has since been claimed by feminist epistemologies of science in a way that omits much of its geographic influence. In cartography, triangulation was traditionally the method of choice for finding the location and elevation for a specific point on the landscape. In short, triangulation is a way of viewing other points in the landscape specifically in order to gain a better understanding of one's own position. To triangulate a point whose exact coordinates are unknown, a surveyor stands on that point and looks through a leveling instrument, similar to a small telescope affixed to a tripod, and which can measure angles, to find other known points in the landscape. At each point, the instrument gives a reading in the form of angles between the current unknown point and the known point being viewed through the instrument. Once two known points have been sighted in turn through the instrument, the surveyor can combine the readings from each point with their known coordinates in order to calculate the coordinates of that unknown point where she or he is standing. 106

Triangulation also has colonial roots, and its use by the British in historic Palestine is one of the main reasons why British colonial maps of the region are considered so effective (Gavish 2005). Timothy Mitchell's observation regarding 19thcentury British triangulation efforts in Egypt-that the production of the nation was predicated on a forced separation between the land and the map-would equally apply to their work in Palestine (see Figures 5.11 and 5.12). Mitchell notes:

The survey began by establishing coordinates not within the village but across the entire country [...] The nation was emerging as this space, this material/structural extension, within which villages, persons, liabilities and exchanges could be organized and contained [....] The connections, linkages, commands, and flows of information that made up this political order [...] appeared to arise in the space of separation between the land and the map. $(2002,90)$

106 GPS devices also find their own location through a form of triangulation. The GPS searches for four satellites whose 'absolute' coordinates in space are known because they have regular orbits. The GPS then calculates the observed angle between the satellite and their known location, which, in combination with the satellite's known position, allows the device to automatically 'find' its current coordinates. 
So in the early and middle 20th century, first the British and then the Israelis attempted to make a nation out of Israel and Palestine by imposing a separation between the land and the map. This contrasts with the post-1967 Israeli settlement project, which has demonstrated that land and map are fully entangled, now more than ever. So it is perhaps not surprising that the notion of triangulation, which seeks to abstract a particular view within a landscape to an abstract network, has been adopted by social scientists writing on Palestine and Israel who seek to demonstrate the intimate connections between abstraction and material positioning. For example, Michael Fischer draws on these implications of triangulation when he argues for "two-eyed" narratives which draw equally on Palestinian and Israeli accounts; he also thereby draws a structural parallel between symmetry, as discussed in Chapter 2, and observation (2006).
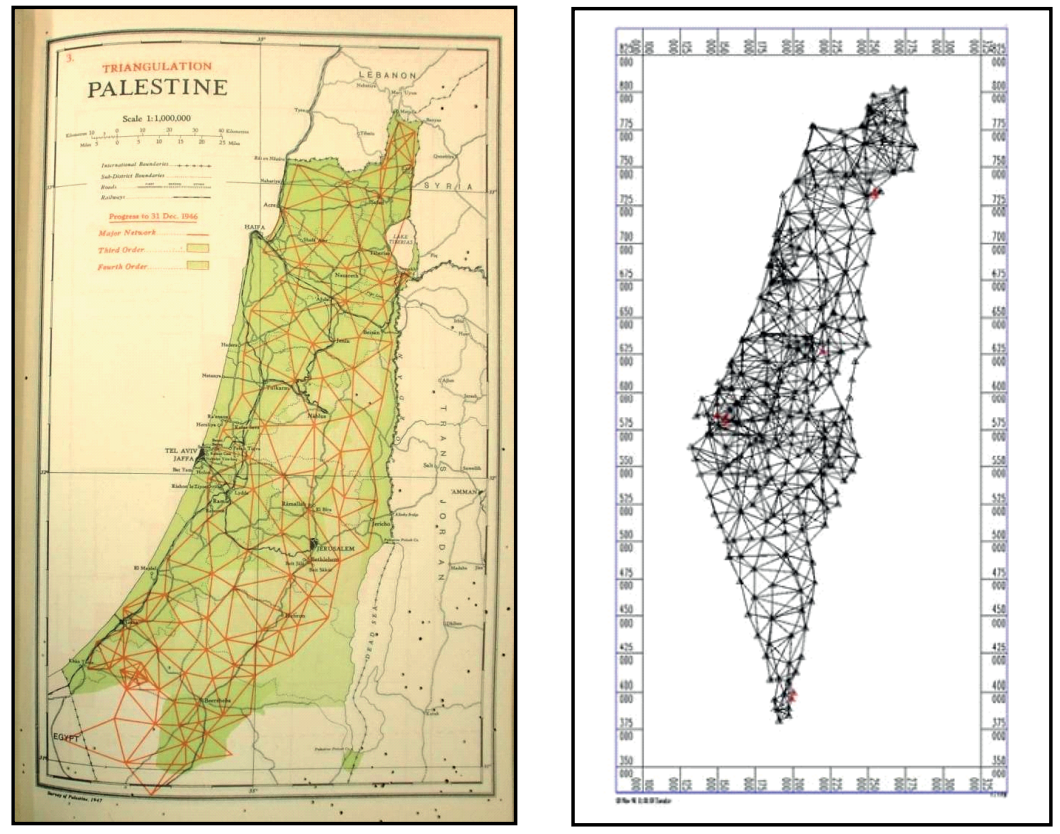

Figures 5.11 and 5.12. Figure 5.11 (left) is a map of the British triangulation network in historic Palestine in the late 1940s (SOP 1948). Figure 5.12 (right) is a map of the Israeli triangulation network as of 2009 (Srebro 2009, 4).

Every point where the orange lines intersect is a point in the network and would be temporarily marked on the ground using flags, beacons, stone towers, or simply by having someone stand in that location. An observer would visit each point in turn, using a surveying instrument to view and measure the markers at 2-3 of the other nearby points in the network. Calculations, based on the measurements from those observations, allowed them to pinpoint the location of every point in terms of latitude and longitude, and therefore to connect the dots to plot and map the overall territory. 
The metaphorical aspects of triangulation have not escaped social theory more broadly, where it has become used in quite a different sense. In feminist studies of science, and contemporary social sciences more generally, triangulation refers, alternately, to the practice of combining several methods of observing, usually qualitative and quantitative approaches, in ways that complement each other (L. Harvey and MacDonald 1993; Webb et al. 1966), and to combining different data types and sources (Denzin 1977; 1970). Scholars such as Harding (2008; 1998) have worked to triangulate different perspectives on science, thereby combining several points of view, particularly from traditionally marginalized groups. Greg Smith has explored (2006) how the sociologist Erving Goffman, for example, advocated a combination of "naturalistic observation" and interviewing. Goffman claimed that, in conducting fieldwork, he tried "to triangulate what people are saying with events" that he observed (cf. G. W. H. Smith 2006, 115).

Triangulation also reintroduces perspectival geographic concerns to conceptions of the local to cases where they have perhaps been prematurely expunged. Thus, Mike Lynch defines the local as a term that "has little to do with subjectivity, perspectival viewpoints, particular interests, or small acts in restricted place. Instead, it refers to the heterogeneous grammars of activity through which familiar social objects are constituted" (Lynch 1993, 125). However, the identification of the local with particularized knowledge, which Lynch aptly notes, cannot be disavowed so easily. In contrast to a conception of the local, which eschews its association with particularism, critical geographers assert that, like science, the local scale is also produced (Marston 2000; N. Smith 1992) through practices which are spatial as well as social. So ethnographic studies of "small acts" and "perspectival viewpoints" such as triangulation-and particularly, of how they come to constitute the localare also an important element of the study of scientific practice.

\section{Triangulating Standpoint Theories}

While perspectives such as those of Goffman and Lynch are certainly useful in specific cases, they could benefit from more concerted attention to research which draws attention to the links between observation and control, and specifically in terms of masculine "mastery" over feminized land (G. Rose 1992). To better understand how such links persist, triangulation would better be conceived of as an ongoing, performative, and relational act-namely, one characterized by how relationships between observers at different places in a landscape serve to reconfigure the very act of observation and the inscriptions of observation which result (Latour 1986). This has been dealt with most extensively in standpoint theory, a body of research which attempts to rework the values of Western science such that it takes greater account of the way that a scientist's social history and identity inform the way that she or he practices science (Harding 1998). Standpoint theory has been quite controversial since its inception, attacked on the one hand during the 'science wars' for being too radical in its reconfiguration, and on the other for being too 
Western, too essentialist, for backhandedly upholding dominant scientific methodology (Harding 2006, 92-93; 2004a).

Nonetheless, two contributions of standpoint theory have been too easily dismissed or overlooked. First, it provides a pragmatic method for democratizing science for those concerned with incorporating textured conceptions of identity, in relation to structural inequality, into the heart of scientific practice. Second, and most relevant here, standpoint theorists rightly focus upon the role of subject formation in the study of scientific practice-namely, they actively reconceptualize the link between the points of view among different social groups at a variety of scales and of scientists as individuals, as scientific subjects, themselves. They therefore draw attention to the interactions, including triangulations, among arenas of knowledge production across multiple scales. Standpoint theory thereby cultivates a healthy respect for the, at times unpredictable and unexpected, ways that alterity contributes to the practice of science.

This chapter, however, while it borrows from the work of Sandra Harding (2008; 2006; 2004b; 1998), as well as from Donna Haraway's conception of situated knowledge (1988), is nonetheless something of an inversion of the main goals of standpoint theory. For where standpoint theorists seek to involve individuals from social standpoints across power imbalances into the production of science, here I aim to investigate how a particular standpoint is produced through the practice of science, and therefore how this standpoint is co-constitutive with scientific practice. Furthermore, while Harding ends by reaffirming strong objectivity, or an objectivity which incorporates social and political values into the heart of its practice, in contrast, I delineate objectivity as a practice with a unique historical and geographic position of its own (Daston and Galison 2007). By comparing and contrasting ARIJ and Peace Now, I also thereby intrinsically triangulate into the analysis my own positioning as an international observer able to collect both sets of data, and whose own presence serves as an intervention (though not necessarily a positive one) in the landscape. This chapter as a whole consists of a form of triangulation, albeit one whose three perspectives neither consistently overlap nor diverge, and these differences are precisely the subject of the analysis. Through the use of triangulation, I therefore move away from the notion of position as a fixed point or set of coordinates, or a reduction of location to position, and move instead towards an understanding of how any single location or subjectivity stands in relation to a variety of landscapes. ${ }^{107}$ With this in mind, I now turn to an analysis of the Israeli

\footnotetext{
107 As van Doorn, Wyatt, and van Zoonen (2008) have pointed out, even if digital technologies do not sever the link between identity and embodiment, nonetheless the relationship between the body and the text, between experience and embodiment, are not always so pre-determined, thereby making them a fruitful subject for analysis in their own right. In its relational understanding of triangulation, my argument therefore can be seen as part of Yuval-Davis's call $(2012,49)$ to better understand "the transitions from positionings to practices, practices to standpoints." Triangulation also parallels shifts in digital cartography from overhead surveys to data collection which indicates perspective. This can be seen in
} 
settlements as sites of geographic research. I specifically analyze how Peace Now's ability to work within the settlements, and ARIJ's position viewing them form without, affect the settlement maps produced by both groups.

\section{Mapping Israeli Settlements: An Atlas of Dirt}

"You see them?" Ofran asks. "Yeah. The dirt mounds?" "I didn't see them before, but now I notice" (Interview 15, Ofran) As she speaks, she accelerates the white SUV we're riding in up the Israeli road outside the Israeli settlement of Tekoa, which lies mid-way between Hebron and Jerusalem in the West Bank, and strategically close to the Palestinian village of Taqu'a discussed at the beginning of this chapter. Ofran had been kind enough to let me tag along as she took an international couple on a field tour into the West Bank. However, it was not only a field tour, for occasionally she stops the car, emerging to take photographs or ask questions.

As we wind our way in and out of the settlement networks, dodging the occasional excavator or dump truck parked alongside the road, Ofran points out the different types and ages of the mounds which the construction equipment have dredged up from the earth. There are a staggering variety, from waste mounds which will be gone in a few days, to dirt piles topped with grass that have likely been there for months or years, to the plateaued hills which are the future sites of settlement apartment blocks, grocery stores, synagogues, and swimming pools. Israeli settlements in the West Bank are built and expanded in developed chunks, multi-story blocks which are imposed upon the land, and thus require excessive reshaping of the terrain before they can be built. Dirt is piled up in some areas, and valleys are carved out in others. Concrete retaining walls are sunk in-between the artificial valleys and plateaus, while roads, like the ones we drove, encircle the newly reshaped hilltops. ${ }^{108}$

The types of ongoing changes which are typical of settlement expansion are too nuanced and rapid to be readable from contemporary aerial photographs without great expense. Updated photographs are too expensive for many NGOs to purchase at a time span that is shorter than several months, if not years, at the scale of the West Bank-a scale which is necessary because the settlements are purposefully

Figures 3.91 and 3.92, which show the transition from the systematic (overhead) progression of the spread of GIS in Israel in the 1990s, towards services such as Google Street View, which allow internet users to view images the landscape at ground level, although the areas covered are also partial, as in the near future Street View is only being made available for the Israeli settlements, and not the Palestinian West Bank.

108 Figure 5.23, a typical photo taken by Peace Now's Settlement Watch on one of Hagit Ofran's regular tours of the West Bank, illustrates the size and extent of the digging into one such hill to the far east of Jerusalem. 
scattered throughout the region. In addition, even in cases where high resolution aerial photos are available, not all features are clearly visible from above. There are numerous ways that particular changes might be interpreted, and for this reason, fieldwork is often regularly included in the process of making a map, even in cases where aerial photos are the primary source for a specific map.

Nonetheless, with the exception of photographs they take from distant hills with high resolution cameras (Interview 9, Palestinian NGO cartographer), Palestinian cartographers must rely on satellite imagery for many of their maps. In 2003, Majed Abu Kubi, who was then working at ARIJ, noted $(2003,71)$ that he turned towards analysis of satellite imagery owing to "the fact that we don't have access to all parts of the West Bank to obtain ground truth points and restrictions on obtaining aerial photos [...] due to security reasons." Such restrictions were particularly evident in the first years of the $21^{\text {st }}$ century, yet they are still very much in effect. Indeed, one cartographer for B'Tselem, an Israeli human rights organization, mentioned the benefit of having a fieldworker suggest updates to his maps, because he works primarily from a computer. Paraphrasing the fieldworker's corrections, he said, "It's not like this. This is here, and this is here, and this is here." Describing the types of updates she wanted him to make, he noted, "She'd say: "This checkpoint doesn't exist. The wall here is built, but you say it is only planned, and there is a road here that I've driven many times, but it's not on your map." (Interview 21, Freelance Israeli NGO cartographer). Fieldwork within settlements is viewed as an essential component of digital cartography in Israeli organizations that make settlement maps (Interview 20, Israeli NGO researcher). Thus, Ofran's travel in the settlements affords a unique opportunity to collect data for Peace Now, which is denied to the researchers at ARIJ.

Through photographs such as Figure 5.23, Ofran has developed an extensive photographic record of settlement construction, and with it a method for distinguishing between the different dirt piles. She travels the settlements often enough to be able to tell which piles are new, which are bigger than before and, occasionally, which have been abandoned. The ability to go to such areas and photograph such views from within is essential to the work of Hagit Ofran and Peace Now more broadly. For when swathes of land are confiscated by the military, both for military purposes and settlement building, once a perimeter goes up, cartographers like Ofran become the only ones who may be able to approach the trailers and construction sites within the new fence.

\section{Settlements from within: Maps without Military Bases}

As an Israeli citizen, Ofran's ability to enter the settlements is part and parcel of her ability to enter Israel. Yet her status as a Jewish citizen of Israel also conveys multiple additional benefits upon her cartographic efforts. The fact that Ofran can travel within Israel is also significant, as it gives her resources which allow Peace Now and other Israeli NGOs to petition the Israeli government for official sources of geo- 


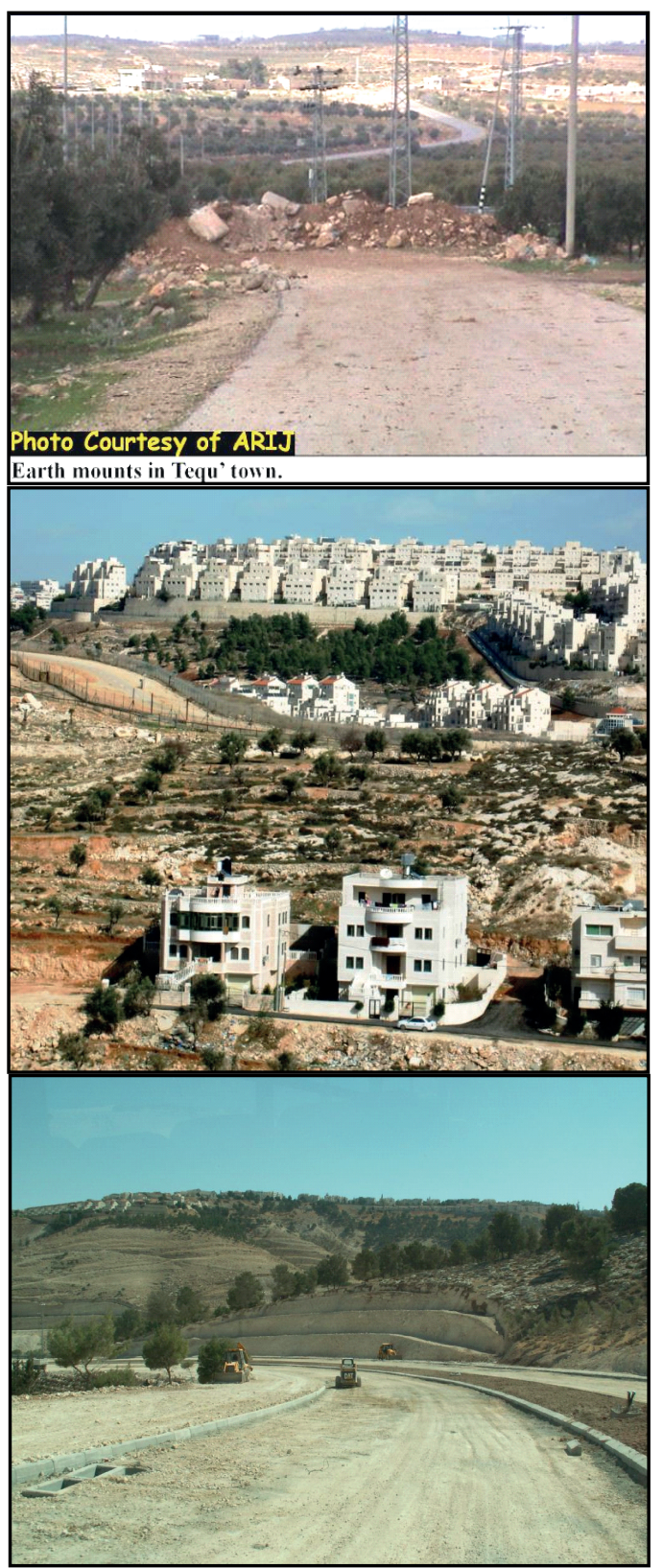

Figures 5.21, 5.22, and 5.23. Figure 5.21 (top) is a photograph taken by an ARIJ field worker which shows an Israeli military roadblock, as seen from within the Palestinian town of Taqu'a (ARIJ 2004a). Figure 5.22 (middle) was taken by the author from the window of the ARIJ offices, and it shows the Israeli settlement of Har Homa (top) from without. Figure 5.23 (bottom) was taken by the Peace Now Settlement Watch, and it shows the E-1 settlement area from within, recording the stages of infrastructure construction (Friedman 2012). 
graphic data, like that used in the reports discussed at the beginning of this chapter-a process which can take years (Interview 14, Ofran; Interview 19, Israeli NG0 urban planner). Mobility within Israel also allows Peace Now greater access to unofficial aerial photographs than ARIJ has. Several times per year, Peace Now is able to charter small planes to take aerial photographs of their own-which although expensive, is still cheaper than buying commercial photographs, whether from planes or satellites, with the added benefits that the photographs are not under copyright. Trips from the air often involve Ofran sitting at the window of a small plane with her digital camera (Interview 14, Ofran). ${ }^{109}$ This is not to say that Ofran has unrestricted access, however-far from it. Sometimes her reputation precedes her and she may be repeatedly refused entry although by law she should be able to visit the settlements as an Israeli citizen (For example, see Klibanoff 2009). ${ }^{110}$ Nonetheless, her ability to travel within both Israel and the Israeli West Bank settlements thoroughly shapes her maps.

The information Ofran gathers within the settlements allows for a much finer level of detail and knowledge as to changes within particular settlements, and in the locations and size of specific buildings than would otherwise be possible (Figure 5.32). 111 This can be seen in Figures 5.31 and 5.32. Figure 5.31 is a map by ARIJ (top), which depicts a large area marked "E1 Plan". These are the areas marked for settlement expansion which is already underway. Yet without direct access to those areas themselves, ARIJ cartographers must rely on official maps that are publicly released online, whose contours are very broad, possibly combined with some modest updates made from perimeter roads. In contrast, Figure 5.32 is the Peace Now map (bottom) of the same area, and it is far more detailed. The map depicts multiple specific areas which together make up the total E1 Plan region. These are displayed at a level that only a position within the settlements can afford, both in terms of fieldwork and access to data.

\footnotetext{
109 Aerial photography, whether purchased or self-made is not a substitution for fieldwork on the ground. Then the choice of which settlements to fly over, and which sites to focus on, was informed by her regular journeys within the settlements. Furthermore, when purchasing images, it is rare to obtain an image of the entire West Bank, as the resolution would be too coarse for cartographic work. Instead, organizations regularly buy specific images of a few selected sights at high resolution, and the choice of which updates are necessary would also be based on fieldwork (Interview 14, Ofran).

${ }^{110}$ Although less frequent than arrests of Palestinian fieldworkers, in recent years Israeli activists have also been arrested, for documenting settlement expansion (Zonszein 2013a).

${ }^{111}$ In some ways, both Figures 5.21 and 5.22 exceed even the access of international cartographers like those at the UN, who must travel in official vehicles, and some of whom are not posted in one particular region for more than a few years and so lack the kind of background knowledge, as well as fluency in Hebrew and Arabic, which many at ARIJ and Peace Now bring to their work (Interview 17, UN cartographer). There are notable exceptions, such as Stefan Ziegler, the project manager of the Barrier Monitoring Unit (BMU) of the United Nations Relief and Works Agency (UNRWA) in the Palestinian Territories (Interview 16, Ziegler).
} 

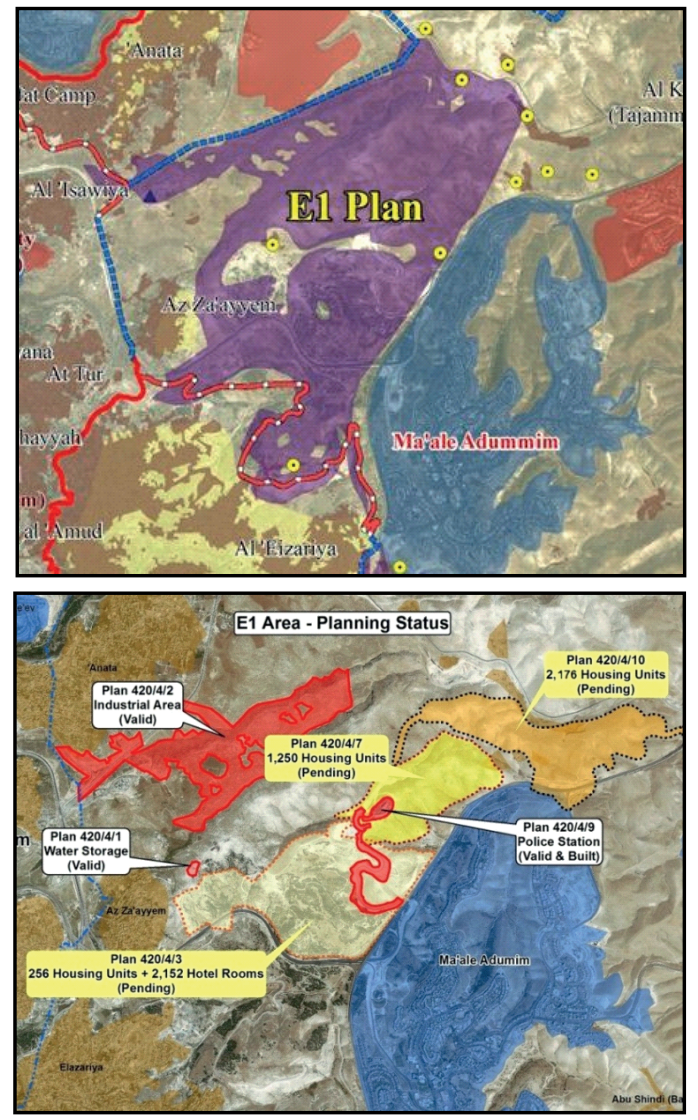

Figures 5.31 and 5.32 consist of an ARIJ map (top) and a Peace Now map (bottom) of the E1 settlement expansion plan and the Israeli settlement of Ma'ale Adumim, located roughly 6 kilometers east of Jerusalem, within the West Bank. While ARIJ's (2013a) presentation of Palestinian areas is very detailed, its depiction of the E1 plan comes from official data and so indicates only one large area of planned settlement construction. In contrast, the Peace Now map (2012) show several different stages of the plan in greater detail, but their representation of Palestinian areas is much broader than in the ARIJ map.

However, Peace Now's position also affects the very constitution of the data that she makes and uses. This can be seen in Peace Now's treatment of one crucial area type which proliferates throughout the West Bank: Israeli military bases. Sensitive sites are routinely censored by law from aerial images released by private Israeli firms. Cartographers have numerous examples of images where a particular detail-for example, a sandy hill or a tuft of scrub brush-had been copied and pasted over another area in the same image, to hide a military installation. So one image might contain two identical dirt hills, but one of these would cover a series military buildings and roads (See Figure 5.4) - often prominent features which, beyond the map, might be quite visible through the car window, including from the 
segregated (and at times more distant) roads for Palestinians (Interview 1, Tufakji; Interview 11, Palestinian NGO cartographer). 112

Aerial images are censored for Israeli and Palestinian organizations alike, and they hide what are often well-known installations. Yet they have a peculiar effect owing to the segregation imposed by the Occupation: Palestinian NGO maps often indicate Israeli military bases, while many Israeli NGO maps do not. Zionist Israeli NGOs must conform to Israeli civilian law in the hopes of deepening their support from the Israeli public, and for this reason they often continue to use the censored aerial images (Figure 5.51). ${ }^{113}$ However, under the Occupation, Palestinian NGOs have little to lose in terms of their relations with the Israeli authorities. So, while they are dependent on Israeli private companies to purchase the images, they are able to combine the Israeli images with lower resolution information from international sources, such as the UN (Figures 5.4 and 5.54). ${ }^{114}$ They do so in an attempt to accurately depict the locations of the numerous military bases and closed zones, which encircle ever greater areas of the West Bank.

The alternating hide and reveal of the military bases also affects the locations and boundaries of the settlements themselves. This can be seen by comparing the detail of Mishor Adumim in Peace Now's map in Figure 5.51, and ARIJ's in Figure 5.52. In Figure 5.51, the smaller circled area near the top of the image is not indicated as being part of the Israeli industrial complex of Mishor Adumim, which lies just east of the settlement of Ma'ale Adumim. In contrast, the ARIJ map in Figure 5.52 shows the nearby military base (large circled area), indicates that the corresponding smaller circled area in fact lies within the boundary of Mishor Adumim. There are several reasons why this could be the case, all of which relate to the corresponding within/without positions of Peace Now and ARIJ with respect to the Israeli settlements.

\footnotetext{
112 Similarly, Google Earth does not depict certain major military installations for reasons of security, and its apparently all-encompassing globe can therefore only provide a partial picture of some regions (Mogel, Paglen, and Bhagat 2008; Paglen 2009).
}

${ }^{113}$ Not all Israeli NGOs omit reference to Israeli military bases, as evident from the map by more internationally-oriented group B'Tselem in Figure 5.53. Nonetheless, such a practice would be viewed skeptically within Israel, which poses a particular challenge to Peace Now, as one of its main goals is to change the perceptions of the Israeli public.

114 The launch of the GoTurk satellite is planned for 2015, and it could have a major impact in terms of serving as a source for alternative forms of satellite imagery. Sponsored by a Turkish company, GoTurk has the potential to affect the Israeli monopoly on public high-resolution satellite images of Palestine and Israel, a monopoly which is also enforced by US law upon companies located within the US (Aleaziz 2011; Arianespace 2013; Reuters 2011). 


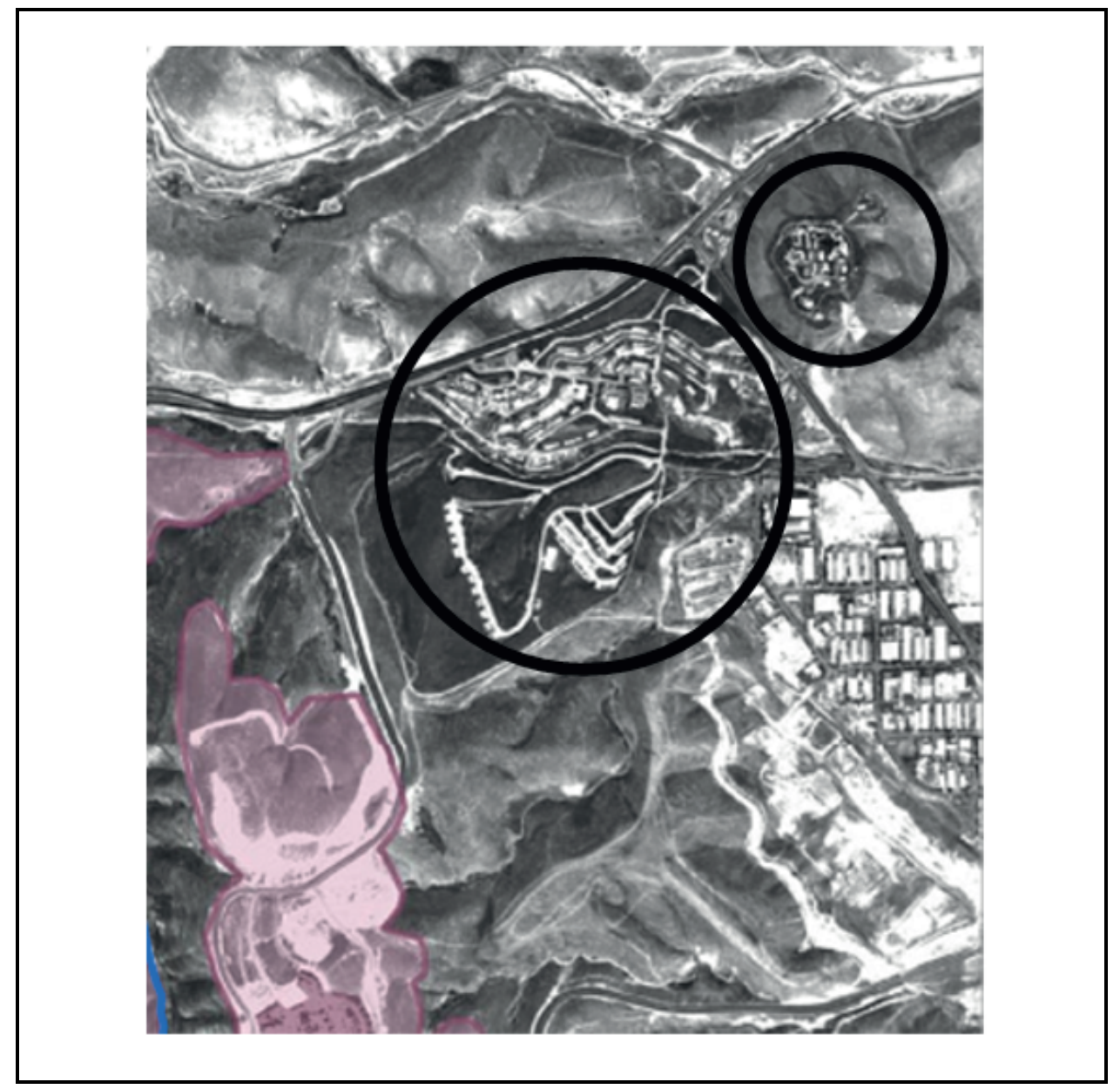

Figure 5.4. An aerial image of Mishor Adumim which shows buildings and roads at the reported site of an Israeli military base. Mishor Adumim is at the right hand edge of the image. The larger circle clearly indicates buildings and related infrastructure in a region that, on ARIJ maps, is marked as a military area. The corresponding spot is shown as an empty plain on Peace Now maps (e.g. Figure 5.51). This image is a detail from a UNOCHA $(2007,27)$ map of Ma'ale Adumim. The background photograph was provided to the UN by the EU, and so it is uncensored. The smaller circle indicates related infrastructure near the base (see Figures 5.51-5.54). Surprisingly, as of September 2013, both of the circled areas are also clearly visible in the satellite layer in Google Maps, which generally uses Israeli images. Circle annotations added by the author. 

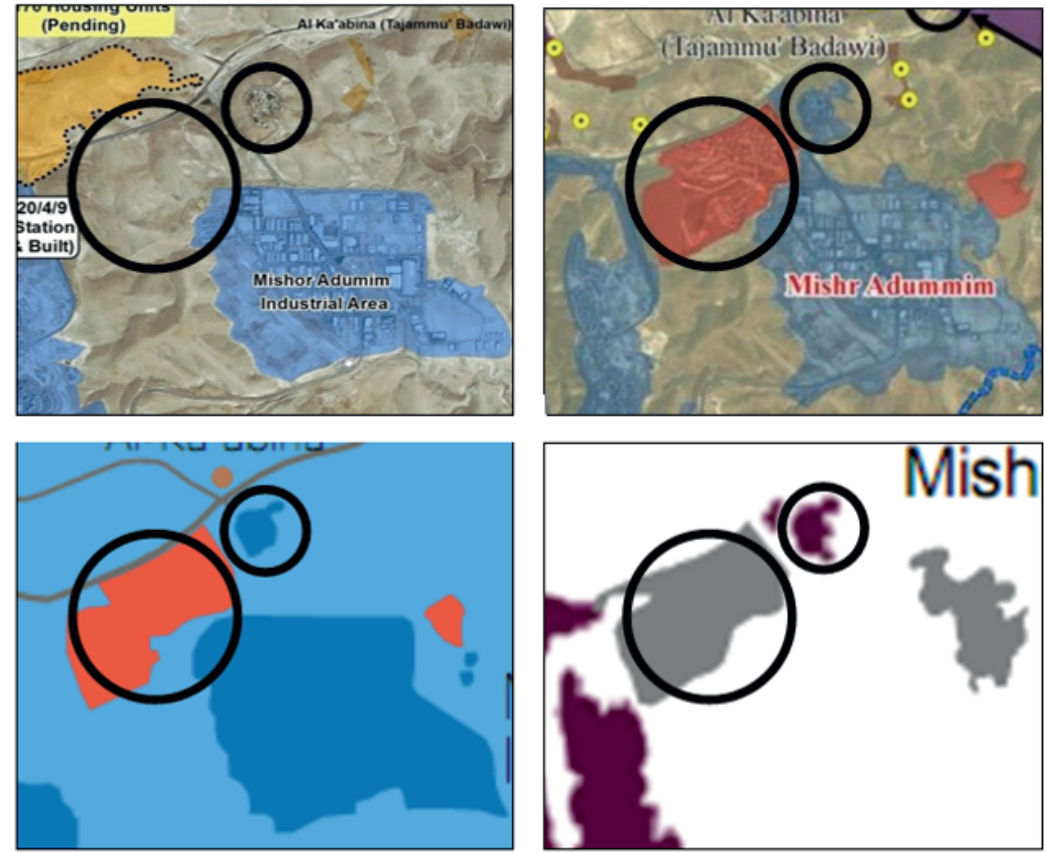

Figures 5.51, 5.52, 5.53, and 5.54. Four maps of Mishor Adumim industrial park. The larger circles indicate an area that is labeled as an Israeli military base on all of the maps except the one at top left, where it is unlabeled. The smaller circles indicate related infrastructure near the base, which is labeled in various ways.

In Figures 5.51, 5.52, and 5.53, Mishor Adumim is the large area that fills the bottom right half of each map. Figure 5.51 (top left) is a detail of the Peace Now map in Figure 5.32. No military base is shown, and the smaller circle is likewise unmarked. Figure 5.52 (top right) is a detail from the ARIJ map in Figure 5.31. A military base is clearly indicated, and the smaller circled area is included within the boundary of Mishor Adumim. Figure 5.53 (bottom left) is a detail from a settlement map produced jointly by B'Tselem and Eyal Weizman (2002). The military base is marked, and the smaller area is included as a separate Israeli settlement. Figure 5.54 (bottom right) is a detail from a 2005 UNOCHA settlement map $(2007,79)$. The military base is indicated. However, the bottom right hand area of the map is blank: the majority of Mishor Adumim is not shown.

In the full map from which this detail is taken, the smaller circled area is labeled (not shown) as the whole of Mishor Adumim. Note that the size and details in the locations of boundaries for individual areas, such as Mishor Adumim, also vary considerably across the four maps. Circle annotations added by the author. 
In Peace Now's case, during their fieldwork they would be able to approach this circled region, or to ask a local resident, and discover that it in fact forms part of the adjacent military base. Then, because Peace Now does not generally show Israeli military bases on their maps, then they would have excluded the smaller circled area from the boundary of Mishor Adumim. ${ }^{115}$ In contrast, ARIJ cartographers would not be able to approach Mishor Adumim to verify whether this particular area in fact belonged to Mishor Adumim or to the nearby base. Thus, they likely would have adopted a cautious stance, choosing to indicate the circled area as being part of Mishor Adumim rather than the military base. The shifting boundaries of Mishor Adumim are not just a case of inclusion and exclusion, however. They also extend to boundary determinations at finer scales, evidence of which can be seen by looking closely at small changes in the boundary of Mishor Adumim in Figures $5.51,5.52,5.53$, and 5.54. For every centimeter of boundary, cartographers must make determinations for whether an individual tree, road, field, or pile of stones belongs to the settlement, base, or neither. Their judgement as to whether a settlement or base was actually present would of course affect such determinations.

The location of the boundaries is intricately related to those organizations' geographic positioning with respect to the Israeli settlements. In this case, although Peace Now's ability to work within the settlements affords them the opportunity for detailed fieldwork, nonetheless that same privilege prevents them from showing the bases, or indicating the status of the circled area anywhere on their maps. This thereby illustrates the complexity of the within/without dynamic, with respect to the settlements, and its effects on cartographic methods and the empirical content of settlement maps. In the next section, I explore the related but varying implications of ARIJ's position within, and Peace Now's position without, Palestinian communities.

\section{Mapping Palestinian Communities: Inside-Out in Palestine}

"We're going back to that Old Testament story, of Samson and Delilah. You know the story?" (Interview 11, Palestinian NGO cartographer). As I sat down to analyze settlement mapmaking practices, I kept coming back to this exchange I participated in with a cartographer at ARIJ. "Samson and Delilah" is the account where Samson is betrayed by his lover, Delilah, and imprisoned in his enemies' temple; he then pulls down the roof of the temple, destroying it and murdering all of his enemies, but also killing himself in the process. The use of a Biblical story to illustrate contemporary politics is nothing new in many places, including the US as well as Palestine and Israel. Furthermore, the adaptation of this tale to claim that the conflict

${ }^{115}$ Even if the Peace Now researchers were simply unable to enter the area, this too would suggest that it in fact belongs to the base and not the industrial park. 
threatens to destroy the very territory which is the goal of the fighting, certainly seemed apt. However, neither of these aspects were what attracted me to it. Instead, it was this very self-evident quality of the story which pulled me back. The storyteller didn't claim that the story is identical to the present day, but later in the interview, he would assert that, referring to the relationship between violent conflict and self-annihilation, "Today, it's practically the same thing [emphasis added]."

This claim that the past is emphatically not identical, but nonetheless commensurable with the present, was mentioned numerous times during my fieldwork, and it made me wonder to what extent the present had been deliberately made to be commensurable with an imagined past. To that end, it drew to mind several more geographical questions: To what extent had the landscape been made to be commensurable or incommensurable with places elsewhere, and in earlier time periods? To what extent is the process of co-production of the landscape, vacillating between social construction and material obduracy, itself a self-fulfilling prophecy, whereby material and discursive goals coalesce step by step? Or, more concretely, why don't ARIJ cartographers also map Vietnam, for example, or other nations around the world, as Israeli cartographers often do?

The very obviousness of the answer points to an additional sense of saying that ARIJ is mapping the settlements without. In addition to the literal sense of being outside the settlement fences, there is also the metaphorical sense- that is, of going without the types of infrastructure, institutions, and freedom from interference which would be one of the aims of the movement to end the Israeli Occupation. Of course, one could argue, ARIJ cartographers don't focus on mapping Vietnam or elsewhere, because-not to mention the politics of the resources at their disposalin the struggle for statehood, they too readily have to deal with the realities of the Occupation. Although it is relatively quiet at times, the Occupation never retreats far from view. The settlement of Har Homa looms over the Bethlehem skyline (Figure 5.22). Road closures and checkpoints interfere with their work, with more or less regularity depending upon the current political situation. This sense of doing without goes hand in hand with ARIJ's position viewing the settlements from without - that of looking upon the settlements from outside the fence, across the segregated bypass road, that of not being able to enter established settlements and outposts at all in most cases, and not casually in any case.

Yet this doing without has its relation to their privileged position within other areas of the West Bank. The ARIJ cartographers' very exclusion from the settlements-and for most of them, Israel as a whole-is due to, and reinforces, the cartographers' positions within the Palestinian communities of the West Bank, and thus their immediate experiences of the effects of the expansion of the Israeli settlement project. Calls come in every day reporting another attack on a farmer, the uprooting of trees, or the impending demolition of blocks of homes. Without documentation, once a particular feature is demolished, it leaves open the possibility that the military could argue that it was never there. In this context, how could ARIJ not map the West Bank and the impacts of Occupation? How could they not attempt 

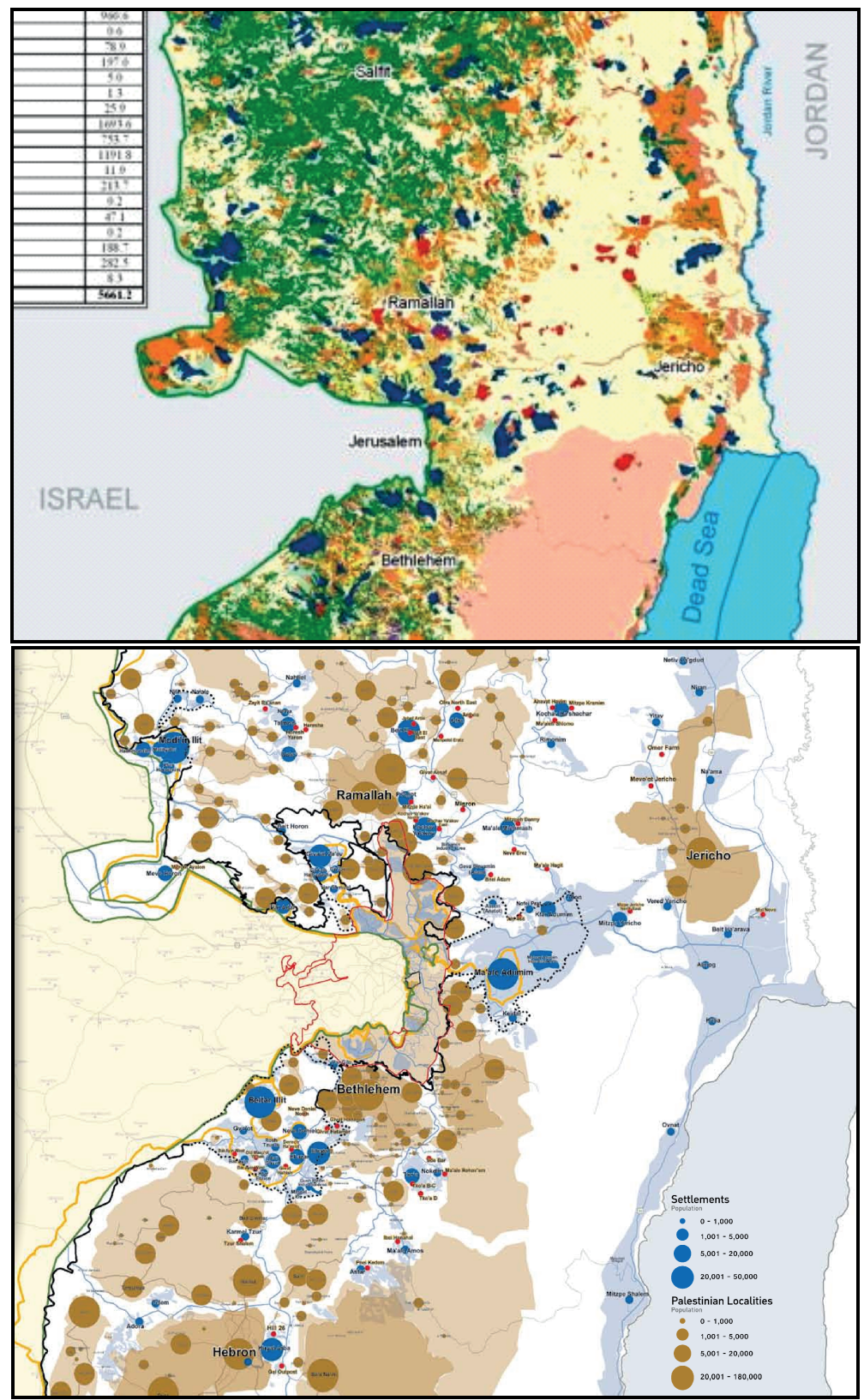

Figures 5.61 and 5.62. Figure 5.61 is a detail of a Palestinian LULC map which indicates Israeli settlements (ARIJ 2008). Crops are shown in shades of green, orange is used for arable land, yellow indicates urbanized Palestinian areas, and blue is for Israeli settlements. The light tan areas are regions with little vegetation. Figure 5.62 is a detail of a recent Israeli map of Israeli settlements in the West Bank (Peace Now 2011). The map combines data from the Palestinian Central Bureau of Statistics (PCBS) and the Israeli Central Bureau of Statistics (CBS). The PCBS data shows Palestinian population and appears in brown. the CBS data shows Israeli settlement population and appears in blue. 
to put Palestine-not just in terms of broad political borders, according to this or that international agreement, but the nuts-and-bolts streets, buildings, houses, and fields - on the map? The way they have done so, by making LULC maps ${ }^{116}$ (Figure 5.61), is affected by their position as observers viewing the settlements from without (as in Figure 5.22), albeit in ways that rely on their ability to participate in the Palestinian West Bank from within, relying on both the cartographers' own experiences in the landscape, as well as a community of local observers that stretches far beyond ARIJ. In what follows, I will explore these two forms of being within, turning first to how cartographic judgments are grounded in personal and group ences in the Palestinian West Bank, and second to how ARIJ's ability to collect consistent data goes hand-in-hand with the development of a network of observers who, like those at ARIJ, have learned to mobilize their collective position of being forced to go without.

\section{Palestinian Communities from within: Visualizing a Politics of Cultivation}

As the name implies, land use maps indicate how people are using space-including for example, farmland and urban residential areas-as well as the types of features which cover the land-including forests, bodies of water, and streets. LULC maps are generally used for planning and management so that, for example, a county developer might know what percentage of low-income housing lies within a short distance to a river, and thus is at risk of flooding. Although a distinction is made between land use, or the ways in which resources are managed, and to what purpose, and land cover, or what physically is covering the land, in practice they are often intertwined (Fisher, Comber, and Wadsworth 2005), and at times cartographers can conflate them purposefully in order to disempower those living in the lands that are being mapped (Hoeschele 2000). An area of olive trees, for example, is both being used for agriculture and covered in rows of trees. For this reason, land use and land cover are often mapped together. This does not mean they are identical, however, given that use does not determine cover, or vice versa. An area of rocky outcrops covered in shrubs, for example, might be abandoned-or it alternately could be used for foraging essential wild plants; the two different types of use (abandonment or foraging) nonetheless result in the same apparent land cover (rocks and shrubs), and the difference couldn't be seen from an aerial photo. Instead, it would require knowledge of the landscape and local agricultural practices.

Land use maps have a special use at ARIJ, for they add a level of detail to areas which remained blank on maps for years (See Chapter 3). Furthermore, if there is a detailed account of what is present on the land, then there is a direct line of argument for indicating what and how much has been destroyed. Far from being complementary, or secondary to quantitative facts, however, land use maps are in fact

116 For simplicity, I refer to LULC maps interchangeably as "land use maps". 
the very foundation for many aerial statistics. The statistics are made using the maps. In the West Bank, for example, statistics for the extent of croplands burned or the percentage of the land taken over by settlements come directly from land use maps, or by comparison of two such maps over time. To find the percentage of land covered by settlements, for example, it is necessary to draw borders around individual settlements, find the area within these borders, and then add them to find the area covered by settlements in the West Bank on the whole. Thus the drawing of borders on a land use map leads directly to the numerical figures, and LULC cartography is thus fundamental to monitoring the effects of the Occupation. Although land use maps are not suitable for navigation, the practical impacts are legion, given that one of the most ready justifications for the confiscation of West Bank land by the Israeli authorities is that the land itself is not in use (Shalev 2012).

Land use maps can be made in a variety of ways. While automated processes are being developed with increasing levels of accuracy and detail to turn aerial photos into LULC maps, and some of these were in use at ARIJ for selected areas, the most detailed and consistent way to make a land use map is to do it by handby tracing an aerial photo, or another set of satellite or remotely sensed data, with a mouse. The procedure is to load an aerial photo, such as one would see in the 'satellite' layer of Google Earth, then trace over the image by hand, piece by piece, tracing buildings, areas of crops, and other noticeable features, thereby digitizing key aspects of the photograph (See Chapter 4). While tracing, the computer converts the traced lines into digital map data files, recording the location of every detail or change in course of the lines that are being drawn. As with digitizing maps (See Chapter 4), it is painstaking and arduous work, but unlike digitizing maps, the goal is not to faithfully reproduce all or most of the aspects in an original map, but instead to 'convert' the original satellite photograph into predetermined categories such as 'Forest' and 'Permanent Crops'. As much as it involves observing and tracing features on the ground, the process of making LULC maps is also necessarily interpretive.

\section{Palestinian Communities from within: Judging the Land, from Inside an Office}

At ARIJ, the decision to update the maps by hand, instead of using available automated methods, was made precisely because the most recent land use maps needed to be consistent with the previous years' maps, which had been made by hand before reliable automated methods had been developed (Interview 9, Palestinian NGO cartographer). ${ }^{117}$ For this same reason, the Corine Land cover classification, developed to standardize LULC maps in the EU and beyond, was used, as it had initially

117 The announcement that a team of 4-6 cartographers would spend months painstakingly making LULC maps using updated aerial photos was greeted lightly, but with dark sarcasm, to gentle laughter: "Why do the Palestinians always have to suffer the most?" 
been chosen to make the maps commensurable with European LULC maps (Büttner et al. 2002; Bossard, Feranec, and Otahel 2000). To produce the LULC maps, each cartographer was given a particular district to complete. Once the districts had been assigned, all of us in the GIS group sat in one room, at individual computer consoles in the GIS unit, and began tracing photos for eight hours per day. The choice to use the Corine classification added a further dimension, due to the need to adapt and add levels of detail to the categories of a classification developed in Europe so that they would allow cartographers to visualize differentiation in the land in the West Bank.

The application of the Corine classification was by no means a straightforward process, and for this reason, it could not be a solitary one. No categories existed, for example, to differentiate between Palestinian and Israeli urban areas. These were classified together as 'Urban Fabric', a standard category, but then sub-categories were created to differentiate them as 'Israeli settlements' and 'Palestinian Built-Up Areas', respectively. The Wall received a new category all its own, classified (consistent with ARIJ's terminology overall) as the 'Segregation Wall', with the subcategory 'Wall Zone'. However, it was not always clear where the boundaries of a specific feature might lie. Also, in some cases it was clear that the aerial photos, which had to be purchased from Israeli firms due to the prohibition on Palestinians flying planes without prior approval (See Chapter 3), had been censored to hide the locations of military bases (Interview 9, Palestinian NGO cartographer; Interview 1, Tufakji). At other times, individual areas of a photo might shift due to technicalities of the angle at which it was taken, and how it was projected from an essentially three-dimensional image (an arc of the surface of the Earth) onto a twodimensional screen. Often, two categories were relevant within a single area, which might include, for example, vegetable fields (arable land) interspersed with olive groves (permanent crops), or urban development (built-up area) intermixed with olive groves (permanent crops). How is it possible to consistently decide which was more important or prominent in each case?

To adapt the Corine classification so that its use was both commensurable with international standards and relevant to the West Bank, the ARIJ cartographers drew on their collective experiences within the physical landscape. The process was often an intersubjective one, an instance of trained judgment (Daston and Galison 2007) to be sure, but one where both the training, and the eventual judgment, were decided by coming to a consensus as to how particular elements of satellite images, viewed in the office, corresponded to what the cartographers had observed during their daily lives. This process of discussing and validating each other's observations was essential, because the maps needed to be comparable across the different districts. So the cartographers had to coordinate their decisionmaking with respect to the individual categories. Although at times, cartographers worked in silence for hours, often the office was a lively place, with several people standing around one computer, admonishing each other, or making suggestions. 
This form of materialized reason was collective on several levels. While the director of the GIS unit was the ultimate arbiter, the emphasis was on the reasoning behind any particular decision-and this was achieved through discussion, given that it was essential for us to coordinate our efforts in order to form a cohesive map. It wasn't unusual for one worker to call across to another, asking a question about a specific category. One afternoon, the other cartographers and I were called in to a discussion in the hallway in reference to two versions of the same settlement map, which were taped next to each other on the wall. Which colors were more objective, the brighter colors or the more muted ones? Which map had the clearest message? The decision, to choose the more muted, arguably more scientific colors, was made again through an extended discussion involving the entire unit. Although the usual power plays and competitions among different technicians came into play in the context of office politics where there might be particular friendships or small rivalries among particular individuals, no single individual was the arbiter of what constituted the most objective decision. The experience of training on the job was a fully intersubjective one, through which skills and the ability to judge were cultivated among the group.

In addition to being continually adjusted within the group, the mapmaking was thoroughly based upon knowledge of the landscape and its forms; in one instance, when I was unsure whether a pile of stones was a quarry or the stones of an old farmstead, I was told that it was a farmstead, which was well known to the colleague I was speaking with, because they are everywhere-the implication being that he saw them all the time in the landscape himself-and on the walk home from the office, another colleague pointed out several on a nearby hill, asking me to compare it to what we saw earlier in the aerial photo. In another instance, on a field trip to the Tulkarem district with a Master's degree course in water management at Birzeit University, a colleague from ARIJ poked fun at me by pointing out of the window of the van. "Look, permanent crops!" she said, referring to the rows upon rows of olive groves that hugged the contours of the hillside, and which I would later classify as 'permanent crops' on the LULC maps. Back at the office, the olive groves themselves were the subject of much discussion, because some were clearly planted in rows from above, while others were more of a jumble; should they all be considered crops, given that, after thousands of years of cultivation, they were almost certainly planted by humans, or should only those in rows, theoretically newer or more carefully tended, be classified as crops?

In the end, they chose the more frugal option: only the trees in rows became 'crops', based in part on assumptions, fully grounded in the experiences in the landscape, that farmers would be systematic by placing trees with enough room to grow and walk among the rows. Such a decision can be viewed as an attempt to conform to previous criticisms that Palestinian cartographers used too broad a definition of cultivable lands. For example, Moshe Brawer argued against including "lower grades" of land in the definition of cultivable lands because the lower grades "have only small scattered patches of arable land, or carry few widely dispersed [...] fruit 
trees" $(1994,341)$. Yet this ignores the fact that all but the wealthiest Palestinian farmers were required precisely to engage in "the cultivation of small patches of soil between the rocks sometimes by means of a pick-axe, or in terracing still smaller pockets and placing olive tree shoots in them [....] Many village families were able to subsist, though miserably, on such land which, according to Government standards, was classified as 'non-cultivable'" (Hadawi 1957, 17). So attempts were made to cultivate every miniscule area using heterogeneous methods, rather than attempting to impose homogenous fields upon the landscape. ${ }^{118}$ In this context, ARIJ cartographers worked to demonstrate why their definitions of crops, for example, were more rigorous than previous characterizations of the entire region as "empty" or "uncultivated". 119

\section{The West Bank from within: Validating a Network of Observers}

If this was the experience in the office, then the Urbanization Monitoring Department took such practices to the scale of the West Bank and East Jerusalem. In contrast to the GIS Unit, which produced the land use maps that themselves were focused largely on agriculture and Palestinian urban areas, the Urbanization Monitoring Department was charged with monitoring settlement expansion, and they were the ones that would input detail into the settlements. This was achieved largely through a combination of aerial photography, remote sensing, and fieldwork. ${ }^{120}$ To some extent, the fieldwork included sightings from nearby hillsides with highresolution cameras, distant views of settlement architecture from afar which, in addition to the often year-old representation of settlement buildings on aerial photographs at their disposal, were the cartographers' main methods of observing settlements from without, through observations conducted beyond the perimeter fence (Interview 9, Palestinian NGO cartographer). However, this was not the primary source of their knowledge of the expanding geographic reach of the settlements. This knowledge came from their ability to act within the Palestinian communities who were directly displaced by settlement expansion. ARIJ cartographers regularly met and phoned with a dispersed network of contacts (Interview 11, Pal-

118 In ways that resonate with the writings of David Amiran-whose negative characterization of Palestinian agriculture is discussed in Chapter 2-Hadawi refers to such methods as "still primitive" (1957, 17). See El-Eini (2006) on British attempts to impose standardized cultivation in Palestine and Israel before 1948 .

${ }^{119}$ See also Walid Khalidi's reply (1993) to Benny Morris's review (1992) of Khalidi's Before Their Diaspora (2004).

${ }^{120}$ For an example case study of remote sensing efforts carried by scholars from Birzeit University, see Sharakes et. al. (2007). Since roughly 2005, remote sensing are increasingly gaining traction in the West Bank as an alternative to field surveys, although the methods and effects on land management are deserving of further study, although they are beyond the bounds of this book. 
estinian NGO cartographer; Interview 9, Palestinian NGO cartographer). Often the meetings were for the purpose of collecting military orders issued by the IDF announcing the confiscation of Palestinian land. This has led to the most extensive freely-available database (of which I am aware) of military orders in the West Bank, although the grainy resolution of the sources included there directly reflects the rough quality of the maps the IDF provides to the Palestinians (ARIJ 2006a). ${ }^{121}$

The most expedient manner to obtain the orders, one cartographer explained in an interview, was to literally get them from the field: "When they have a military order, they throw the maps in the fields, and the people collect these maps and bring them to us." When asked if it was possible to collect all of the military orders in this way, he answered that, while over 1,400 orders have been collected, this only represents a tiny part of the total number. When asked why this is the case, he answered, "Sometimes it was raining." (Interview 11, Palestinian NGO cartographer). In the case where settlement construction efforts took place beyond established fences - that is, generally within areas used daily by Palestinians-the Israeli military was required, both legally and practically, to announce further construction efforts to the Palestinians.

Throwing grainy photocopies of the military orders directly into the fields was the most expedient-and ephemeral-method for them to do so. So by coordinating their efforts and involving communities throughout the West Bank in an effort to preserve a record of the expulsions, ARIJ worked to produce facts and to counter the Occupation using methods that were only possible due to their positioning within Palestinian areas. The practice of taking leaflets announcing the confiscation of particular lands, and dropping them on those lands themselves, indicates a double function of ARIJ's wider contacts: the people call them to tell the ARIJ employees that orders have been dropped, at which point the employees drive to the spot to collect samples of the orders; they then often proceed by interviewing those present, both verifying the observation made and turning the locals' accounts into facts by taking videos and photographs. This material assists them when they return to the office to map the changes through a combination of observations on the ground and from above, of sightings by one and by many. In this way, the locals and the cartographers train each other by coordinating their efforts to become trained observers. I was told that the Military can 'play games' with the numbers, claiming in their statistics that they confiscate much less land than that which is indicated on the map; in order to verify this, it is necessary to digitize the maps from the military orders, which are usually released only to the Palestinian farmers who are directly affected, after which the ArcGIS mapmaking software can determine the area of the resulting file (Interview 9, Palestinian NGO cartographer). In turn, these maps also are used to inform LULC maps.

${ }^{121}$ Also see ARIJ's interactive settlement outpost map (n.d.) and their village profile map (2009b). 
As in the office, monitoring land confiscations involves extensive knowledge of the landscape-including how to get to sensitive areas without getting arrestedthat is brought into fact by the resulting map. The choice to make LULC maps to highlight the variety of Palestinian land use, the observations that constitute the maps, and the contents of the maps themselves, are intrinsically shaped both by the status of ARIJ without the settlements and the privileges they receive from the Israeli state, and within the Palestinian communities directly affected by settlement expansion. The position of ARIJ cartographers in the landscapes are thus inflected throughout their LULC maps. In the next section, I examine how Peace Now settlement maps are differently shaped by the very different within/without position of Israeli cartographers in the West Bank.

\section{Palestinian Communities from without: The Borders between Datasets}

"The Applied Research Institute - Jerusalem (ARIJ) deplores and condemns the death threats against Hagit Ofran, the Settlement Watch Director [...] of the Israeli Peace Now movement. ARIJ considers that such threats are against international human rights norms..." (ARIJ n.d.). Six months after I first traveled to Ofran's home in an apartment block in West Jerusalem, she stepped out of her door one morning to find graffiti scrawled along the walls of the stairwell, including "Peace Now, the end is near!!!" Two months later, there was new graffiti outside her door, including the ominous, "Rabin is waiting for you," referring to prime minister Yitzhak Rabin's assassination in 1995 by a right-wing Israeli who was upset about Rabin's signing of the Oslo Accords. As I sat down to write this chapter, still more graffiti had been found at Ofran's home, including "Hagit, you're dead." The Peace Now offices have been subject to similar graffiti, bomb threats have been called in at intervals, and the members of the group have received death threats by email, all allegedly from far right Israeli groups. ${ }^{122}$

Such threats indicate the unique position of Peace Now, and Ofran in particular, for while they benefit from their incorporation into Israeli and international landscapes, and are able to move within Israel and internationally with less obstruction than many of those at ARIJ, nonetheless their position within also has its own vulnerabilities. Yet they must look to Israeli and international society as a means of coping with these, as their ability to map the settlements from within, means that, with respect to the Palestinian communities, Peace Now must work largely from without. In order to better understand how Ofran's within/without position in the

\footnotetext{
${ }^{122}$ In 2011, a law was even put to the Knesset, and ultimately passed in a weaker form, with the goal of monitoring the funding of NGOs, thereby increasing surveillance practices under the suspicion that peace organizations are merely puppets or double-agents for international governments, in a move that not only sparked a series of mass protests, but also which was widely viewed to be aimed at Peace Now (Oster 2011; Paraszczuk 2011; Rosenberg 2012; US Department of State 2010).
} 
landscape affects the maps she makes for Peace Now, I first turn to an analysis of the ways her cartographic data is enriched by her work within the settlements, before discussing the challenges of mapping West Bank areas while viewing Palestinian towns from without.

Although it is not easily visible in Figure 5.31, the ARIJ map includes a wealth of detail for the Palestinian area of al-Izariyah (bottom left on both images), is far greater than those same areas in the Peace Now image. In both Palestinian and Israeli areas, these differences extend not just to the level of detail, but also to the borders and extent of specific regions. This indicates that, despite the benefits for mapping settlement expansion, Ofran's position as one who is able to access the settlements from within has nonetheless forced her to deal with mapping Palestinian communities largely from without. In this way, the borders of the settlements have created metaphorical borders within their respective offices, even within the different datasets of population, for example, that are used to make a single map. For in cases where Ofran wants to map Palestinian areas, she must use Palestinian data, because her ability to collect data in Palestinian areas is somewhat limited. ${ }^{123}$ Yet she cannot always obtain data directly from Palestinian organizations like ARIJ, because they too are located within Palestinian areas of the West Bank, combined with a climate of suspicion due to the Occupation. Thus, she must find sources that are publicly available online, such as that of the PA's Central Bureau of statistics (PCBS), the census conducted by the PA. The results of this reproduction of borders in a single map can be seen in the 2011 Peace Now Settlement map (Figure 5.62), where Peace Now combines Israeli government data with PA data. On the map, the data for the West Bank Palestinian population is taken directly from the PCBS. In so doing, the map seems to acknowledge Palestinian sovereignty in the collection of knowledge of their own populations. So despite the availability of aerial photo and international UN datasets, the actual degree of focus, scale, and detail of data mimics the sphere of mobility of the cartographers themselves, and the 'holes' in their landscapes are filled by the knowledge of groups which are defined in part by that very segregation.

Thus the boundaries on the ground are reproduced by boundaries in the data. Segregation is recursively reinforced, with geographical borders both influencing map data and, through the combination of segregated datasets, as in Figure 5.62, incorporated into maps. The very separation of groups, by divorcing their bodies of experience on a geographical level, affects their position in the landscape, and thus their data collection and display. This can further differentiate the goals and strengths of the data collected by each group, which means that the maps of one

123 This is not to say that Israeli and Palestinian organizations can never work together, as it is possible at times. Likewise, Israeli NGO workers are sometimes able to maintain contacts within Palestinian communities. However, these are the exceptions, and it is necessary to draw attention to the multiple levels on which produced landscapes in the region serve to discourage such efforts. 
group might be interesting or useful for the other, thereby encouraging crossborder work, even as it makes it practically impossible (Interview 18, Palestinian NGO researcher). Yet this doesn't mean that implicit alignment, a form of productive non-cooperation, is impossible. For example, an ARIJ report on the expansion of the settlement block of Modi'in includes a table whose sources are listed in combination as the "ARIJ database" and a "Peace Now Settlement Watch report" (2000; also see 2006b). While such public shows of support on the part of each organization can be difficult, it is not unusual for staff members or related academics and activists , as independent citizens, to appear across sides on panels (e.g. Ofran et al. 2011), news outlets (e.g. Eviction in East Jerusalem 2009), or to be published in the same journals and edited books (e.g. Ma'oz and Nusseibeh 2000). Such noncooperation resembles an agreement of non-interference, a working conception of alterity and the limits of one's own knowledge.

\section{Conclusion: Validating the View from the Top of the Wall}

In this chapter I have triangulated the work of ARIJ and Peace Now, with my own position as an international researcher with access, albeit limited, to both organizations. I have done so in order to investigate the effects of such physical and social segregation on maps of Israeli settlements in the West Bank. ARIJ and Peace Now are differently positioned in the landscapes of the West Bank, and thus draw on unique sets of experiences which result from their divergent and unequal positions. ARIJ is without/within in terms of, respectively, Israeli settlements and Palestinian communities, whereas Peace Now is within/without these same spaces. Their experiential backgrounds in these positions in turn shape the kinds of observations their cartographers are able to make, with the result that the geographic borders that the cartographers seek to map, themselves intrinsically filter in to the kinds of maps that they are able to make. For their part, ARIJ cartographers must make do with being without in terms of the settlements. Yet in mapping settlement expansion beyond existing fences, ARIJ cartographers have access to their own experiences in the land and a network of observers throughout the territory-both of which are only possible due to ARIJ's recognition as an organization that operates within Palestinian communities. ${ }^{124}$ In contrast, Peace Now cartographers benefit from a privileged position in both Israeli and international landscapes, and the access to the settlements from within that this affords them. However, they simultaneously must make do with mapping Palestinian areas from without. By analyzing how the being within/without differently affects the work of ARIJ and Peace Now cartogra-

${ }^{124}$ ARIJ cartographers told me that they also spoke regularly with academics and observers in Gaza, although due to the closure and permit restrictions this took place via Skype and phone conversations, rather than the more extensive in-person meetings they would have preferred. 
phers, I have sought to demonstrate how power imbalances between the two NGOs are more complex than any one dichotomy might allow.

ARIJ's position without/within, and Peace Now's position within/without with respect to the settlements and Palestinian areas, are part of a larger context of suspicion. Words that have benign meanings elsewhere have particularly dismal connotations in the context of an occupation. Normalization, which elsewhere might imply a sort of settling down, a return to the rhythms and regularities of life, instead implies the acceptance of the status quo, any act which encourages a view that the Israeli Occupation is normal, which naturalizes its seeming inevitability. Even the word peace, after years of rounds and rounds of negotiations, has come to mean stagnation and false promises; it is easy to experience its pyrrhic silence while walking abandoned roads of shuttered shops which line the separation Wall.

This is the upside-down (Galeano 2000) world in which Palestinian organizations and Israeli organizations might seek to work together. This is acknowledged by Ofran herself, in an interview with Al Jazeera English, where in response to a question about voluntary relocation for Palestinians evicted due to settlement construction, she notes, "That is up to the Palestinians who live there to decide. I cannot decide for them" (Eviction in East Jerusalem 2009). In this light, Ofran's recognition of Palestinian organizations suggests that respect be paid to their right to selfdefinition, and as a result, segregation becomes a productive condition. In the con-

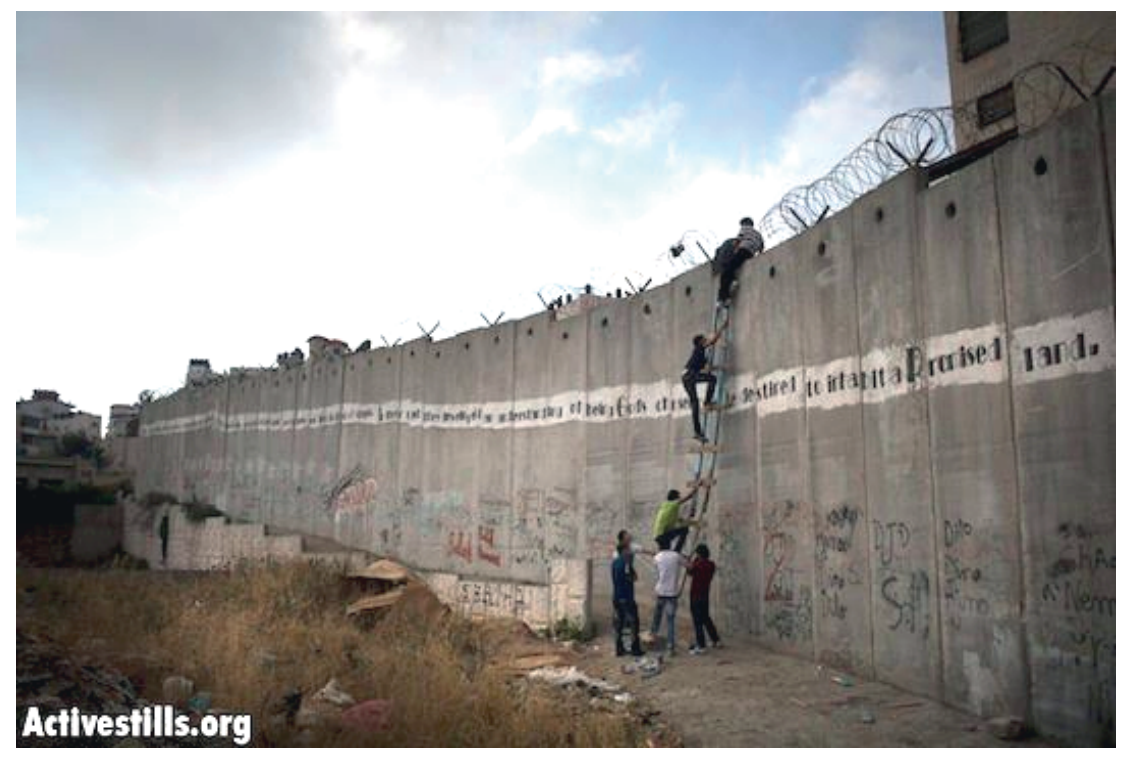

Figure 5.7. A photograph said to be of Palestinian teenagers climbing the Wall to go to Friday prayers in the Old City of Jerusalem during Ramadan in 2013. To do so, they risk arrest and indefinite detention, among other consequences. 
text of standpoint theory and triangulation, such labor is in effect an attempt to produce new subjectivities, which include alternative ways of inhabiting and observing the landscape.

This does not mean that the Wall and the entire apparatus of the Occupation are not having damaging effects-across the board they are criticized for the severe impact they have on daily life. Nor does it indicate that the segregation is absolute, for there are numerous areas that fall within or in-between borders. These include slips of space between particular settlements and Palestinian towns where activists are sometimes able to meet discreetly, as well as temporary activist spaces, such as the Palestinian settlement of Bab el-Shams which was set up on private Palestinian land to draw attention to the double-standard of settlement policy, and subsequently demolished within 48 hours by Israeli authorities (Nasser 2013). This is not to mention out-of-the-way sections of the wall which can be climbed-albeit with a fair amount of physical danger-for a small fee by means of a ladder and rope (Figure 5.7). Yet even the danger of accessing such areas, due in part to visa regimes, and the ability to make productive use of the development of technologies like telephones, Skype and Google Hangout which might allow cartographers to speak across borders, differs based on cartographers' social and material positioning within the geographic landscape.

Such asymmetrical material conditions indicate that free movement is not always ideal. ${ }^{125}$ As a response, ARIJ and Peace Now cartographers must negotiate the challenges of repositioning themselves in ways that serve to question the notion of position itself. As part of such work, they have also come to acknowledge that although heightened mobility can be to the benefit of all, nonetheless 'free' mobility is at best an illusionary goal, and in certain circumstances may even be detrimental. For example, the ongoing reproduction of distinctly Palestinian spaces has the potential to further solidarity and visibility more broadly.

Similarly, authors have pointed to how, in particular refugee camps and destination cities, Palestinian refugees internally self-segregated themselves according to village or region as a means of reproducing familiar geographical orders, with varying effects (al-Araj 2008, 25). In recent activist contexts, where young Israeli protesters routinely find ways around imposed segregation and thereby build up alternative networks of their own with Palestinians in towns like Nabi Saleh and

\footnotetext{
125 Ofran's hesitancy to speak for the Palestinians, which is partly the result of her inability to maintain extensive contacts due to the segregation imposed by the Occupation, is also related to the longstanding debate over what is known as the one-state (as in, one state of Palestine/Israel) versus the 'two-state' (two separate states, one Palestinian and one Israeli) solution. However, arguments over one state versus two have begun to seem increasingly hollow, as both sides benefit from an either/or conception of space, as if the question of one versus two states mattered more than the conditions on the ground.
} 
Bil'in, ${ }^{126}$ Elisha Baskin and Donna Nevel, two Jewish anti-Occupation activists, have nonetheless argued for self-segregated spaces on the part of Jewish activists who are privileged in the context of joint Palestinian-Israeli solidarity work, thereby avoiding turning "Palestine solidarity spaces into support groups for Jewish activists" (Baskin and Nevel 2013). While the politics and practices of maintaining such spaces can be incredibly difficult (A. Smith 2013), they deserve to further illustrate my critique of the triangulation literature-namely, they force scholars and activists to take into account how attempts to alter positions and mobilities in the landscape can also transform one's own personal and group subjectivity, and thus the practice of observation. In the conclusion, I will consider the possibilities and constraints among such attempts at differently producing landscapes and subjectivities.

126 In terms of textual volumes available internationally, alternative representations of space come through perhaps most effectively in graphic novels such as Ashery and Sansour (2009), Sacco (2009; 2001), Modan (2008), Keret and Hanuka (2005), as well as several graphic novels on Jerusalem, including Deslile (2012) as well as Yakin and Bertozzi (2013). 


\section{Chapter 6}

\section{The Geographic Production of Knowledge}

"[To a semi-Orientalist] Let's say things are the way you think they arethat I am stupid, stupid, stupid

and that I cannot play golf

or understand high technology

nor can fly a plane!

Is that why you have ransomed my life to create yours?"

(Mahmoud Darwish, Halat Hasar [State of Siege] (2002), English translation by Ramsis Amun (n.d.))

\section{Mapping This Book's Hidden, Ubiquitous International Landscapes}

In the poem which opens this chapter, Mahmoud Darwish, perhaps the most famous Palestinian poet of the $20^{\text {th }}$ century, references the connection between Orientalism, a regime built upon discrimination based in geography, and a belief that, as a Palestinian, he might lack fluency in technology. In his work, Darwish also returned time and again to the themes of maps and borders. "Our country / has the map of absence" he claims in one poem, lamenting his estrangement from the reshaped landscape of Palestine and Israel after 1948, noting that "I become distant from my epoch / When I approach the place's topography" (2004; English translation from Antoon 2008, 224). In response, he poses the questions-is a lack of an ability, or a different method for using technology, worth ransoming his life? In this 
book I have sought to better understand how power imbalances-like those which result in part from Orientalist legacies (see Chapter 1)-are materialized in such reshaped landscapes, and the effect that this has on the ability to produce knowledge based on experience and observations in the field. Whereas the geographical specificities of technoscientific knowledge are often hidden in debates about the role of maps in Palestine and Israel, I have shown that technological knowledge is geographically produced as well as socially constructed, in geographic landscapes. 127

Cartography in the occupied Palestinian territories is sometimes significantly different from that in the annexed areas of Israel, yet the two are joined in an unequal relationship through the Israeli Occupation of the West Bank and Gaza Strip. Palestinian and Israeli societies are often studied separately-and with good reason given their cultural, historical, linguistic, and power differences. However, this book, by including Palestinian and Israeli cartography together as part of a single analysis while delineating the internationalization of both, analyzes the relations between them without reducing the analysis to an all-or-nothing argument, which would assert that they are either wholly commensurable or wholly incommensurable. It therefore allows me to analyze the at times mutual constitution of distinct practices. It also provides an opportunity to demonstrate the role that international researchers (at times despite our best efforts) and constructed hierarchies of knowledge play in perpetuating power imbalances in the region.

In each chapter I have examined how material landscapes affect cartographers at multiple scales, particularly international ones, in ways which serve in part to reformulate those scales (N. Smith 1992). Like other forms of knowledge, scientific and technological knowledge are embedded in particular geographical landscapes, and the implications of this reverberate across space and time. To investigate the impact of landscapes on the production of knowledge, and thus the content of science and technology, I analyzed three representative case studies of digital cartography in the region: Israeli population maps 1967-1995, Palestinian Authority (PA) governance maps 1995-2011, and a comparison of Palestinian and Israeli nongovernmental organization (NGO) settlement maps. I selected these cases in order to highlight imbalances of power which disproportionally affect Palestinian cartog-

\footnotetext{
127 Darwish's poetry is replete with geographic themes, and he is widely popular in a region where poets are as generally well-known and venerated as musicians are elsewhere. One of his most well-known poems is entitled "Passport", and in the poem "Earth Presses Against Us" he asks, "Where should we go after the last border?" (Translation from 2003, 9). He has also famously written on the accusations of Palestinian nonexistence in the poem "I Am There" and the longer work, Ara Ma Urid [I See What I Want] (1993), which includes repeated lines such as "I am from here. And here I am." and "I am here, and here I am." See also the appropriately titled collection, Victims of a Map (Darwish, al-Qasim, and Adonis 1995; cf. Wood 2010). Geographic motifs also abound in related literature and music. For example, see the description of drawing maps on the ground from memory in Elias Khoury's Bab al-Shams [Gate of the Sun] $(2005,192)$ and the song "At the Border" from the French-Lebanese musician Marcel Khalife's album (1980) of the same name.
} 
raphers, particularly those in alternative NGOs. Thus, I began with a case from the Israeli state (population), proceeded to one from the emerging Palestinian state (governance), and ended with a comparison of one Palestinian with one Israeli NGO (settlements).

In chapter 2, I laid out my theoretical claims regarding how cartography has been analyzed with respect to conceptions of landscape, materiality, and the production of knowledge. In chapter 3 (population), I argued that the presence of Palestinians in the territories that Israel occupied after the 1967 war shaped the statistical methods that Israeli cartographer Roberto Bachi used to count and map Jewish Israeli populations. Even the very abstract statistical methods which Bachi used, methods which both prefigured and contributed to the later spread of Geographic Information Science (GIS), and which were designed to omit reference to Palestinians, nonetheless were affected by the presence of large Palestinian populations. In chapter 4 (governance), I turned from the Israeli state to the newly-founded Palestinian Authority (PA), analyzing how the high stasis-the ability to persist in place-of British colonial maps of Palestine combined with the fragmentary stasis of the PA in ways that served to restrict the content of maps that the PA produced, particularly in the years before and during the Second Intifada. Like the Israeli census maps, PA cartographers were continuously affected by the fact that their cartographic work was undertaken in the landscapes of Palestine and Israel. However, unlike the Israeli cartographers who experienced extensive mobility and stasis, the PA's attempts to further sumud, or steadfastness, through their institutions and digital infrastructure were countered alike by contemporary colonialism, in the form of the ongoing Israeli Occupation, and historical colonialism, through the legacy of the British regime which was in power prior to 1948.

In chapter 5 (settlements), I analyzed contemporary digital cartography in Jerusalem and the West Bank. Israeli settlements are urban developments which have been built in the occupied West Bank with the express purpose of wreaking a form of "infrastructural violence" (Ferguson 2012; Rodgers and O'Neill 2012) by complicating attempts to separate the area into two distinct states, one Palestinian and one Israeli, thereby adversely affecting Palestinian urban development (Abdelhamid 2006) while pragmatically reinforcing the current situation where many Palestinians have neither formal Israeli citizenship, nor any internationallyrecognized state of their own. The settlement maps made by both groups should ostensibly be the same, given that all of the maps have the goal of displaying empirical facts about settlement expansion, yet this is not the case. Settlement-building also has the effect of complicating the ways that the geography of the West Bank is known and thus that maps of settlement expansion are made. I teased out some of this complexity by analyzing how the content of the maps are affected by differences in access, with Palestinian cartographers at ARIJ mapping the settlements from without, while working from within Palestinian areas, whereas Israeli cartographers at Peace Now, and Hagit Ofran in particular, work within the settlements, but must largely do without the help of Palestinian communities. In their Land Use 
maps, ARIJ cartographers focus on adding details of Palestinian land use, using a network of observers in Palestinian communities, to areas which long have remained blank on the map. Yet the cartographers themselves operate in areas where Palestinian viewpoints have historically been discounted. Peace Now, in contrast, benefits from access to the settlements to map the details of construction efforts there, but they are unable to work extensively within Palestinian areas, which limits the detail for those regions on their maps, although they can moderate this to some extent using the limited Palestinian data that is available on the internet. Yet this within/without dynamic has complex results, as was outlined in the description of how the display or omission of an Israeli military base affected the mapping of the boundaries of settlement areas outside Jerusalem. Such changes are significant, because the segregated landscapes of the Israeli Occupation do not simply serve to divide political areas, but they also allow forms of scientific observation to develop in distinct ways and through distinct sets of experiences, which thereby makes the observations on the other side-which is now produced as distinct and separate from one's own-appear to lack scientific rigor to even sympathetic observers.

The three cases in this book also combine to allow for an analysis of how elite Palestinian cartographers' work is discounted on multiple levels due to the material imbalances engendered by the production of geographic landscapes. First, their right to produce knowledge, to be acknowledged in terms of their very existence and ability to call themselves Palestinians, is continually challenged. This was seen in Chapter 3, in the efforts of Israeli population cartographers like Roberto Bachi to avoid drawing the boundaries of the West Bank. However, the presence of Palestinians in the landscape reasserted itself, leading to the alternate exclusion and inclusion of the West Bank boundary from Israeli population maps. Second, Palestinian cartographers' practical ability to build the institutions and infrastructures that undergird the production of knowledge, is repeatedly subverted in ways that, in concert with colonial legacies, continues to shape the content of even the simplest governance maps of district boundaries and national borders, as I analyzed in Chapter 4. Third, as argued in Chapter 5, even when Palestinians are relatively wellfunded and frame their assertions in ways which fit dominant conceptions of knowledge, in the case of ARIJ, by producing empirical facts about Israeli settlements, the content of that knowledge is considered unverifiable, and thus invalid in scientific conceptions, because it reflects the relatively unique experiences of Palestinians in the field. Nonetheless, although Israeli academics are often privileged over Palestinian scholars, they are not all-powerful and at times they too have been discriminated against as a result of anti-Semitism.

In either case, the analysis here is not meant to excuse the broader complicity between universities around the world in developing tools of military domination. Nor, where relevant, is it intended to pardon academics whose methods contribute to the escalation of the Occupation. The pairing between the military and academia in particular has increased in intensity over the course of the $20^{\text {th }}$ and $21^{\text {st }}$ centuries (Bowler and Morus 2005, 483), and universities have had a role in the ongoing 
military cooperation between the Israeli and US governments (Graham 2011). However, greater attention to the complexities of the relationship between scientific knowledge and power directs focus away from unilateral condemnation on the basis of identity, and towards the necessity of studying just such broader international regimes of complicity.

\section{The Significance of Cartographic Maps}

My analysis of how landscapes affect the practice of digital cartography is theoretically significant for critical social theory and, specifically, for studies of scientific and technical knowledge. Historically, scientific practice was built in part upon a belief that observations are repeatable and therefore verifiable across different observers (Daston and Galison 2007). This could be seen as an attempt to standardize scientific knowledge-to make it always and everywhere the same. Nonetheless, the influence of this idealized characterization of science has attenuated in recent years. The cartographers that I worked with were all too aware of the specific need to make their practices relevant to the contexts of Palestine and Israel. At the same time, many of them continually emphasized that they were producing objective knowledge which could travel beyond a particular context, even if this ability to travel and become part of international scientific practice was itself historically and culturally contingent (Radder 1996, 101-03).

Rather than simple lip-service to vague ideals, this belief was borne out not just by the type of knowledge which they aimed to produce, but throughout their practices at every level. In Chapter 5, settlement cartographers struggled daily to undertake data collection in ways that only ever afforded them a partial view of the Israeli settlements they sought to map, yet they did so precisely because they believed that the kinds of facts that they produced could travel beyond their specific challenges and be understood by those who had never set foot in the West Bank. Such similarities and differences within particular practices across time and space need to be studied in terms of how they are shaped at multiple geographic scales, as well as by the work it takes to maintain and enforce particular scales as being especially salient.

However, such research cannot be conceived solely in terms of the free circulation of individuals or groups against a blank geographic backdrop. For the materiality of the landscapes in which such practices play out is also one significant influence upon the varied kinds of practices which are in place. For example, in Chapter 3, I argued that Roberto Bachi could not simply choose at will the geographical scale or frame at which he conducted his observations (N. Smith 1992). Instead, his choice was a relational one, made in concert both with political considerations, his ability to collect data in the field, and his own imaginings of what he would find at particular scales. In Bachi's case, his role in establishing the Department of Geogra- 
phy at the Hebrew University of Jerusalem, his almost constant travel to international conferences, and most importantly, the presence of Palestinians in those landscapes, all would come to shape the kinds of statistics he produced.

Throughout this book, I have argued that knowledge and landscapes are fully imbricated. For the Israeli census, the PA, and NGOs who map the settlements, methodological decisions are made in concert with knowledge of the kinds of infrastructures which might help or hinder cartographers' travel both locally and abroad. Likewise, the research choices of STS scholars are also embedded in such material and geographic landscapes. They are also relational choices, if they are to be at all effective. For these reasons, geography cannot be separated from the study of knowledge, neither in terms of mapping variations in paradigms at multiple scales, nor in terms of how scientific and technological practices in particular are embedded in material landscapes which too often are framed out of the analysis. Thus isolated case studies are neither entirely local nor fully generalizeable, but require a better understanding of the relations between specific practices and their framings at variegated landscapes and scales. With this in mind, I intend the geographic production of knowledge as a call to attentiveness both to the geographic boundaries, and related exclusions, inherent in the practices studied by STS scholars and others, as well as to our selection and framing of our own research. Particularly in cases where conflict, and the networks which are part of them, exceed the boundaries of any one state (Bank and Van Heur 2007), this requires a more detailed and pragmatic middle-range theory which incorporates multiple senses of the word middle (Wyatt and Balmer 2007).

\section{International Knowledges}

A study of the impact of geographic landscapes on knowledge production also allows for a greater attention to the role of internationalism in the use of technology. While the international influence in Palestine and Israel is well-known and a continual subject of the history and political theory of the region, the role of internationals is often hidden in the background of studies of science and technology. Over the course of this book, I have investigated the role of international researchers and produced hierarchies, not in terms of explicit ideology, but instead based on how diffuse yet concrete practices have been central to cartography in the region. Forms of international control, which are often implicit in terms of setting the standards for the allegedly right way to practice science, continue to exert significant influence over how areas are mapped, both literally and metaphorically, and as such, scientific and technological practice is neither ever fully localized nor fully global. Thus forms of internationalism and their related ideologies and practices, both of which have greatly influenced Palestinian and Israeli cartographers even as they contribute to international networks more broadly, require further study that is attuned to the geographic production of knowledge across discrete spaces. 
This points to the need for internationally-influenced actors and organizations to deal more concertedly with the epistemological power of science and technology, as is evident across the case studies in this book. Bachi often looked to the international scientific networks of which he was a part in order to legitimize his statistical claims. Yet he was often constrained in terms of how much he could vary from idealized notions of science-that is, from science as it was practiced in Europe and North America-that were sometimes ill-suited for studying the practical geographies of Israel after the onset of the 1967 Occupation. Like the settlement mapping NGOs in Chapter 5, the PA agencies in Chapter 4 were consistently subject to the judgments of international bodies in terms of whether or not they are seen as being fit for self-rule. Such judgments had decisive impacts on political negotiations and the possibilities for the future funding of the PA. Yet the legacy of British colonialism, in combination with the ongoing Israeli Occupation, restricted their access to data infrastructures and landscapes for data collection in ways that have apparently gone unrecognized by those actors who judge their output. Instead, responsibility was often shifted onto the PA, by way of informal accusations that they were not capable or willing to practice 'real' science-in this case empirical mapping of local political boundaries-in the 'right' (read: international) way. Thus science and technology are inextricably bound up in international landscapes, and their complex overlapping hierarchies, in varied ways. These deserve further acknowledgement in order to enable international actors, and supranational governing bodies like the UN, to take fuller responsibility for their role in the region.

\section{Material Academic Hierarchies}

In addition to the geographic production of knowledge and internationalism, the material imbalances that influence knowledge production are also more broadly significant. For while innovative studies have been completed on the interrelationship of science and industry (Mackenzie 1990; J. C. Scott 1998), I have aimed to show here that the content of knowledge is shaped by political and economic imbalances within systems of research-which, in turn are also imbricated within geographic landscapes of science and technology. This emerged most starkly in the analysis of mobility and stasis in Chapter 4, through the description of the raids on Palestinian Authority offices and theft of digital equipment, but it also affects knowledge production more broadly, as do regional and international restrictions on travel which disproportionately affect Palestinians. ${ }^{128}$

\footnotetext{
${ }^{128}$ In this context, neither are internationals all-powerful. For the security measures carried out by the Israeli authorities also impact the ability of academics who don't hold local passports or residence permits to carry out work there. At any checkpoint, entrance might be rejected, and it has been reported that Israeli airport authorities regularly ask to search private email and social media accounts in an attempt to gain access to information on others working to end the Israeli occupation (e.g. Friedman
} 
The economic impacts of such policies are no less significant, particularly for Palestinians. Palestine and Israel are areas which have seen a continuous influx of international funding, albeit funds which are unequally distributed, with varying degrees of control over how they are used, and which have achieved mixed results. This is partly for reasons analyzed in this book, and which have also been discussed elsewhere, including studies which demonstrate that aid at times may be used simply to shore up the status quo in an effort to stave off the kind of complete humanitarian crisis which could challenge existing regimes (Bouillon 2004; Essex 2008; Hanafi 2005; Hanafi and Tabar 2003; Incite! 2007; Qarmout and Beland 2012; Redfield 2012; Rogers and Ben-David 2008; Tawil-Souri 2006). ${ }^{129}$ Every visa delay or restriction is expensive, even if it only costs time, and this in addition to the travel required mean that those whose families cannot direct their human and economic resources towards education are simply framed out of the picture.

In addition, even in the privileged cases where funding abounds, the costs of operating under the Occupation are vast. In the documents of PA funders which I consulted for Chapter 4, the delays in mapping due to political developments are constantly underestimated. Furthermore, routine tasks like keeping electricity running and maintaining their buildings were ongoing challenges for all of the NGOs where I worked. This was above and beyond the usually high commitment that is necessary elsewhere. The material and economic hierarchies which result influence research in complex ways and at multiple levels, begging further study of material exclusion in knowledge production, as well as the construction of academic hierarchies both within and beyond the nation state, of the kind pursued in this book. ${ }^{130}$

2012; see also Hass 2011a). The policies of refusal of entry are supported by visa regimes which limit most international researchers to temporary stays of not more than three months.

${ }^{129}$ Activists in particular are beginning to use crowdsourced funds via social media. In small discrete cases, virtual mobility may in fact increase corporeal mobility. For example, Ezra Nawi successfully applied to Indiegogo, a crowd-funding website, to obtain financing for a new pickup truck, which enables him to help shuttle activists back and forth to protests and otherwise support anti-Occupation efforts: http://www.indiegogo.com/projects/ezra-nawi-truck-campaign?c=home.

130 This is reminiscent of Audre Lorde's famous remark that "the master's tools will never dismantle the master's house" $(2007,110)$. Since Lorde first spoke, conception of the master's tools has been used widely in critical theory. In diverse texts, it is taken to mean any method which comes from and supports existing systems of power, particularly by perpetuating dominant forms of discourse and knowledge . In this light, GIS also might be considered a master's tool. However, Lorde herself used the phrase in a more restricted sense, referring to the paltry efforts to reach out to Black academics among the organizers of the conference at which she was speaking when she first made the remarks. So Lorde intended the master's tools to refer not only to concepts, or practices, but also to how the movement, networks, and the concentration of resources among academics themselves can affect the constitution of knowledge. Also see the discussion at: http://userpages.umbc.edu/ korenman/wmst/masterstools.html. 


\section{Next Steps: Permanent Visas for Traveling Cartographers}

With geographic production, internationalism, and the economic power imbalances among scholars in mind, it is my hope that this book convincingly illustrates the need to take seriously the material imbalances of the production of knowledge. For one, doing so makes it possible to address significant gaps in current research. In Palestine and Israel, the subject of contemporary cartography is tremendously rich, lending itself to a related analysis of multiple topics in digital mapmaking in the region. These include the contemporary atlases of the Palestinian villages that were destroyed after 1948, many of whose ruins are still visible in the landscape (see Chapter 4), as well as maps of the intricacies of mapping natural water resources such as lakes and watersheds. Such features do not conform to political boundaries even though the data that are used to study them often do. Just to name a few, further possibilities for research in digital cartography in the region could include a detailed analysis of the history of aerial photography and access to air space for the purposes of mapping, the politics of mapping the coastline which the Gaza Strip shares with Israel, and attempts to map animal migration in the region across borders in comparison with controls on the movement of scientists.

Also fascinating are the politics of creating maps of infrastructure, including for information technology, electricity, and transportation, specifically those which cross boundaries yet are managed differently within particular sovereign spaces. In addition, there is an immense collection of historical material from the decades following 1948, particularly on the role of Israeli state institutions in cartography, concerning for example the Israeli Central Bureau of Statistics (CBS) or the Survey of Israel (SOI), as well as on central Palestinian and international figures like Sami Hadawi-whose papers are in the UN archive in New York (Fischbach 2003), and much of it is only just beginning to become publicly available, although unfortunately the vast majority is likely still classified by the Israeli government. The role of transnational institutions, such as the United Nations, in cartographic pursuits also begs further exploration, particularly at sites abroad where Palestinian cartographers are regularly trained in-depth in GIS, albeit for short periods ranging from several days to several years. This would lead to a more detailed exploration of the broader ramifications of funding and types of training abroad, as well as the geographic connections across regions.

The concept of the geographical production of science and technology is also broadly applicable to cases around the world. As I argue in Chapter 3, too often geographic landscapes are assumed to be flat backgrounds for the study of the production of knowledge. To adapt the phrase Wisdom Sits in Places, the title of the well-known book (1996) by the recently-deceased anthropologist Keith Basso, who worked among the Western Apache in the United States, here I have demonstrated that knowledge is produced in landscapes. As I have shown, there is a series of diverse relationships which hold between landscapes and knowledge, and which might be applied as an analytic wherever technology is used to produce and man- 
age information. To give a few of many examples, such work might include the impact of political boundaries on the management and use of mobile devices as surveillance mechanisms, as well as their constitution in terms of software and hardware, or the role of international treaties in shaping scientific data collection in the deep ocean. In addition, researchers could investigate how the positioning and ownership of satellites shape the collection and visualization of astronomical data, as well as the circulation and subjectivities of the scientists themselves. Such studies would allow for research which both include and exceed conceptions like transnationalism and diaspora, while contributing further to conceptions of the diverse geographies of scientific and technological knowledge.

These types of research touch upon themes that reverberate beyond any single discipline or mode of writing. For example, in addition to the poem cited at the beginning of this chapter, Mahmoud Darwish also wrote of how land and ideas can reinforce one another through maps: "We have a land without borders, like our idea / of the unknown, narrow and wide. A land ... / when we walk in its map it becomes narrow with us" (2007, 205, translated by Fady Joudah). Darwish thus recasts the struggle for Palestinian nationhood in a positive light, as having created a borderless land that is both narrow and wide. He contrasts this with more dominant views, because walking, not in the land but its map, is what narrows it. Yet ideas of land which eschew dominant conceptions of sovereignty, territory, and nation, might also help to produce alternative forms of the land, and these in turn can help to generate ever more varied maps and epistemologies through the alternative passages that they create. Despite the difficulties evident in the cases here, then it is not completely impossible that dominant knowledge forms might yet themselves be dismantled, with a little creativity and a fuller understanding of the material challenges to alternative knowledges. Their parts then might be ingeniously recombined, in ways that bear little resemblance to the original. Restrictive legacies might yet be remade, piece by piece, into methodologies and dispositions that are helpful for wholly new purposes, the likes of which have yet to be fully imagined or understood. 


\section{Appendix A: List of Interviews and Fieldwork}

\section{Numbered List of Interviews Cited 131}

1 Palestinian cartographer Khalil Tufakji, former director of the Orient House Maps and Survey Department, Jerusalem, 2 July 2010

2 Palestinian cartographer in private geoinformatics firm, Bethlehem, 12 July 2010

3 Israeli geography professor, Tel Aviv, 27 July 2010

4 Israeli geographer Moshe Brawer, Tel Aviv, 2 August 2010

5 Palestinian geography professor, Birzeit, 18 January 2011

6 Former PPIB cartographer, Ramallah, 18 January 2011

7 PA transport cartographer, Bethlehem, 27 January 2011

8 PA transport engineer, Bethlehem, 27 January 2011

9 Palestinian NGO cartographer, Bethlehem, 27 January 2011

10 PA Ministry of Planning urban planner, Ramallah, 2 February 2011

11 Palestinian NGO cartographer, Bethlehem, 3 February 2011

12 PA civil engineer, Beit Sahour, 3 March 2011

13 Israeli geography professor, Jerusalem, 7 March 2011

14 Hagit Ofran, Director of the Peace Now Settlement Watch, Jerusalem, 8 March 2011

15 Hagit Ofran (small group tour), West Bank, 15 March 2011

16 UNRWA BMU project manager Stefan Ziegler, Jerusalem 12 April 2011

17 UN cartographer, Jerusalem, 14 April 2011

18 Palestinian NGO researcher, Jerusalem, 16 May 2011

19 Israeli NGO urban planner, Jerusalem, 19 May 2011

131 This list only includes interviews which are explicitly cited or quoted in the text. They are numbered in chronological order by interview date. 
20 Israeli NGO researcher, Jerusalem, 25 May 2011

21 Freelance Israeli NGO cartographer, Tel Aviv, 31 May 2011

\section{Organizations where Interviews and Participant-Observation Were Conducted ${ }^{132}$}

Applied Research Institute Jerusalem (ARIJ) (8)

Arab Studies Society

Bimkom: Planners for Planning Rights

B'Tselem: The Israeli Information Center for Human Rights

Birzeit University Department of Geography

Birzeit University Department of Urban and Rural Development

Birzeit University Water Management Workshop

Engineers without Borders Palestine (EWB)

Friends of the Earth Middle East (FOEME)

International Geographers Union (IGU) Annual Conference in Tel Aviv

The International Peace and Cooperation Center (IPCC)

Israel Central Bureau of Statistics (CBS)

Municipal Development and Lending Fund (MLDF)

Palestinian Academic Society for the Study of International Affairs (PASSIA)

Palestinian Authority (PA) Ministry of Planning (MOP)

Palestinian Authority (PA) Ministry of Transportation (MOT)

Palestine Mapping Center (PalMap)

Peace Now

Survey of Israel (SOI)

Tel Aviv University Geography Department

132 This is a complete list of organizations and groups consulted. It includes those organizations where the cited interviews in the previous list were conducted, as well as additional groups where interviews and participant-observation were conducted, but which are not cited in the text. At several organizations, more than one interview was conducted. 
Tel Aviv University Spatial Simulation for the Social Sciences (S4) Modeling Workshop

Tel Aviv University Urban Modeling Seminar

United Nations Office for the Coordination of Humanitarian Affairs (UNOCHA) in the Occupied Palestinian Territories (OPT)

United Nations Relief and Works Agency (UNRWA) Barrier Monitoring Unit (BMU)

Wadi Hilweh Information Center

\section{Archives Consulted}

Applied Research Institute Jerusalem (ARIJ) Library

Ben Gurion Institute Archives, Roberto Bachi Collection

British Library St. Pancras, Maps Reading Room

Hebrew University of Jerusalem, Bloomfield Library for the Humanities and Social Sciences

Israel Central Bureau of Statistics, GIS Unit Archives

Israel State Archives

National Library of Israel Archives, David Amiran Collection

Tel Aviv University Map Library

Birzeit University Palestine Archive (digital archive at

http://www.awraq.birzeit.edu/)

\section{Additional Tours Undertaken}

Al Quds University, Centre for Jerusalem Studies

Alternative Information Center (AIC)

The City of David Foundation (Amutat El-Ad)

Emek Shaveh

Green Olive Tours

International Geographers' Union (IGU) Urban Delegation to the Galilee

Ir-Amim 
APPENDIX A

Israeli Committee against Housing Demolitions (ICAHD)

Jerusalem Reality Tours

Ta'ayush

West Bank Hiking Group 


\section{Bibliography}

Abbas, Mokarram, and Bas Van Heur. 2013. “Thinking Arab Women's Spatiality: The Case of 'Mutanazahat' in Nablus, Palestine." Gender, Place, and Culture: 1-16.

Abdel Fattah, Awad. 2013. "Just Another Interrogation: My Encounter with the Shin Bet." +972 Magazine, April 4.

Abdelhamid, Ali. 2006. "Urban Development and Planning in the Occupied Palestinian Territories: Impacts on Urban Form" presented at the Conference on Nordic and International Urban Morphology: Distinctive and Common Themes, September 3, Stockholm.

Abdullah, Abdullah S. 2005. An Approach Towards the Development of National Geographic Information Strategy in Palestine. The Lower Jordan Basin Programme Publications 4. Ramallah: Birzeit University.

Abowd, Thomas. 2000. "The Moroccan Quarter: A History of the Present.” Jerusalem Quarterly (7): 6-16.

_-_ 2007. "Present and Absent: Historical Invention and the Politics of Place in Contemporary Jerusalem." In Reapproaching Borders: New Perspectives on the Study of Israel-Palestine, edited by Sandra Marlene Sufian and Mark LeVine, 243-265. Lanham, MD: Rowman and Littlefield.

Abu El-Haj, Nadia. 2001. Facts on the Ground: Archaeological Practice and Territorial Self-Fashioning in Israeli Society. Chicago: University of Chicago Press.

_- 2 2002. "Producing (Arti) Facts: Archaeology and Power During the British Mandate of Palestine." Israel Studies 7 (2): 33-61.

Abu Kubi, Majed. 2003. "Detection and Mapping of the Land Use/Land Cover (LULC) Changes in the Jordan Valley Using Landsat Imageries." In Environmental Monitoring in the South-Eastern Mediterranean Region Using RS/GIS Techniques, edited by Ioannis Z. Gitas and Jesús San Miguel Ayanz, 6984. Chania: Centre International de Hautes Etudes Agronomiques Méditerranéennes.

Abu-Libdeh, Hassan. 2001a. "An Urgent Appeal: The Israeli Military Forces Take Over PCBS”. Ramallah: Palestine Central Bureau of Statistics (PCBS).

_- _. 2001b. "Update No. 2, The Israeli Military Forces Withdraw from the PCBS Premises Leaving Behind Ruins, Stolen Property, Missing Files, Missing Computers, and Missing Datasets". Ramallah: PCBS.

——_. 2001c. "Update No. 3, The Day After: PCBS Inspects Its Hardware for Harmful Devices”. Ramallah: PCBS.

_- - 2001d. "Update No. 4, War Against the PCBS: The Days After, PCBS Response to IDF Claims". Ramallah: PCBS.

Abu Raya, Ali Hussein. 2010. Atlas Ma'alam Filistin Qibl 'Am 1948 [Atlas of the Landmarks of Palestine before 1948]. Sakhnin: Dar al-Ma'alam.

Abu Sitta, Salman. 2004. The Atlas of Palestine 1948. London: Palestine Land Society.

- - - 2007. The Return Journey: A Guide to the Ethnically Cleansed and Present Palestinians Towns, Villages, and Holy Sites in English, Arabic, and Hebrew. London: Palestine Land Society.

Abujidi, Nurhan. 2011. "Surveillance and Spatial Flows in the Occupied Palestinian Territories." In Surveillance and Control in Israel/Palestine: Population, Territory, and Power, edited by E. Zureik, D. Lyon, and Y. Abu-Laban, 313-334. London: Routledge.

ACA. n.d. "The Witnessing Roots.” Arabic Cultural Association (ACA). Accessed October 1, 2013. http://www.roots48-aca.org/media-eng/articles/270/The-Witnessing-Roots/.

Adalah. 2013. "Demolition and Eviction of Bedouin Citizens of Israel in the Naqab (Negev): The Prawer Plan." Adalah: The Legal Center for Arab Minority Rights in Israel. July.

Adas, Michael. 1989. Machines as the Measure of Men: Science, Technology, and Ideologies of Western Dominance. Cornell Studies in Comparative History. Ithaca: Cornell University Press.

Agamben, Giorgio. 1998. Homo Sacer: Sovereign Power and Bare Life. Stanford: Stanford University Press. - _ - 2005. State of Exception. Chicago: University of Chicago Press. 


\section{B I B L I O G RA P HY}

Ahlqvist, Ola. 2005. "Transformation of Geographic Information Using Crisp, Fuzzy and Rough Semantics." In Re-Presenting GIS, edited by Peter Fisher and David J. Unwin, 99-112. Chichester, UK: John Wiley and Sons.

Akerman, James R. 2006. Cartographies of Travel and Navigation. Chicago: University of Chicago Press.

Alatout, Samer. 2009. "Bringing Abundance into Environmental Politics: Constructing a Zionist Network of Water Abundance, Immigration, and Colonization." Social Studies of Science 39 (3): 363-394.

Aleaziz, Hamed. 2011. "Why Google Earth Can't Show You Israel.” Mother Jones, June 10.

Alkhalili, Nura. 2012. "Contestation of Space.” Berkeley Planning Journal 25 (1):160-180.

Allen, Lori. 2008. "Getting by the Occupation: How Violence Became Normal During the Second Palestinian Intifada." Cultural Anthropology 23 (3): 453-487.

- - - 2013. The Rise and Fall of Human Rights: Cynicism and Politics in Occupied Palestine. Stanford Studies in Human Rights. Stanford: Stanford University Press.

Amiran, David. 1987. "Land Transformation in Israel." In Land Transformation in Agriculture, edited by M. Gordon Wolman and F.G.A. Fournier, 291-317. Scientific Committee on Problems of the Environment (SCOPE) 32 of the International Council of Scientific Unions (ICU). New York: John Wiley and Sons.

Amit, Gish. 2008. "Ownerless Objects?: The Story of the Books Palestinians Left Behind in 1948." Jerusalem Quarterly 33: 7-20.

Amnesty International. 2003. "Israel and the Occupied Territories: Surviving Under Siege: The Impact of Movement Restrictions on the Right to Work". London:

Amnesty International.

Anderson, Benedict. 1991. “Census, Map, Museum." In Imagined Communities, 163-186. New York: Verso.

Antoon, Sinan. 2008. "Returning to the Wind: On Darwish's La Ta'tadhir 'Amma Fa'alta." In Mahmoud Darwish, Exile's Poet: Critical Essays, edited by Hala Khamis Nassar and Najat Rahman, 215-238. Northampton, Mass.: Olive Branch Press.

Aouragh, Miriyam. 2011. Palestine Online: Transnationalism, Communications and the Reinvention of Identity. London: I.B.Tauris.

al-Araj, Sheerin. 2008. "Social Ties between the People of Al-Walaja Village at Home and Abroad." In Crossing Borders, Shifting Boundaries: Palestinian Dilemmas, edited by Sari Hanafi, 12-26. Cairo Papers. Cairo: American University in Cairo Press.

Arianespace. 2013. "Arianespace to Launch Goturk-1 High-Resolution Observation Satellite.” Aerospace and Defense News, June 19.

ARIJ. n.d. "Israeli Settlement Outposts in the West Bank". Digital interactive. Bethlehem: Applied Research Institute Jerusalem (ARIJ).

_- - n.d. "The Applied Research Institute Jerusalem (ARIJ) Deplores and Condemns the Death Threats Against Hagit Ofran [....]". Bethlehem: ARIJ.

-_- 2000. "Attempt at Annexing the Modi'in Settlement Block". Bethlehem: ARIJ.

. 2004a. "Israeli Settlers Annex More Lands in [Taqu'a] Town". Bethlehem: ARIJ.

2004b. "Ecocide in [Taqu'a] Town". Bethlehem: ARIJ.

2006a. "Israeli Military Orders Database”. Accessed October 1, 2013. http://orders.arij.org/.

2006b. "New Expansions in the Israeli West Bank Settlements". Bethlehem: ARIJ.

. 2009a. A Geopolitical Atlas of the Occupied Palestinian Territory. Bethlehem: ARIJ.

. 2009b. "The Palestinian Locality Profiles". Accessed October 1, 2013. http://vprofile.arij.org/.

. 2013a. "The Location of Kfar Adumim Settlement and the Targeted Palestinian School".

Bethlehem: ARIJ.

_-_. 2013b. "Israeli Authorities Ban Entry of ARIJ Intern". Bethlehem: ARIJ.

Ashery, Oreet, and Larissa Sansour. 2009. The Novel of Nonel and Vovel. Milan: Charta.

B’Tselem. 2004. "Forbidden Roads: Israel's Discriminatory Road Regime in the West Bank". Jerusalem: B'Tselem.

B’Tselem, and Eyal Weizman. 2002. "Jewish Settlements in the West Bank: Built-up Areas and Land Reserves". Jerusalem: B’Tselem. 
Bachi, Roberto. 1955. "The Graphical Representation of Geographical Series." In Bulletin of the International Statistical Institute, 34, Book 4:455-470. International Statistical Institute.

- — . , ed. 1956. Studies in Economic and Social Sciences. Scripta Hierosolymitana III. Jerusalem: Magnes Press.

- - 1962a. "Some New Methods for the Graphical Representation of Statistical Data." In Bulletin of the International Statistical Institute, 40:343-361. Paris: International Statistical Institute.

- _- 1962b. "Standard Distance Measures and Related Methods for Spatial Analysis." In Regional Science Association: Papers X, 83-132. Zurich: Regional Science Association.

-_- 1968. Graphical Rational Patterns: A New Approach to Graphical Presentation of Statistics. Jerusalem: Israel Universities Press.

- - . 1974a. The Population of Israel. Jerusalem: Institute of Contemporary Jewry and Hebrew University of Jerusalem.

- — . 1974b. “The Jewish Population.” In Society, 1-28. Jerusalem: Keter.

- _ 1975. "Graphical Methods for Presenting Statistical Data: Progress and Problems." In Proceedings of the International Symposium on Computer-Assisted Cartography, 74-98. Washington, DC: US Department of Commerce, Bureau of the Census.

- - 1980. "A Population Policy for Israel?" Jewish Journal of Sociology 22 (2): 163-179.

- - 1981. "Mapping the Characteristics of Distributions of Populations over Territories." In Bulletin of the International Statistical Institute, 49, Book 2:1003-1026. Rome: International Statistical Institute.

- — 1989. "Rational Maps and Parameters of Geographical-Statistical Data." Espace, Populations, Sociétés 7 (3): 337-348.

- - 1999. New Methods of Geostatistical Analysis and Graphical Presentation: Distributions of Populations Over Territories. New York: Kluwer Academic and Plenum.

Bachi, Roberto, H. Gil, M. Mühsam, and M. Sicron. 1955. "Registration of Population, Part A: Towns, Villages and Regions (Extract)". Special Series No. 368 XI 1948. Jerusalem: Israel Central Bureau of Statistics (CBS).

Bahat, Kobi. 1997. "Census Mapping Using the GIS System" presented at the EUROSTAT and the Israeli Central Bureau of Statistics: New Technologies for the 2000 Census Round: Sharing the Israeli Experience from the 1995 Census, March 16, Kibbutz Ma'ale Hachamisha, Israel.

Balibar, Etienne. 1990. "The Nation Form: History and Ideology." Review: Fernand Braudel Center 13 (3): 329-361.

Bank, André, and Bas Van Heur. 2007. "Transnational Conflicts and the Politics of Scalar Networks: Evidence from Northern Africa." Third World Quarterly 28 (3): 593-612.

Bar-Gal, Yoram. 2013. "Professor David Amiran (1910-2003)." Memorial Site on Israeli Geographers. Accessed September 12, 2013. http://geo.haifa.ac.il/ bargal/history/english/amiran_english.htm.

Barak, Aharon. 2005. Mara'abe V. The Prime Minister of Israel. The High Court of Justice of Israel.

Barak, Dafna. 1997. "Producing Maps and Data-Files for the Census and Post-Census Geographical Products" presented at the EUROSTAT and the Israeli Central Bureau of Statistics: New Technologies for the 2000 Census Round: Sharing the Israeli Experience from the 1995 Census, March 16, Kibbutz Ma'ale Hachamisha, Israel.

Barnard, Ryvka. 2013. "Seeing How the Natives Live: On the Pitfalls and Potential of Alternative Tourism" Jadaliyya, April 16.

Barnes, Barry, D. Bloor, and J. Henry. 1996. Scientific Knowledge: A Sociological Analysis. London: Athlone.

Barnes, Trevor J. 2001. "Lives Lived and Lives Told: Biographies of Geography's Quantitative Revolution." Society and Space 19 (4): 409-429.

Baskin, Elisha, and Donna Nevel. 2013. "Thoughts About Our Role and Work as Jews Committed to Justice in Palestine." Mondoweiss, May 8.

Basso, Keith. 1996. Wisdom Sits in Places: Landscape and Language Among the Western Apache. Albuquerque: University of New Mexico Press. 
Beaulieu, Anne, S. de Rijcke, and B. Van Heur. 2013. "Authority and Expertise in New Sites of Knowledge Production." In Virtual Knowledge: Experimenting in the Humanities and the Social Sciences, edited by P. Wouters, A. Beaulieu, A. Scharnhorst, and S. Wyatt, 25-56. Cambridge, Mass.: MIT Press.

Bekker, Vita. 2013. "Palestinian Activists Sue Israel for the Return of 6,000 Books." The National (Abu Dhabi), May 19.

Bektas, Yakup. 2000. "The Sultan's Messenger: Cultural Constructions of Ottoman Telegraphy, 18471880." Technology and Culture 41 (4): 669-696.

Ben-Moshe, Eliahu. 1997a. "Integration of a National GIS Project Within the Planning and Implementation of a Population Census" presented at the EUROSTAT and the Israeli Central Bureau of Statistics: New Technologies for the 2000 Census Round: Sharing the Israeli Experience from the 1995 Census, March 16, Kibbutz Ma'ale Hachamisha, Israel.

- - . 1997b. "Planning a Census By the End of the Nineties" presented at the EUROSTAT and the Israeli Central Bureau of Statistics: New Technologies for the 2000 Census Round: Sharing the Israeli Experience from the 1995 Census, March 16, Kibbutz Ma'ale Hachamisha, Israel.

- - - 1997c. "The Israeli 1995 Census-GIS Integration Project" presented at the Work Session on Geographical Information Systems of the Statistical Commission and Economic Commission for Europe Conference of European Statisticians, September 22, Brighton.

Bender, Barbara, and Margot Winer, ed. 2001. Contested Landscapes: Movement, Exile and Place. Oxford, UK: Berg.

Benvenisti, Meron. 1984. "US Government Funded Projects in the West Bank and Gaza (1977-1983)". Working Paper 13. Jerusalem: The West Bank Data Base Project.

- - . 1999. "Bikini on Jerusalem's Beach." Ha'aretz, July 29.

- - . 2000. Sacred Landscape: The Buried History of the Holy Land Since 1948. Berkeley: University of California Press.

Benvenisti, Meron, and Shlomo Khayat. 1988. The West Bank and Gaza Atlas. Jerusalem: West Bank Data Base Project.

Benziman, Uzi. 2006. "Moving on to the Next Scandal..." Ha'aretz, December 20.

Bhabha, Homi K. 2004. The Location of Culture. Routledge Classics. London: Routledge.

Bijker, Wiebe E. 1995. Of Bicycles, Bakelites, and Bulbs: Toward a Theory of Sociotechnical Change. Cambridge, Mass.: MIT Press.

Bijker, Wiebe E., R. Bal, and R. Hendriks. 2009. The Paradox of Scientific Authority: The Role of Scientific Advice in Democracies. Inside Technology. Cambridge, Mass.: MIT Press.

Bishara, Amahl. 2003. "House and Homeland: Examining Sentiments About and Claims to Jerusalem and Its Houses." Social Text 21 (2): 141-162.

Blake, Gerald. 1995. "The Depiction of International Boundaries on Topographic Maps.” International Boundaries Research Unit Boundary and Security Bulletin: 44-50.

Bland, Sally. 2004. "Sami Hadawi: The Scholar Who Couldn't Go Home." Middle East Window and Jordan Times, May 17.

Bloor, David. 1976. Knowledge and Social Imagery. London: Routledge and Kegan Paul.

Blum, Olivia. 1997. "Logical Structure and Guiding Principles" presented at the EUROSTAT and the Israeli Central Bureau of Statistics: New Technologies for the 2000 Census Round: Sharing the Israeli Experience from the 1995 Census, March 16, Kibbutz Ma'ale Hachamisha, Israel.

Bossard, M., J. Feranec, and J. Otahel. 2000. Corine Land Cover Technical Guide: Addendum 2000. Copenhagen: European Environment Agency.

Bouillon, Markus E. 2004. The Peace Business: Money and Power in the Palestine-Israel Conflict. London: I.B. Tauris.

Bowler, Peter J., and Iwan Rhys Morus. 2005. Making Modern Science: A Historical Survey. Chicago: University of Chicago Press.

Braidotti, Rosi. 2013. Nomadic Subjects: Embodiment and Sexual Difference in Contemporary Feminist Theory. New York: Columbia University Press.

Braverman, Irus. 2009. "Planting the Promised Landscape: Zionism, Nature, and Resistance in Israel/Palestine." The Natural Resources Journal 49 (2): 317-361.

Brawer, Moshe. 1990. “The 'Green Line': Functions and Impacts of an Israeli-Arab Superimposed 
Boundary." In International Boundaries and Boundary Conflict Resolution, edited by Carl GrundyWarr, 63-74. Durham, UK: Boundaries Research Press.

- — . 1994. "All That Remains?" Israel Affairs 1 (2): 334-345.

- - . 2008. "The Image of Israel's Geographical Transformation, In Honor of Israel Prize Recipient, Prof. Elisha Efrat." Israel Studies 13 (1): 152-159.

Bronner, Ethan. 2008. "3 Fulbright Winners in Gaza Again Told They Can't Travel." New York Times, August 5.

Brown, Wendy. 2010. Walled States, Waning Sovereignty. New York: Zone Books.

Buckley, Craig, and Mark Wasiuta, ed. 2013. Collecting Architecture Territories. New York: GSAPP and Deste Foundation for Contemporary Art.

Bunge, William. 1966. “Gerrymandering, Geography, and Grouping." Geographical Review 56 (2): 256-263.

Büttner, George, J. Feranec, G. Jaffrain, C. Steenmans, A. Gheorghe, and V. Lima. 2002. Corine Land Cover Update 2000: Technical Guidelines. Copenhagen: European Environment Agency.

Callon, Michael, and Bruno Latour. 1992. "Don't Throw the Baby Out with the Bath School! A Reply to Colins and Yearly." In Science as Practice and Culture, edited by Andrew Pickering. Chicago: University of Chicago Press.

Calvo, Rinat. 1997. "Redistricting Enumeration Areas and Defining the Organizational Structure" presented at the EUROSTAT and the Israeli Central Bureau of Statistics: New Technologies for the 2000 Census Round: Sharing the Israeli Experience from the 1995 Census, March 16, Kibbutz Ma'ale Hachamisha, Israel.

Cameron, Angus. 2011. "Ground Zero - the Semiotics of the Boundary Line." Social Semiotics 21 (3): 417-434.

Carmon, Naomi. 1999. "Three Generations of Urban Renewal Policies: Analysis and Policy Implications." Geoforum 30 (2): 145-158.

Carta. 2005. Super Atlas Carta Eretz Israel [Carta's Super Atlas of the Land of Israel]. Jerusalem: Carta.

CBS. 1963. "Average Number of Persons in Household by Natural Region." In The Settlements of Israel, Part II: Sex, Age, Residence and Population Group: Data From Stage A of the Census, 11:n.p. 1961 Population and Housing Census. Jerusalem: Israeli Central Bureau of Statistics (CBS).

- - - 1967. West Bank of the Jordan, Gaza Strip and Northern Sinai, Golan Heights: Data from Full Enumeration. Jerusalem: CBS.

- - . 1969a. "Distribution of the Jewish and Non-Jewish Population in 1968 By Locality". Jerusalem: CBS. GL-3556/16. 94.0/1-226. 02-105-06-04-09. Israel State Archives.

- - 1969b. "1972 Census of Population and Housing: Methodology." Jerusalem: CBS. 7-731-13221972-0011/8, 29/10/1968-3/10/1969. Israel State Archives.

-_- 1985a. "Localities (2,000 Inhabitants and More) and Statistical Areas." In Population and Households, Socio-Economic Characteristics from the Sample Enumeration. Vol. 5. 1983 Census of Population and Housing. Jerusalem: CBS.

- - . 1985b. Population and Households, Socio-Economic Characteristics from the Sample Enumeration. Vol. 5.1983 Census of Population and Housing. Jerusalem: CBS.

-_- 2000a. "Census 1995". Jerusalem: CBS GIS Unit. Accessed October 1, 2013. http://gis.cbs.gov.il/website/eng/viewer.htm.

- - 2000b. Characterization and Classification of Geographical Units by the Socio-Economic Level of the Population. Vol. 13. 1995 Census of Population and Housing. Jerusalem: CBS.

- - 2. 2012. "Monthly Bulletin of Statistics of Israel, Population Table B-1: Population by Population Group, Thousands." Jerusalem: CBS. December.

Chadwick, Alex. 2006. "Israeli Group: Leaked Maps Counter Government." National Public Radio (NPR) News.

Clark, Nigel, D. B. Massey, and P. Sarre, ed. 2008. Material Geographies: A World in the Making. Living in a Globalised World. London: Sage Publications.

Claudet, Sophie. 2001. "Israeli Army Raid Sets Dangerous New Precedent." The Daily Star (Beirut), December 10.

Clifford, James. 2001. “Indigenous Articulations.” The Contemporary Pacific 13 (2): 468-490. 
- - 2 2003. On the Edges of Anthropology: Interviews. Chicago: Prickly Paradigm Press.

Cohen, Shaul. 1993. The Politics of Planting: Israeli-Palestinian Competition for Control of Land in the Jerusalem Periphery. Chicago: University of Chicago Press.

_-_. 1994. “Greenbelts in London and Jerusalem.” Geographical Review 84 (1):74-89.

-_- 2000. "An Absence of Place: Expectation and Realization in the West Bank." In Cultural Encounters with the Environment: Emerging and Evolving Geographic Themes. Lanham, Maryland: Rowman and Littlefield.

-__. 2002. "As a City Besieged: Place, Zionism, and the Deforestation of Jerusalem." Society and Space 20 (2): 209-230.

Coignet, Gildas. 2009. “Espaces Publics et Identité Nationale, de la Capitale Arabe Moderne à la Métropole Mondialisée [Public Spaces and National Identity: From the Modern Arab Capital to the Globalized Metropolis]." Les Cahiers d'EMAM: Études sur le Monde Arabe et la Méditerranée (18): 123-126.

Coogan, Mike. 2013. "Senator Boxer's Far-fetched Defense of the Visa Waiver Exemption for Israel." Mondoweiss, May 10.

Coon, Anthony G. 1990. "Development Plans in the West Bank." GeoJournal 21 (4): 363-373.

Cosgrove, Denis. 2007. “Epistemology, Geography, and Cartography: Matthew Edney on Brian Harley's Cartographic Theories." Annals of the Association of American Geographers 97 (1): 202-209.

_-_. 2008. Geography and Vision: Seeing, Imagining and Representing the World. International Library of Human Geography London: I.B. Tauris.

Courbage, Youssef. 1999. "Reshuffling the Demographic Cards in Israel/Palestine." Journal of Palestine Studies 28 (4): 21-39.

Coutard, Olivier, and Simon Guy. 2007. "STS and the City Politics and Practices of Hope." Science, Technology, and Human Values 32 (6): 713-734.

Craib, Raymond B. 2009. "Relocating Cartography." Postcolonial Studies 12 (4): 481-490.

Crampton, Jeremy W. 2010. Mapping: A Critical Introduction to Cartography and GIS. Malden, Mass.: Wiley-Blackwell.

Crampton, Jeremy W. 2001. "Maps as Social Constructions: Power, Communication and Visualization." Progress in Human Geography 25: 235-252.

_-_. 2003. "Cartographic Rationality and the Politics of Geosurveillance and Security." Cartography and Geographic Information Science 30 (2): 135-148.

Crampton, Jeremy W., and Stuart Elden, ed. 2007. Space, Knowledge and Power: Foucault and Geography. Aldershot: Ashgate.

Crampton, Jeremy W., and John Krygier. 2006. “An Introduction to Critical Cartography.” Acme 4 (1): 11-33.

Cranor, John D., G. L. Crawley, and R. H. Scheele. 1989. "The Anatomy of a Gerrymander.” American Journal of Political Science 33 (1): 222-239.

Cresswell, Tim. 1999. "Embodiment, Power and the Politics of Mobility: The Case of Female Tramps and Hobos." Transactions of the Institute of British Geographers 24 (2): 175-192.

_-_. 2011. “Mobilities I: Catching Up.” Progress in Human Geography 35 (4): 550-558.

Culcasi, Karen. 2008. "Cartographic Constructions of the Middle East”. Dissertation, Syracuse, NY: Syracuse University, Department of Geography.

_- - 2010. "Constructing and Naturalizing the Middle East." Geographical Review 100 (4): 583-597.

_-_. 2012. "Mapping the Middle East from Within: (Counter-)Cartographies of an Imperialist Construction." Antipode 44 (4): 1099-1118.

Curry, Michael R. 1998. Digital Places: Living with Geographic Information Technologies. London: Routledge.

Daoud, Ribhi M. 2000. "An Evaluation of the Role of the Palestine Economic Council for Development and Reconstruction (PECDAR) in Palestine's Infrastructure Development Since the 1993 Oslo Accords”. Dissertation, Minneapolis: Walden University.

Darwish, Mahmoud. n.d. "Halat Hasar [State of Siege] [selection]." Translated by Ramsis Amun. Best Poems Encyclopedia. Accessed October 1, 2013.

http://www.best-poems.net/mahmoud_darwish/state_of_siege.html.

——_. 1993. Ara Ma Urid [I See What I Want]. Beirut: Dar al-Awdat. 
-——. 2002. Halat Hasar [State of Siege]. Beirut: Riad El-Rayyes Books.

2003. Unfortunately, It Was Paradise. Translated by Munir Akash and Carolyn Forché. Berkeley:

University of California Press.

_-_. 2004. La Ta'tadhir 'Amma Fa'alta [Do Not Apologize for What you Have Done]. Beirut:

Riad El-Rayyes Books.

_- - 2007. The Butterfly's Burden: Poems. Translated by Fady Joudah. Port Townsend, Wash.: Copper Canyon Press.

Darwish, Mahmoud, S. al-Qasim, and Adonis. 1995. Victims of a Map: A Bilingual Anthology. London: Saqi Books.

Daston, Lorraine, and Peter Galison. 2007. Objectivity. New York: Zone Books.

Dattel, Lior. 2013. "In the World of Charity, Israel Is Still Receiving a Lot More Than It Gives Back." Ha'aretz, May 23.

Davis, Angela Y. 1971. “Lessons from Attica to Soledad.” New York Times, October 8.

Davis, Rochelle. 2011. Palestinian Village Histories: Geographies of the Displaced. Stanford Studies in Middle Eastern and Islamic Societies and Cultures. Stanford: Stanford University Press.

Davis, Uri, A. E. L. Maks, and J. Richardson. 1980. “Israel's Water Policies.” Journal of Palestine Studies $9(2): 3-31$.

Delisle, Guy. 2012. Jerusalem: Chronicles of the Holy City. Montreal: Drawn and Quarterly.

Denzin, Norman K. 1970. The Research Act in Sociology: A Theoretical Introduction to Sociological Methods. Methodological Perspectives. London: Butterworths.

- - - 1977. The Research Act: A Theoretical Introduction to Sociological Methods. New York: McGraw-Hill.

Derrida, Jacques. 1981. Positions. Translated by Alan Bass. Chicago: University of Chicago Press.

Dodge, Martin, R. Kitchin, and C. Perkins, ed. 2009. Rethinking Maps: New Frontiers in Cartographic Theory. Routledge Studies in Human Geography. New York: Routledge.

Doerr, Arthur H., J. F. Coling, and W. S. Kerr. 1970. "Agricultural Evolution in Israel in the Two Decades Since Independence." Middle East Journal 24 (3): 319-337.

Domosh, Mona. 1996. Invented Cities: The Creation of Landscape in Nineteenth-Century New York \& Boston. New Haven: Yale University Press.

van Doorn, Niels, S. Wyatt, and L. van Zoonen. 2008. "A Body of Text.” Feminist Media Studies 8 (4): 357-374.

Dorrian, Mark, and Gillian Rose, ed. 2003. Deterritorialisations... Revisioning: Landscapes and Politics. London: Black Dog.

Duncan, Sally L. 2006. "Mapping Whose Reality? Geographic Information Systems (GIS) and 'Wild Science'." Public Understanding of Science 15 (4): 411-434.

Dunne, Christine E., P. J. Atkins, M. J. Blakemore, and J. G. Townsend. 1999. "Teaching Geographical Information Handling Skills for Lower-income Countries." Transactions in GIS 3 (4): 319-332.

Edgerton, David. 2007. "Creole Technologies and Global Histories: Rethinking How Things Travel in Space and Time." Host: Journal of History of Science and Technology 1: 75-112.

Edney, Matthew H. 1997. Mapping an Empire: The Geographical Construction of British India, 1765-1843. Chicago: University of Chicago Press.

_- - 2005. "Putting 'Cartography' into the History of Cartography: Arthur H. Robinson, David Woodward, and the Creation of a Discipline." Cartographic Perspectives 51: 14-29.

_- _. 2009. "The Irony of Imperial Mapping." In The Imperial Map: Cartography and the Mastery of Empire, edited by James R. Akerman, 11-45. Chicago: University of Chicago Press.

Efrat, Elisha. 1994. “Israel's Planned New 'Crossing Highway'.” Journal of Transport Geography 2 (4): 274-277.

El-Eini, Roza. 2006. Mandated Landscape: British Imperial Rule in Palestine: 1929-1948. New York: Routledge.

Elia, Nada. 2004. "Epistemic Violence, Smear-Campaigns, and Hit-Lists: Disappearing the Palestinians." In Cultural Shaping of Violence: Victimization, Escalation, Response, edited by Myrdene Anderson, 187-192. West Lafayette, Indiana: Purdue University Press.

__- 2005. "The Burden of Representation: When Palestinians Speak Out." Edited by R. Abdulhadi, 
N. Naber, and E. Alsultany. The MIT Electronic Journal of Middle East Studies Special Issue: Gender, Nation, and Belonging, Arab and Arab American Feminist Perspectives 5: 58-70.

Elwood, Sarah. 2009. "Geographic Information Science: New Geovisualization Technologies - Emerging Questions and Linkages with GIScience Research." Progress in Human Geography 33 (2): 256-263.

Essex, Jamey. 2008. "Deservedness, Development, and the State: Geographic Categorization in the US Agency for International Development's Foreign Assistance Framework." Geoforum 39 (4): 1625-1636.

Ettinger, Yair. 2007. "Radical Black Panther Group Buries Sa'adia Marciano, 'the Face of Protest'." Ha'aretz, December 23.

Eviction in East Jerusalem. 2009. Inside Story. Doha, Jerusalem, and Tel Aviv: Al Jazeera English, February 24.

Fabian, Johannes. 2002. Time and the Other: How Anthropology Makes Its Object. New York: Columbia University Press.

Falah, Ghazi. 1985. “How Israel Controls the Bedouin in Israel.” Journal of Palestine Studies 14 (2): 35-51.

- - . 1989. "Israeli State Policy Toward Bedouin Sedentarization in the Negev." Journal of Palestine Studies 18 (2): 71-91.

Fanon, Frantz. 2008. Black Skin, White Masks. New York: Grove Press.

Farah, Joseph. 2002. "Palestinian People Do Not Exist.” World Net Daily (WND), July 11.

Farman, Jason. 2010. "Mapping the Digital Empire: Google Earth and the Process of Postmodern

Cartography." New Media \& Society 12 (6): 869-888.

Feldman, Ilana. 2008. Governing Gaza. Durham, North Carolina: Duke University Press.

Ferguson, James. 2012. "Structures of Responsibility." Ethnography 13 (4): 558-562.

Fields, Gary. 2010. "Enclosure: Palestinian Landscape in a 'Not-Too-Distant Mirror'."

Journal of Historical Sociology 23 (2): 216-250.

- - 2012. "This Is Our Land': Collective Violence, Property Law, and Imagining the Geography of Palestine." Journal of Cultural Geography 29 (3): 267-291.

Fischbach, Michael R. 2003. Records of Dispossession: Palestinian Refugee Property and the Arab-Israeli Conflict. New York: Columbia University Press.

- - - 2011. "British and Zionist Data Gathering on Palestinian Arab Landownership and Population During the Mandate." In Surveillance and Control in Israel/Palestine: Population, Territory, and Power, edited by E. Zureik, D. Lyon, and Y. Abu-Laban, 297-312. London: Routledge.

Fischer, Michael M. J. 2006. “Changing Palestine-Israel Ecologies: Narratives of Water, Land, Conflict, and Political Economy, Then and Now, and Life to Come." Cultural Politics 2 (2).

Fischhendler, Itay. 2008. "When Ambiguity in Treaty Design Becomes Destructive: A Study of Transboundary Water." Global Environmental Politics 8 (1): 111-136.

Fisher, Peter, A. Comber, and R. Wadsworth. 2005. "Land Use and Land Cover: Contradiction or Complement." In Re-Presenting GIS, edited by Peter Collier and David J. Unwin, 85-98. Chichester, UK: John Wiley and Sons.

Fisher, Peter, and David J. Unwin, ed. 2005. Re-Presenting GIS. Chichester, UK: John Wiley and Sons.

Forte, Tania. 2003. "Sifting People, Sorting Papers: Academic Practice and the Notion of State Security in Israel." Comparative Studies of South Asia, Africa, and the Middle East 23 (1): 215-223.

Foster, Zachary J. 2013. "Ottoman and Arab Maps of Palestine, 1880s-1910s." The Afternoon Map, July 30 .

Foucault, Michel. 1986. "Of Other Spaces." Diacritics 16: 22-27.

Friedman, Lara. 2012. "What You Need to Know About E-1." Washington, DC: Americans for Peace Now.

Galeano, Eduardo H. 2000. Upside down: A Primer for the Looking-Glass World. New York: Metropolitan Books.

Garb, Yaakov. 2004. “Constructing the Trans-Israel Highway's Inevitability." Israel Studies 9 (2): 180-217.

Gasteyer, Stephen P., and Cornelia Butler Flora. 2000. "Modernizing the Savage: Colonization and Perceptions of Landscape and Lifescape." Sociologia Ruralis 40 (1): 128-149. 
Gavish, Dov. 1996. "Foreign Intelligence Maps: Offshoots of the 1:100,000 Topographic Map of Israel." Imago Mundi 48: 174-184.

-—- 2005. A Survey of Palestine Under the British Mandate, 1920-1948. New York: Routledge.

2006. "Barrel in the Courtyard of the Survey of Israel." In Working Group on the History of Colonial Cartography in the 19th and 20th Centuries. Utrecht: International Cartographic Association (ICA).

Gavish, Dov, and Ron Adler. 1999. 50 Years of Mapping Israel, 1948-1999. Tel Aviv: Survey of Israel (SOI).

Gavish, Dov, and Avishai Ben-Porath. 2003. "Mapot Emek ha-Hulah: Saman Derek bi-Mipuwi Otimani baEretz Israel [The Hulah Valley Map of 1887: A Landmark in Ottoman Cartography in Palestine]." Cathedra (109): 131-138.

Ghussein, Walaa, and Annie Robbins. 2013. “Two Friends Meet for 5 Minutes in Jerusalem.” Mondoweiss, May 19.

Gibson-Graham, J .K. 2002. "Beyond Global Vs. Local: Economic Politics Outside the Binary Frame." In Geographies of Power: Placing Scale. Oxford: Blackwell.

Gieryn, Thomas F. 1999. Cultural Boundaries of Science: Credibility on the Line. Chicago: University of Chicago Press.

- - 2000. "A Space for Place in Sociology." Annual Review of Sociology 26: 463-496.

_-_. 2006. "City as Truth-Spot: Laboratories and Field-Sites in Urban Studies." Social Studies of Science 36 (1): 5-38.

Gisha. 2012. "What Is the 'Separation Policy'?” Tel Aviv: Gisha Legal Center for Freedom of Movement.

Godlewska, Anne. 1999. Geography Unbound: French Geographic Science from Cassini to Humboldt. Chicago: University of Chicago Press.

Godlewska, Anne, and Neil Smith, ed. 1994. Geography and Empire. The Institute of British Geographers Special Publications Series 30. Oxford, UK: Blackwell.

Goering, Kurt. 1979. "Israel and the Bedouin of the Negev." Journal of Palestine Studies 9 (1): 3-20.

Golan, Tal. 2004. "Introduction." Israel Studies 9 (2): iv-viii.

"Golda Meir Scorns Soviets.” 1969. Washington Post, June 16.

Goldshleger, Naftaly, I. Amit-Cohen, and M. Shoshany. 2006. "A Step Ahead of Time: Design, Allocation and Preservation of Private Open Space in the 1920s--the Case of a Garden Suburb in Israel." GeoJournal 67 (1): 57-69.

Gordon, Neve. 2011. “Israel's Emergence as a Homeland Security Capital." In Surveillance and Control in Israel/Palestine: Population, Territory, and Power, edited by E. Zureik, D. Lyon, and Y. Abu-Laban, 153-170. London: Routledge.

Gorenberg, Gershom. 2012. "Draw the Line: How Israel Erases Itself.” The Daily Beast, March 26.

Gorney, Edna. 2007. “(Un)Natural Selection: The Drainage Of The Hula Wetlands, An Ecofeminist Reading." International Feminist Journal of Politics 9 (4): 465-474.

Government of the United Kingdom. 1924. Railway Clearing House, Coaching Arrangements Book: Passenger Traffic Section, Embracing the General Regulations Relating to Fares, Tickets, Luggage, Etc. London: Jas. Truscott and Son.

Graham, Stephen. 2011. "Laboratories of War: Surveillance and US-Israeli Collaboration in War and Security." In Surveillance and Control in Israel/Palestine: Population, Territory, and Power, edited by E. Zureik, D. Lyon, and Y. Abu-Laban, 133-152. London: Routledge.

Gratien, Chris. 2013. "Mapping Minorities in Syria”. The Afternoon Map, August 29.

Gregory, Derek. 1994. Geographical Imaginations. Cambridge, Mass.: Blackwell.

Guarnieri, Mya. 2013. "Palestinian University Shuts down in Wake of Violence, Teacher Strikes." +972 Magazine, March 16.

Gurvitz, Yossi. 2011. "Palestinians Handcuffed, Detained for Picking Wildflowers.” +972 Magazine, March 8.

Hadawi, Sami. 1957. Land Ownership in Palestine. New York: Palestine Arab Refugee Office.

-_- 1970. "Village Statistics 1945: A Classification of Land and Area Ownership in Palestine". Beirut: Palestine Liberation Organization (PLO) Research Center.

Haffner, Jeanne. 2013. The View from Above: The Science of Social Space. Cambridge, Mass.: MIT Press. 


\section{B I B L I O G RA P H Y}

Halabi, Usama. 2011. "Legal Analysis and Critique of Some Surveillance Methods Used by Israel.” In Surveillance and Control in Israel/Palestine: Population, Territory, and Power, edited by E. Zureik, D. Lyon, and Y. Abu-Laban, 199-218. London: Routledge.

Halffman, Willem. 2003. "Boundaries of Regulatory Science: Eco/toxicology and Aquatic Hazards of Chemicals in the US, England and the Netherlands, 1970-1995”. Dissertation, Amsterdam: University of Amsterdam.

Hammerman, Ilana. 2011. "Illegal in Their Own Country." Ha'aretz, September 9.

Hanafi, Sari. 2005. The Emergence of a Palestinian Globalized Elite: Donors, International Organizations, and Local NGOs. Jerusalem: Institute of Jerusalem Studies and Muwatin, Palestinian Institute for the Study of Democracy.

——_. 2009. "Spacio-cide: Colonial Politics, Invisibility and Rezoning in Palestinian Territory." Contemporary Arab Affairs 2 (1): 106-121.

Hanafi, Sari, and Linda Tabar. 2003. "The Intifada and the Aid Industry: The Impact of the New Liberal Agenda on the Palestinian NGOs." Comparative Studies of South Asia, Africa, and the Middle East 23 (1-2): 205-214.

Handel, Ariel. 2009. "Where, Where to, and When in the Occupied Territories: An Introduction to Geography of Disaster." In The Power of Inclusive Exclusion: Anatomy of Israeli Rule in the Occupied Palestinian Territories, edited by A. Ophir, M. Givoni, and S. Hanafi. New York: Zone Books.

___. 2011. "Exclusionary Surveillance and Spatial Uncertainty in the Occupied Palestinian Territories." In Surveillance and Control in Israel/Palestine: Population, Territory, and Power, edited by E. Zureik, D. Lyon, and Y. Abu-Laban, 199-218. London: Routledge.

Hannah, Matthew G. 2001. "Sampling and the Politics of Representation in US Census 2000."

Environment and Planning D: Society and Space 19 (5): 515 - 534.

_- 2 2009. "Calculable Territory and the West German Census Boycott Movements of the 1980s." Political Geography 28 (1): 66-75.

Hannam, Kevin, Mimi Sheller, and John Urry. 2006. "Editorial: Mobilities, Immobilities and Moorings." Mobilities 1 (1): 1-22.

Haraway, Donna. 1988. "Situated Knowledges: The Science Question in Feminism and the Privilege of Partial Perspective." Feminist Studies 14: 575-599.

Harding, Sandra. 1998. Is Science Multicultural? Postcolonialisms, Feminisms, and Epistemologies. Bloomington: Indiana University Press.

_-_. 2004a. "Introduction: Standpoint Theory as a Site of Political, Philosophic, and Scientific Debate." In The Feminist Standpoint Theory Reader: Intellectual and Political Controversies, edited by Sandra Harding, 1-16. New York: Routledge.

_—_. , ed. 2004b. The Feminist Standpoint Theory Reader: Intellectual and Political Controversies. New York: Routledge.

_-_. 2006. Science and Social Inequality: Feminist and Postcolonial Issues. Race and Gender in Science Studies. Urbana, IL: University of Illinois Press.

_-_ 2008. Sciences from Below: Feminisms, Postcolonialities and Modernities. Durham, North Carolina: Duke University Press.

Harley, J. B. 1989. “Deconstructing the Map.” Cartographica 26: 1-20.

- - 2001. The New Nature of Maps: Essays in the History of Cartography. Edited by Paul Laxton. Baltimore: Johns Hopkins University Press.

Harris, Leila M., and Helen D. Hazen. 2006. "Power of Maps: (Counter) Mapping for Conservation.” Acme 4 (1): 99-130.

Harvey, David. 1997. Justice, Nature and the Geography of Difference. Oxford: Blackwell.

- - 2005. Paris, Capital of Modernity. Second. New York: Routledge.

. 2006. Spaces of Global Capitalism: Towards a Theory of Uneven Geographical Development. New York: Verso.

Harvey, Lee, and Morag MacDonald. 1993. Doing Sociology: A Practical Introduction. Houndmills, UK: Palgrave Macmillan.

Hashemite Kingdom of Jordan, and State of Israel. 1998. Treaty of Peace Between the State of Israel and the Hashemite Kingdom of Jordan. Vol. 2042, I-35325. 
Hass, Amira. 2001. “Break-in at the Statistics Bureau.” Ha'aretz, December 10.

___. 2011a. "West Bank Travel Restrictions Take Their Toll on International Aid Budgets." Ha'aretz, June 7.

- - - 2011b. "Israel Allows Gaza Athletes to Cross into West Bank, but Bars Outstanding Academics." Ha'aretz, December 26.

- _ . 2012. "What Happens When a Palestinian Journalist Dares Criticize the Palestinian Authority?" Ha'aretz, April 2.

Hasson, Nir. 2011. "Israel Sanctions East Jerusalem Family for Straddling Palestinian Border." Ha'aretz, September 27.

_—_. 2012a. “Google Street View Catches the Beauty and Hardships of Jerusalem's Old City." Ha'aretz, April 23.

_—_. 2012b. “Rare Photograph Reveals Ancient Jerusalem Mosque Destroyed in 1967.” Ha'aretz, June 15.

_——. 2013. "Caught on Tape: Recording Reveals East Jerusalem Park Is About Politics, Not Environment.” Ha'aretz, September 30.

Hecht, Gabrielle. 2011. Entangled Geographies: Empire and Technopolitics in the Global Cold War. Inside Technology. Cambridge, Mass.: MIT Press.

Henke, Christopher R., and Thomas F. Gieryn. 2008. "Sites of Scientific Practice: The Enduring Importance of Place." In Handbook of Science and Technology Studies, edited by E. Hackett, 0. Amsterdamska, M. Lynch, and J. Wajcman, 353-375. Cambridge, Mass.: MIT Press.

Herod, Andrew, and Melissa W. Wright, ed. 2002. Geographies of Power: Placing Scale. Malden, Mass.: Blackwell.

Heruti-Sover, Tali. 2012. "Arab Town, Both Israeli and Palestinian, Divided by Shopping Israel News.” Ha'aretz, February 1.

Hewitt, Rachel. 2010. Map of a Nation: A Biography of the Ordnance Survey. London: Granta.

Hirsch, Dafna. 2009. "We Are Here to Bring the West, Not Only to Ourselves?: Zionist Occidentalism and the Discourse of Hygiene in Mandate Palestine." International Journal of Middle East Studies 41 (04): 577-594.

Hirschkind, Charles. 2006. The Ethical Soundscape: Cassette Sermons and Islamic Counterpublics. New York: Columbia University Press.

Hoeschele, Wolfgang. 2000. "Geographic Information Engineering and Social Ground Truth in Attappadi, Kerala State, India." Annals of the Association of American Geographers 90 (2): 293-321.

Hommels, Anique. 2005. Unbuilding Cities: Obduracy in Urban Socio-technical Change. Inside Technology. Cambridge, Mass.: MIT Press.

Hostetler, Laura. 2009. “Contending Cartographic Claims? The Qing Empire in Manchu, Chinese, and European Maps." In The Imperial Map: Cartography and the Mastery of Empire, edited by James R. Akerman, 93-132. The Kenneth Nebenzahl Jr. Lectures in the History of Cartography. Chicago: University of Chicago Press.

Houk, Marian. 2008. “Atarot and the Fate of the Jerusalem Airport.” Jerusalem Quarterly 35: 64-75.

Hull, Matthew S. 2003. "The File: Agency, Authority and Autography in an Islamabad Bureaucracy." Language and Communication 23: 287-314.

Human Rights Watch. 2008. "D2. Human Rights Watch, 'Off the Map: Land and Housing Rights Violations in Israel's Unrecognized Bedouin Villages,' New York, 31 March 2008 (excerpts).” Journal of Palestine Studies 37 (4): 176-178.

Ibn Khaldun, 'Abd al-Rahman. 1967. The Muqaddimah: An Introduction to History. London: Routledge and Kegan Paul.

Ibrahim, Nassar. 2011. Illusion of Development Under Israeli Occupation: The Political Motivations of Donors to the Palestinians. Bethlehem: Latin Patriarchate Printing Press.

“In Memory of Roberto Bachi." 1996. Genus: Organo Del Comitato Italiano Per Lo Studio Dei Problemi Della Popolazione 52 (1-2): 13-14.

Inbar, Moshe. 2002. "A Geomorphic and Environmental Evaluation of the Hula Drainage Project, Israel." Australian Geographical Studies 40 (2): 155-166. 


\section{B I B L I O G RA P HY}

Incite! Women of Color Against Violence, ed. 2007. The Revolution Will Not Be Funded: Beyond the NonProfit Industrial Complex. Cambridge, Mass.: South End Press.

InfoAmazonia. 2013. “About.” InfoAmazonia. Accessed September 19, 2013. http://infoamazonia.org/about/.

Ingham, Richard. 2013. “Cheers for Palestinian Film of Love and Betrayal.” Daily Star (Beirut), May 20.

International Business Publications. 2011. Israel Lobby in the United States Handbook: Organization, Operations, Performance. Vol. 1. Washington, D.C.: International Business Publications.

IPCC. 2009. Jerusalem, the Old City: The Urban Fabric and Geopolitical Implications. Jerusalem: International Peace and Cooperation Center (IPCC).

"Israel Unveils Controversial Plan for West Bank Rail Network." 2013. Al Akhbar English, July 25.

Jasanoff, Sheila. 2004. States of Knowledge: The Co-Production of Science and Social Order. London: Routledge.

Jensen, Rolf H., S. Abed, and U. Tellefsen. 1997. "Institution Building for Sustainable Physical Planning in Palestine." In The Reconstruction of Palestine: Issues, Options, Policies, and Strategies, edited by Antoine B. Zahlan, 76-85. London: Kegan Paul.

Jessop, Bob, and Stijn Oosterlynck. 2008. "Cultural Political Economy: On Making the Cultural Turn Without Falling into Soft Economic Sociology." Geoforum 39 (3): 1155-1169.

Jiryis, Sabri, and Salah Qallab. 1985. "The Palestine Research Center.” Journal of Palestine Studies 14 (4): 185-187.

Jones, Peris Sean. 2002. "The Etiquette of State-Building and Modernisation in Dependent States: Performing Stateness and the Normalisation of Separate Development in South Africa." Geoforum 33 (1): 25-40.

Jordan, June. 2002. Some of Us Did Not Die: New and Selected Essays of June Jordan. New York: Basic Books.

Jordanian Department of Lands and Surveys. 1966. "Annual Report”. The Hashemite Kingdom of Jordan. Uncatalogued. Tel Aviv University Map Library.

Jubras, Hanna, F. Nasser, and F. Haj Yahya. 2008. The Witnessing Roots: A Guidebook of Palestine. Arab Cultural Association.

Kagan, Oren. 1997. "The World of Scanning" presented at the EUROSTAT and the Israeli Central Bureau of Statistics: New Technologies for the 2000 Census Round: Sharing the Israeli Experience from the 1995 Census, March 16, Kibbutz Ma'ale Hachamisha, Israel.

Kalpagam, U. 2000. "The Colonial State and Statistical Knowledge." History of the Human Sciences 13 (2): 37-55.

Kanaaneh, Rhoda Ann. 2002. Birthing the Nation: Strategies of Palestinian Women in Israel. California Series in Public Anthropology 2. Berkeley: University of California Press.

Kanaaneh, Rhoda Ann, and Isis Nusair, ed. 2010. Displaced at Home: Ethnicity and Gender Among Palestinians in Israel. Albany: State University of New York Press.

Karsh, Efraim. 2000. Fabricating Israeli History: The "New Historians". Cass Series: Israeli History, Politics, and Society 10. London: Frank Cass.

Katz, Cindi. 1994. "Playing the Field: Questions of Fieldwork in Geography.” Professional Geography 46 (1): 67-72.

——_. 2001. “On the Grounds of Globalization: A Topography for Feminist Political Engagement." Signs: Journal of Women in Culture and Society 26 (4): 1213-1234.

_- - 2006. "Messing with 'The Project'." In David Harvey: A Critical Reader, edited by Noel Castree and Derek Gregory, 234-46. Oxford: Blackwell.

Katz, Cindi, and Andrew Kirby. 1991. "In the Nature of Things: The Environment and Everyday Life." Transactions of the Institute of British Geographers 16 (3): 259-271.

Katz, Kimberly. 2003. “Legitimizing Jordan as the Holy Land: Papal Pilgrimages-1964, 2000." Comparative Studies of South Asia, Africa, and the Middle East 23 (1-2): 181-189.

Kavornen, Andrew, and Bas Van Heur. Forthcoming. "Urban Laboratories: Experiments in Reworking Cities." International Journal of Urban and Regional Research

Keane, Webb. 2007. Christian Moderns: Freedom and Fetish in the Mission Encounter. Berkeley: University of California Press. 
Kedar, Benjamin Z. 1999. The Changing Land Between the Jordan and the Sea: Aerial Photographs from 1917 to the Present. Jerusalem and Tel Aviv: Yad Ben-Zvi Press and MOD Publishing House.

Kestler-DAmours, Jillian. 2013. “Bulldozers Flatten Bedouin Village 49 Times.” Al Jazeera English, April 18.

Khalidi, Rashid. 2006. The Iron Cage: The Story of the Palestinian Struggle for Statehood. Boston: Beacon Press.

- - 2010. Palestinian Identity: The Construction of Modern National Consciousness. New York: Columbia University Press.

Khalidi, Walid. 1988. "Plan Dalet: Master Plan for the Conquest of Palestine." Journal of Palestine Studies 18 (1): 4-33.

- - - 1992. All That Remains: The Palestinian Villages Occupied and Depopulated by Israel in 1948. Washington, DC: Institute for Palestine Studies.

- - 1993. "Benny Morris and Before Their Diaspora." Journal of Palestine Studies 22 (3): 106-119.

- - . 2004. Before Their Diaspora: A Photographic History of the Palestinians 1876-1948. Washington, DC: Institute for Palestine Studies.

Khalife, Marcel. 1980. 'Al-Hudud [At the Border]. CD Audio. Beirut.

Khatib, Hisham. 2003. Palestine and Egypt Under the Ottomans: Paintings, Books, Photographs, Maps and Manuscripts. London: Tauris Parke.

Khoury, Elias. 2005. Bab al-Shams [Gate of the Sun]. Translated by Humphrey Davies. Brooklyn: Archipelago Books.

Kitchin, Rob, and Martin Dodge. 2007. "Rethinking Maps." Progress in Human Geography 31 (3): 331-344.

Kivelson, Valerie A. 2009. “'Exalted and Glorified to the Ends of the Earth': Imperial Maps and Christian Spaces in Seventeenth- and Early Eighteenth-Century Russian Siberia." In The Imperial Map: Cartography and the Mastery of Empire, edited by

James R. Akerman, 47-92. The Kenneth Nebenzahl Jr. Lectures in the History of Cartography. Chicago: University of Chicago Press.

Klibanoff, Lea. 2009. Ha-Mashiach Tamid Yavo [The Messiah Will Always Come].

Knorr Cetina, K. 1981. The Manufacture of Knowledge: An Essay on the Constructivist and Contextual Nature of Science. Pergamon International Library of Science, Technology, Engineering, and Social Studies. Oxford: Pergamon Press.

- — . 1999. Epistemic Cultures: How the Sciences Make Knowledge. Cambridge, Mass: Harvard University Press.

Kohler, Robert E. 2002. Landscapes \& Labscapes: Exploring the Lab-Field Border in Biology. Chicago: University of Chicago Press.

Kreimer, Sarah. 2007. A Policy Framework for the Interim Period. Jerusalem: Peace and Democracy Forum and Ir Amim.

Kuhn, Thomas S. 1996. The Structure of Scientific Revolutions. Chicago: University of Chicago Press.

Kurgan, Laura. 2013. Close up at a Distance: Mapping, Technology, and Politics. Brooklyn: Zone Books.

Kwan, Mei-Po. 2004. "Beyond Difference: From Canonical Geography to Hybrid Geographies." Annals of the Association of American Geographers 94 (4): 756-763.

Laila Atshan. 2011. "Keeping the Candle Lit". Bethlehem: TEDx Ramallah.

Lasman, Benjamin. 1997. "Overview of the 1995 Census of Population and Housing in Israel" presented at the EUROSTAT and the Israeli Central Bureau of Statistics: New Technologies for the 2000 Census Round: Sharing the Israeli Experience from the 1995 Census, March 16, Kibbutz Ma'ale Hachamisha, Israel.

Latour, Bruno. 1986. "Visualization and Cognition." Knowledge and Society 6: 1-40.

- - - 1987. Science in Action: How to Follow Scientists and Engineers through Society. Cambridge, Mass.: Harvard University Press.

- - 1988. The Pasteurization of France. Cambridge, Mass.: Harvard University Press. 1993. We Have Never Been Modern. Cambridge, Mass.: Harvard University Press.

- - - 1999. "On Recalling ANT." In Actor Network Theory and After, edited by John Law and John Hassard, 15-25. The Sociological Review Monographs. Oxford: Blackwell. 


\section{B I B L I O G RA P HY}

Latour, Bruno, and Emilie Hermant. 1998. Paris: Ville Invisible [Paris: Invisible City]. Les Empêcheurs de Penser en Rond. Paris: La Découverte et Institut Synthélabo pour le Progrès de la Connaissance.

Latour, Bruno, and Steve Woolgar. 1986. Laboratory Life. Princeton: Princeton University Press.

Law, John, and Annemarie Mol. 2001. "Situating Technoscience: An Inquiry into Spatialities." Environment and Planning D: Society and Space 19 (5): 609 - 621.

Lee, Benjamin, and Edward LiPuma. 2002. "Cultures of Circulation: The Imaginations of Modernity." Public Culture 14 (1): 191-213.

Lefebvre, Henri. 2002. The Production of Space. Oxford: Blackwell.

Leibler, Anat. 2004. "Statisticians' Ambition: Governmentality, Modernity, and National Legibility." Israel Studies 9 (2): 121-149.

- - - 2007. "Establishing Scientific Authority--Citizenship and the First Census of Israel." In Tel Aviver Jahrbuch Für Deutsche Geschichte XXXV, edited by Jose Brunner, 221-36. Göttingen: Wallstein Verlag.

Leibler, Anat, and Daniel Breslau. 2005. "The Uncounted: Citizenship and Exclusion in the Israeli Census of 1948." Ethnic and Racial Studies 28 (5): 880-902.

Leuenberger, Christine. 2012. "Map-Making for Palestinian State-Making." The Arab World Geographer 16 (1): 54-74.

Leuenberger, Christine, and Izhak Schnell. 2010. "The Politics of Maps: Constructing National Territories in Israel." Social Studies of Science 40 (3): 803-842.

Levin, Noam. 2006. "The Palestine Exploration Fund Map (1871-1877) of the Holy Land as a Tool for Analysing Landscape Changes: The Coastal Dunes of Israel as a Case Study." The Cartographic Journal 43 (1): 45-67.

Levin, Noam, E. Elron, and A. Gasith. 2009. "Decline of Wetland Ecosystems in the Coastal Plain of Israel During the 20th Century: Implications for Wetland Conservation and Management." Landscape and Urban Planning 92 (3-4): 220-232.

Levinson, Meira. 2007. "Making the Desert Bloom: Israel's Environmental Past and Zionist Future." PresenTense.

Livingstone, David N. 1992. The Geographical Tradition. Oxford: Blackwell.

Longley, Paul, and Michael Batty. 2003. Advanced Spatial Analysis: The CASA Book of GIS. Redlands, Calif.: ESRI Press.

Loolwa, Khazoom. 2013. “Jews of the Middle East.” Jewish Virtual Library, May 11.

Lorde, Audre. 2007. Sister Outsider: Essays and Speeches. Berkeley: Crossing Press.

Louder, Dean R., M. Bisson, and P. La Rochelle. 1974. "Analyse Centrographique de la Population du Québec de 1951 à 1971 [Centrographic Analysis of the Population of Quebec from 1951 to 1971]." Cahiers de Géographie Du Québec 18 (45): 421-444.

Low, Setha M., and Denise Lawrence-Zúñiga. 2003. The Anthropology of Space and Place: Locating Culture. Hoboken, New Jersey: Wiley-Blackwell.

Lowdermilk, Walter C. 1960. “50 Years Ago: The Reclamation of a Man-Made Desert.” Scientific American, March.

Lynch, Michael. 1993. Scientific Practice and Ordinary Action: Ethnomethodology and Social Studies of Science. Cambridge, UK: Cambridge University Press.

Mackenzie, Donald A. 1990. Inventing Accuracy: An Historical Sociology of Nuclear Missile Guidance. Inside Technology. Cambridge, Mass.: MIT Press.

MacKenzie, Donald A., and Judy Wajcman, ed. 1999. The Social Shaping of Technology: How the Refrigerator Got Its Hum. Philadelphia: Milton Keynes, Open University Press.

Macleod, Roy M., and Deepak Kumar. 1995. Technology and the Raj: Western Technology and Technical Transfers to India, 1700-1947. New Delhi: Sage Publications.

Mahmood, Saba. 2005. Politics of Piety: The Islamic Revival and the Feminist Subject. Princeton: Princeton University Press.

Ma'oz, Moshe, and Sari Nusseibeh, ed. 2000. Jerusalem: Points of Friction, and Beyond. The Hague: Kluwer Law International.

“Map of Palestine." 2013. Accessed September 21, 2013. http://www.mapofpalestine.com/.

Margalit, Meir. 2010. Seizing Control of Space in East Jerusalem. Jerusalem: Sifrei Aliat Gag. 
Markell, Patchen. 2003. Bound by Recognition. Princeton: Princeton University Press.

Marston, Sallie A. 2000. "The Social Construction of Scale." Progress in Human Geography 24 (2): 219-242.

Martino Martin, Enrique. 2011. "Largely a Trojan Horse: Provincializing the Scale Debate in the Political Economy of Globalisation" presented at the Frankfurt Research Center for Postcolonial Studies Conference: Colonial Legacies, Postcolonial Contestations: Decolonizing the Social Sciences and the Humanities, June, Frankfurt.

Massad, Joseph Andoni. 2001. Colonial Effects: The Making of National Identity in Jordan. New York: Columbia University Press.

_-_. 2003. "The Ends of Zionism: Racism and the Palestinian Struggle." Interventions 5 (3): 440-451.

- - 2006. The Persistence of the Palestinian Question: Essays on Zionism and the Palestinians. New York: Routledge.

Massey, Doreen. 1994. Space, Place, and Gender. Minneapolis: University of Minnesota Press.

- - 2005. For Space. London: Sage.

Matar, Haggai. 2012. "Watch: Three Palestinian NGO Offices Raided by IDF Overnight." +972 Magazine, December 11.

MCW. 2013. "Two Boys, Two Laws: The Discriminatory Application of Law in the West Bank". Military Court Watch (MCW).

Meir-Glitzenstein, Esther. 2011. “Operation Magic Carpet: Constructing the Myth of the Magical Immigration of Yemenite Jews to Israel." Israel Studies 16 (3): 149-173.

Mermelstein, Hannah. 2011. “Overdue Books: Returning Palestine's 'Abandoned Property' of 1948.” Jerusalem Quarterly 47: 46-64.

Merrifield, Andy. 2000. "Henri Lefebvre: A Socialist in Space." In Thinking Space, edited by Mike Crang and Nigel J. Thrift, 167-182. Critical Geographies 9. London: Routledge.

MIFTAH. 2010. "Palestinian Avatars Protest Israeli Measures.” Miftah, February 13.

Miller, Anna Lekas. 2013. “'No Falasteen for You!' Shin Bet Banned Me from Israel for 10 Years.” +972 Magazine, August 31.

Misselwitz, Philipp, and Tim Rieniets, ed. 2006. City of Collision: Jerusalem and the Principles of Conflict Urbanism. Basel: Birkhauser.

Mitchell, Andrew P. 1948. "Supplement to 'Report for 1940-1946' for the Period up to [31 March 1948]." In Report for the Years 1940-1946. Jerusalem: British Mandate Survey of Palestine (SOP).

Mitchell, Timothy. 1991. Colonising Egypt. Berkeley: University of California Press.

-__. 2002. Rule of Experts: Egypt, Techno-Politics, Modernity. Berkeley: University of California Press.

——_. 2008. "Rethinking Economy." Geoforum 39 (3): 1116-1121.

MOD. 1973. The Administered Territories 1972/73: Data on Civilian Activities in Judea and Samaria, the Gaza Strip, and Northern Sinai. Israeli Ministry of Defense (MOD), Coordinator of Government Operations in the Administered Territories.

Modan, Rutu. 2008. Exit Wounds. Montreal: Drawn and Quarterly.

Mogel, Lize, T. Paglen, and A. Bhagat, ed. 2008. An Atlas of Radical Cartography. Los Angeles: Journal of Aesthetics and Protest Press.

Monmonier, Mark S. 1991. How to Lie with Maps. Chicago: University of Chicago Press.

Mood, Fulmer. 1946. "The Rise of Official Statistical Cartography in Austria, Prussia, and the United States, 1855-1872." Agricultural History 20 (4): 209-225.

Moody, Rebecca, M. Kouw, and V. Bekkers. 2013. "Virtually Visual: The Visual Rhetoric of Geographic Information Systems in Policy Making." In Virtual Knowledge: Experimenting in the Humanities and the Social Sciences, edited by P. Wouters,

A. Beaulieu, A. Scharnhorst, and S. Wyatt, 127-150. Cambridge, Mass.: MIT Press.

Moore, Kate. 2007. "Towards a Post-Colonial GIS." In GIS Research UK (GISRUK) 2007 Proceedings. Maynooth: National University of Ireland, Maynooth.

MOPIC. 1996. Landscape Assessment of the West Bank Governorates: Emergency Natural Resources Protection Plan. Ramallah: Palestinian National Authority Ministry of Planning and International Cooperation (MOPIC), Directorate for Urban and Rural Planning. 
-_- 1998. The Regional Plan for the West Bank Governorates. Ramallah: MOPIC.

Morris, Benny. 1992. "Palestine to 1948." Journal of Palestine Studies 22 (1): 109-111.

- - . 2004. The Birth of the Palestinian Refugee Problem Revisited. Cambridge Middle East Studies 18. Cambridge, UK: Cambridge University Press.

Mrázek, Rudolf. 2002. Engineers of Happy Land: Technology and Nationalism in a Colony. Princeton: Princeton University Press.

Munayyer, Yousef. 2012. "A State That Fears the Womb." The Daily Beast, April 5.

Nagra, Ruhan. 2013. "Academia Undermined: Israeli Restrictions on Foreign National Academics in Palestinian Higher Education Institutions". Right to Enter (RTE).

Nassar, Issam. 2003. "Remapping Palestine and the Palestinians: Decolonizing and Research." Comparative Studies of South Asia, Africa, and the Middle East 23 (1-2): 149-151.

Nasser, Irene. 2013. "In Bab Al-Shams, Palestinians Create New Facts on the Ground." +972 Magazine, January 25.

Natour, Salman, and Yusuf Abu Ta'ah. 2000. Filistin 'ala al-Tariq min al-Nasira ila Bayt Laham [Palestine on the Road: From Nazareth to Bethlehem]. Ramallah: Tamer Institute for Community Education.

Newman, David. 2001. "From National to Post-National Territorial Identities in Israel-Palestine." GeoJournal 53 (3): 235-246.

"NGO Monitor." 2013. Wikipedia. September 30.

Nitzan, Jonathan, and Shimshon Bichler. 2002. The Global Political Economy of Israel. London: Pluto Press.

November, Valérie, E. Camacho-Hübner, and B. Latour. 2010. "Entering a Risky Territory: Space in the Age of Digital Navigation." Environment and Planning D: Society and Space 28 (4): 581-599.

Noy, Chaim. 2008. "Writing Ideology: Hybrid Symbols in a Commemorative Visitor Book in Israel." Journal of Linguistic Anthropology 18 (1): 62-81.

Nusseibeh, Jamal. 2012. "Israeli Army Invades and Closes University Community Media Center". Al-Quds University.

Nyel, Moe Ali. 2013. "Palestinian Refugees Are Not at Your Service." The Electronic Intifada, May 17.

O’Sullivan, David. 2006. "Geographical Information Science: Critical GIS." Progress in Human Geography 30 (6): 783-791.

Ofran, Hagit, J. Isaac, H. Ben-Sasson, O. Yousef, and A. Abdelrazek. 2011. "Talking About Jerusalem" presented at Palestine-Israel Journal: Jerusalem in the Eye of the Storm, April 13, Jerusalem.

Ophir, Adi, M. Givoni, and S. Hanafi, ed. 2009. The Power of Inclusive Exclusion: Anatomy of Israeli Rule in the Occupied Palestinian Territories. New York: Zone Books.

Orient House. 2001a. "The Looted Archives of the Orient House." Jerusalem Quarterly (13): 3-5.

—_- 2001b. "Orient House Begins Its Commemoration Ceremony Despite Israeli Obstacles". Orient House.

- - . 2001c. "Israel Continues Its Efforts to Strangle the Orient House". Orient House, 20 July.

- - 2001d. "Urgent Appeal from the Orient House". Orient House, 14 August.

- - 2001e. "Press Release from the Orient House". Orient House, 30 August.

- - 2 2005. "Statement from the Orient House to the International Community". Orient House, 19 July.

Oster, Marcy. 2011. "Critics of Knesset NGO Bills Say Israel's Democracy Being Undermined." Jewish Telegraphic Agency (JTA), November 14.

Paasi, Anssi. 2004. "Place and Region: Looking Through the Prism of Scale." Progress in Human Geography 28 (4): 536-546.

PACBI. 2009. "Guidelines for the International Academic Boycott of Israel." Palestinian Campaign for the Academic and Cultural Boycott of Israel (PACBI), October.

- - - 2011. "Israel's Exceptionalism: Normalizing the Abnormal." PACBI, October.

Paglen, Trevor. 2009. Blank Spots on the Map: The Dark Geography of the Pentagon's Secret World. New York: Dutton.

"Palestinian Economy Minister Charged with Embezzlement, Insider Trading." 2011. Ha'aretz, November 29.

PalMap. 2011. Jerusalem Street Atlas. Bethlehem: Palestine Mapping Center (PalMap) and Good Shepherd Engineering and Computing (GSE). 
Pappé, Ilan. 1992. The Making of the Arab-Israeli Conflict, 1947-51. London: I.B. Tauris.

Paraszczuk, Joanna. 2011. "NGOs: Bill Is a 'Shameful Moment' for Israel." Jerusalem Post, November 13.

Parker, Christopher. 1999. Resignation Or Revolt: Socio-Political Development and the Challenges of Peace in Palestine. London: I. B. Tauris.

Parsons, Nigel. 2011. "The Palestinian Authority Security Apparatus: Biopolitics, Surveillance, and Resistance in the Occupied Palestinian Territories." In Surveillance and Control in Israel/Palestine:

Population, Territory, and Power, edited by E. Zureik, D. Lyon, and Y. Abu-Laban, 355-370. London: Routledge.

Pavlovskaya, Marianna, and Jess Bier. 2012. "Mapping Census Data for Difference: Towards the Heterogeneous Geographies of Arab American Communities of the New York Metropolitan Area." Geoforum 43 (3): 483-496.

Pavlovskaya, Marianna E. 2006. “Theorizing with GIS: A Tool for Critical Geographies?” Environment and Planning A 38 (11): 2003-2020.

PCBS. 2008. "Press Conference on the Preliminary Findings". Population, Housing, and Establishment Census 2007. Ramallah: Palestinian Central Bureau of Statistics (PCBS).

Peace Now. 2011. "West Bank and Jerusalem Map, The Settlements: The Biggest Threat to a Two-State Solution". Jerusalem: Peace Now Settlement Watch.

-__. 2012. "E1 Area: Planning Status". Jerusalem: Peace Now Settlement Watch.

Peled, Ammatzia. 1996. "Generating the Israeli National GIS." In The Mosaic of Israeli Geography, edited by Yehuda Gradus and Gabriel Lipshitz, 485-96. Beer Sheva: Negev Center for Regional Development and Ben-Gurion University of the Negev Press.

Peters, Peter, S. Kloppenburg, and S. Wyatt. 2010. "Co-ordinating Passages: Understanding the Resources Needed for Everyday Mobility." Mobilities 5 (3): 349-368.

Pickles, John, ed. 1995. Ground Truth: The Social Implications of Geographic Information Systems. Mappings: Society/Theory/Space. New York: Guilford Press.

- - - 2004. A History of Spaces: Cartographic Reason, Mapping and the Geo-Coded World. New York: Routledge.

Pinch, Trevor, and Wiebe E. Bijker. 1989. "The Social Construction of Facts and Artefacts: Or, How the Sociology of Science and the Sociology of Technology Might Benefit Each Other." In The Social Construction of Technological Systems, edited by W.E. Bijker, T.P. Hughes, and T. Pinch, 17-50. Cambridge, Mass.: MIT Press.

Piper, Karen. 2002. Cartographic Fictions: Maps, Race, and Identity. New Brunswick: Rutgers University Press.

PLO, and State of Israel. 1995. Annex I: Protocol Concerning Redeployment and Security Arrangements [Oslo II Agreement between the Palestinian Liberation Organization (PLO) and Israel].

Porter, Theodore M., and Dorothy Ross, ed. 2003. The Cambridge History of Science. Vol. 7. Cambridge, UK: Cambridge University Press.

Povinelli, Elizabeth A. 2006. The Empire of Love: Toward a Theory of Intimacy, Genealogy, and Carnality. Public Planet Books. Durham, North Carolina: Duke University Press.

Pratt, Mary Louise. 2007. Imperial Eyes: Travel Writing and Transculturation. London: Routledge.

Pullan, Wendy, and Britt Baillie, ed. 2013. Locating Urban Conflicts: Ethnicity, Nationalism and the Everyday. Houndmills, UK: Palgrave Macmillan.

Qarmout, Tamer, and Daniel Beland. 2012. "The Politics of International Aid to the Gaza Strip." Journal of Palestine Studies 41 (4): 32.

Radcliffe, Sarah A. 2009. "National Maps, Digitalisation and Neoliberal Cartographies: Transforming Nation-state Practices and Symbols in Postcolonial Ecuador." Transactions of the Institute of British Geographers 34 (4): 426-444.

Radder, Hans. 1996. In and About the World: Philosophical Studies of Science and Technology. SUNY Series in Science, Technology, and Society. Albany: State University of New York Press.

- - . 2006. The World Observed, the World Conceived. Pittsburgh: University of Pittsburgh Press.

Raj, Kapil. 2007. Relocating Modern Science: Circulation and the Construction of Knowledge in South Asia and Europe, 1650-1900. Houndmills, UK: Palgrave Macmillan. 


\section{B I B L I O G RA P H Y}

Rappert, Brian. 2009. Experimental Secrets: International Security, Codes, and the Future of Research. Lanham, MD: University Press of America.

Rashi Foundation. 2012. "Funding the Future: Advancing STEM in Israeli Education”. Conference Summary. New York: Rashi Foundation and Jewish Funders Network.

Razin, Assaf. 1993. The Economy of Modern Israel: Malaise and Promise. Chicago: University of Chicago Press.

Redfield, Peter. 2012. "The Unbearable Lightness of Ex-Pats: Double Binds of Humanitarian Mobility." Cultural Anthropology 27 (2): 358-382.

Reuters. 2011. “Turkish Satellite to Roll Back Israel's Turf Veil.” Jerusalem Post, March 10.

Ricca, Simone. 2007. Reinventing Jerusalem: Israel's Reconstruction of the Jewish Quarter After 1967. London: I.B. Tauris.

Robbins, Annie, and Phil Weiss. 2013. “Jewish Settlements on West Bank’ Are Now Comedy Central Fare". Mondoweiss, August 15.

Rodgers, Dennis, and Bruce O’Neill. 2012. "Infrastructural Violence: Introduction to the Special Issue." Ethnography 13 (4): 401-412.

Rogers, Richard, and Anat Ben-David. 2008. "The Palestinian-Israeli Peace Process and Transnational Issue Networks: The Complicated Place of the Israeli NGO.” New Media and Society 10 (3): 497-528.

Romani, Vincent. 2008. “Sciences Sociales et Lutte Nationale Dans Les Territoires Occupés Palestiniens: La Coercition Comme Contrainte et Comme Ressource Scientifique [Social Science and National Struggle in the Occupied Palestinian Territories: Coercion as a Constraint and as a Scientific Resources]." Revue D’Anthropologie Des Connaissances 2 (3): 487-504. Cairn Online.

Rose, Gillian. 1992. "Geography as the Science of Observation: The Landscape, the Gaze, and Masculinity." In Nature and Science: Essays in the History of Geographical Knowledge, edited by Felix Driver and Gillian Rose, 8-18. Historical Geography Research Series 28. Lancaster: Historical Geography Research Group of the Institute of British Geographers.

Rose, Mitch, and John Wylie. 2006. "Animating Landscape.” Environment and Planning D: Society and Space 24 (4): 475-479.

Rosen, Rhoda. 2008. Imaginary Coordinates. Chicago: Spertus Press.

Rosenberg, Oz. 2012. "Peace Now Activist's Home Vandalized for the Third Time in a Year." Ha'aretz, July 16.

Rosenblum, Keshet. 2012. "Jerusalem Official Demands 'Zionist Architect' for National Library." Ha'aretz, November 6.

Sacco, Joe. 2001. Palestine. Seattle: Fantagraphics Books.

-_- 2009. Footnotes in Gaza. New York: Metropolitan Books.

Safian, Alex. 2007. "Peace Now's Blunder: Erred on Ma'ale Adumim Land by 15,900 Percent." Committee for Accuracy in Middle East Reporting in America (CAMERA).

Safieddine, Hicham. 2004. "Sami Hadawi, 100: Canadian Palestinian Scholar.” Toronto Star, November 25.

Safier, Neil. 2009. "The Confines of the Colony: Boundaries, Ethnographic Landscapes, and Imperial Cartography in Iberoamerica." In The Imperial Map: Cartography and the Mastery of Empire, edited by James R. Akerman, 133-184. The Kenneth Nebenzahl Jr. Lectures in the History of Cartography. Chicago: University of Chicago Press.

Said, Edward W. 1983. "Traveling Theory." In The World, the Text, and the Critic, 226-247. Cambridge, Mass.: Harvard University Press.

-_—. 1995. Peace and Its Discontents: Essays on Palestine in the Middle East Peace Process. New York: Vintage Books.

-_- 2001. The End of the Peace Process: Oslo and After. New York: Knopf Doubleday.

Saleh, Ahmad. 2008. "Reshaping Palestinian Urban Structure Towards Sustainable Urban Development" presented at the First International Conference on Urban Planning in Palestine: Current Challengers and Future Prospects, Nablus.

Sauer, Carl. 1918. "Geography and the Gerrymander." The American Political Science Review 12 (3): 403-426.

-_—. 1925. The Morphology of Landscape. Berkeley: University of California press. 
Sayegh, Faris. 2000. "Geographic Data Survey, Needs Analysis, and Implementation Plan". Annex 1. Ramallah, West Bank: Negotiations Support Unit. Physical Planning Box 1. ARIJ Library.

Scham, Sandra Arnold. 2003. "From the River Unto the Land of the Philistines': The 'Memory' of Iron Age Landscapes in Modern Visions of Palestine." In Deterritorialisations... Revisioning: Landscapes and Politics, edited by Mark Dorrian and Gillian Rose, 73-79. London: Black Dog.

Schivelbusch, Wolfgang. 1987. "The Policing of Street Lighting." Yale French Studies (73): 61-74.

Schmelz, Usiel O., and Nathan Gad, ed. 1986. Studies in the Population of Israel in Honor of Roberto Bachi. Scripta Hierosolymitana XXX. Jerusalem: Magnes Press.

Scholten, H. J., R. J. van de Velde, and N. van Manen, ed. 2009. Geospatial Technology and the Role of Location in Science. The GeoJournal Library 96. Dordrecht: Springer.

Schuurman, Nadine. 1999. "Critical GIS: Theorizing an Emerging Discipline." Cartographica $36(4): 1-101$.

- - 2000. "Trouble in the Heartland: GIS and Its Critics in the 1990s." Progress in Human Geography 24 (4): 569-590.

Scott, Heidi V. 2006. "Rethinking Landscape and Colonialism in the Context of Early Spanish Peru." Environment and Planning D: Society and Space 24 (4): 481-496.

Scott, James C. 1998. Seeing Like a State: How Certain Schemes to Improve the Human Condition Have Failed. Yale Agrarian Studies. New Haven: Yale University Press.

Segal, Rafi, and Eyal Weizman, ed. 2003a. A Civilian Occupation: The Politics of Israeli Architecture. London: Verso.

_- - 2003b. "Occupation in Space and Time." Index on Censorship 32 (3): 186-192.

Seikaly, May. 1995. Haifa: Transformation of a Palestinian Arab Society 1918-1939. London: I.B. Tauris.

Sekhsaria, Pankaj. 2011. "Jugaad as a Conceptual and Materials Commons." Common Voices (8): 21-23.

- - 2013. "The Making of an Indigenous Scanning Tunneling Microscope." Current Science 104 (9): 1152-1158.

Senor, Dan, and Saul Singer. 2009. Start-up Nation: The Story of Israel's Economic Miracle. New York: Twelve.

Shahin, Mariam. 2005. Palestine: A Guide. Northampton, Mass.: Interlink Books.

Shalev, Nir. 2012. "Under the Guise of Legality: Israel's Declarations of State Land in the West Bank." Translated by Zvi Shulman. Jerusalem: B'Tselem.

Shamir, Ronen. 1996. "Suspended in Space: Bedouins Under the Law of Israel." Law \& Society Review 30 (2): 231-257.

Shamsavari, Ali. 2007. “The Technology Transfer Paradigm: A Critique”. Discussion paper. Kingston upon Thames, UK: Kingston University.

Shapin, Steven. 1985. Leviathan and the Air-Pump: Hobbes, Boyle, and the Experimental Life. Princeton: Princeton University Press.

Sharakas, Othman, A. Nubani, A. Abu Hammad, and A. Abdullah. 2007. Land Degradation Risk Assessment in the Palestinian Central Mountains Utilizing Remote Sensing and GIS Technique. The Lower Jordan River Basin Programme Publications 14. Ramallah: Birzeit University.

Sharp, Joanne P. 2009. Geographies of Postcolonialism: Spaces of Power and Representation. Los Angeles: SAGE.

Shea, K. Stuart, and Robert B. McMaster. 1989. "Cartographic Generalization in a Digital Environment: When and How to Generalize." In Autocarto 9:56-67.

Shehadeh, Raja. 1982. The Third Way, a Journal of Life in the West Bank. Quartet Books.

- - 2007. Palestinian Walks: Forays into a Vanishing Landscape. New York: Scribner.

- - - 2013. "Stones Unturned." International Herald Tribune: Latitude Blog.

Sheizaf, Noam. 2012. "Google Street View to Feature West Bank Settlements." +972 Magazine, September 27.

- - 2013. "Stephen Hawking's Message to Israeli Elites: The Occupation Has a Price." +972 Magazine, May 8.

Sheller, Mimi, and John Urry. 2006. "The New Mobilities Paradigm." Environment and Planning A 38 (2): 207-226.

Shenhav, Yehouda, and Yael Berda. 2009. "The Colonial Foundations of the State of Exception: 


\section{B I B L I O G RA P HY}

Juxtaposing the Israeli Occupation of the Palestinian Territories with Colonial Bureaucratic History." In The Power of Inclusive Exclusion: Anatomy of Israeli Rule in the Occupied Palestinian Territories, edited by A. Ophir, M. Givoni, and S. Hanafi, 337-374. New York: Zone Books.

Sherstyuk, Katerina. 1998. "How to Gerrymander: A Formal Analysis." Public Choice 95 (1-2): 27-49.

Shohat, Ella. 1992. "Antimonies of Exile: Said at the Frontiers of National Narrations." In Edward Said: A

Critical Reader, edited by Michael Sprinker, 121-143. Oxford, UK: Blackwell.

- - . 2002. "Area Studies, Gender Studies, and the Cartographies of Knowledge." Social Text

20 (3): 67-78.

- - . 2004. "The 'Postcolonial' in Translation: Reading Said in Hebrew." Journal of Palestine Studies 33 (3): 55-75.

Shoshan, Malkit. 2010. Atlas of the Conflict: Israel-Palestine. Rotterdam: 010.

Silverstein, Richard. 2010. “Oopsie, NGO Monitor Hauled Into Court, Apologizes for Smearing Palestinian NGO." Tikun Olam, 1 March.

Sismondo, Sergio. 2010. An Introduction to Science and Technology Studies. 2nd ed. Chichester, UK: Wiley-Blackwell.

Smith, Andrea. 2013. "Unsettling the Privilege of Self-Reflexivity." In Geographies of Privilege, edited by France Winddance Twine and Bradley Gardener, 263-280. New York: Routledge.

Smith, Gregory W. H. 2006. Erving Goffman. Abingdon, UK: Routledge.

Smith, Merritt Roe, and Leo Marx, ed. 1984. Does Technology Drive History? The Dilemma of Technological Determinism. Cambridge, Mass.: MIT Press.

Smith, Neil. 1992. "Geography, Difference, and the Politics of Scale." In Postmodernism and the Social Sciences, edited by J. Doherty, E. Graham, and M. Malek. London: Macmillan.

- - 2008. Uneven Development: Nature, Capital and the Production of Space. Athens, USA: The University of Georgia Press.

Söderström, Ola, S. Randeria, D. Ruedin, G. D’Amato, and F. Panese, ed. 2013. Critical Mobilities. Lausanne: EPFL Press.

SOI. 1964. "Jerusalem". Tel Aviv: Survey of Israel (SOI). Drawer 88, Sheet 11-II. Tel Aviv University Map Library.

—— 1970. "Atlas of Israel: Cartography, Physical Geography, Human and Economic Geography,

History". Jerusalem: SOI and the Israeli Ministry of Labour.

- - . 2009. Atlas Israel ha-Hadash: Ha-Atlas ha-Leumi [The New Atlas of Israel: The National Atlas]. Jerusalem: SOI and the Hebrew University of Jerusalem.

Soja, Edward W. 1996. Thirdspace: Journeys to Los Angeles and Other Real-and-Imagined Places. Oxford:

Blackwell.

-_- 2000. Postmetropolis: Critical Studies of Cities and Regions. Oxford: Blackwell.

SOP. 1937. "Central Judea”. British Mandate Survey of Palestine (SOP).

———. 1941. "Motor Map". Road. Jaffa: SOP. National Library of Australia Digital Collections.

- - . 1945. "Maps and Publications". Jaffa: SOP. Uncatalogued. Tel Aviv University Map Library.

——_. 1948. "Report for the Years 1940-1946". Jerusalem: SOP. Uncatalogued. Tel Aviv University

Map Library.

Sorkin, Michael. 2002. The Next Jerusalem: Sharing the Divided City. New York: The Monacelli Press.

Spinner, Jackie. 2012. "The Cool New Palestinians: Geeks." Christian Science Monitor, 18 February.

Spivak, Gayatri Chakravorty. 1988. "Can the Subaltern Speak?" In Marxism and the Interpretation of

Culture, edited by Cary Nelson and Lawrence Grossberg, 271-316. Urbana: University of

Illinois Press.

-_- 1999. A Critique of Postcolonial Reason: Toward a History of the Vanishing Present. Cambridge, Mass.: Harvard University Press.

Srebro, Haim. 2009. "A Status Report of the Activity of the Survey of Israel." International Federation of Surveyors (FIG).

Srebro, Haim, R. Adler, and D. Gavish. 2009. 60 Years of Surveying and Mapping Israel: 1948-2008.

Tel Aviv: Survey of Israel (SOI).

St. Martin, Kevin, and John Wing. 2007. "The Discourse and Discipline of GIS." Cartographica 42 (3): 235-248. 
Stamatopoulou-Robbins, Sophia. 2011. "In Colonial Shoes: Notes on the Material Afterlife in Post-Oslo Palestine." Jerusalem Quarterly 48: 54-77.

Stein, Rebecca Luna. 1998. "National Itineraries, Itinerant Nations: Israeli Tourism and Palestinian Cultural Production.” Social Text 56: 91-124.

Stier, Michael. 1997. "Project GIS: The Planning and Design of a Geographical Information System within the 1995 Census" presented at the EUROSTAT and the Israeli Central Bureau of Statistics: New Technologies for the 2000 Census Round: Sharing the Israeli Experience from the 1995 Census, March 16, Kibbutz Ma'ale Hachamisha, Israel.

Stoler, Ann Laura. 1995. Race and the Education of Desire: Foucault's History of Sexuality and the Colonial Order of Things. Durham, North Carolina: Duke University Press.

Stone, Jeffrey C. 1988. "Imperialism, Colonialism and Cartography." Transactions of the Institute of British Geographers (13): 57-64.

"Student's Journey from Gaza to Oxford." 2013. British Broadcasting Corporation (BBC), April 4.

Sufian, Sandra M. 2007. Healing the Land and the Nation: Malaria and the Zionist Project in Palestine, 1920-1947. Chicago: University of Chicago Press.

Sukarieh, Mayssoun, and Stuart Tannock. 2012. "On the Problem of Over-researched Communities: The Case of the Shatila Palestinian Refugee Camp in Lebanon.” Sociology 47 (3): 494-508.

Swedenburg, Ted. 1995. Memories of Revolt: The 1936-39 Rebellion and the Palestinian National Past. Minneapolis: University of Minnesota Press.

Swyngedouw, Erik. 2004. "Scaled Geographies. Nature, Place and the Politics of Scale." In Scale and Geographic Inquiry: Nature, Society and Method, edited by Robert Brainerd McMaster and Eric S. Sheppard, 129-153. Oxford: Wiley-Blackwell.

_- _ 2006. "Metabolic Urbanism. The Making of Cyborg Cities." In The Nature of Cities, edited by N. Heynen, M. Kaika, and E. Swyngedouw, 21-40. New York: Routledge.

Szepesi, Stefan. 2012. Walking Palestine: 25 Journeys into the West Bank. Interlink Walking Guides. Northampton, Mass.: Interlink Books.

Tamari, Salim. 2001. "Jerusalem: Subordination and Governance in a Sacred Geography." In Capital Cities: Ethnographies of Urban Governance in the Middle East, edited by Seteney Khalid Shami, 175203. Toronto: Centre for Urban \& Community Studies, University of Toronto.

_- - 2009. "The Great War and the Erasure of Palestine's Ottoman Past." In Transformed Landscapes: Essays on Palestine and the Middle East in Honor of Walid Khalidi, edited by Camille Mansour and Leila Fawaz, 105-136. Cairo: American University in Cairo Press.

Tamari, Salim, and Elia Zureik, ed. 2001. Reinterpreting the Historical Record: The Uses of Palestinian Refugee Archives for Social Science Research and Policy Analysis. Jerusalem: Institute of Jerusalem Studies.

Taraki, L. 2008. "Urban Modernity on the Periphery: A New Middle Class Reinvents the Palestinian City." Social Text 26 (2 95): 61-81.

Tawil-Souri, Helga. 2006. “Marginalizing Palestinian Development: Lessons Against Peace." Development 49 (2): 75-80.

—_- 2011a. "Orange, Green, and Blue: Color-Coded Paperwork for Palestinian Population Control." In Surveillance and Control in Israel/Palestine: Population, Territory, and Power, edited by E. Zureik, D. Lyon, and Y. Abu-Laban, 219-238. London: Routledge.

_—_. 2011b. "Hacking Palestine: A Digital Occupation." Al Jazeera English, November 9.

_- - 2011c. "The Hi-Tech Enclosure of Gaza". Social Science Research Network (SSRN) Scholarly Paper 1764251. Rochester, NY: SSRN.

_——. 2012. "Uneven Borders, Coloured (Im)mobilities: ID Cards in Palestine/Israel." Geopolitics 17: $153-176$.

Taylor, Peter J. 1990. “Editorial Comment GKS.” Political Geography Quarterly 9 (3): 211-212.

van Teeffelen, Toine, and Giacaman, Fuad. 2008. "Sumud: Resistance in Daily Life." In Challenging the Wall: Toward a Pedagogy of Hope, edited by Toine van Teeffelen. Bethlehem: Arab Educational Institute.

Tesli, Arne. 2008. "Physical Planning and Institution Building: Lessons Learned and Documentation of the PPIB Project in Palestine”. Oslo: Norwegian Institute for Urban and Regional Research. 


\section{B I B L I O G RA P HY}

Thomson, Janice E. 1996. Mercenaries, Pirates, and Sovereigns: State-Building and Extraterritorial Violence in Early Modern Europe. Princeton: Princeton University Press.

Todd, Jan. 1995. Colonial Technology: Science and the Transfer of Innovation to Australia. Studies in Australian History. Cambridge, UK: Cambridge University Press.

Trouillot, Michel-Rolph. 1994. Silencing the Past: Power and the Production of History. Boston: Beacon Press.

Tufakji, Khalil. n.d. "Maps and Survey Department." Orient House. Accessed October 1, 2013. http://www.orienthouse.org/dept/maps_dept.html.

Turnbull, David. 1996. "Cartography and Science in Early Modern Europe: Mapping the Construction of Knowledge Spaces." Imago Mundi 48: 5-24.

-_- 2000. Masons, Tricksters and Cartographers: Comparative Studies in the Sociology of Scientific and Indigenous Knowledge. Amsterdam: Harwood.

UNICEF. 2008. “Barrier Crossing Daunting for Deaf Palestinian Girl.” Jerusalem: United Nations Children's Fund (UNICEF), October 29.

UNOCHA. 2007. "The Humanitarian Impact on Palestinians of Israeli Settlements and Other Infrastructure in the West Bank". Jerusalem: United Nations Office for the Coordination of Humanitarian Affairs, Occupied Palestinian Territory (UNOCHA-OPT).

_-_. 2008. "West Bank: Access and Closure". Jerusalem: UNOCHA-OPT. . 2009. "Shrinking Space: Urban Contraction and Rural Fragmentation in the Bethlehem Governorate". Jerusalem: UNOCHA-OPT.

—_- 2010a. "The Occupied Palestinian Territory: Overview Map". Jerusalem: UNOCHA-OPT. 2010b. "Area C Humanitarian Response Plan Fact Sheet". Jerusalem: UNOCHA-OPT. 2011a. “West Bank: Area C Map”. Jerusalem: UNOCHA-OPT.

- 2011b. "East Jerusalem: Key Humanitarian Concerns". Jerusalem: UNOCHA-OPT.

- 2012a. Humanitarian Atlas. Jerusalem: UNOCHA-OPT.

_- 2012b. "West Bank Movement and Access Update”. Jerusalem: UNOCHA-OPT.

Urry, John. 2002. "Mobility and Proximity." Sociology 36 (2): 255-274.

US Department of State. 2010. "Knesset Considers Controversial NGO Legislation to Register as Foreign Agents". Wikileaks. US Diplomatic Cable from the Tel Aviv Embassy to the Washington, D.C. Office of the Secretary of State. \#10TELAVIV439. Wikileaks.

Van Heur, Bas. 2009. "The Clustering of Creative Networks: Between Myth and Reality.” Urban Studies 46 (8): 1531-1552.

-_- 2010. Creative Networks and the City: Towards a Cultural Political Economy of Aesthetic Production. Bielefeld: Transcript.

Vannini, Phillip. 2011. "Constellations of Ferry (Im)mobility: Islandness as the Performance and Politics of Insulation and Isolation." Cultural Geographies 18 (2): 249-271.

Vergano, Dan. 2013. "Contrary to Reports, Mount McKinley Not Shrinking." National Geographic: Daily News, November 13.

de Vet, Annelys ed. 2007. Subjective Atlas of Palestine. Rotterdam: 010.

Visvanathan, Shiv. 1988. "Atomic Physics: The Career of an Imagination." In Science, Hegemony, and Violence: A Requiem for Modernity, edited by Ashis Nandy, 113-166. Delhi: Oxford University Press and United Nations University.

Wagner, Peter. 2001. A History and Theory of the Social Sciences: Not All That Is Solid Melts into Air. Theory, Culture and Society. London: Sage.

Warf, Barney, and Santa Arias, ed. 2009. The Spatial Turn: Interdisciplinary Perspectives. Routledge Studies in Human Geography 26. London: Routledge.

Watzman, Haim. 1993. "Israel Floods Drained Swamp to Bring in Tourists.” New Scientist, April 17.

Webb, Eugene J., D.T. Campbell, R.D. Schwartz, and L. Sechrest. 1966. Unobtrusive Measures. Chicago: Rand McNally.

Wegman, Edward J., and Carr, Daniel B. 1993. "Statistical Graphics and Visualization." In Handbook of Statistics, Vol. 9: Computational Statistics, edited by C.N.R. Rao, 857-958. Amsterdam: North Holland and Elsevier. 
Weizman, Eyal. 2002. “The Politics of Verticality.” Accessed October 1, 2013.

http://www.opendemocracy.net.

- - 2007. Hollow Land: Israel's Architecture of Occupation. London: Verso.

2011. The Least of All Possible Evils: Humanitarian Violence from Arendt to Gaza. London: Verso.

"Who's [sic] Land Is It Anyway?" n.d. Wild Olive. http://www.wildolive.co.uk/land.htm.

Winichakul, Thongchai. 1994. Siam Mapped: A History of the Geo-Body of a Nation. Honolulu: University of Hawaii Press.

Wittgenstein, Ludwig. 2001. Philosophical Investigations. Oxford: Blackwell.

Wolf, Aaron, and John Ross. 1992. "The Impact of Scarce Water Resources on the Arab-Israeli Conflict." Natural Resources Journal 32: 919-958.

Wolfson, Zev. 2005. "Funders Ignoring Deceit by Palestinian Eco-NGOs.” NGO Monitor.

Wood, Denis. 2010. Rethinking the Power of Maps. New York: Guilford Press.

Wouters, Paul, A. Beaulieu, A. Scharnhorst, and S. Wyatt, ed. 2013. Virtual Knowledge: Experimenting in the Humanities and the Social Sciences. Cambridge, Mass.: MIT Press.

Wyatt, Sally. 1998. "Technology's Arrow: Developing Information Networks for Public Administration in Britain and the United States". Dissertation, Maastricht: Maastricht University.

_- - 2003. "Non-Users Also Matter: The Construction of Users and Non-Users of the Internet." In How Users Matter: The Co-Construction of Users and Technology, edited by Nelly Oudshoorn and Trevor Pinch, 67-79. Cambridge, Mass.: MIT Press.

- — 2008a. "Technological Determinism Is Dead; Long Live Technological Determinism." In Handbook of Science and Technology Studies, edited by E. Hackett, O. Amsterdamska, M. Lynch, and J. Wajcman, 165-180. Cambridge, Mass.: MIT Press.

- - . 2008b. "Challenging the Digital Imperative". Inaugural lecture presented upon the acceptance of the Royal Netherlands Academy of Arts and Sciences (KNAW) Extraordinary Chair in Digital Cultures in Development. Maastricht: Maastricht University.

Wyatt, Sally, and Brian Balmer. 2007. "Home on the Range What and Where Is the Middle in Science and Technology Studies?" Science, Technology \& Human Values 32 (6): 619-626.

Wyly, Elvin. 2011. "Positively Radical." International Journal of Urban and Regional Research 35 (5): 889-912.

Yakin, Boaz, and Nick Bertozzi. 2013. Jerusalem: A Family Portrait. New York: First Second.

Yaron, Oded. 2011. “Israel Allows Google to Operate Controversial Street View.” Ha'aretz, August 21.

_-_. 2012. "Google to Launch Street View for Israel, with Government Nod.” Ha'aretz, April 16.

Yousef, Omar. 2011. "From Salah Eddin to A-Ram, an Everyday Journey." Palestine-Israel Journal of Politics, Economics and Culture 17 (12): n.p.

Yuval-Davis, Nira. 2012. "Dialogical Epistemology-An Intersectional Resistance to the 'Oppression Olympics'." Gender and Society 26 (1): 46-54.

Zawawi, Zahraa, E. Corijn, and B. Van Heur. 2013. "Public Spaces in the Occupied Palestinian Territories." GeoJournal 78 (4): 743-758.

Zonszein, Mairav. 2013a. "Watch: Israeli Activists Detained for Filming Illegal Settlement Construction." +972 Magazine, April 3.

__—. 2013b. "Official Admits East Jerusalem Park Meant to Stop Palestinian Expansion." +972 Magazine, September 30.

Zrahiya, Zvi. 2011. "How Can Israelis Protect Their Privacy with Google Street View on the Prowl?" Ha'aretz, February 22.

Zukin, Sharon. 1991. Landscapes of Power: From Detroit to Disney World. Berkeley: University of California Press.

Zureik, Elia. 2001. “Constructing Palestine through Surveillance Practices.” British Journal of Middle Eastern Studies 28 (2): 205-227.

Zureik, Elia, D. Lyon, and Y. Abu-Laban, ed. 2011. Surveillance and Control in Israel/Palestine: Population, Territory, and Power. London: Routledge. 



\section{Samenvatting}

Mapping Israel, Mapping Palestine is een onderzoek naar de manieren waarop gesegregeerde ruimtelijke omgevingen voor de praktijk van cartografie in Jeruzalem en de Westbank hebben beïnvloed sinds 1967. ${ }^{133}$ Het is een voortzetting van en een uitbreiding op eerder werk op het gebied van de sociale constructie van technologie, en onderzoekt de manieren waarop kennis geografisch geproduceerd wordt. Technowetenschappelijke praktijken bevinden zich in ruimtelijke contexten, die tegelijkertijd maatschappelijk en materieel zijn. Dit gesitueerde karakter beïnvloedt de inhoud van kennis op soms onverwachte wijze. Ik betoog daarom dat een reflexieve verhouding tot materialiteit noodzakelijk is, om landschappen mogelijk te maken die een grotere diversiteit aan praktijken en vormen van kennis toestaan.

De complexe geografieën van Palestina en Israël zijn de centrale plekken in dit onderzoek naar hoe ruimtelijke omgevingen de vorm, inhoud, en circulatie van kennis bepalen. 1967 markeert het begin van de Israëlische Bezetting van de Palestijnse Gebieden, waaronder de Westbank en de Gazastrook. Met OostJeruzalem als belangrijke uitzondering zijn de meeste van deze bezette gebieden tegenwoordig noch formeel onderdeel van de Israëlische staat, noch is hun toegestaan een onafhankelijke, soevereine natie te vormen. In plaats daarvan zijn er kleine gebieden van Palestijns gezag uitgekerfd door een reeks van internationale onderhandelingen, gericht op de ondubbelzinnige definitie van aparte staten voor Palestijnen en Israëliërs - onderhandelingen die dikwijls plaatsvinden boven tafels bezaaid met kaarten.

Maar terwijl kaarten worden ingezet bij pogingen om de Bezetting te beëindigen, zijn soortgelijke methodes ook gebruikt voor de bouw van gecompliceerde infrastructurele netwerken, die de bewegingsvrijheid binnen de Palestijnse Gebieden beperken. Hieronder vallen de 8 meter hoge Muur die door de Westbank slingert, gesegregeerde sets van wegen en gebouwen, en een reeks reizende checkpoints en wegversperringen, alle ontworpen met het doel de Palestijnen te begrenzen en hen te scheiden van de Israëli's. De planning, bouw, en het bestuur van dergelijke controlesystemen worden mogelijk gemaakt door dezelfde Geografic Information Science (GIS) cartografische praktijken, die gebruikt worden in pogingen om het conflict te verminderen. Om te begrijpen hoe dit kan, moeten we onderzoeken hoe zulke praktijken op verschillende manieren deel

133 Voortbouwend op de geografische literatuur over landscapes, zoals besproken in hoofdstuk 2. 
uitmaken van dezelfde regio die de cartografen proberen in kaart te brengen en te hervormen.

De centrale rol van kaarten in debatten over de toekomst van Palestina en Israël is verder geïntensiveerd nu de komst van digitale cartografie heeft geleid tot steeds fijnmaziger vormen van surveillance en controle. Onderdeel van de tegenwoordige cartografie is een serie praktijken in Jeruzalem en de Westbank, variërend van aanpassingen van beelden van ontmantelde spionage satelietten tot een wegenkaart gemaakt door Palestijnse studenten die hun eigen bewegingen bijhielden op hun mobiele telefoons. Empirische kaarten worden ontworpen voor de presentatie van objectieve feiten, maar leiden vaak tot uitgebreide discussies waarin deelnemers een verscheidenheid aan waarnemingskaders tentoonspreiden. Deze kunnen niet los gezien worden van de ongelijkheid in hun positie en bewegingsvrijheid binnen precies die gebieden die ze in kaart willen brengen. Het is daarom essentieel om te onderzoeken hoe Palestijnse, Israëlische, en internationale wetenschappers en technici op ongelijke wijze beïnvloed worden door de gesegregeerde landschappen die hun technologieën mede gecreëerd hebben.

Mapping Israel, Mapping Palestine adresseert deze belangrijke thema's door middel van een analyse van de empirische kaarten en cartografische praktijken die ontstaan wanneer verschillende cartografen reizen om dezelfde landschappen in kaart te brengen die hun bewegingen zo sterk bepalen. Het onderzoekt de ontelbare manieren waarop de gesegregeerde ruimtelijke contexten van de Israëlische Bezetting voorwaarden scheppen voor de mogelijkheid van kennis over de Bezetting. Het doel van dit onderzoek is echter niet om het waarheidsgehalte van specifieke claims te onderzoeken. In plaats daarvan concentreert de analyse zich op de wijze waarop kennis materieel gesitueerd wordt in praktijken die niet kunnen worden gevat in een dichotomie van waar of vals.

Om beter te begrijpen hoe landschappen technowetenschappelijke kennis vormen, combineert dit boek drie representatieve case studies: 1) bevolkingskaarten van de Israëlische staat, 2) bestuurskaarten van de Palestijnse Autoriteit (PA), en 3) een vergelijking van nederzettingskaarten gemaakt door een Palestijnse non-gouvernementele organisatie (NGO) met die van een Israëlische NGO. Deze drie cases bevinden zich symmetrisch op het spectrum tussen (zelfgedefinieerde) Palestijnse en Israëlische weergaven. In plaats van een simpele tegenstelling of evenredigheid te suggereren, wordt de symmetrie juist gebruikt om zichtbaar te maken welke machtsongelijkheden er bestaan tussen Palestijnse en Israëlische cartografen, hoewel beide afkomstig zijn van technische elites.

Mapping Israel, Mapping Palestine levert een bijdrage aan een groeiende verzameling literatuur over de rol van technowetenschappelijke kennis in de verschansing van de Israëlische Bezetting, en is relevant voor een brede verscheidenheid aan studies naar de verspreide snijpunten van macht en expertise. De case studies zijn gebaseerd op meer dan 50 semi-gestructuureerde interviews, 30 veld bezoeken, en vijf maanden participerende observatie uitgevoerd in 2011 bij 
belangrijke cartografische NGO's, kantoren van de Palestijnse Autoriteit, en VN agentschappen (zoals ARIJ, PASSIA, UNOCHA en UNRWA), en op meer dan 10,000 foto's van kaarten in relevante archiefcollecties (zoals de Israëlische Nationale Archieven, de kaartenbibliotheek van Universiteit Tel Aviv en de kaartenkamer van de British Library). Het boek is verdeeld in zes hoofdstukken. Hoofdstuk 1, de Introductie, maakt gebruik van Edward Said's notie van "traveling theory" om te pleiten voor een reflexieve methode van traveling ethnography. Hoofdstuk 2 zet de voordelen uiteen van het combineren van geografisch onderzoek naar cartografie en empire met een Science en Technology Studies (STS) benadering die onderzoekt hoe specifieke technologieën intrinsiek worden gevormd door hun maatschappelijke en materiële contexten.

Hoofdstuk 3, de eerste case study, biedt een analyse van Israëlische bevolkingskaarten, 1967-1995. Middels een onderzoek naar de afwisselende inclusie en exclusie van de Palestijnse gebieden op kaarten geproduceerd door het Israëlische Centrale Bureau voor Statistiek (CBS), schetst Hoofdstuk 3 hoe zelfs de meest abstracte statische feiten worden bepaald door de ruimtelijke contexten waarin ze worden geproduceerd. Na 1967 vormde de geografische nabijheid van Palestijnen een probleem voor het geldende beleid waarbij de grenzen van de Palestijnse Gebieden niet werden aangegeven op Israëlische kaarten. Roberto Bachi, de directeur van de Israëlische bevolkingscensus, probeerde deze uitdaging het hoofd te bieden en tegelijkertijd empirisch wetenschappelijke cartografie te blijven bedrijven. Als gevolg daarvan leiddde hij de census weg van het gebruik van gearceerde gebieden van uniforme bevolking, en in de richting van stippenkaarten van bevolkingsverdeling. Dergelijke inspanningen dienden ertoe de methoden waarover de census cartografen konden beschikken te beperken. Er bleek eveneens uit dat, terwijl Israëlische politici herhaaldelijk beweerden dat Palestijnen niet bestonden, de methoden van Israëlische cartografen in feite inherent werden gevormd door de aanwezigheid van grote aantallen Palestijnen in de regio.

Hoofdstuk 4, de tweede case study, is een onderzoek naar hoe de koloniale erfenis de schaal en omvang van de cartografie van de Palestijnse Autoriteit (PA) beperkte, 1995-2008. Volgend op de Oslo Akkoorden van de midden jaren 1990 werd de PA opgericht als de eerste officiële vorm van Palestijns zelfbestuur met beperkte jurisdictie over bevolkingscentra in de Westbank en Gaza Strook. Kort na zijn oprichting startte de PA met een gecoördineerd project om een Palestijnse nationale vorm van digitale cartografie te ontwikkelen. Deze inspanningen vielen min of meer samen met de tweede Intifada, of Palestijnse opstand tegen Israëlisch bestuur, en kunnen als zodanig worden gezien als deel van de bredere politieke praktijkd van sumud, of standvastigheid, in een poging om de blijvende aanwezigheid van Palestijnen in het plaatselijke landschap te bevorderen.

In deze vroege cartografische projecten kreeg de PA echter te maken met voortdurende testen van zijn institutionele stasis, wat ik conceptualiseer als het vermogen om in stand te blijven. Deze testen kwamen in de vorm van het wijdverspreide behoud van Britse kaarten, in een context van omvangrijke 
vernietiging van Palestijnse kennisvormen, gecombineerd met overvallen van het Israëlische leger op PA kantoren om de digitale cartografische data te confisceren. Gedeeltelijk als gevolg van deze twee ontwikkelingen, slaagde de PA er uitsluitend in de West Bank op grotere geografische schaal af te beelden, en op manieren die de eerdere omissie van belangrijke Palestijnse gebieden op de kaart verder verscherpten. Ondanks de PA's beste nationalistische inspanningen, waren zijn digitale cartografische methoden grondig bepaald door zowel de Israëlische Bezetting als de erfenis van Brits kolonialisme in de regio. PA cartografie illustreert daarom de moeilijkheden bij het vestigen van materiële soevereiniteit over kennis in koloniale en postkoloniale landschappen.

Terwijl Hoofdstuk 3 zich richt op Israëlische cartografie, en Hoofdstuk 4 op Palestijnse inspanningen, analyseert Hoofdstuk 5 Palestijnse en Israëlische cartografische praktijken om aan te tonen hoe ingewikkeld segregratie de verzameling en vastlegging van geografische data beïnvloedt. Na 1967 verhuisden er meer en meer Israëlische kolonisten naar de Westbank. Ze vestigden er kleine maar talrijke bewaakte nederzettingen met als expliciet doel om de Israëlische greep op de Palestijnse Gebieden te verzekeren, een proces dat geleid heeft tot complexe, maar daarom niet minder rigide vormen van segregatie. Palestijnse cartografen kunnen momenteel alleen kaart data verzamelen binnen de hoofdzakelijk Palestijnse gebieden, en moeten Israëlische nederzettingen dus van buiten bekijken. Omgekeerd is het Israëlische cartografen slechts wettelijk toegestaan te werken binnen het verspreide netwerk van Israëlische nederzettingen, zodat ze de Palestijnse gebieden grotendeels van buiten in kaart moeten brengen.

Deze kunstmatige binnen/buiten dichotomie helpt een formele scheiding af te dwingen tussen Palestijnen en Israeliërs-twee groepen die in toenemende mate worden beschouwd als verschillend en wederzijds uitsluitend. Tegelijkertijd versterkt dit machtsongelijkheden zowel binnen individuele kaarten, waarop de Israëlische gebieden duidelijk zichtbaar zijn terwijl de Palestijnse gebieden vaak naar de achtergrond wijken, als tussen de respectievelijke groepen van Palestijnse en Israëlische cartografen, wier werk ongelijk ontvangen wordt in internationale contexten. Maar de cartografische gevolgen van segregatie zijn geenszins eenduidig. Hoofdstuk 5 schetst de uiteenlopende gevolgen van binnen/buiten landschappen door middel van twee voorbeelden: 1) Landgebruik en landbedekking (LULC) kaarten, die gebruik maken van luchtfoto's om Palestijnse landbouwgronden tot in detail weer te geven, en 2) kaarten van nederzettingsuitbreiding, die de toenemende Israëlische aanwezigheid in de Westbank illustreren maar grote militaire bases op inconsistente wijze weergeven. Beide voorbeelden tonen aan hoe binnen/buiten landschappen er niet alleen toe dienen cartografen fysiek te scheiden, maar ook het type waarneming dat zij doen bepalen. Hoofdstuk 5 biedt daarom een verkenning van hoe segregatie gescheiden, maar complex gedifferentieerde observaties reproduceert onder cartografen die schijnbaar dezelfde gebieden in kaart brengen, met schijnbaar dezelfde technologieën. 
Als geheel is Mapping Israel, Mapping Palestine een uitvoerige kritiek op de notie dat technologie als een onpartijdige arbiter functioneert in internationale, empirische conflicten. Hoofdstuk 6, de conclusie, bouwt voort op dit overkoepelende thema en verkent het belang ervan voor onderzoek in bredere zin naar postkoloniale kennis en expertise. Het hoofdstuk is een voortzetting van de literatuur op het gebied van sociale constructie door te pleiten voor onderzoek naar de geografische productie van kennis. Het onderzoek naar geografische productie vestigt de aandacht op de materialiteiten en ruimtelijkheden van wetenschap en technologie, en indiceert tegelijkertijd een nieuwe laag van reflexiviteit voor kritische theorie. Bovendien onderstreept het hoe noodzakelijk het is dat internationale onderzoekers het onderzoeksproces in materiële zin veranderen om meer heterogene kennislandschappen mogelijk te maken. 



\section{Summary}

Mapping Israel, Mapping Palestine is an analysis of the ways that segregated landscapes have shaped the practice of cartography in Jerusalem and the West Bank since 1967. Building upon and extending work on how technology is socially constructed, it investigates the ways that knowledge is geographically produced. Technoscientific practices are situated in spatial contexts which are at once both social and material. This situated character influences the content of knowledge in ways that can be unpredictable. Therefore, I argue that it is necessary to reflexively engage with materiality in order to enable landscapes that allow for more diverse practices and forms of knowledge.

The complex geographies of Palestine and Israel provide central sites for the study of how landscapes shape the form, content, and circulation of knowledge. 1967 marks the beginning of the Israeli Occupation of the Palestinian Territories, including the West Bank and Gaza Strip. With the notable exception of East Jerusalem, currently most of the occupied areas have been neither formally incorporated into the Israeli state, nor have they been allowed to form an independent sovereign nation. Instead, small pockets of Palestinian control have been carved out through a series of international negotiations aimed at clearly defining separate states for Palestinians and Israelis-negotiations which often take place over tables strewn with maps.

Yet even as maps are employed in attempts to end the Occupation, similar methods have been used to build intricate infrastructure networks for curtailing human movement within the Territories. These include the 8-meter Wall which snakes through the West Bank, segregated sets of roads and buildings, as well as roving series of checkpoints and roadblocks, all designed with the purpose of confining Palestinians and separating them from Israelis. The planning, construction, and administration of such systems of control are made possible by the same Geographic Information Science (GIS) mapmaking practices which are used in attempts to ameliorate the conflict. To understand how this is possible, it is necessary to explore the ways that such practices are differently incorporated throughout the very region which cartographers seek to map and reshape.

The centrality of maps to debates over the future of Palestine and Israel has only intensified since the advent of digital cartography has led to increasingly minute forms of surveillance and control. Contemporary cartography incorporates a range of practices in Jerusalem and the West Bank, from adaptations of decommissioned spy satellite images to a road map made by Palestinian students who tracked their own movements on their mobile phones. Intended to display objective facts, empirical maps often inspire extensive discussion. Participants in these dis- 
cussions exhibit a variety of observational frames that cannot be divorced from their unequal positions and mobilities within the very terrains that they seek to portray. Therefore it is essential to investigate how Palestinian, Israeli, and international scientists and technicians are unevenly affected by the segregated landscapes which their technologies have helped to create.

Mapping Israel, Mapping Palestine addresses these important issues by presenting an analysis of the empirical maps and mapmaking practices which result when diverse cartographers travel to chart the same landscapes that so condition their movement. As such, it investigates the myriad ways that the segregated landscapes of the Israeli Occupation shape the conditions of possibility for knowledge about the Occupation. However, the overall goal is not to investigate the veracity of particular claims. Instead, it is to consider how knowledge is materially situated in ways that go beyond a dichotomy between truth and falsity.

To better understand how landscapes shape technoscientific knowledge, this book combines three representative case studies: 1) Israeli state population maps, 2) Palestinian Authority (PA) governance maps, and 3) a comparison of settlement maps made by a Palestinian non-governmental organization (NGO) with those made by an Israeli NGO. These three cases are structured symmetrically between (self-defined) Palestinian and Israeli accounts. However, rather than suggesting simple opposition or commensurability, symmetry is employed precisely to highlight imbalances of power that hold among Palestinian and Israeli cartographers, although both come from technical elites.

Mapping Israel, Mapping Palestine contributes to a growing body of literature on the role of technoscientific knowledge in entrenching the Israeli Occupation, and it is relevant to a broad variety of studies of the distributed intersections of power and expertise. The case studies draw on over 50 semi-structured interviews, 30 field visits, and five months of participant-observation conducted in 2011 at core cartographic NGOs, PA offices, and UN agencies (for example, ARIJ, PASSIA, UNOCHA and UNRWA), as well as over 10,000 photographs of maps in relevant archival collections (for example, the Israeli National Archives, Tel Aviv University Map Library and the British Library Map Room). The book is divided into six chapters. Chapter 1, the Introduction, draws on Edward Said's notion of traveling theory to present an argument for a reflexive method of traveling ethnography. Chapter 2 outlines the benefits of combining geographical studies on cartography and empire with Science and Technology Studies (STS) research that examines how specific technologies are intrinsically shaped by their social and material contexts.

Chapter 3, the first case study, provides an analysis of Israeli population maps, 1967-1995. Through an investigation of the alternating inclusion and exclusion of Palestinian areas on maps produced by the Israeli Central Bureau of Statistics (CBS), Chapter 3 outlines ways that even the most abstract statistical facts are conditioned by the landscapes where they are produced. After 1967, the close geographic proximity of Palestinians posed a challenge to the broader policy of not indicating the borders of the Palestinian Territories on Israeli maps. Roberto Bachi, 
the director of the Israeli population census, sought to address this challenge while also continuing to practice empirically scientific cartography. As a result, he led the census away from mapping shaded areas of uniform population, and towards dot maps of population distribution. Such efforts served to limit the methods at the census cartographers' disposal. They also revealed that, despite repeated claims by Israeli politicians that Palestinians did not exist, in fact Israeli cartographers' methods were inherently shaped by the presence of large numbers of Palestinians in the region.

Chapter 4, the second case study, is an examination of how colonial legacies circumscribed the scale and extent of Palestinian Authority (PA) cartography, 1995-2008. Following the Oslo Accords of the mid-1990s, the PA was created as the first official form of Palestinian self-government with limited jurisdiction over population centers in the West Bank and Gaza Strip. Soon after its founding, the PA began a concerted project to develop a Palestinian national form of digital cartography. Its efforts roughly coincided with the second Intifada, or Palestinian uprising against Israeli rule, and as such it can be viewed as part of the broader political practice of sumud, or steadfastness, in an effort to further the ongoing presence of Palestinians in the local landscape.

However, throughout its early cartographic projects, the PA experienced ongoing tests to its institutional stasis, which I conceptualize as the ability to remain in place. These tests came in the form of the widespread preservation of British maps, in a context which has seen extensive destruction of Palestinian knowledge forms, combined with Israeli military raids on PA offices in order to confiscate digital cartographic data. Partly as a result of both of these developments, the PA was only able to depict the West Bank at broader geographic scales, and in ways that exacerbate the prior omission of key Palestinian areas from the map. So despite the PA's best nationalist efforts, their digital cartographic methods were thoroughly conditioned by both the Israeli Occupation as well as the legacy of British colonialism in the region. PA cartography therefore illustrates the challenges of establishing material sovereignty over knowledge in colonial and postcolonial landscapes.

Whereas Chapter 3 focuses on Israeli cartography, and Chapter 4 on Palestinian efforts, Chapter 5 analyzes Palestinian and Israeli mapmaking practices in order to demonstrate how intricately segregation affects the process of collecting and mapping geographic data. After 1967, Israeli settlers moved to the West Bank in increasing numbers. They established small but numerous gated settlements with the stated aim of securing Israel's hold on the Palestinian Territories. This process has engendered forms of segregation which are complex, but no less rigid for being so. Currently, Palestinian cartographers are able to collect map data only within the majority Palestinian areas, and thus must view Israeli settlements from without. In contrast, Israeli cartographers are legally allowed to work only within the dispersed network of Israeli settlements, but must largely map Palestinian areas from without. 
This produced within/without dichotomy serves to enforce a formal separation of Palestinians and Israelis-two groups that are increasingly viewed as distinct and mutually exclusive. Simultaneously, it also buttresses imbalances of power both within individual maps, where Israeli areas are highly visible while Palestinian areas often recede into the background, and between respective groups of Palestinian and Israeli cartographers, whose work receives unequal receptions in international contexts. Yet the cartographic implications of segregation are by no means straightforward. Chapter 5 delineates the variegated effects of within/without landscapes through two examples: 1) Land Use and Land Cover (LULC) maps, which draw on aerial photographs to depict rural Palestinian lands in detail, and 2) maps of settlement expansion, which illustrate the growing Israeli presence in the West Bank but inconsistently depict large military bases. Both examples demonstrate how within/without landscapes serve not only to physically separate cartographers, but also to condition the kinds of observations that they make. Chapter 5 therefore offers an exploration of how segregation reproduces disjunct, but complexly differentiated, observations among cartographers who map areas, and use technologies, that ostensibly are the same.

Overall, Mapping Israel, Mapping Palestine provides an extended critique of the notion that technology functions as an impartial arbiter in international empirical disputes. Chapter 6, the concluding chapter, draws on this overarching theme in order to explore its significance for broader research on postcolonial knowledge and expertise. The chapter extends the literature on social construction by arguing for research on the geographic production of knowledge. The study of geographic production draws attention to the materialities and spatialities of science and technology, while also indicating a further layer of reflexivity for critical theory. In addition, it highlights the need for international scholars to materially alter the process of research in order to enable more heterogeneous knowledge landscapes. 


\section{About the Author}

Jess Bier (18 August 1980) is a Ph.D. candidate at Maastricht University (20092013) in the Department of Technology and Society Studies and the Maastricht Virtual Knowledge Studio. She received her Masters of Philosophy degree in geography from the City University of New York (CUNY) Graduate Center (2005-2008), and her Bachelor of Arts degree in mathematics from Middlebury College (19982002). In the Netherlands, Jess completed the Maastricht Graduate School and the research program of the Netherlands Graduate Research School of Science, Technology, and Modern Culture (WTMC). In New York, she also pursued additional coursework in anthropology, Middle Eastern studies, and Arabic language at Columbia University through an inter-university consortium (2006-2008). During her enrollment at Middlebury, she completed one semester studying Arabic at the American University in Cairo (2000), one semester studying global economic history at Leiden University (2001), and one summer at the Middlebury Arabic Language School (2002).

Jess has worked as a teacher, community organizer, literary associate, laboratory assistant, and cartographer. While conducting the fieldwork for this book (see Appendix A), Jess was a GIS consultant for the Barrier Monitoring Unit (BMU) of the United Nations Relief and Works Agency (UNRWA). At Maastricht University, she was a teaching assistant in science and technology studies (STS), ethnographic research, anthropology, development studies, and history. While at CUNY, Jess conducted three years of independent research in Arab American communities in New York city, with a focus on the politics of the Arabic language in relation to migration, technology, and everyday economic life. She also taught or co-taught social theory, academic writing, introductory physics, and the history of mathematics. In addition, she worked as a freelance cartographer making maps for public schools and community planning initiatives. Before beginning her graduate studies, Jess served on the board of directors of the Queer Immigrant Rights Project (QUIR) while working professionally in publishing, including at the Women's Studies Quarterly.

Jess is currently a postdoctoral fellow in sociology at the European Research Council (ERC) funded Monitoring Modernity project at Erasmus University Rotterdam, led by Professor Willem Schinkel. In Rotterdam, she heads the Visualizing Capital subproject, where she analyzes the spatialities of financial regulation in the wake of the 2008 economic crisis. She has published in Information, Communication, and Society; Geoforum; The Journal of Linguistic Anthropology; Human Geography; The History of Cartography; and The Encyclopedia of Geography. Chapter 4 of this book received the 2013 Student Paper Prize of the Middle East Section of the American Anthropological Association (AAA). She regularly presents her research at international conferences, including the annual meetings of the Society for Social Studies of Science (4S) and the American Association of Geographers (AAG). 